\title{
Selected solo piano works by contemporary Malaysian composers: An analysis
}

\author{
Khe Sin Khoo \\ West Virginia University
}

Follow this and additional works at: https://researchrepository.wvu.edu/etd

\section{Recommended Citation}

Khoo, Khe Sin, "Selected solo piano works by contemporary Malaysian composers: An analysis" (2014). Graduate Theses, Dissertations, and Problem Reports. 504.

https://researchrepository.wvu.edu/etd/504

This Dissertation is protected by copyright and/or related rights. It has been brought to you by the The Research Repository @ WVU with permission from the rights-holder(s). You are free to use this Dissertation in any way that is permitted by the copyright and related rights legislation that applies to your use. For other uses you must obtain permission from the rights-holder(s) directly, unless additional rights are indicated by a Creative Commons license in the record and/ or on the work itself. This Dissertation has been accepted for inclusion in WVU Graduate Theses, Dissertations, and Problem Reports collection by an authorized administrator of The Research Repository @ WVU.

For more information, please contact researchrepository@mail.wvu.edu. 


\title{
SELECTED SOLO PIANO WORKS BY CONTEMPORARY MALAYSIAN COMPOSERS: AN ANALYSIS
}

Khe Sin Khoo

\author{
A Doctoral Research Project submitted to the \\ College of Creative Arts \\ at West Virginia University \\ in partial fulfillment of the requirements for the degree of \\ Doctor of Musical Arts \\ in \\ Piano Performance
}

\author{
Peter Amstutz, D.M.A., Committee Chair \\ Andrew Kohn, Ph.D., Research Advisor \\ Mary Ferer, Ph.D. \\ John Goldwasser, Ph.D. \\ James Miltenberger, D.M.A.
}

School of Music

Morgantown, West Virginia 2014

Keywords: Malaysia, piano, contemporary Malaysian composers, Chong Lim Ng, A Distant Voice of the Rain Forest, Adeline Wong, Paces, Kah Hoe Yii, My Spirit is Dancing!

Copyright 2014 Khe Sin Khoo 


\section{ABSTRACT \\ Selected Solo Piano Works by Contemporary Malaysian Composers: An Analysis}

\section{Khe Sin Khoo}

Although the influence of Western art music has been present in Malaysia for a little short of two centuries, much of the scholarly research, both locally and globally, has shown more interest in traditional music and popular music. As such, this study serves as an introduction to the art-music scene in Malaysia, particularly through the analyses of selected solo piano works by three contemporary Malaysian composers - namely, Chong Lim Ng's A Distant Voice of the Rain Forest (Fragments from "Rimba”...), Adeline Wong's Paces for solo piano and electronics, and Kah Hoe Yii's My Spirit is Dancing!

These works show that Malaysian composers can be traditional and experimental, national and international at the same time. Most importantly, they reflect a common aspiration to incorporate and retain a certain quality or sound that defines these composers' identities and cultural origins, which is not necessarily determined by ethnicity or nationality. This is achieved by assimilating foreign knowledge and technique with local or regional influences and inspirations.

This small but carefully chosen sampling of contemporary art music by Malaysian composers not only symbolizes the country's diversity in culture, it also represents the essence of the contemporary art music in Southeast Asia. For that reason, it is the author's hope that this research will promote interest and further studies in the contemporary art music by Malaysian composers and composers from the Southeast Asian region. 
To

My family 


\title{
With utmost gratitude to
}

\author{
Dr. Andrew Kohn \\ Dr. Peter Amstutz \\ Dr. James Miltenberger \\ Dr. Mary Ferer \\ Dr. John Goldwasser \\ Chong Lim Ng \\ Adeline Wong \\ Kah Hoe Yii \\ Kee Yong Chong \\ Dr. Tazul Izan Tajuddin \\ Dr. Nicholas Ong \\ Sulong Ismail \\ Mohd. Kamrulbahri Hussin and Geng Wak Long
}




\section{TABLE OF CONTENTS}

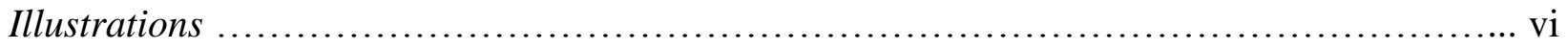

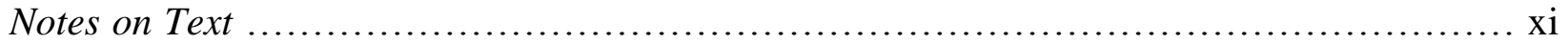

CHAPTER ONE: PREFACE

I. Introduction

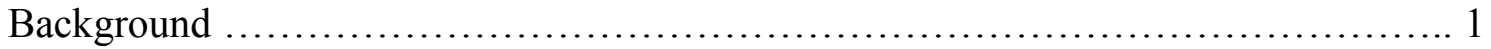

Overview of the Problem and the Need for the Study ........................... 37

II. Statement of Topic

Purpose of the Study ...................................................... 40

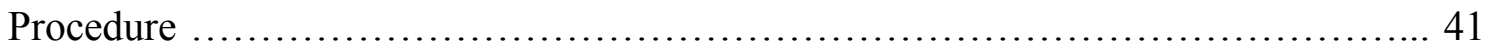

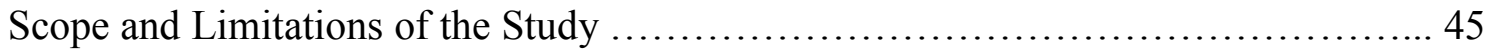

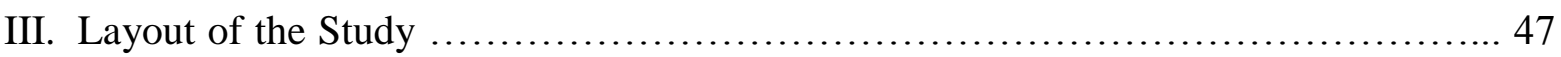

CHAPTER TWO: REVIEW OF RELATED LITERATURE ...................... 49

CHAPTER THREE: CHONG LIM NG

I. Biography .......................................................... 59

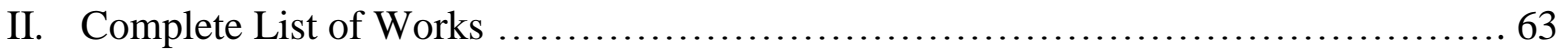

III. Analysis of Selected Work for Piano ...................................... 64

\section{CHAPTER FOUR: ADELINE WONG}

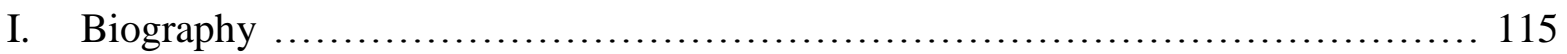

II. Complete List of Works .................................................. 119

III. Analysis of Selected Work for Piano ..................................... 121

CHAPTER FIVE: KAH HOE YII

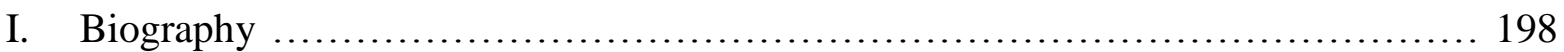

II. Complete List of Works ................................................... 200

III. Analysis of Selected Work for Piano ..................................... 203

CHAPTER SIX: SUMMARY ................................................... 242

CHAPTER SEVEN: CONCLUSION ............................................. 246

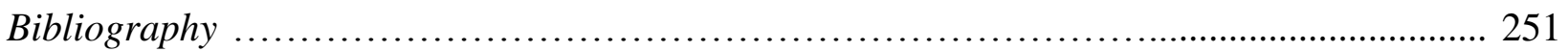

Appendix: List of Known Solo Piano Works by Malaysian Composers ....................... 261 


\section{ILLUSTRATIONS}

\section{EXAMPLES}

Chapter 3 Chong Lim Ng: A Distant Voice of the Rain Forest

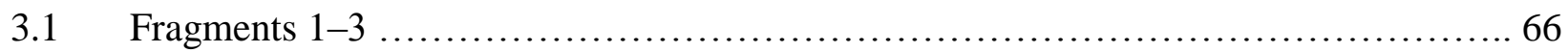

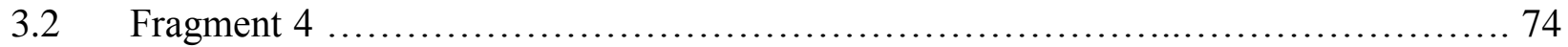

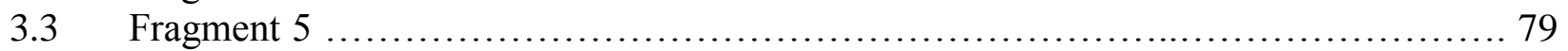

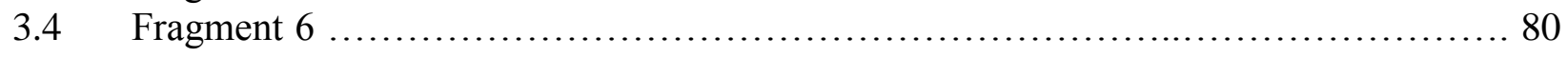

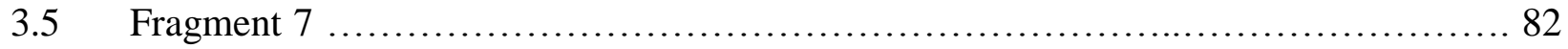

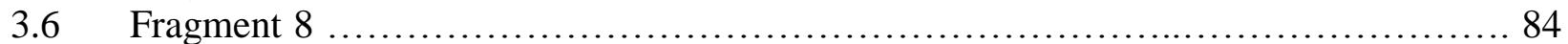

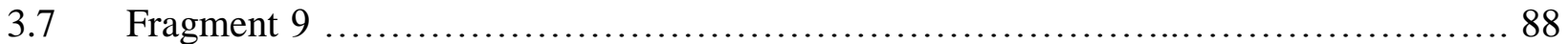

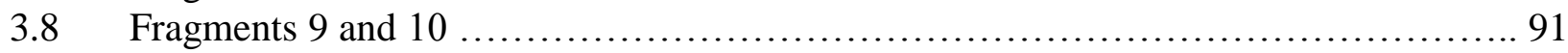

3.9 Fragment 11, Section 1, mm. 1-15 ......................................... 95

3.10 Fragment 11, Section 2, mm. 16-19 ............................................... 105

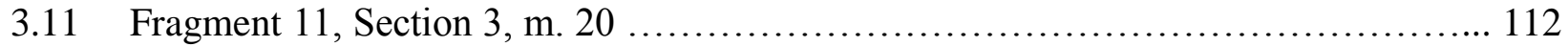

Chapter 4 Adeline Wong: Paces

4.1 Section I, "Construction/Industrial," mm. 1-33 …......................... 124

4.2 Section II, "Metal Grating," mm. 34-57 ...................................... 130

4.3 Transition I, mm. 58-59, and Section III, "Piano Solo," Brief Intro, mm. 60-63 ..... 133

4.4 Section III, "Piano Solo," Part A, mm. 64-87 ................................. 133

4.5 Section III, "Piano Solo," Part B, mm. 88-106 ................................. 134

4.6 Section III, "Piano Solo," Part A', mm. 107-128 .................................. 135

4.7 Section III, "Piano Solo," Part C, mm. 129-149 .................................. 136

4.8 Section III, "Piano Solo," Coda, mm. 150-159, and Transition II, m. 160 ............ 137

4.9 Section IV, "Gameboy/Digital,” Part A, mm. 161-201 ............................. 174

4.10 Section IV, "Gameboy/Digital," Part B, mm. 202-223 ........................... 175

4.11 Section IV, “Gameboy/Digital,” Part C, mm. 224-243 ............................... 176 


\section{FIGURES}

\section{Chapter 3 Chong Lim Ng: A Distant Voice of the Rain Forest}

3.1 Similarity between the final two grace notes in Fragments 1 and $3 \ldots \ldots \ldots \ldots \ldots \ldots \ldots . \ldots 6$

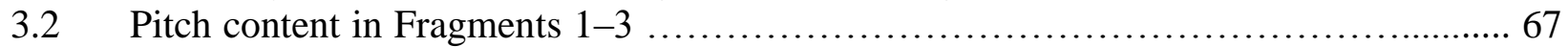

3.3 Transpositional relationships between subsets of Fragments 1 and $3 \ldots \ldots \ldots \ldots \ldots \ldots .68$

3.4 Similar intervallic relationships between pitch-classes in Fragments 1-3 ............... 69

3.5 Pelog barang ........................................................ 70

3.6 Intervallic relationships between grace notes and whole notes in Fragments 1-3 ...... 71

3.7 Recurrences of pitch interval span of a $9^{\text {th }}$ in Fragments 1, 2, 7, and $9 \ldots \ldots \ldots \ldots \ldots . . . . .72$

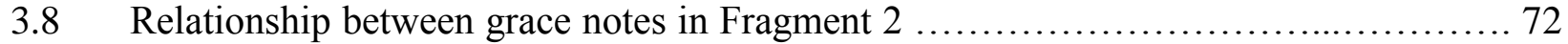

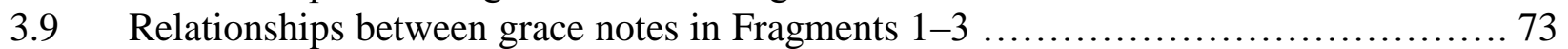

3.10 Fragment 4, Part 1 ..................................................................................... 74

3.11 Pitch content in Fragment 4, Part 1, Segments 1-4 ............................... 75

3.12 Interrelationships between pitch content in Fragment 1, 2, and 4 (Part 1) ............. 75

3.13 Pitch content in Fragment 4, Part 2, Segment 1 .................................... 77

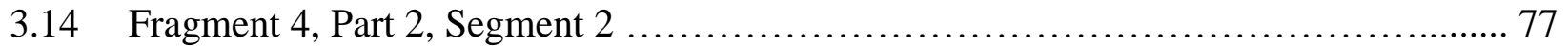

3.15 Pitch content in Fragment 4, Part 2, Segment 3 ................................... 78

3.16 Pitch content in Fragment 6, Segments 1-4 ................................... 80

3.17 Interrelationships between pitch content in Fragment 6, Segments/Sets 1-4 .......... 80

3.18 Pitch content in Fragment 7, Part 1 .......................................... 82

3.19 Interrelationship between pitch content in Fragments 1, 2, and 7 (Part 1) ............ 83

3.20 Pitch content in Fragment 8, Parts 1-3 ......................................... 85

3.21 Interrelationships between pitch content in Fragment 8, Parts 1 and 2 .................... 85

3.22 Relationships between main notes and grace notes in Fragment 8, Parts 1 and 2 ....... 86

3.23 Gaps between tetrachord sets in Fragment 8, Parts 1 and 2 .......................... 87

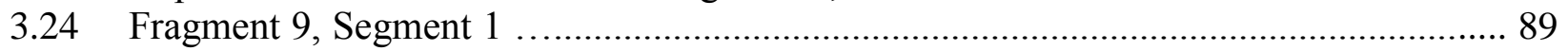

3.25 Fragment 9, Segment 4 ................................................... 90

3.26 Fragment 9, Segment 2 and Fragment 10, Segment 2 ........................... 92

3.27 Pitch content in Fragment 10, Segment 2 and Fragment 6, Segment 3 ...................... 93

3.28 Pitch content relationships Fragment 10, Segment 2 and Fragment 6, Segment 3 ....... 93

3.29 Fragment 11, Section 1, Part 1, mm. 1-6 ........................................ 96

3.30 Pitch content in Fragment 11, Section 1, Part 1, Segment 2 ........................... 97

3.31 Interrelationships between sets in Fragment 11, Section 1, Part 1, Segment 2 ............ 97

3.32 Pitch content in Fragment 11, Section 1, Part 1, Segment 4 ........................... 98

3.33 Interrelationships between Sets 1-3 in Fragment 11, Section 1, Part 1, Segment 4 ....... 99

3.34 Relationships, Sets 1, 2, 4, and 5 in Fragment 11, Section 1, Part 1, Segment 4 ....... 100

3.35 Fragment 11, Section 1, Part 2, mm. 9-12 .................................... 101

3.36 Pitch content relationships in Fragment 11, Section 1, Part 2, Segment 3 ................ 102

3.37 Pitch content relationships in Fragment 11, Section 1, Part 2, Segment 5 .................. 103

3.38 Pitch content relationships in Fragment 11, Section 1, Part 2, Segment 6 ................. 104

3.39 Fragment 11, Section 2, Part 1, mm. 16-17 .................................. 106

3.40 Fragment 11, Section 2, Part 1a (m. 16) and Part 1b (m. 17) ........................ 106

3.41 Pitch similarities, Fragment 11, Section 2, Part 1a, Segment 3;

Section 1, Part 2, Segment 5; and Section 1, Part 1, Segment 4 ............................... 107 
3.42 Pitch content of the trichords in the upper staff of Fragment 11, Section 2, Part 3 ....... 109

3.43 Single pitches in Fragment 11, Section 2, Part 3; pitch content in Fragments 1-3 ....... 109

3.44 Fragment 11, Section 2, Part 3 (m. 19) ......................................... 110

3.45 Pitch content of the vertical chords in Fragment 11, Section 2, Part 3 ........................ 110

3.46 Pitch relationships, Fragment 11, Section 2, Part 3, and Fragments 1, 2, and 3 .......... 111

\section{Chapter 4 Adeline Wong: Paces}

4.1 Derivation of three- $16^{\text {th }}$-note cells in Section I, mm. 3-20 ......................... 123

4.2 Derivation of three-16 ${ }^{\text {th }}$-note cell motives in Section I, mm. 20-21 ................. 126

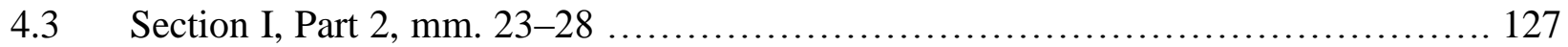

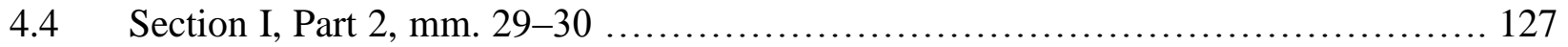

4.5 Section I, Part 2, mm. 31-33 _.............................................. 128

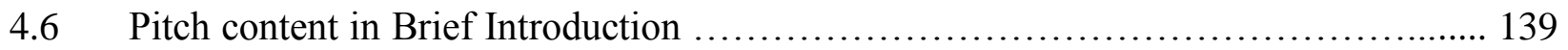

$4.7 \quad$ Pitch content in Part A ......................................................... 140

4.8 Interrelationships between the three primary sets in Part A ......................... 141

4.9 Derivation of Set A3 from Sets A1 and A2 .................................... 142

4.10a Derivation of Sets A1, A2, and A3 from Set I1 ................................... 142

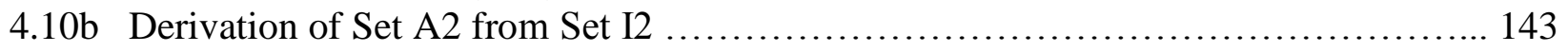

4.11 Pitch content in Part B ............................................................ 143

4.12 Interrelationships between pitch content of sets in Parts A and B ....................... 144

4.13 Circle of tetrachordal transformations in Part B ..................................... 146

4.14 Pitch content in Part A' .............................................................. 146

4.15 Interrelationships between sets in Part $\mathrm{A}^{\prime}$ and in previous parts ................... 148

4.16 Pitch content in Part C, Phrase 1 (Part C1) ...................................... 150

4.17a Sets with direct relationships with Set C1.c ..................................... 151

4.17b Sets with transformative relationships with Set C1.c .............................. 151

$4.17 \mathrm{c}$ Other transformative relationships with Set C1.c ............................... 152

4.18a Sets with direct relationships with Set C1.e ........................................ 152

4.18b Sets with transformative relationships with Set C1.c ............................. 152

4.19 Sets formed through the combination of Sets C1.c and C1.e ........................ 153

4.20 Interrelationships between sets in Part $\mathrm{C} 1$ and in previous parts ................... 155

4.21 Pitch content in Part C, Phrase 2 (Part C2) ...................................... 156

4.22a Sets with direct relationships with Set C2.c .................................... 158

4.22b Sets with transformative relationships with Set C2.c ............................... 158

4.23a Sets with direct relationships with Set C2.e ....................................... 158

4.23b Sets with transformative relationships with Set C2.e .............................. 158

$4.23 \mathrm{c}$ Other transformative relationships with Set C2.p ................................ 159

4.24 Set formed through the combination of Sets C2.e and C2.p ......................... 159

4.25 Interrelationships between sets in Part $\mathrm{C} 2$ and in previous parts ................... 161

4.26 Pitch content in Part C, Phrase 3 (Part C3) ......................................... 162

4.27a Sets related to Set C3.e ........................................................ 162

4.27b Derivation of Set C3.b from Sets C3.d and C3.e ................................ 163

4.28 Interrelationships between sets in Part C3 and in previous parts ..................... 163

4.29 Section III, "Piano Solo," Coda, mm. 150-159 .......................................... 164 


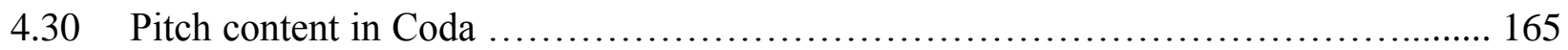

4.31 Derivation of sets from Set Cd.i ................................................. 166

4.32 Interrelationships between sets in Coda and in previous parts ..................... 167

4.33 Section III, "Piano Solo," harmonic rhythm, tempo, meter, dynamics, articulation .... 168

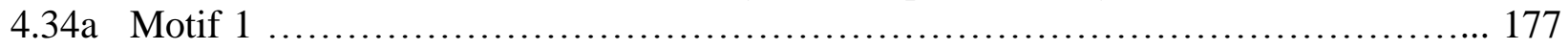

4.34b Three sets of three-note cells, Motif 1 ....................................... 178

4.35 Recurrences of Motif 1 and the intro of Motif 2 in Part A, Phrases 1a and 1a' ......... 178

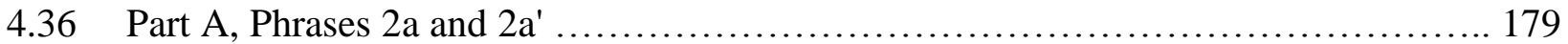

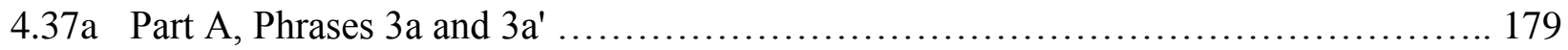

4.37b Similarities between Motif 3 and the gamelan motif in Brief Introduction, m. 60 ..... 180

4.38a Partial recurrences of Motif 1 in Part A, Phrase 4 .................................. 180

4.38b Derivation of the incomplete Motif 1 from the piano parts in Part A, Phrase 2a ........ 180

4.39 Counterpoint, electronics and piano parts; traces of Motif 2 in Part A .......................... 181

4.40 Extension of Motif 1 into Motif 2 ................................................ 182

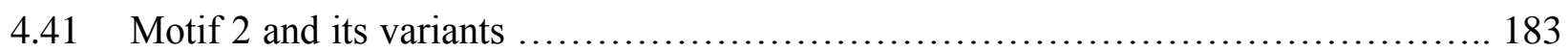

4.42 Common traits between Motif 2 and its variants in mm. 187-188 and m. 191 ........... 185

4.43 Traces of Motives 1, 2, 3, and 4 in Part A, mm. 192-201 ............................... 186

4.44a Treatment of gaps between motives in the electronics in Part A ....................... 187

4.44b Treatment of gaps between electronics and piano parts in Part A ....................... 188

4.45 Traces of Motives 2, 3, and 4 in Part B, mm. 202-223 ............................... 189

4.46a Pitch content in Part B, Segments 1-3 ............................................. 190

4.46b Intervallic relationships between pitch content in Part B, Segments 1-3 ............... 190

4.47a Adeline Wong: Paces, Section IV, "Gameboy/Digital," Part C, mm. 224-243 ......... 192

4.47b Similarities in harmonies between Section IV, Part C and Section III, Part A' ............ 193

4.48 Pitch relationships in Section IV, Part C and other parts in Section III ........................ 194

\section{Chapter 5 Kah Hoe Yii: My Spirit is Dancing!}

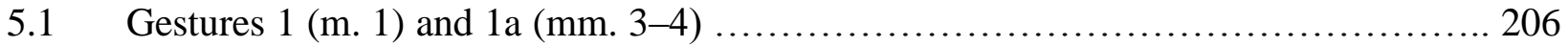

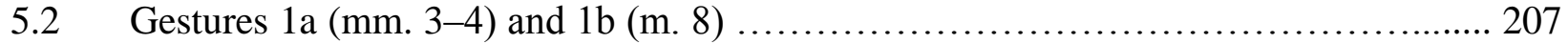

5.3 Gesture 1c (mm. 17-18) and corresponding gestures ............................ 208

5.4 Gestures 1c' (m. 28), 1 b' (m. 29), 1b" (m. 30) and corresponding gestures .............. 209

5.5 Gestures 1b" (m. 30) and 1b"' (m. 62) ........................................... 210

5.6a Gesture 1 and its variants: step-wise descending motions in sounding pitches .............. 211

5.6b Simplification of step-wise descending motions in sounding pitches ................... 212

5.7 Gesture 2a (mm. 5-7) and corresponding gestures ................................ 214

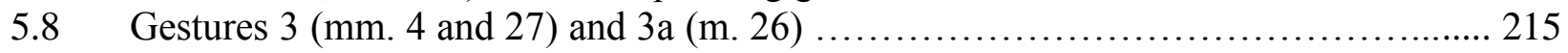

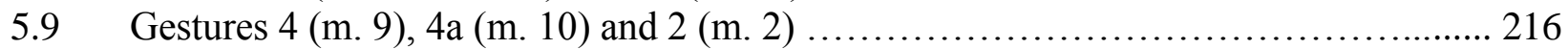

5.10 Derivations of Main Gestures: Gestures 1-4 f.................................... 217

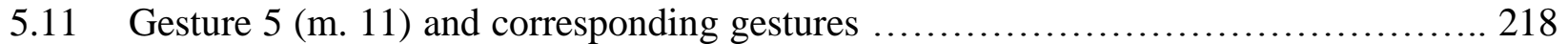

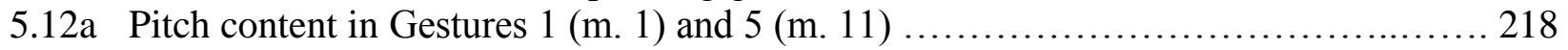

$5.12 \mathrm{~b}$ Relationships between pitch content in Gestures 5 and 1 ........................... 219

5.13 Derivations of Main Gestures: Gestures 1-5 ...................................... 219

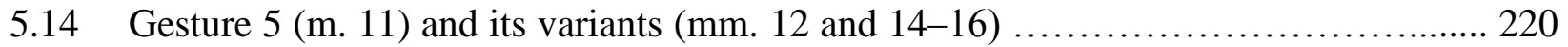

5.15a Pitch content in Gestures 5a (m. 12), 5a' (m. 14), and 5a" (m. 15) ................... 221 
5.15b Relationships between pitch content in Gestures 5a, 5a', and 5a" .................. 221

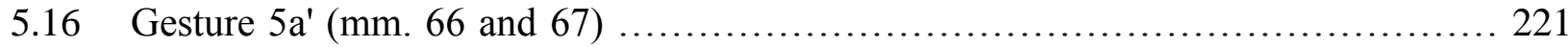

5.17 Gesture $6(\mathrm{~m} .18)$ and corresponding gestures ................................ 223

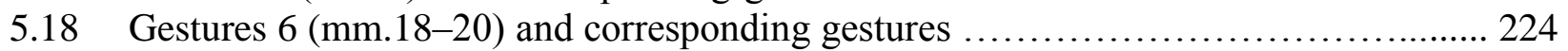

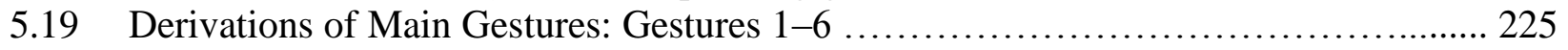

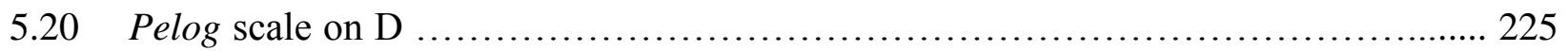

5.21 Gesture $6 a(\mathrm{~mm} .21-25)$ and corresponding gestures ............................. 226

5.22 Gesture $6 \mathrm{~b}(\mathrm{~mm} .31-33)$ and corresponding gestures ........................... 228

5.23 Gestures 6a (mm. 21-23) and 6a' (mm. 34-37) ................................. 229

5.24 Gestures 6a" (mm. 37-43), 1e (m. 44), and 1 (m. 1) ............................................. 230

5.25 Gestures 6a" (m. 37), 6a"' (m. 50), and corresponding gestures (mm. 52-54) ......... 231

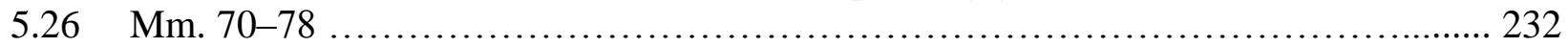

5.27 Gesture 6c (mm. 45-49) and corresponding gestures ........................... 233

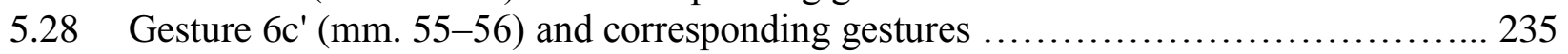

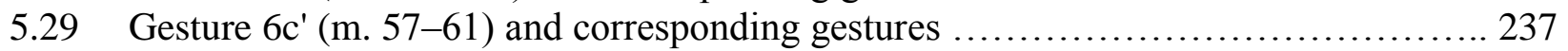

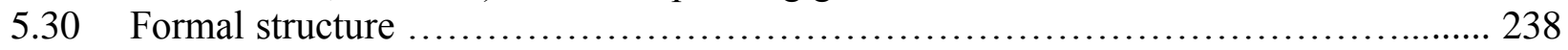

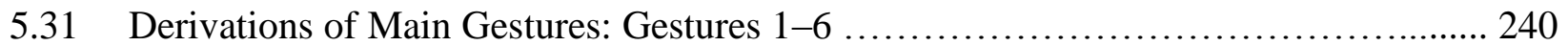




\section{NOTES ON TEXT}

Non-English words - including musical terms, as well as names of instruments, scales, architectures, and organizations - are italicized. Titles of musical compositions, whether in English or in foreign language, are italicized as well. Simplified Chinese characters are also provided next to Chinese terms in parenthesis.

While it is the Chinese tradition to present last name (family name) first, followed by first name (given name), such order is changed in this study for the convenience of Western readers. In addition, during the initial mention of a Chinese name in the body of the text (excluding footnotes and bibliography), the last name is also capitalized to distinguish it from the first name. For example, Ng Chong Lim's name is reordered as Chong Lim NG. 


\section{CHAPTER ONE}

\section{Preface}

\section{Introduction}

\section{Background}

Situated in Southeast Asia, surrounded by Thailand, Indonesia, Singapore, Brunei, and the Philippines, Malaysia is a relatively young developing country with rapid economic and technological growth. The latest report prepared by the Malaysian Department of Statistics (in 2010) indicated a total population of 28.3 million in Malaysia, of which " 91.8 per cent were Malaysian citizens and 8.2 per cent were non-citizens. Malaysian citizens consist of the ethnic groups Bumiputera (67.4\%), Chinese (24.6\%), Indians (7.3\%), and Others (0.7\%)."1

The multi-ethnic, multi-cultural society was a result of former occupations in Malay Peninsula territories by different colonial nations between 1511 and 1957, for its strategic geographical location at the heart of Southeast Asia was most ideal for trade between various Asian regions and Europe. ${ }^{2}$ The colonial nations were namely Portugal (1511-1641), the Netherlands (1641-1786), and Great Britain (1786-1957) ${ }^{3}$ — whose reign was briefly taken over

\footnotetext{
1 "Population Distribution and Basic Demographic Characteristic Report 2010," Department of Statistics, Malaysia, last updated August 5, 2011, accessed March 19, 2012, http://www.statistics.gov.my/portal/index.php?option=com_content\&view=article\&id=1215\%3Apopulationdistribution-and-basic-demographic-characteristic-report-population-and-housing-census-malaysia-2010-updated2972011\&catid=130\%3Apopulation-distribution-and-basic-demographic-characteristic-report-population-andhousing-census-malaysia-2010\&lang=en. Bumiputera or bumiputra (Malay, literally "sons of the soil") refers to the indigenous Malay in Malaysia.

2 John Lah Boh Yong, "The Roles of the Malaysian Government and Private Sectors in the Development of Music Education" (MM thesis, University of Florida, 2003), 3-4, accessed November 19, 2010, http://etd.fcla.edu/UF/UFE0000829/yong_j.pdf.

${ }^{3}$ Patricia Matusky and James D. Chopyak, "Peninsular Malaysia," in The Garland Encyclopedia of World Music, ed. Terry E. Miller and Sean Williams (New York: Routledge, 1998), 4: 401.
} 
by Japan between 1942 and 1945 — who laid the foundations for the formation and development

of modern Malaysia in terms of politics, economy, education, culture, and arts:

The implementation of British colonial policies has resulted in the emergence of a multiracial Malaysian society with each ethnic group preserving its own customs, religions, social norms and musical practices.... In addition there appears to be a desire to adopt Western social practices which are perceived to be synonymous with modernization and socio-economic advancement. This quest includes the assimilation of Western musical practices, adding to the myriad musical practices that accompanied the early migrants to Malaya.... Thus the country's peculiar musical practice is predominantly an offshoot of such historical and political influences. ${ }^{4}$

\section{Colonial Era: Western European Music in Malaya}

One of Malaya's earliest, if not first, encounters with Western European music was during the British era when formal public schools were established beginning from 1816. Music, in the form of singing over piano accompaniment, was adopted into the teaching of English language to locals in order to equip them for employment at civil service, which would ultimately "serve British political and economic interests." Marching bands, recorder ensembles, and choirs were also eventually introduced in larger urban schools as extracurricular

\footnotetext{
4 ““'Acquiring a Music Education': Social and Symbolic Significance of External Public Music Examinations in Malaysia," in Sentuhan: Proceedings of the 27th World Conference of the International Society for Music Education, 16-21 July, 2006, Kuala Lumpur, Malaysia, ed. Wendy L. Sims and Ramona Tahir (Nedlands, WA, Australia: International Society for Music Education (ISME), 2006), 1065-66. Malaya or British Malaya refers to the British territories on Malay Peninsula, preceding the independence of Malaysia.

5 Johami Abdullah, "Music Education in Malaysia: An Overview," The Quarterly Journal of Music Teaching and Learning 1, no. 4 (Winter 1990): 44-45. Abdullah also indicates that there were "three other types of primary schools [or, "elementary schools" in the American term]: the Malay, Chinese, and Indian (Tamil) schools. In each, the medium of instruction was the respective vernacular tongue; consequently, they are called vernacular schools... [These schools] were attended mostly by the children of the lower socioeconomic classes" (ibid., 46). Vernacular schools' music education system differed from that of the British public schools in that traditional and religious songs in each respective native language were taught instead. Some small-scale instrumental music making was also noted in Chinese schools (ibid.).
} 
activities. Although insignificant on the surface, the inclusion of music in education was believed to have made a powerful impact on the younger generations of the different ethnic groups. ${ }^{6}$

Outside of school, military-style wind bands were formed as a means of public and civil entertainment. The musicians were, however, brought in from India and the Philippines, as there was a shortage of local musicians who were Western-trained. This phenomenon generated intercultural marriages and offspring who, more often than not, also became musicians. Together, "they formed Malaysian dance and cabaret bands in the early 1900s, performed in bangsawan theaters, and even played for Malaysian productions of Chinese opera." ${ }^{77}$ At the same time, private and individual lessons of Western instruments began to be given to locals, primarily by the musicians from Goa, India. ${ }^{8}$

After World War II and the Japanese occupation, music education in British public schools notably progressed. This can be seen, for instance, in the expansion of instruments included in instruction, which grew to include such groups as percussion. In addition, music lessons in some of the urban schools were conducted over radio broadcasts by Radio Malaya. ${ }^{9}$ It was also reported that the Associated Board of the Royal Schools of Music (ABRSM) first

\footnotetext{
${ }^{6}$ James D. Chopyak, "The Role of Music in Mass-media, Public Education and the Formation of a Malaysian National Culture," Ethnomusicology 31, no. 3 (Fall 1987): 433.

${ }^{7}$ Matusky and Chopyak, "Peninsular Malaysia," 440. Bangsawan (Malay, literally "nobility") or Malay opera "is a form of theater $\ldots$ at the end of the $19^{\text {th }}$ and beginning of the $20^{\text {th }}$ centuries $\ldots$ as a result of the influence of the Parsi troupes from Bombay ... [Although] the term ... referred to the stories and characters that mainly concerned the Malay royalty, [its performances includes] Malay, Arab, Chinese, Indian, and Western stories and tunes ... [Its music not only] combines Malay and Western musical elements, but some features of Chinese, Indian, Middle Eastern, and Javanese music are also included. [Today, bangsawan is a vanishing cultural heritage]." Patricia Matusky and Sooi Beng Tan, The Music of Malaysia: The Classical, Folk and Syncretic Traditions (Ashford, UK: Ashgate, 2004), 63-67.

${ }^{8}$ Abdullah, "Music Education in Malaysia," 47.

${ }^{9}$ Yong, "Roles of Government and Private Sectors," 20.
} 
conducted (piano) examinations in Malaya in $1948,{ }^{10}$ although there was no record of any private instructions of piano to the locals.

\section{Post-Colonial Era: In Search of a National Identity}

Following the rise of nationalist movements in the British-governed territories, the Malayan Union was formed in 1946 and subsequently in 1948 the Federation of Malaya was formed, achieving its independence from direct British colonial rule and taking its place in the Commonwealth of Nations on August 31, 1957. The Federation of Malaysia was officially established on September 16, 1963 "when the former British colonies of Singapore, as well as Sabah and Sarawak on the northern coast of Borneo, joined the Federation. The first several years of the country's independence were marred by a communist insurgency, Indonesian confrontation with Malaysia, Philippine claims to Sabah, and Singapore's withdrawal in 1965."11

Nevertheless, the ultimate challenge faced by the newly formed government was to strengthen unity amongst the three prevailing ethnic groups in the nation, especially after the socially scarring racial rioting in 1969. It was felt that the creation of a national culture, one that is common to its entire nation, could promote unity. ${ }^{12}$ Hence, a National Culture Policy was established in 1971 with the following principles as guidelines:

\footnotetext{
10 “Acquiring a Music Education," 1064. First established in 1889, ABRSM links with four leading British conservatoires: the Royal Academy of Music (London), Royal College of Music (London), Royal Northern College of Music (Manchester), and the Royal Conservatoire of Scotland (Glasgow). It is "the leading authority on musical assessment ... [with] more than 600,000 candidates, in 93 countries, [enrolling for its examinations] every year." "About Us," The Associated Board of the Royal Schools of Music, accessed January 24, 2014, http://gb.abrsm.org/en/about-us/.

11 "Introduction: Malaysia," The World Factbook, Central Intelligence Agency, last updated January 8, 2014, accessed January 24, 2014, https://www.cia.gov/library/publications/the-world-factbook/geos/my.html.

${ }^{12}$ Sooi Beng Tan, "The Performing Arts in Malaysia: State, Society and the Entertainment Industry," Asian Music 21, no. 1 (Fall-Winter 1989): 137.
} 
1) The national culture of Malaysia music be based on the cultures of the people indigenous to the region [that is, the indigenous Malay];

2) Elements from other cultures which are suitable and reasonable may be incorporated into the national culture; and

3) Islam will be an important element in the national culture. ${ }^{13}$

As rules and legislation were outlined in the newly established policy, respective government institutions were also appointed for the implementation of such policy, all with the objective to shape and to promote a centralized, unified national culture. ${ }^{14}$ As a result, Bahasa Malaysia (or, the Malay language) was assigned as the official national language in conjunction with the combining of British schools and vernacular schools "with the Malay language as the main language of instruction,"15 although over the years, the education system has evolved and changed to meet the needs and interests of the different ethnic groups.

Along the same line, music played a prominent role in being the medium to enforce unity within a multi-ethnic nation, primarily through preservation of traditional music, through education of the younger generation, and through the homogenization of mass media. ${ }^{16}$ Subsequently, the government regulated and supervised the contents of the school curriculum, radio and television broadcasts of domestic and foreign programs, music recordings, and performing arts of the different ethnic groups. This eventually raised controversy amongst local artists and musicians-Malay and Chinese alike — when the government disapproved of anything that it deemed undesirable and against nation-building. ${ }^{17}$

\footnotetext{
${ }^{13}$ Tan, "Performing Arts in Malaysia," 138.

${ }^{14}$ Ibid., $137-41$.

${ }^{15}$ Yong, "Roles of Government and Private Sectors," 27-28.

${ }^{16}$ Chopyak, "Role of Music," 431-33.

${ }^{17}$ Tan, "Performing Arts in Malaysia," 141-60.
} 
Upon independence, it was indicated that the Malaysian government at once "declared Western classical music a colonial legacy [Malaysia] could do without, and dropped music altogether from the public school curriculum." ${ }^{18}$ Instead, the government intended to reintroduce traditional music, particularly that of the Malay, as a national culture for the newly formed nation. Hence, competitions, festivals, seminars, and workshops of "what [the government] called the traditional Malay performing arts" ${ }^{, 19}$ were organized.

However, the government faced several difficulties and conflicts in the process of cultivating a national culture, first of which was deciding the identity of Malay culture. As Malaysia is a Muslim country, it was essential that the national culture includes only traditional Malay art forms that conformed to Islamic rules. For example, nasyid was highly promoted for its close association with Islam, while other art forms—-such as the Malay wayang kulit and mak yong - were neglected, even though they were considered as national heritage, for they conflicted with Islamic beliefs. ${ }^{20}$

Another obstacle was the fact that the nation might have become politically independent from the British, but that is not the same as cultural independence. ${ }^{21}$ As "Britishness" was

\footnotetext{
${ }^{18}$ Roe-Min Kok, "Music for a Postcolonial Child: Theorizing Malaysian Memories," in Learning, Teaching, and Musical Identity: Voices Across Cultures, ed. Lucy Green (Bloomington, IN: Indiana University Press, 2011), 77.

${ }^{19}$ Tan, "Performing Arts in Malaysia," 142.

${ }^{20}$ Ibid., 142-45. Nasyid is "a type of Arabic cantillation of poetry with noble and Islamic themes" (ibid, 142-43). Wayang kulit (Malay, literally "shadow-puppet" theater) is a play with puppets made of leather, whose shadows are projected on a screen, with a narrator and accompaniment music. The traditional wayang kulit depicts the ancient Hindu epics of Ramayana; however, in Malaysia it also includes local elements such as Malay folklore. Mak yong or ma'yong is a type of folk dance-drama which also includes singing. It is usually "performed as part of the ritual healing ceremony known as main puteri." Jack Percival Baker Dobbs and Patricia Matusky, "West Malaysia," in The New Grove Dictionary of Music and Musicians, $2^{\text {nd }}$ ed., ed. Stanley Sadie (New York: Grove, 2001), 15: 666.

${ }^{21}$ Kok, "Music for a Postcolonial Child," 75-77.
} 
frequently associated with "power, with economic and social success," 22 with modernization and internationalism, Malaysians (formerly, Malayans) were imbued with the idea to admire and to adopt the British culture and lifestyle, a part of which was music-making, in order to become British-like. To them, "Western music was the music, and nothing else was accepted as 'culture.",23 As observed by a British visiting musician in 1960:

Traditional Malayan music, although propagandized by radio all day and every day, is quite incapable of being rebuilt to serve as an element in social or intellectual evolution. Instead of Malayans buying their native instruments their fantastic and ever-continuing increase in individual wealth has boosted the sale of pianofortes on which purely Malayan music is unplayable. These sales are largely to households of Chinese, Indian or Ceylonese extraction which are said to form more than half the population. ${ }^{24}$

It is evident that these social groups' valuation of education and music, both traditional and cultivated, is closely related to their country's background, in terms of its cultural background and its economic growth. The perception that "Western" symbolizes a prestigious social status, international recognition, and modernization adds more value to acquiring a Western European music education. "Hence, there appears to be a clear distinction between music that is heard or performed in a social context and music as a form of education, the former being generally associated with traditional music and the latter with Western (including popular) music." 25

Other problems faced in the realization of a national culture included budget constraints, shortage of trained personnel in the responsible ministry, the lack of teaching materials, and thus,

\footnotetext{
${ }^{22}$ Kok, "Music for a Postcolonial Child," 76. David Tze Wan Wong also provides interview excerpts in his book that support this notion of superiority when one is being associated or immersed with Western culture. David Tze Wan Wong, Music of the Chinese in Sabah: The Keyboard Culture (Kota Kinabalu, Malaysia: Opus, 2009), 66-69.

${ }^{23}$ Daud Hamzah, "Malaysia," in New Music in the Orient: Essays on Composition in Asia since World War II, ed. Harrison Ryker (Buren, Netherlands: Frits Knuf, 1991), 91.

${ }^{24}$ Kok, "Music for a Postcolonial Child," 77.

25 ““Acquiring a Music Education,” 1066.
} 
the lack of trained teachers to teach traditional music. "As a result, though the school curriculum was and is being revised to include traditional Malay arts, much of the formal music teaching is still geared towards Western music.",26

\section{Western European Art Music in Malaysian Music Education}

Subsequently, local teacher training institutions began providing basic Western musical training in vocal and choral singing, recorder, and theory to student teachers. Some students were even sent abroad to further their studies in music education, initially only in Great Britain, then in the United States of America beginning in the 1970s, which contributed to the addition of guitar, music pedagogy, and music history to the curriculum of teacher-training programs in Malaysia. $^{27}$

More trained teachers made formal music education in government-funded public schools possible. Music was added to the curriculum of primary schools as a compulsory subject in 1983 with the aim to "develop an interest in and appreciation for music, songs, and dances of the Malaysian culture. Specifically, Western music is taught to enable students to recognize and read musical notes and terminologies and later, to compose melodies according to their levels of creativity." 28 That is, Western European art music provides tools that are valuable in transmitting Malay culture, such as music notation. At the secondary level, music was offered as an optional elective or as a part of extracurricular activities in the form of music clubs, choir, and

\footnotetext{
${ }^{26}$ Tan, "Performing Arts in Malaysia," 144-45.

${ }^{27}$ Abdullah, "Music Education in Malaysia," 49. British colonialism left a deep impression in former colonies that anything British was perceived as superior. Therefore, the act of seeking knowledge elsewhere other than Great Britain signifies, in a way, that Malaysia no longer relies as heavily on the British as a source of information and influence.

${ }^{28}$ Yong, "Roles of Government and Private Sectors," 48.
} 
ensembles. ${ }^{29}$ However, the quality of the music curriculum and the teachers' qualification were less than ideal. Moreover, most of the public schools lacked resources and facilities; hence, instrumental lessons were either limited or close to non-existent. ${ }^{30}$

For the aforementioned reasons, most students received music education outside of school at commercial music centers and/or private music studios, with the piano and guitar being the most popular choice of instrument. ${ }^{31}$ These music centers have long employed the British graded music syllabus in the instrumental teachings, with that of the Associated Board of the Royal Schools of Music (ABRSM) being the most prevalent of all. Other music syllabi found in Malaysia included that of the Trinity Guildhall (Trinity College of Music, London, amalgamated with Guildhall School of Music and Drama, London, in 2004), ${ }^{32}$ Yamaha Music Education System (Japan), Technics Academy, Kawai Music School, ${ }^{33}$ Australian Music Examinations Board (AMEB), Australian and New Zealand Cultural Arts (ANZCA), and the most recently established International Music Examination Board (IMEB, Australia).

In these graded systems, students' music proficiency and their ability to progress to the next level are determined by an international or external music examination at the end of each grade. These examinations, assessed by music professionals from the respective countries, are held once or twice a year, every year, for up to three months' period each. In 1983, it was

\footnotetext{
${ }^{29}$ Yong, "Roles of Government and Private Sectors," 49.

${ }^{30}$ To date, government-funded public schools still face similar dilemmas. On the other hand, recent years have seen the growth of international schools in cities such as Kuala Lumpur, Penang, and Melaka, where music education is more advanced and more complete. Individual and/or group instrumental lessons are generally available; some even have their own bands, choirs, and musical theater productions.

${ }^{31}$ Yong, "Roles of Government and Private Sectors," 69-70.

${ }^{32}$ Wong, Music of Chinese in Sabah, 5.

${ }^{33}$ Yong, "Roles of Government and Private Sectors," 79.
} 
estimated that up to 10,000 students enrolled for piano examinations held by ABRSM yearly. ${ }^{34}$ By the end of the $20^{\text {th }}$ century, the figure multiplied by seven times and it was reported that Malaysia even manufactured pianos for export. ${ }^{35}$

In general, the British and Australian syllabi share some similarities. Both syllabi consist of the practical study of various instruments and voice (both solo and ensemble), music theory, history, and basic musicianship skills. The curricula consist predominantly of, but are not completely limited to, Western European classical music and contemporary music. The main difference between both syllabi is that the British grading system begins from Grade 1 to 8 in ascending order, with Grade 8 being the highest level of achievement while the Australian contains three additional grades before Grade 1, which are known as Pre-Grades 1 to 3 or Introductory, Preparatory, and Preliminary. Upon completion of the graded examinations, students may proceed to obtaining the diploma certificates (commonly, the Diploma or Associate, Licentiate, and Fellowship diplomas), after which they may qualify for a teaching position at music centers. Some of the examination boards also conduct teacher development seminars on teaching strategies, theory pedagogy, music history, performance practice, stylistic analysis of examination pieces, and updates on examination syllabi.

Next in importance after the ABRSM, the Yamaha Music Education System (YMES) from Japan has been popular in Malaysia since 1974 following the establishment of Yamaha Music Malaysia. ${ }^{36}$ YMES is also a graded examination system but it "broadly targets two groups: students and instructors. Student grades [Grades 13-6] are used as an objective

\footnotetext{
${ }^{34}$ Abdullah, "Music Education in Malaysia," 47.

35 “"Acquiring a Music Education,” 1064.

${ }^{36}$ Yong, "Roles of Government and Private Sectors," 76.
} 
assessment of the progress made in learning music, while the instructor grades [Grades 5-3] certify the performance ability as well as overall musical knowledge needed to provide music instruction." ${ }^{37}$ Honorary awards [Grades 2 and 1] "are bestowed on individuals of outstanding performance achievements in the concert circuit.",38

Although YMES is catered to students of all ages, its methods are "designed to teach music from the fundamentals... with the objective of bringing out children's potential and nurturing their capabilities to express themselves through music. ${ }^{\prime 39}$ This is achieved by incorporating three approaches: 1) comprehensive music education, 2) timely education, and 3) lessons in groups. YMES believes that "an essential point in enjoying music is a comprehensive understanding of the elements of music: 'listen', 'sing', 'play', 'read', and 'compose'.,40 Group lessons are usually conducted on the electronic organ or the Yamaha Electone and are believed to be effective in promoting musical learning and creativity in young children. ${ }^{41}$ Ear training and solfege singing, which are the two fundamental aspects in YMES, are also introduced from the early stage; as a result, students who undergo this system more often than not possess perfect pitch. Students also learn about basic functional harmonic progressions (including transposition of such progressions), improvisation, composition, and ensemble playing, to name a few skills.

37 "What is Yamaha Grade?," Yamaha Music Foundation, accessed January 28, 2014, http://www.yamahamf.or.jp/english/grade/about.html. Grades 13-11 are currently offered for keyboard beginners only (ibid.). See also "Yamaha Grade Examination Chart," Yamaha Music Foundation, accessed January 28, 2014, http://www.yamahamf.or.jp/english/grade.

${ }^{38}$ Patricia Marie Ooi, “A Description and Comparison of Two Prominent Keyboard Music Education Systems and Their Implications for Music Education in Malaysia" (MM thesis, University of Miami, 1999), 49.

39 "Features of Yamaha Music Education System," Yamaha Music Foundation, accessed January 28, 2014, http://www.yamaha-mf.or.jp/english/edu_system/about/index.html.

40 “Three Features for Nurturing the Musical Skills of Children in a Relaxed Environment," Yamaha Music Foundation, accessed January 28, 2014, http://www.yamaha-mf.or.jp/english/edu_system/about/features.html.

${ }^{41}$ Yong, "Roles of Government and Private Sectors," 77-78. In Malaysia, Yamaha Music School is more known for the study of Electone-partly a marketing strategy to boost the sales of the Electone-while ABRSM is still the primary choice when it comes to the study of piano. 
The repertoire includes Western European classical music, music written by Japanese composers in Western European styles, and arrangements of popular, jazz, and film music.

"YMES is only operated in the Yamaha Music Schools where the music teachers are trained totally for the specific music courses, ... [which] are designed and developed according to specific age groups." ${ }^{42}$ Therefore, YMES instructors are, in a way, trained specialists, in comparison with those who teach the British and Australian syllabi, many of whom may have obtained qualifications through examinations but not necessarily pedagogical training.

Nonetheless, both ABRSM and YMES have, to a great extent, contributed "to the enrichment of the music education program in Malaysia, [in that] both boards are responsible for introducing Western art music to the people of Malaysia ... [and] both systems are the main forces in upgrading the performance skills of music students. ${ }^{, 43}$ Yamaha Music Malaysia, in particular, "has undertaken the task of assisting the Malaysian government [through the Ministry of Education] in the cultivation of mass music literacy in the country ... [by providing instrumental] training [to] public school music teachers ...; providing assistance in setting up drum corps and marching bands in the public schools; ... conducting pilot projects in selected public schools in the area of keyboard ensembles; ... [and developing] a four-year electronic keyboard curriculum in collaboration with the Institute of Technology in Malaysia."

Towards the end of the $20^{\text {th }}$ century, music enthusiasts were given another option in furthering their musical studies locally and abroad. Both local government universities and private institutes at the tertiary level began offering music degrees, which now extend to the level

\footnotetext{
${ }^{42}$ Yong, "Roles of Government and Private Sectors," 76.

${ }^{43}$ Ibid., 79.

${ }^{44}$ Ooi, "Two Prominent Keyboard Systems," 55.
} 
of Doctor of Philosophy. In this regard, a certain level of achievement in external public music examinations is usually the pre-requisite for admission to the music program at universities and colleges.

Private institutes commonly started with twinning programs with foreign universities, whereby students may partially begin their studies at local private institutes and complete the degree at the respective universities abroad. In the early $21^{\text {st }}$ century, upon assessing and recognizing the quality and standard of education at local institutes, the twinning program evolved into a totally different concept, whereby completion of the degree entirely at local institutes was allowed, with the degree still being conferred by participating foreign universities. Eventually, some of the local institutes began to offer their own degree programs, which encouraged more attendance in tertiary level as costs of study and living are comparatively lower. This phenomenon not only applies to music education but also to the general higher education in private Malaysian institutes.

\section{The Study of Piano}

As addressed earlier, the acquisition of a Western European music education by a group of non-Western colonies was predominantly a result of the colonies' aspiration to adopt Western social and cultural practices, which were typically perceived as superior and privileged. Inevitably, this trend applied to Malaysia as well, where Western European art music was portrayed as “a 'cultured-art,' synonymous with success and refined taste."45

The piano became the primary icon of European culture. During the British colonial era, the middle-class Malayans - mostly the Chinese and Indian — who recognized the social

\footnotetext{
45 “"Acquiring a Music Education,”" 1067.
} 
implications of the piano began welcoming it into their homes. ${ }^{46}$ On this account, Roe-Min $\mathrm{KOK}^{47}$ recalls her experiences while learning to play the piano between late-1970s and mid1980s, in which she reasoned:

Respect for British systems of education remained deeply ingrained among those in my parents' generation [presumably, those who were born before World War II in preindependent Malaya]... The ABRSM's elaborate system and its Commonwealth-wide reputation gained unquestioning respect and approval from Her Majesty's Malaysian subjects from the very beginning.... Successful completion of each grade would result in both "international" recognition (since the system was known throughout the Commonwealth) and local respect. The high price tags of lessons and examination fees, the latter converted directly from British pounds [which at that time, according to the author, fluctuated between the ratio of 7-8 Malaysian ringgit to 1 British pounds], were prohibitive for all but the wealthy or the most committed. Thus the enterprise of taking piano lessons became wreathed in an aura of pride and prestige for its middle-class adherents. ${ }^{48}$

In a four-year study on ““Acquiring a Music Education’: Social and Symbolic

Significance of External Public Music Examinations in Malaysia” (2006), researchers came to the conclusion that "a certificate of 'international value' [like that offered by ABRSM] has the ability to transform itself into a significant symbol that influences local perception, insinuating itself into existing domestic practices. Internationalism has fostered the emergence of new world societies which are marked by their distinctive status anxieties." 49

Undeniably, the attraction of international recognition and the pride of such achievement constitute a major motivation behind the study of Western European art music, particularly the piano. However, the costs of piano lessons and relevant expenses these days are comparatively higher than that of three decades ago, even with inflation considered. It is also more costly to

\footnotetext{
${ }^{46}$ Kok, "Music for a Postcolonial Child," 77.

${ }^{47}$ Roe-Min Kok is a third-generation Chinese-Malaysian who currently serves as Associate Professor in the Department of Music Research at McGill University, Quebec, Canada.

${ }^{48}$ Kok, "Music for a Postcolonial Child," 79.

49 ““'Acquiring a Music Education,” 1069.
} 
learn to play the piano than, for example, the guitar, but this does not seem to have a negative impact on the former. In contrary, the piano is still "by far the most commonly studied instrument" ${ }^{, 50}$ in Malaysia and the population of piano students is constantly growing, as evident in the enrollments in the international examinations yearly.

It seems there must be additional motivations that drive the burgeoning study of the piano. Indeed, given the many academic subjects undertaken at school that are already keeping a child occupied, learning to play the piano might seem dispensable-but in practice this does not seem to be such a case. Again, one may suggest that music is a pleasant pastime, a stressreleasing tool-however, in this case, it is a rather expensive hobby, and the process of learning may add more stress to a child. Although, arguably, scientific studies have proven that arts aid in the development of a child's brain and affect one's behavior, one still has the choice to select a more economical method. Therefore, the trend of piano studies in Malaysia — which at times may seem “disproportionate to the country's population, ... [in that an] unusually high [number] of examination candidates [enroll in the international examinations] annually" ${ }^{, 51}$ _raises curiosity on the general public's need and demand for such education.

The question is sharpened by a 2006 study that also reveals a peculiar norm in the study of piano in Malaysia:

Given such a large number of students who learn the piano, one might reasonably expect a healthy development of musical talent in the country, with aspiring concert pianists eager to demonstrate their musical talents. One might also expect a high standard of playing, a lively interest in public performance and frequent concert attendance by music students. Strangely however, this does not seem to be the case. A paradoxical situation has emerged in the disparity between playing in private for the music examiner and

\footnotetext{
${ }^{50}$ Minni Kim Huai Ang, An Introduction to Malaysian Music, $2^{\text {nd }}$ ed. (Malaysia: Musicmall Conservatoire Productions, 2002), 10, accessed March 5, 2012, http://www.musicmallasia.com/minni/General/Malaysian_Music.pdf. Site discontinued, but PDF file is available at http://jiwaansos.webs.com/Malaysian_Music.pdf (accessed January 24, 2014).

${ }^{51}$ Kok, "Music for a Postcolonial Child," 82.
} 
playing in public. This state of affairs seems to suggest that many of these students learn the piano for the sake of passing examinations, or perhaps there is more to it. ${ }^{52}$

Despite the fact that the study of piano is costly, especially in that it requires years of learning, more parents are prone to provide their children with an external music education at commercial music centers or private music studios nowadays. However, other than acquiring the instrumental playing skills and relevant musical knowledge, there seem to be little effort in cultivating what one might call a musical lifestyle. This raises questions pertaining to the general public's concept of music education, and implies that there may be other reasons that encourage the study of piano in Malaysia.

One reason is the development of character. A study of "Parental Attitudes Regarding Children's Music Learning in Kuala Lumpur" (2008) reveals that some parents believed the study of piano cultivates extra-musical qualities such as "self-discipline ..., self-control, patience, and good temperament." ${ }^{, 53}$ David Tze Wan WONG also provides several interview excerpts in his book, Music of the Chinese in Sabah: The Keyboard Culture, that supports the same perception that piano studies help build such qualities in a child's character. ${ }^{54}$

In this regard, Kok also shares her view:

To the Malaysian Chinese community, Western classical music and the piano offered additional attractions. As the piano requires much discipline and time to master, the enterprise of learning the instrument is in line with Confucian teachings, which emphasize among other things continuous, in-depth, and committed efforts in all educational undertakings. Confucius had also taught that cultivation of music would lead to "goodness" of character. Thus a Chinese child's successful mastery of music and the piano would engender satisfaction and guarantee respect for the family from within as well as outside of the Chinese community. ${ }^{55}$

52 “"Acquiring a Music Education,"” 1064.

${ }^{53}$ Grace Kah Yan Leong, “Love It, Love It Not: Parental Attitudes Regarding Children's Music Learning in Kuala Lumpur" (BMus hons thesis, University of Sydney, Australia, 2008), 45-46, accessed February 29, 2012, http://hdl.handle.net/2123/3993.

${ }^{54}$ Wong, Music of Chinese in Sabah, 84-85.

${ }^{55} \mathrm{Kok}$, "Music for a Postcolonial Child," 77. 
However, how is growth in character assessed? Due to the fact that it requires an incredible amount of time and effort to master piano playing skills, some parents tend to appraise effort in the learning process, more than the amorphous measure of a child's ability at the instrument. ${ }^{56}$ This attitude is in line with many Asian teachings, in that "knowledge and ability cannot be obtained straightaway but [are] accumulated gradually over a long period of time. [Thus,] the more effort one exerts on a task, the more successful the outcome will be." ${ }^{57}$ The 2006 study also found that a student's "musical talent and performance ability are regarded as secondary to the discipline of practice and goal-attainment." ${ }^{, 58}$ This shows that music education in Malaysia is generally not performance-oriented. Perhaps this is one of the reasons for the lack of participation in public performances by local piano students.

Moreover, Confucian ideals can undermine concert life, with its emphasis on the capacity of music to give pleasure, in other ways as well. Wong raises another pointed issue with regard to treating the study of piano as a form of discipline, particularly the need of adhering closely to what is written on the music score. He suggests:

A child may show enjoyment in playing the piano pieces but may play them without any attempt at improving skills; they are simply enjoying playing and listening to their musicmaking. But soon the child is likely to develop a "guilty conscience" because he or she is supposed to practice to improve his or her skills rather than "wasting" time having a pleasurable experience ... [because] playing around is strongly discouraged [in the Chinese family]..$^{59}$

This is especially true when so much of the piano education in Malaysia aims to prepare students for examinations, hence focusing on the technical aspects of piano playing, but not

\footnotetext{
${ }^{56}$ Leong, "Parental Attitudes," 48.

${ }^{57}$ Ibid., 14.

58 ،“'Acquiring a Music Education,” 1067.

${ }^{59}$ Wong, Music of Chinese in Sabah, 85-86.
} 
necessarily cultivating passion for the music in the process. ${ }^{60}$ In general, most of a piano student's repertoire constitute of examination pieces, which he or she would have lost interest in, after being drilled with the same pieces for several months. This suppression of pleasure as a component of the experience of music also explains the phenomenon where many piano students tend to drop out before completing — or as soon as they have achieved — the highest grade in the examination system.

Along the same line, Kok offers the following insight on the value of music education within Malaysian culture, based on her experience:

For lower-middle-class families such as my own, the piano offered the additional attraction of a long-term investment: music could "round off" the children's education, strengthen their chances for admission to good universities, and provide an alternate means of future income if necessary (a belief held especially true for females in late twentieth-century Hong Kong, Japan, Korea, the People's Republic of China, Singapore, and Taiwan as it had been for females in nineteenth-century Europe and North America). In other words, piano both represented and provided an avenue to upward mobility. ${ }^{61}$

This position has broader applicability as well. The notion of acquiring a "well-rounded" education has as its goal the acquisition of a basic knowledge of every academic subject—in which case, due to the fact that a majority of schools in Malaysia either offer a low-quality general music course or do not offer music at all, some parents may feel that a child's academic training is incomplete without "proper" education in music. ${ }^{62}$ Thus, they see the need to provide their children with external music education in order to "round-off" his or her education.

However, when such education is provided, it is often ranked the least important among all

\footnotetext{
${ }^{60}$ Wong, Music of Chinese in Sabah, 77-80.

${ }^{61}$ Kok, "Music for a Postcolonial Child," 79-80.

${ }^{62}$ Leong, "Parental Attitudes," 40.
} 
academic subjects, which suggests a contradicting attitude towards the significance of acquiring a music education. ${ }^{63}$ It is a necessary and expensive component, yet a minor one.

It is also essential to understand that "the operations and assessment focus of the [international or] external public music examinations are congruent with the examinationorientation of the Malaysian national education system. It shares similar goals and value towards the purpose and product of learning and teaching." 64 Therefore, music is often treated as one of the academics determined by a set of grades (usually ranging from passed to merit, distinction, and high distinction), with parents expecting their children to achieve a certain benchmark in such examinations; hence, the notion of one learning to play an instrument merely for the purpose of passing examinations. This shows that some of the public's concept of acquiring a music education was not so much so as to be able to perform, but more so that one strives to score high in yet another academic subject. Public musical performance, in this context, is as tangential as a public demonstration of mathematical skills.

Indeed, there are reasons to class music with other, quite different, skills, including those quite definitely not intended for public display. In Asia, admission to top universities has increasingly become more competitive, such that one not only has to be outstanding academically, but also has to excel in extra-curricular activities - any additional sports, skills, awards, or involvement in authorized organizations may be a bonus; this includes obtaining a high level of achievement in international music examinations. As such, some parents enroll their children in music lessons "to maximize their children's potential ... [with the hope] that their children would have an extra skill when compared to peers, ... [and partly also due to the

\footnotetext{
${ }^{63}$ Leong, "Parental Attitudes," 31.

64 “"Acquiring a Music Education,"” 1067.
} 
fact that] other parents are doing [the same]. ${ }^{, 65}$ Therefore, in a way, music education has become a trend, in which piano is the most popular choice for such study.

Gender provides another lens for understanding the small scope of public music-making. Throughout the world's history, it was not uncommon that females were prohibited from receiving formal education in institutes like males did. Instead, they were "home-schooled" to master household skills such as culinary arts and sewing, as well as art skills such as painting, playing music instruments, singing, and dance. These skills were considered fundamental criteria of being a good wife, and the mastery of these skills would increase one's chance of marrying into a wealthy household. This is also reflected in a "seemingly sexist [Chinese] ideology of the responsibilities of both genders" ${ }^{26}$ that goes, "The male takes care of the household by working outside, while the female takes care of the household, literally."

In some Asian of culture, this still holds true. Generally, the arts are perceived as "feminine" in comparison with the science, law and enforcement, or business. Thus, in the past, parents encouraged their daughters instead of their sons to learn music. Even if music education was provided to the latter, they were seldom encouraged to pursue a music career, especially as a piano teacher. Therefore, most piano teachers back in the days were female. A teaching career was perceived as a noble job; hence, teachers normally earned respect from the community, even more so if the career received international recognition, such as the teaching of ABRSM piano syllabus. When commercial music centers and private studios flourished in the late $20^{\text {th }}$ century, it seemed increasingly promising for females to pursue a piano teaching career.

\footnotetext{
${ }^{65}$ Leong, "Parental Attitudes," 30.

${ }^{66}$ Ibid., 11.
} 
Yet despite the cultural advantages of a career as a music teacher, in modern day Malaysia, it was found that "very few [parents] would encourage their children to pursue tertiary levels of music education or to carve out a career in the music profession ... [despite having invested] large amounts of money into what is considered a luxury in a child's education." ${ }^{.67}$ As Kevin Field, the Associate Conductor of the Malaysian Philharmonic Orchestra (MPO), emphasized in the following remarks in a 2002 interview:

The Malays [or, presumably, Malaysians] are inherently artistic. They are artists, dancers, singers, and musicians. It's in their nature, their grace, their warmth. You can see it in their dress sense with the fabrics and the colours. You can see it in the theatres and art galleries here - and the food, even. When they are ultimately artistic by nature, it's then interesting to see them "forced" through professions such as accountancy, law, science and engineering. Persuading a parent that their child has a potential career in the arts as a musician is sometimes met with a smile that suggests: "Not before they get a degree in law they won't!",68

How can we account for this? Although the reasons remain unknown, one may speculate its association with the different perceptions and attitudes discussed above. First, music is often seen as the least important subject in school, if it is offered at all. Therefore when it is acquired outside of school, music is of secondary importance as well. This may also be the main cause for dropouts upon completion of the highest grade of the examination, if not midway through such education.

Again, since having musical skill increases one's chance of admission to a good university, perhaps music is treated as a supplementary subject, a means to that end. Or, considering music's historically gendered position, the ability to play and teach music is perceived as a back-up survival skill that may bring in extra income in an increasingly competitive society and not an honorable public profession.

\footnotetext{
${ }^{67}$ Leong, "Parental Attitudes," 3.

${ }^{68}$ John Robert Brown, "Twin Peaks (Malaysian Philharmonic Orchestra Audience Receptive to New Music)," Classical Music: The Magazine of the Classical Music Profession (England) no. 711 (June 8, 2002): 25.
} 
Nevertheless, there are parents who recognize their children's musical potential, and support them with music education in hope to "nurture their musical ability and to provide the enjoyment of playing a musical instrument, ${ }^{~} 69$ perhaps as they did not have the opportunity to enjoy such luxury when they were young. It was presumably most of them who grew up in this supportive environment that survived the long pathway of musical learning, and in turn have the passion to contribute to the education of future generations.

\section{The Current State of Western European Art Music in Malaysia}

Upon independence, the Malaysian National Culture Congress felt the need of having a Western orchestra as part of the effort in building a modern nation. Thus, a national orchestra, the Orkestra Radio Television Malaysia (RTM Orchestra), was formed in $1961 .{ }^{70}$ Developed as a dance orchestra, the RTM Orchestra has since been responsible for accompanying singers and performing instrumental music in pre-recorded and live studio performances for national broadcast. $^{71}$

In the late $20^{\text {th }}$ century, a number of government-funded professional orchestras were gradually set up, most of which promote Western European art music in periodical concerts. These orchestras include the Orkestra Kuala Lumpur, which is based in the capital's City Hall, and the National Symphony Orchestra (NSO), which is based in the Istana Budaya (Malay, literally "Cultural Palace") in Kuala Lumpur. The NSO was established by the Ministry of

\footnotetext{
${ }^{69}$ Leong, "Parental Attitudes," 32.

${ }^{70}$ Tan, "Performing Arts in Malaysia," 143. Radio Television Malaysia (RTM) is the national broadcasting department responsible for providing entertainment and information authorized by the government. Yong, "Roles of Government and Private Sectors," 60.

${ }^{71}$ Chopyak, "Role of Music," 442.
} 
Culture, Arts and Tourism in 1993, a year after the formation of the National Choir. ${ }^{72}$ It was the "standard bearer for Malaysian orchestras"73 until the founding of the Malaysian Philharmonic Orchestra (MPO) in 1998 - the latter is currently the primary and only professional symphony orchestra in Malaysia of international standard. $^{74}$

Housing the MPO is the Dewan Filharmonik PETRONAS (DFP) (PETRONAS Philharmonic Hall), Malaysia’s first "concert hall devoted specifically to classical music,"75 which is located at the base, between the PETRONAS Twin Towers in Kuala Lumpur. The innovation is in line with the Malaysian government's vision of developing the country into a modern nation and an international center for culture and arts. As Jamie James observes, "Ten years ago [presumably, ca. 1994] Asia's cities were all building cathedral-like airports; now, they must have their performing-arts palaces."76 Opened in 1998, the DFP has since hosted 15 seasons

\footnotetext{
${ }^{72}$ Yong, "Roles of Government and Private Sectors," 66-67. In 1998, the NSO also "launched the Youth Symphony Orchestra and the Youth Choir to encourage youth's participation in music and to provide mentorship to young musicians" (ibid., 67).

${ }^{73}$ Ang, Introduction to Malaysian Music, 10.

${ }^{74}$ Ibid. "Professional" here means that the orchestra comprises of all full-time musicians (at the present, there are some 80 players in the MPO), in contrast with the NSO which, according to Ang, consists of a mixture of full-time and part-time musicians. The notion of "international standard" is also literal, in that majority of the orchestra members are foreign musicians, and the pay is of European standard. Nonetheless, it is reassuring to know that the management recognizes the local assets and intends to keep them in the orchestra by offering tuition scholarships and salary wedges. Brown, "Twin Peaks," 24-25.

75 “About Dewan Filharmonik PETRONAS,” Malaysian Philharmonic Orchestra, accessed January 25, 2014, http://mpo.com.my/About-DFP/About-Us.aspx. Petroliam Nasional Berhad (PETRONAS) is Malaysia's national oil and gas company. It was reported that this innovation is part of PETRONAS's "aspiration and its holistic development approach which combined business with science, technology and the arts." "Orchestra is Part of Petronas' CSR,” MySinchew (Malaysia), June 30, 2008, accessed April 8, 2012, http://www.mysinchew.com/node/13309?tid=14.

76 Jamie James, “The Rise of a Musical Superpower,” Time, June 28, 2004, accessed March 13, 2012, http://www.time.com/time/asia/magazine/article/0,13673,501040705-658369,00.html.
} 
of MPO's concerts as well as that of foreign artists and orchestras. It also continues to promote local music and traditional performing art forms through its annual Seni Festival (Art Festival). ${ }^{77}$

Besides the DFP, Istana Budaya and the Kuala Lumpur Performing Arts Centre (KLPac) are also acoustically designed concert venues that host various genres of performing arts by both international and local artists. With the construction of these facilities, "the number of [music] concerts has tremendously increased in the recent years, [exposing the nation to a variety of musical genres, and] showing that this developing country has given emphasis to enhance culture and arts. ${ }^{.78}$

Outside of Kuala Lumpur, the state government of Penang in northern Peninsular Malaysia funded the Penang Philharmonic Orchestra (PPO) (formerly known as the Penang State Symphony Orchestra and Chorus [PESSOC]), and the Radio Television Malaysia (RTM) also houses the Orkestra Kuching in the state of Sarawak in East Malaysia. Other than the government, local art communities have also shown their support in cultivating the arts, especially among youth, through the organizations of amateur orchestras and choirs. One of the earliest non-governmental, amateur musical organizations is the Philharmonic Society of Selangor, which began producing musical theatre and choral performances as early as 1958 . Throughout the years, many other performance groups were formed with the aim of providing a platform for amateur musicians to share their passion and skills with the local communities, and at times, communities abroad. These performance groups were mainly found in Kuala Lumpur; for instance, the Kuala Lumpur Symphony Orchestra (KLSO), Malaysian

\footnotetext{
77 “About Dewan Filharmonik PETRONAS” (website).

${ }^{78}$ Fung Chiat Loo, "A Case Study of the Audience at Three Art Music Concerts in Malaysia," Pertanika Journal of Social Science and Humanities (Universiti Putra Malaysia) 17, no. 2 (September 2009): 79, accessed March 9, 2012, http://www.pertanika.upm.edu.my/Pertanika\%20ARCHIVES/JSSH/2009/JSSH\%20Vol\%2017\%20(2)\%20Sep\%202 009.pdf (article removed).
} 
Philharmonic Youth Orchestra (MPYO), KLPac Orchestra, PJ Youth Symphonic Band, Young KL Singers (YKLS), and the Dithyrambic Singers. Some of the government universities and private institutes also have their own orchestras and choirs; for example, the Universiti Putra Malaysia (UPM) Symphony Orchestra, and the Malaysian Institute of Arts (MIA) Choir. ${ }^{79}$ In addition to nurturing musical talents, some of these music organizations are active in reaching out to the local communities, especially by holding charity concerts. One of the noteworthy programs is the MPO's Education and Outreach Program, entitled ENCOUNTER, which "reaches beyond the concert platform to develop musical awareness, appreciation, and skills through dedicated activities that include instrumental lessons, workshops, and school concerts." $\$ 0$ It is mandatory that each MPO orchestra member take on at least one student, through which the MPYO was formed. In 2013 a new orchestra, the Encounter Training Ensemble (ETE), was added where "novice and intermediate musicians ... [are given the opportunity to] rehearse and perform at DFP ... accompanied by a variety of guest conductors." ${ }^{\prime 81}$ Smaller teams of MPO musicians are also sent out to rural areas, which at times are remote, to work with local communities based on the resources available to them. ${ }^{82}$ The program also reaches out to the underprivileged by holding concerts at local community service facilities. ${ }^{83}$

Undoubtedly, the growth of these music organizations alongside commercial music schools with foreign assessments encouraged local communities to engage more actively in

\footnotetext{
${ }^{79} \mathrm{Ang}$, Introduction to Malaysian Music, 10-11.

80 “Orchestra History,” Malaysian Philharmonic Orchestra, accessed February 27, 2012, http://www.mpo.com.my/Meet-The-MPO/World-Tours.aspx.

81 "Encounter Ensembles," Malaysian Philharmonic Orchestra, accessed December 23, 2013, http://www.mpo.com.my/Education---Outreach/Encounter-Ensembles.aspx.

${ }^{82}$ Brown, “Twin Peaks," 25.

83 "Orchestra History" (website).
} 
music-making. As a result, the recent decade saw an increase in the number of music camps, workshops, and festivals (which often comprise seminars, masterclasses, recitals, and a competition at the end of the festival) held annually by both governmental and private agencies, especially in metropolitan areas. For instance, the government has sponsored music training camps for youth, the Chorale Festival of Kuala Lumpur, and the Song Festival of Malaysia; ${ }^{84}$ the ABRSM often collaborates with the British Council in holding concerts and competitions; ${ }^{85}$ and the Yamaha Music School continues to organize its annual Yamaha Electone Concourse and Festival, which encourages solo and ensemble performances as well as composition.

Besides providing a platform for local musicians to showcase their talents and to receive constructive suggestions from music professionals and guest artists, these musical programs also play an important role in raising public awareness of the essence of music and its education. Subsequently, a number of organizational bodies initiated funding and financial assistance to young musical talents to further their studies both locally and abroad. For instance, the Malaysian Youth Orchestra Foundation (MYOF) was founded in 1997, with the aim of assisting "in the development and greater appreciation of orchestral music and the performing arts" 86 through the collection of donations and direct involvement in musical activities organized for youth, such as the Malaysian Youth Music Festival. ${ }^{87}$ Besides that, it also offers financial aid and scholarships, in addition to sponsoring musical instruments and books. ${ }^{88}$

\footnotetext{
${ }^{84}$ Hamzah, "Malaysia," 95-96.

${ }^{85}$ Yong, "Roles of Government and Private Sectors," 79.

86 “About MYOF,” Malaysian Youth Orchestra Foundation, accessed January 26, 2014, http://www.myof.org.my/about.

87 "Malaysian Youth Music Festival," Malaysian Youth Orchestra Foundation, accessed January 26, 2014, http://www.myof.org.my/festival.

88 "About MYOF" (website).
} 
Similarly, the Persatuan Chopin Malaysia (Chopin Society Malaysia) formed in 2002 also "supports promising and talented young [Malaysian] musicians in fulfilling their career aspirations ${ }^{989}$ by providing them with the opportunities to participate in concerts and public performances, music festivals, and competitions. Although its main objective is to promote Polish culture and such cultural exchange in Malaysia, especially through the promotion of Fryderyk Chopin's works, it also “encourages collaborative efforts in developing appreciation of classical as well as other kinds of music in Malaysia." ${ }^{90}$ This is achieved, for instance, through the inclusion of topics related to the elements of Malaysian traditional music in the workshops during its International Festival of Classical Music in 2011. During the press conference of this particular festival, pianist-composer, Chong Lim NG expressed that he "wished such [a] festival existed when he was a student 20 years ago. ${ }^{.91}$ He recalled, "There were not many concerts, auditions, and competitions back then. We just played (the musical instruments) and sat for exams." ${ }^{92}$ This shows that music has evolved from being merely an academic subject to being a part of the Malaysian culture, as more have come to participate in public musical activities rather than just learning and playing music for examinations.

In addition to government-sponsored initiatives, some of the private firms and business companies have also shown their interests in the conservation of culture and the development of

\footnotetext{
89 “Our Mission," Persatuan Chopin Malaysia (Chopin Society Malaysia), accessed January 26, 2014, http://chopinsociety.com.my/main/page/our-mission.

90 “About Us," Persatuan Chopin Malaysia (Chopin Society Malaysia), accessed January 26, 2014, http://chopinsociety.com.my/main/page/about-us. The organization is described as a "part of the international network of Chopin Societies in more than 60 countries around the world. In turn, these networks are controlled by the International Federation of Chopin Societies (IFCS), under the patronage of Queen Beatrix of the Netherlands" (ibid.).

91 "Festival Features Classes and Concerts for Young Musicians," The Star Online (Petaling Jaya, Malaysia), November 2, 2011, accessed February 26, 2012, http://thestar.com.my/metro/story.asp?file=/2011/11/2/central/9763531\&sec=central.

${ }^{92}$ Ibid.
} 
arts in Malaysia. For example, HSBC Bank Malaysia Berhad (Berhad, in Malay, means

"limited") launched a program in 2005 entitled, "HSBC in the Arts,"93 under which aegis a series of "HSBC Classics" events has been held annually in collaboration with the KLPac. Each year, the event features a specific theme, ranging from instrumental festivals (piano in 2005 and 2008, wind in 2006, and string in 2007) to special events (such as a concert featuring Malaysian talents in 2009, a series of events in memory of Chopin in 2010, and a celebration of operatic works in 2011). In addition to sponsoring its own events, the program also allocates funds to support local performing arts organizations, such as the DAMA Orchestra, ASWARA Dance Company, the Northern Jazz Ensemble, ${ }^{94}$ and Rhythm in Bronze. In 2007, the bank set up the annual HSBC Classics Bursary award, offering scholarships which enable young music students to pursue a higher education in music. ${ }^{95}$

\section{The Composers and the Contemporary Art Music of Malaysia}

Musical activities [in Malaya] during the colonial days were confined to what was available from the West. Music, in the true sense, was thought to be anything that originated in Europe. Hence there was no attempt to create anything with a local identity of its own. Everyone who learned music, even up to the present day [in the early 1990s], had to undergo a kind of basic formal training developed in the West: so much so that there has been a kind of prejudice towards the undiscovered potential of the mother country. The diatonic and chromatic scales of the West were thought to be standard, and

\footnotetext{
93 "About HSBC in the Arts," HSBC Bank Malaysia, accessed April 4, 2012, http://www.hsbc.com.my/1/PA_ES_Content_Mgmt/content/website/pdf/about_us/arts/arts_profile.pdf. The program "is also a further extension of the bank's contribution in the area of education, with hopes that the community will benefit and gain knowledge from the various projects ranging from theatre development, preservation of cultural assets, and heritage conservation ... By preserving local heritage and cultural skills, the younger generation will have the opportunity to understand their cultural roots, which may otherwise be lost" (ibid.).

${ }^{94}$ Jastin Ahmad Tarmizi, "Boost for Arts, Culture and Heritage," The Stars Online (Petaling Jaya, Malaysia), March 21, 2011, accessed April 4, 2012, http://thestar.com.my/metro/story.asp?sec=central\&file=/2011/3/21/central/8283478.

95 “HSBC Classics Music Festival and Bursary," HSBC Cultural Exchange, April 17, 2010, accessed April 5, 2012, http://www.hsbcculturalexchange.com/page/HSBC-Classics-Music-Festival-and-Bursary/114 (site discontinued).
} 
other scales derived from the numerous forms of local folk music were brushed aside in favour of the newly-achieved knowledge. ${ }^{96}$

Upon its independence from the British rule in 1957, the Malaysian government took certain precautions in handling the nation's emotions towards the country's colonial past. It has helped its people "understand that not everything colonial was bad, and lessons could be learnt from the past." ${ }^{, 97}$ It was crucial to avoid evoking colonial memories in all ways possible, and, at the same time, essential to foster unity amongst its multi-racial nation through the promotion of a common national culture. As such, musicians at that time had limited resources to work with, for most of the music known was of Western origin, and local music was not notated nor was there any original Western-style art-music compositions written by Malaysian composers. Therefore, early composers (such as Tony Fonseka, Alfonzo Soliano, Alias Arshad, Johari Salleh, Gus Steyn, Mario Thin Khoon LIM, Lok Hung CHAN, Nagasamy, and Chong Yew TAN), most of whom received Western musical training, began turning to the various musical genres of the different ethnic groups in Malaysia as sources of inspiration for their new works. ${ }^{98}$ Although these composers wrote for Western mediums (for example, orchestra, chamber ensembles, and opera) utilizing Western harmony, they incorporated in their music Malaysian idioms such as the association with "historical events, [and the] use of Malay lyrics, folk rhythms, instruments as well as some elements from the music of other ethnic groups." 99 This compositional approach is very similar to that of nationalistic composers such as Béla Bartók from Hungary and Charles Ives from the United States of America.

\footnotetext{
${ }^{96}$ Hamzah, "Malaysia,” 91.

${ }^{97}$ Ibid., 92.

${ }^{98}$ Hamzah, “Malaysia,” 92-95.

99 Tan, "Performing Arts in Malaysia," 143.
} 
As James D. Chopyak notes, "It was accepted at this time [presumably, between the 1960s and 80s] that the Malaysian style included Indian, Chinese, Malay (various different types from different regions) and Western music, but molding them into a truly Malaysian music was potentially as difficult as producing a unified society." ${ }^{100}$ With this in mind, some composers began experimenting with the inclusion of traditional musical instruments in the Western orchestra, in both Western classical-romantic and $20^{\text {th }}$ century compositional styles; some composers even went as far as combining the different traditional musical instruments of the three main ethnic groups in Malaysia in a single orchestral work. ${ }^{101}$ The result of such acculturation is often described in Malaysia as "cross-over" music, "that is, music that crosses the boundaries that separate one style from another [or one region from another]." ${ }^{102}$ In a way, it may be understood as demonstrating the emergence of the various ethnic groups in the nation. Today, "intercultural blend of musical movements is one major factor influencing the foundation directing the paths taken within local musical [territories, both art music and popular music alike]." ${ }^{103}$ Other than the aforementioned composers, Sunetra Fernando, Valerie Ross, and Sooi Beng TAN also incorporate this style of writing in their works. ${ }^{104}$

\footnotetext{
$\overline{{ }^{100} \text { Chopyak, "Role of Music," } 443 .}$

${ }^{101}$ Hamzah, "Malaysia," 94-95.

${ }^{102}$ Carleton Macy, "Tradition and Concert Music in Malaysia, 2002," Macalester International 12, no. 1 (October 2002): 190, accessed March 2, 2012, http://digitalcommons.macalester.edu/macint1/vol12/iss1/19.

${ }^{103}$ Johan Othman, "Cultural Decentralization within a Post Colonial Territory: Movements in Malaysia's Music Culture" Wacana Seni: Journal of Arts Discourse (Universiti Sains Malaysia) 1 (2002): 79, accessed March 2, 2012, http://wacanaseni.usm.my/WACANA\%20SENI\%20JOURNAL\%20OF\%20ARTS\%20DISCOURSE/ JOURNAL_1\%20PDF/CULTURAL\%20DECENTRALIZING\%20WITHIN\%20A\%20POST\%20COLONIAL\%20 TERRITORY\%20MOVEMENTS\%20IN\%20MALAYSIA'S\%20MUSICAL\%20CULTURE_JOHAN\%20OTHMA N.pdf.

${ }^{104}$ Macy, “Tradition and Concert Music,” 190.
} 
These experiments result in "a rich tapestry of music that is a combination of traditional and contemporary experimentation that both celebrates heritage and respects change."105 They may best represent the composer's response to the new nation's search for a national identity, and are presumably their "attempts to express the assimilation of their musical experience, education, and upbringing as 'Malaysians,' regardless of their ethnicity." ${ }^{106}$ In fact, this phenomenon is not uncommon in other colonial countries around the world, as described by Michael Tenzer in his article on the Filipino composer, Jóse Maceda:

During the early and mid-twentieth century, the cultivation of contemporary art music composition in urban centers throughout Asia, Africa, and South America created new cultural contexts for Western music.... Over time [composers] attempted to make their approach to the Western tradition not just a replication of imported European knowledge received at colonial and missionary hands, but a living, local entity. This process was social as well as musical, insofar as composers envisioned new cultural landscapes with themselves as empowered agents in their creation. ${ }^{107}$

Perhaps this may also be seen as one of the ways to preserve the essence of local musical traditions, for these cultural heritages are declining in popularity as a result of modernization and industrialization of the country. ${ }^{108}$

Nevertheless, even as it is in instrumental music education, in that most who study a musical instrument more often than not pursue a non-musical career, so also the composing profession has received little attention within the local communities. In fact, it is not a surprise that few are even aware of the existence of Malaysian composers - apart from commercial composers - there are so few opportunities for performance and exposure for Malaysian

\footnotetext{
${ }^{105}$ Anandhi Gopinath, "Defining Malaysian Music," Malaysiancomposers.com, Malaysian Composers Collective, accessed February 27, 2012, http://www.futureasia.net/malaysiancomposers/resources/media_art2_options08.pdf. Originally published in Options February 4, 2008.

106 ““Acquiring a Music Education,”" 1065-66.

${ }^{107}$ Michael Tenzer, "José Maceda and the Paradoxes of Modern Composition in Southeast Asia: With List of Maceda's Compositions to Date" Ethnomusicology 47, no. 1 (Winter 2003): 93.

${ }^{108}$ Macy, “Tradition and Concert Music,” 189, 192.
} 
composers of art music, let alone for publication of their works. ${ }^{109}$ This was partly due to the lack of professional ensembles and other appropriate infrastructure. ${ }^{110}$ Even so, art-music composers do exist in Malaysia; most of them received their music education from abroad, such as China, Germany, the United Kingdom, and the United States of America. While a small number of them are fortunate to have had their works performed abroad and made a name in international competition arenas, most composers "generally [write] for themselves, a small audience of friends, and a very small, but aware, public (including many expatriates)."111 Thus, Malaysian composers typically are simply unable to sustain their lives by composing full-time, even though they are passionate about writing music. Like composers everywhere else, most of them are employed as professors or lecturers in government universities or private institutes or both. $^{112}$

At the turn of the century, the founding of the MPO brought new light to the local composing scene. Since 1999 the MPO, under the baton of Associate Conductor, Kevin Field, has frequently exposed Malaysian audience to $20^{\text {th }}$ century music and new music, which in turn raises awareness and generates increasing acceptance of such new sounds. ${ }^{113}$ As part of its vision to nurture local musical talents, especially composers, the MPO has commissioned between 2002 and 2003 new compositions from Sunetra Fernando (Wayang for mixed ensemble and gamelan), Kee Yong CHONG (The Echoed Dream), and Tazul Izan Tajuddin (Sebuah Nadian Warna-

\footnotetext{
${ }^{109}$ Ang, Introduction to Malaysian Music, 13.

110 "Malaysian Contemporary Music," Wikipedia, last modified December 15, 2013, accessed March 4, 2012 and January 26, 2014, http://en.wikipedia.org/wiki/Malaysian_contemporary_music.

${ }^{111}$ Macy, “Tradition and Concert Music," 189.

112 Ibid.

${ }^{113}$ Brown, “Twin Peaks,” 24.
} 
Tenunan III [Pulsating Colors-Weave Texture III]). ${ }^{14}$ This is a major historical event as it represents "the first local commission by a [fully] professional symphony orchestra in the country." ${ }^{115}$ It also symbolizes, to a certain degree, interest in and recognition of local talents by an organizational body of international standard. This marks the beginning of many more opportunities to come, and this was when the "Malaysian contemporary [art] music as a phenomenon really started to gain visibility and momentum."116

Following the success of the premiere of these new works, Maestro Field instigated in 2002 the MPO Forum for Malaysian Composers, "a two-year program for Malaysian composers to work extensively with both the MPO and an international panel of composers. ${ }^{117}$ Field adds, "The [first round of the] Forum allows the individual to grow, free from the burden of total competition. Only later in the second round does it get a bit juicy in that regard!"118 The winner of the pilot Forum, Kee Yong Chong, then proceeded to partake in, and to win, the pioneering 2004 MPO International Composers Award (MPOICA). ${ }^{119}$

\footnotetext{
${ }^{114}$ CH Loh, "Sowing the Seeds," CH Loh's Portfolio, accessed February 26, 2012. http://www.geocities.ws/contact_chloh/articles/sowingseeds.html. Originally published in Options, The Edge March, 2003.

${ }^{115}$ Gopinath, "Defining Malaysian Music."

116 “About Malaysian Composers," Malaysiancomposers.com, Malaysian Composers Collective, accessed March 4, 2012, http://www.futureasia.net/malaysiancomposers/composers/about_composers.htm.

117 "Conductors: Kevin Field, Associate Conductor," Malaysian Philharmonic Orchestra, accessed February 27, 2012, http://www.mpo.com.my/Meet-The-MPO/Conductors/Kevin-Field.aspx (content removed from page).

${ }^{118}$ CH Loh, "Risky Business," CH Loh's Portfolio, accessed February 27, 2012, http://www.geocities.ws/contact_chloh/articles/riskybusiness.htm. Originally published in Options ${ }^{2}$, The Edge November, 2004.

${ }^{119}$ HueyChing Chong, Mohd Nasir Hashim, and Young-Hwan Yeo, eds., The MPO Composers Forum: And its Impact on the Performance of Contemporary Western Classical Music by Malaysian Composers in Kuala Lumpur (Saarbrücken, Saarland, Germany: VDM Verlag, 2009), 7.
} 
After being held twice, the MPO Forum evolved into the MPO Forumplus in 2008, whereby participation was by invitation only instead of application. ${ }^{120}$ To date, the MPO Forum and Forumplus have nurtured "over 21 emerging [Malaysian] composers and [premiered] 40 new works for orchestra," ${ }^{121}$ and continues to raise public awareness of new local talents in art music, talents such as Adeline WONG, Ahmad Muriz Che Rose, Johan Othman, Kah Hoe YII, Chong Lim Ng, Tze Siew TEH, and Mohd Yazid Zakaria.

Upon receiving renewed attention both locally and internationally, Malaysian composers began to emerge as an entity through the creation of musical communities, such as the Malaysian Composers Collective. ${ }^{122}$ Such organizations allow composers to exchange musical thoughts and to join forces in embarking new projects for the promotion of contemporary art music in

Malaysia. The advancement in multi-media technology also helps in promoting composers and their works as well as upcoming musical events and activities through the internet. Moreover, it makes documentation and archiving of such events possible, aiding in sustaining and promoting further interest in such musical culture.

In 2008, the HSBC Classics Piano Competition was organized in conjunction with the HSBC Classics Piano Festival. A positive innovation in the competition was the inclusion of nine works by Malaysian composers, from which list each semi-finalist had to choose to include one in their competition programs. This was seen as "a big step forward in expanding the scope of the annual festival to embrace an essential component of Malaysia's classical/contemporary music scene, and one that will bring young performers closer to their home composers to foster

\footnotetext{
${ }^{120}$ Chong, Hashim, and Yeo, 9.

121 "Conductors: Kevin Field, Associate Conductor" (website, accessed December 23, 2013).

${ }^{122}$ Formed in 2007 by Hardesh Singh and CH Loh, Malaysian Composers Collective is a member of the Asian Composers League. "Full Members," Asian Composers League, accessed April 8, 2012, http://asiancomposersleague.com/members/fullmembers.html\#malaysia.
} 
that much-needed synergy between musician and composer that is the catalyst for a vibrant local music scene." 123 Towards the end of the festival, the inaugural HSBC Young Composers Workshop 2008 was held in collaboration with the Malaysian Composers Collective, receiving tremendous response from aspiring Malaysian composers. ${ }^{124}$

In the very same year, Malaysia’s first anthology $\mathrm{CD}$ of contemporary art music was released under the title, "Faith, Hope \& Chaos: Malaysian Contemporary Music Vol. 1." The compilation includes works by "young and obscure local composers who were generally off the radar screen," language. The realization of this project was possible through the joint effort by Off the Edge $e^{126}$ magazine, the Malaysian Composers Collective, and HSBC Bank Malaysia Berhad, with additional funding support from individuals and private agencies.

A year after, the Malaysian Composers Collective collaborated with Goethe-Institut Malaysia $^{127}$ and SEGi College Subang Jaya in organizing the ground-breaking Kuala Lumpur Contemporary Music Festival 09 (KLCMF 09) with the theme, "Urban Soundscapes.” The festival included the Asian Composers' Conference, a series of contemporary art-music concerts

123 "HSBC Classics Piano Festival 2008 to include Works by 9 Malaysian Composers as Compulsory Piano Competition Set Pieces," Malaysiancomposers.com, Malaysian Composers Collective, January 31, 2008, accessed February 26, 2012, http://www.futureasia.net/malaysiancomposers/general/news2.htm\#news2.

124 “HSBC Young Composers Workshop 2008," Malaysiancomposers.com, Malaysian Composers Collective, accessed April 8, 2012, http://www.futureasia.net/malaysiancomposers/special/ycw2008.htm.

125 Gopinath, "Defining Malaysian Music.”

${ }^{126}$ Off The Edge was an award-winning "monthly print magazine [in Malaysia] that explored culture, lifestyle, and politics, with an accent on business. It was a spin-off title from The Edge business weekly.... It ceased publication in mid-2010 [after printing for 5 years]." Off The Edge's Facebook page, accessed March 5, 2012, https://www.facebook.com/pages/OFF-THE-EDGE/118269411534527.

${ }^{127}$ The Goethe-Institut Malaysia is "the cultural institute of the Federal Republic of Germany with a global reach. [It] promotes knowledge of the German language abroad and foster international cultural cooperation, [including the arts. It often sponsors concert performances, music workshops, and festivals. It also offers information on music scholarships in Germany]." "About Us," Goethe-Institut Malaysia, accessed March 5, 2012, http://www.goethe.de/ins/my/kua/uun/enindex.htm. 
based on the festival's theme, and the Young Composers Competition, which extended its invitation to young composers in other Southeast Asian countries- the first of its kind in the region. ${ }^{128}$

Beginning in 2010, the Faculty of Music of Universiti Teknologi MARA (UiTM) has been joining forces with KLPac in holding its Malaysian Composers Concert Series to showcase new works by its student composers and other local composers. It is hoped that the annual event will provide a platform for the performance of new music, thereby encouraging new compositions from local composers, which, in turn, will aid in sustaining and broadening the musical culture in Malaysia. ${ }^{129}$ From 2011 onward, this concert series has been co-organized by the Society of Malaysian Contemporary Composers (SMCC)—a newly-formed association led by Kah Hoe Yii, Kee Yong Chong, and Tazul Izan Tajuddin, with the aims of uniting local contemporary music communities; promoting interest in such music both locally and internationally, especially among youth; and providing musical exchanges with other contemporary music societies around the world. ${ }^{130}$

Active since 2010, the SMCC plays a leading role in the current contemporary art-music scene in Malaysia. It frequently offers instrumental, vocal, and compositional workshop; concerts featuring contemporary art music written by local and foreign composers; and recitals

\footnotetext{
128 “About KLCMF,” Malaysiancomposers.com, Malaysian Composers Collective, accessed April 8, 2012. http://www.futureasia.net/malaysiancomposers/klcmf09/about.htm.

129 "Malaysia Composer Series $2011\left(30^{\text {th }}-31^{\text {st }}\right.$ July)," The Kuala Lumpur Performing Arts Centre, accessed April 8, 2012. http://www.klpac.org/?p=2161.

130 “About SMCC,” The Society of Malaysian Contemporary Composers, accessed December 23, 2013, http://www.smccomposers.com/about-smcc.html.
} 
by both local and foreign artists. ${ }^{131}$ In October 2013, the first SMCC Contemporary Music Festival, "SoundBridge,” was held in Petaling Jaya, Selangor, Malaysia.

With the many efforts put into cultivating new compositional talents, a new generation of composers has emerged (among the most notable are Khairil Ridzwan bin Annuar, Ainolnaim Azizol, Isaac CHIA, Hong Da CHIN, Jessica CHO, HueyChing CHONG, Jun Yan CHOW, Jun Yi CHOW, Chie Tsang LEE, Nai Wen NEO, Jyotsna Nithyanandan, Chor Guan NG, Shyh Poh NG, Tzu En NGIAO, Isabella PEK, Zihua TAN, Chee Wei WONG, and Chee Yean WONG), some of whom have already won a place in international competitions. As the Chinese saying goes, "The young generation is the future pillars of the nation." It is hoped that these emerging composers will carry forth in their works the rich and diverse Malaysian cultural heritage, for the fate of such traditions lays in their hands. Together with the older generations, it is also hoped that they will work towards elevating the art-music culture and promoting a higher level of awareness of the contemporary art-music scene in Malaysia.

\section{Overview of the Problem and the Need for the Study}

Although the influence of Western art music has been present in Malaysia for a little short of two centuries, much of the scholarly research, both locally and globally, has shown more interest in traditional music and popular music. In 1991, Daud Hamzah wrote about the lack of documentation on the development of art music in Malaysia; ${ }^{132}$ at the beginning of the new millennium, Minni Kim Huai ANG also expressed the need of research into identifying

\footnotetext{
${ }^{131}$ HueyChing Chong, Vice Secretary of Society of Malaysian Contemporary Composers, e-mail message to author, April 10, 2012.

${ }^{132}$ Hamzah, "Malaysia," 91.
} 
Malaysian composers and the need to examine their works. ${ }^{133}$ However, to date there is still a lack of such studies and writings, let alone theoretical analysis of the works by Malaysian composers, despite the fact that the art-music scene in Malaysia has grown rapidly over the past two decades, and the fact that a good number of creative musical compositions have been produced by local composers who received formal Western musical training.

The lack of local interest in Malaysian composers' works is partly due to the fact that art music is a cultivated culture in Malaysia; hence, there exists, to a certain degree, prejudice and doubt towards the quality of local craftsmanship. As pointed out by Charmaine Blythe Siagian, "The assumption that art music is only produced by Western composers is prevalent: many remain unaware that regional composers write serious, playable music that is artistic, and may in some cases be more relatable — more of a reflection of their own milieu. There also still exists a mindset of not truly 'making it' until one makes it abroad, and this remains a detriment to the growth and progress of the local composer."134 Even so, some composers have been recognized internationally but remain virtually unknown in their home country.

Even though most Malaysian composers' knowledge in composition is of Western origin, their works are not mere replicas of the Western tradition. Rather, just as composers everywhere else, they strive to infuse within their works their own identity. For a multi-cultural nation with a colonial past, this identity is more often than not a reflection of the different cultural heritages present within Malaysia. Therefore, most local composers attempt to create music that the people of the nation could identify with and relate to. Unfortunately, art-music compositions are hardly

\footnotetext{
${ }^{133}$ Ang, Introduction to Malaysian Music, 10, 13.

${ }^{134}$ Charmaine Blythe Siagian, "Selected Solo Piano Works by Contemporary Malaysian and Indonesian Composers from 1979 to 2007: An Introduction” (DMA diss., University of Oklahoma, 2007), 2, accessed October 22, 2010, http://gradworks.umi.com/32/88/3288838.html.
} 
performed within the country, partly due to "the lack of infrastructure, funds, and a real interest in the art,"135 and perhaps because, due to the lack of music publishing companies in Malaysia, the majority of these works remain unpublished. ${ }^{136}$ This study intends to identify the traits that make representative selections from these composers' works significant, in hopes that more of them will receive greater attention, including publication, in the near future.

As mentioned earlier, the study of piano, especially those that employ a foreign graded syllabus, is very popular in Malaysia. However, it is a topic of lively debate whether these foreign syllabi are appropriate for the use in the Malaysian context. Roe-Min Kok questions "the depth to which [the ABRSM's] directors understood the complex cultural situation and musiceducational needs of the Malaysian market:"137

Had the Board researched Malaysians' attitudes and needs with regard to Western classical music? Did the Board know about the lack of resources Malaysians faced? Was the Board concerned that the ears and brains of those who processed the music it prescribed had otherwise had little exposure to and experience with the cultures of which the music was inextricably part? The ABRSM directors seem to have been contented to transfer its methods, created and practiced in culturally, politically, and economically different Britain, directly into a postcolonial setting, instead of adapting the methods in ways that would have shown sensitivity to the Malaysian context. ${ }^{138}$

Johan Othman states forthrightly that "Western ... repertoire introduced by these external examination boards [is] culturally removed from the culture of local students as well as most local teachers, " 139 which he argues is symptomatic of the cultural decentralization in Malaysia. He continues, "From an early age, many local children were indirectly made unaware of being removed from their potential culture center in order to be cultivated in the misunderstanding of

\footnotetext{
${ }^{135}$ CH Loh, "Sowing the Seeds."

${ }^{136}$ Ang, Introduction to Malaysian Music, 12.

${ }^{137}$ Kok, "Music for a Postcolonial Child," 82.

${ }^{138}$ Ibid.

${ }^{139}$ Othman, "Movements in Malaysia's Music Culture," 83.
} 
culture of the others." ${ }^{\prime 14}$ This suggests the advisability of the study of local compositions which include elements of Malaysian traditions, which may draw local music students closer to their cultural roots. These works may also give new perspectives to the idea of "Malaysian" music even while they add welcome variety to one's musical repertoire and recital program. By providing close examinations — including both cultural context and theoretical analysis_ —of the selected piano works, this study hopes to aid in understanding the concept and structure of each selected work, which in turn may assist in the performance of these and other such works.

\section{Statement of Topic}

\section{Purpose of the Study}

The purpose of this study is:

1) To serve as an introduction to the available range of solo piano literature written by Malaysian composers through theoretical analysis of a selection of works that could best represent the full breadth of contemporary art music for solo piano in Malaysia, in hopes that through a better understanding of these composers' works more will come to recognize and perform them.

2) To serve as a reference for future study of similar topics as we still lack research and publication of literature on the current state of art music in Southeast Asia, particularly in Malaysia.

\footnotetext{
${ }^{140}$ Othman, "Movements in Malaysia’s Music Culture," 83-84.
} 


\section{Procedure}

Interest in researching solo piano music by contemporary Malaysian composers embarked after a performance of Wayang Kulit for two pianists (with piano and percussion instruments) by Kee Yong Chong in late 2009. In order to grasp the current state of art music for solo piano from Malaysia and the need of this study, it is essential to compile a list of Malaysian composers - in this context, art-music composers.

Personal contacts were established through occasional meetings in Malaysia between 2010 and 2011 with university professors and lecturers, both pianists and composers, particularly Kee Yong Chong and Tazul Izan Tajuddin, from whom further recommendations and contact information were acquired. Tajuddin suggested consulting Charmaine Blythe Siagian's D.M.A. dissertation, "Selected Solo Piano Works by Contemporary Malaysian and Indonesian Composers from 1979 to 2007: An Introduction” (2007), as both the above-mentioned composers participated in her study, alongside two other Malaysian composers, Chong Lim Ng and Chee-Hwa TAN. As such, contact was initiated on a social network and the dissertation was obtained with permission.

Siagian's work is the primary model for this research as both share similar purpose and ideas. The approach of the study, however, differs in nature as Siagian applies a stylistic approach in analysis while this research aims to offer a theoretical one. Siagian includes in the appendix a "List of Known Solo Piano Pieces by Malaysian Composers" which this study—and hopefully future studies, too-will continue to build upon. As she indicates at the end of her dissertation, "A more extensive annotation or compilation of piano works by Malaysians and Indonesians needs to be published in both countries." 141

\footnotetext{
${ }^{141}$ Siagian, "Selected Solo Piano Works," 108.
} 
In the course of her research, Siagian referred to the website, The Living Composers Project, ${ }^{142}$ and found a record of four Malaysian composers. To date, one other composer has been added to the database. The database either provides an onsite profile with contact information and work list of each composer, or links directly to the composer's personal website; however, the link to composer Minni Kim Huai Ang's profile appears to be a glitch.

Search in online databases such as WorldCat and RILM Abstracts of Musical Literature for publications on similar topic by using keywords, "Malaysia" and "piano" and "music" led to several relevant results which will be further discussed in Chapter Two: Review of Related Literature. It is important to note that there are only very limited researches conducted concerning piano literature — let alone solo piano literature — by Malaysian composers, hence making this study the more necessary.

The New Grove Online Dictionary of Music and Musicians lists a few composers who are otherwise unknown. Attempt to search for more potential composers in encyclopedias such as The Garland Encyclopedia of World Music and The Encyclopedia of Popular Music yielded no relevant result.

The search continued on the World Wide Web, particularly on Google. The use of keywords, "Malaysian composers" led to the official website of Malaysian Composers Collective known as Malaysiancomposers.com which turned out to be the golden gateway to the current state of art music in Malaysia. As mentioned earlier in "The Composers and the Contemporary Art Music of Malaysia" under "Background," Malaysian Composers Collective is "a non-profit initiative to promote local new music, ... [which] has collaborated with local composers,

\footnotetext{
${ }^{142}$ The Living Composers Project, Dan Albertson and Ron Hannah, eds., accessed April 17, 2012, http://www.composers21.com. The Living Composers Project is "a nonprofit database begun in 2000, which aims to provide composers, listeners, performers, and researchers with a source of information about the music of our time." Siagian, "Selected Solo Piano Works," 9.
} 
musicians, and partners such as HSBC Bank Malaysia [Berhad], Goethe Institute Malaysia, Annexe Gallery, and Off The Edge on pioneering projects such as the HSBC Young Composers Workshop 08, the anthology CD of Malaysian Contemporary Music [entitled,] 'Faith, Hope \& Chaos,' and the KL Contemporary Music Festival 09."143 Most importantly, the website also provides a directory of Malaysian composers, some of the entries of which with contact information attached. Though not exhaustive and last updated in 2009, the directory helped added a few more potential composers to the list.

The second attempt on Google search using a different set of keywords, "Malaysian music" prompted Musical Malaysia, a website established in 1997 "covering ALL aspects of Malaysian music" ${ }^{144}$ which was later published by the author, Minni Kim Huai Ang, in 2002 as An Introduction to Malaysian Music, $2^{\text {nd }}$ edition. The opening chapter introduces the historical, social, and political background of Malaysia. Ang's discussion in "Trends and Developments in Music" as well as "Music in Multicultural Society: Malaysia and the USA" is especially enlightening as she made comparison and drew similarities in a multicultural social context between both countries and its effect on the acculturation of music. ${ }^{145}$ Subsequent chapters give an overview of the history, as well as the current state, of popular music and contemporary art music in Malaysia, while the rest deals heavily with traditional music. Both the book and the

\footnotetext{
143 “About Us,” Malaysiancomposers.com, Malaysian Composers Collective, accessed March 4, 2012, http://www.futureasia.net/malaysiancomposers/general/about_us.htm. Launched in January 2007 as a center for contemporary arts, Annexe Gallery frequently hosts art exhibitions, theatrical and dance performances, film screenings, and music recitals among many other events. "About The Annexe Gallery," Annexe Gallery, accessed 5 March 2012. http://www.annexegallery.com/index.php?option=com_content\&view=article\&id=45\&Itemid=54.

${ }^{144}$ Musical Malaysia, Minni Kim Huai Ang, accessed March 4, 2012, http://www.musicmall-asia.com/malaysia (site discontinued).

${ }^{145}$ Ang, Introduction to Malaysian Music, 3-5.
} 
website name additional Malaysian composers who were not previously known; however, only a few have written for the piano.

The Google searches above also brought up two entries from Wikipedia, entitled "Malaysian Contemporary Music"146 and "Music of Malaysia."147 The former contains similar content found in Malaysiancomposers.com while the latter gives an outline of the different musical styles found in Malaysia, including folk, classical, pop, hip hop, and rock. Although the credibility of the writings on Wikipedia has often been questioned because "anyone who can access the site can edit almost any of its articles, "148 due to the lack of resource in regards with Malaysian music — let alone art music — these two articles nevertheless provide a general idea of what is commonly found in Malaysia.

Upon the completion of the list of Malaysian composers, contacts were made to identify those with music for piano - particularly for solo piano - and when possible, music scores and recordings were also acquired directly from the composers as most of the music was not published or recorded. The final "List of Known Solo Piano Works by Malaysian Composers” as seen in Appendix is an end result from responses received and is thus as extensive as possible, but presumably not exhaustive.

\footnotetext{
146 "Malaysian Contemporary Music" (website).

147 “Music of Malaysia," Wikipedia, last modified October 31, 2013, accessed March 4, 2012 and January 26, 2014, http://en.wikipedia.org/wiki/Malaysian_music.

148 “Wikipedia,” Wikipedia, last modified January 25, 2014, access January 26, 2014, http://en.wikipedia.org/wiki/Wikipedia.
} 


\section{Scope and Limitations of the Study}

From the list above, a selection of three contrasting solo piano works was made with the notion that the selected works, as pertained to the purpose of the study, could best represent the full breadth of contemporary art music for piano in Malaysia. Correspondently, the following criteria were observed:

1) The selected work must be an original composition written for solo piano.

2) The selected work must be written by an active Malaysian composer, whether by birth or by emigration.

3) The selected work must be of substantial length; that is, it must be a concert piece, suitable to be programmed in a recital performance, but not a short character piece or a pedagogical piece.

4) The selected works must contrast and vary between one another in terms of genre, character, style, and cultural influence, if present. For example, a character piece for solo piano and electronics (in the form of pre-recorded tape or compact disc), modeled after the electronic music of Western Europe and North America, portraying urban soundscapes; in comparison with a work that requires props and gestures in order to reenact the Balinese baris dance scene.

5) The selected work must be accessible. As majority of the compositions by Malaysian composers in general remain unpublished, manuscripts may only be acquired directly from the composers. Professional recordings are almost non-existent; however, where works had been performed, composers might own recordings of the live performances, which may be obtained upon request. 
Other aspects were also taken into considerable account in order to achieve a balanced selection of works:

1) Gender. The selection should include the work of at least one female composer. It is evident that, like anywhere else in the world, "the early Malaysian composers were predominantly male," while it was not until towards the beginning of the $21^{\text {st }}$ century that more Malaysian women emerged as composers. ${ }^{149}$ Nowadays, interest in women composers and their works has surfaced globally; hence, it is hoped that this study will be able to contribute somewhat to the research of women in the arts.

2) Major area of the composer. There should be a mixture of works by pianistcomposers and non-pianist composers. As columnist, musician, and composer $\mathrm{CH}$ LOH noted, "While [Malaysia has its] own share of notable concert pianists, pianistcomposers are a little harder to find." 150 Thus, this study also aims to identify respective Malaysian pianist-composers.

Selected composers and their works are discussed in separate chapters. Each chapter begins with a brief biography of the composer along with a complete list of works, followed by a general overview of the selected work, which includes - but is not limited to - the context surrounding the composition, the source of inspiration, stylistic traits, and any unusual features. This is followed by a detailed theoretical analysis — an area that has hardly been explored —in

\footnotetext{
${ }^{149}$ Ming Huey Lam, "Malaysian Music and Composer Valerie Ross," Journal of the IAWM (The International Alliance for Women in Music) 7, no. 3 (2001), accessed September 20, 2011, http://www.iawm.org/articles_html/huey_valerie_ross.html (page removed).

${ }^{150} \mathrm{CH}$ Loh, "On the Quiet - Interview with Ng Chong Lim,” Malaysiancomposers.com, Malaysian Composers Collective, June 1, 2010, accessed February 28, 2012,

http://www.futureasia.net/malaysiancomposers/focus/focus30_chonglim.htm. Originally published in Off The Edge July, 2007.
} 
order to highlight distinctive compositional strategies and possible influences from local or other regional culture, which may constitute the purpose of the work or the message that the composer wished to convey - after all, music is a means of expression and communication.

Due to the lack of resources and research, interviews were conducted with each composer, with the hope that information gathered may assist in the analysis of their music. Communication were often established through email correspondence due to the different time zones between Southeast Asia and the United States of America, as well as the fact that most composers have a busy professional life, hence making phone conversations difficult to accommodate.

\section{Layout of the Study}

The study consists of seven chapters. The first two chapters are Chapter One: Preface, and Chapter Two: Review of Related Literature, which gives a bibliographical review of related literature that includes dictionaries, encyclopedias, books, theses and dissertations, periodical articles, and internet sources.

Chapters Three through Five provide an overview of the selected solo piano works by three living Malaysian composers, comparing as well as contrasting the nature and characteristic of these works, drawing attention to how these works as a whole showcase the full breadth of contemporary art music for piano in Malaysia. Each chapter includes a brief biography, a complete list of works, and a general overview of the selected work. The center of each chapter, however, is the detailed theoretical and stylistic analysis of a selected work for solo piano by each composer. This is followed by a brief conclusion. These works are: 
Chapter Three: Chong Lim Ng, A Distant Voice of the Rain Forest (Fragments from "Rimba"...), a work for solo piano resembling the compositional style of the Darmstadt school of music, especially Karlheinz Stockhausen's Klavierstück XI, in that it comprises both numbered and random fragments of passages taken from the composer's work for chamber orchestra, Rimba [Rain Forest $]$.

Chapter Four: Adeline Wong, Paces for solo piano and electronics, a programmatic work depicting life in the city by incorporating pre-recorded sounds, including electronic sources, sound samples, and the voices of children.

Chapter Five: Kah Hoe Yii, My Spirit is Dancing!, a solo piano work that is inspired by the Balinese baris dance and requires special performance effects (such as stamping of the feet and playing in the air) from the pianist, who will be equipped with dancing bells (such as the Indian Ghungaroo) around the ankles and wrists.

Chapter Six: Summary summarizes the characteristics of each piano work examined and recapitulates the discussion of how these works, taken together, represent the full breadth of contemporary art music for piano in Malaysia; while Chapter Seven: Conclusion provides a conclusion that reaffirms the purpose of the study, along with proposing future directions. A bibliography and an appendix, "List of Known Solo Piano Works by Malaysian Composers," are included at the end of the study. 


\section{CHAPTER TWO}

\section{Review of Related Literature}

Searching through music dictionaries, encyclopedias, online databases, and the World Wide Web, it is evident that interest in the music of Malaysia — and Southeast Asia, in general— lies primarily in the fields of traditional music and popular music. Such literature provides insights into the historical background of Malaysia, the different traditional musical genres practiced, and the traditional instruments found in Malaysia.

There is a good amount of writings - mostly in the forms of published articles and dissertations - concerning the large topic of the development of Western European art music in Malaysia. Most of these are related to music education in the country, some with specific mention of the study of piano. Information specific to the current state of contemporary art music in Malaysia is chiefly found in published journal articles, dissertations, and online websites. However, there are very few resources pertaining to contemporary art music written for piano.

Given that some of the relevant literature has already been addressed in the Chapter One: Preface, under "I: Introduction" and "II: Statement of Topic," this chapter concentrates on the most significant sources in relation to the topics discussed in those sections. 


\section{Background}

Minni Kim Huai Ang's An Introduction to Malaysian Music $\left(2^{\text {nd }} \text { edition }\right)^{1}$ and John Lah Boh YONG's M.M. thesis ${ }^{2}$ provide a thorough understanding of the historical, socio-economic, and political background of Malaysia. Although most of Ang's book is devoted to introducing the various musical traditions of the different ethnic groups, there is a concise section on the trends and developments in music as well as the current state of contemporary art music in Malaysia.

The $4^{\text {th }}$ volume ("Southeast Asia") of The Garland Encyclopedia of World Music ${ }^{3}$ and the $15^{\text {th }}$ volume of The New Grove Dictionary of Music and Musicians ( $2^{\text {nd }}$ edition $)^{4}$ also write extensively about the various traditional performing art forms and instruments found in Malaysia, both concluding with a brief discussion on the Western European art-music tradition and the contemporary art-music scene in the country.

\section{Colonial Era: Western European Music in Malaya}

Information on pre-independent Malaya's early encounters with Western European music during the British colonial period is drawn from a few sources; namely, The Garland Encyclopedia of World Music, and the journal articles by Johami Abdullah and James D.

\footnotetext{
${ }^{1}$ Ang, Introduction to Malaysian Music.

${ }^{2}$ Yong, "Roles of Government and Private Sectors."

${ }^{3}$ Matusky and Chopyak, "Peninsular Malaysia."

${ }^{4}$ Dobbs and Matusky, "West Malaysia."
} 
Chopyak. ${ }^{5}$ They mention the use of music as a means of education and the purpose of such education, as well as the function of music in public and private settings.

\section{Post-Colonial Era: In Search of a National Identity}

The journal articles by Chopyak ${ }^{6}$ and Sooi Beng $\operatorname{Tan}^{7}$ provide insights on the newly formed government's efforts in fostering unity among its multi-ethnic people through the cultivation of a common national culture, particularly by means of mass media and education in school. Tan's article also indicates the difficulties faced by the government in the process of implementing its National Culture Policy, and the resistance from several performing art groups in Malaysia.

These issues — and those pertaining "the process of hybridity in intercultural music and its deployment as sites for the politics of identity, of both racial and national..." — are also examined and discussed in great length by Amy Wai Yee CHAN in her Ph.D. thesis, “Composing Race and Nation: Intercultural Music and Postcolonial Identities in Malaysia and Singapore" (2005). ${ }^{9}$

In addition, Roe-Min Kok’s article ${ }^{10}$ also discusses the British cultural imperialism in post-colonial Malaysia, especially in the social groups' preference in music education.

\footnotetext{
${ }^{5}$ Matusky and Chopyak, "Peninsular Malaysia;" Abdullah, "Music Education in Malaysia;" Chopyak, "Role of Music."

${ }^{6}$ Chopyak, "Role of Music."

${ }^{7}$ Tan, "Performing Arts in Malaysia."

${ }^{8}$ Amy Wai Yee Chan, "Composing Race and Nation: Intercultural Music and Postcolonial Identities in Malaysia and Singapore,” (PhD diss., Australian National University, Canberra, Australia, 2005), ii.

${ }^{9}$ Ibid.

${ }^{10} \mathrm{Kok}$, "Music for a Postcolonial Child."
} 


\section{Western European Art Music in Malaysian Music Education}

Apart from Abdullah's writing, ${ }^{11}$ Yong's M.M. thesis ${ }^{12}$ gives a comprehensive account on music education in government funded schools at all levels, and in private institutes at a higher level. Yong also draws attention to the emergence of private commercial music centers and international examination boards in Malaysia, particularly two graded music educational systems: Britain's Associated Board of the Royal Schools of Music (ABRSM) and Japan's Yamaha Music Education System (YMES).

Similarly, Patricia Marie OOI's M.M. thesis ${ }^{13}$ provides insights to the socio-economic and educational background in Malaysia, with specific attention on comparing and contrasting the ABRSM and YMES systems. Areas of focus include "the philosophy, curriculum, teaching approach, examination-related issues, the music popularization and educational activities of each of these two systems."14

\section{The Study of Piano}

Specifically regarding the area of private piano studies, Kok's article ${ }^{15}$ and a previous article edited by Wendy L. Sims and Ramona Tahir ${ }^{16}$ focus on the social implications of such education in Malaysia, which is a model often traced back to the nation's colonial history. Grace

\footnotetext{
${ }^{11}$ Abdullah, "Music Education in Malaysia."

${ }^{12}$ Yong, "Roles of Government and Private Sectors."

${ }^{13}$ Ooi, "Two Prominent Keyboard Systems."

${ }^{14}$ Ibid, 15.

${ }^{15}$ Kok, "Music for a Postcolonial Child."

16 “"Acquiring a Music Education."”
} 
Kah Yan LEONG's B.Mus. Honors thesis ${ }^{17}$ surveys the reasons for such education from the perspectives of parents.

In-depth studies on the Malaysian approach to music education-particularly, the study of piano through graded public music assessments held by the Associated Board of the Royal Schools of Music (ABRSM) — and its social implications is found in Valerie Ross's Ph.D. thesis, “External Public Piano Examinations: Social and Symbolic Significance” (2002). ${ }^{18}$

Of special note is David Tze Wan Wong's Music of the Chinese in Sabah: The Keyboard Culture, ${ }^{19}$ which concentrates on the teaching and studying of piano and electronic organ within the Chinese community in the state of Sabah in East Malaysia. Although the surveyed area is confined to Sabah's capitol city, Kota Kinabalu, and its Chinese community only, the book nonetheless sheds some light into the general trends in keyboard studies which, in many ways, is similar to such phenomenon in West Malaysia at that time: Western music education in public schools, the popularity of private piano studies and its social implications, and the popularity of ABRSM and YMES systems, to name a few overlapping topics.

\section{The Current State of Western European Art Music in Malaysia}

The current state of Western Art Music in Malaysia must be pieced together from disparate sources, one of which is Ang's An Introduction to Malaysian Music ( $2^{\text {nd }}$ edition $),{ }^{20}$ which gives an overview of the current state of art music in Malaysia. The journal articles by

\footnotetext{
${ }^{17}$ Leong, "Parental Attitudes."

${ }^{18}$ Valerie Ross, "External Public Piano Examinations in Malaysia: Social and Symbolic Significance," (PhD diss., Deakin University, Victoria, Australia, 2002), accessed December 29, 2013, http://dro.deakin.edu.au/eserv/DU:30023143/ross-externalpublicpiano-2002.pdf.

${ }^{19}$ Wong, Music of Chinese in Sabah.

${ }^{20}$ Ang, Introduction to Malaysian Music.
} 
$\operatorname{Tan}^{21}$ and Chopyak, ${ }^{22}$ as well as Yong's dissertation ${ }^{23}$ outline the government's innovations in the cultivation of art and music, as part of its vision in building a modern nation. News on the recent trends and development of music in Malaysia can be found on the World Wide Web, particularly in press companies' websites, such as The Star Online (http://www.thestar.com.my), MySinchew (http://www.mysinchew.com), and the New Straits Times (http://www.nst.com.my). Websites by organizational bodies and private agencies that are supportive of the arts-such as the Malaysian Philharmonic Orchestra (MPO) (http://www.mpo.com.my) and The Kuala Lumpur Performing Arts Centre (KLPac) (http://www.klpac.org)—also provide information on the various musical events held in Malaysia. These websites are especially helpful in grasping the current state of art music in the country.

\section{The Composers and the Contemporary Art Music of Malaysia}

As the contemporary art-music scene in Malaysia is relatively new, resources are rather limited. Edited by Harrison Ryker, New Music in the Orient: Essays on Composition in Asia since World War II is one of the rare resources that compile writings on the post-World War II compositional movement in Asia, as submitted by representatives from those respective countries who are members of the Asian Composers League. Daud Hamzah's writing ${ }^{24}$ in this collection of essays gives a report on the new compositions and innovations by Malaysian composers between the 1950s and 80s, which include reference to folk idioms and the experimentation with the combination of traditional and Western instruments.

\footnotetext{
${ }^{21}$ Tan, "Performing Arts in Malaysia."

${ }^{22}$ Chopyak, "Role of Music."

${ }^{23}$ Yong, "Roles of Government and Private Sectors."

${ }^{24}$ Hamzah, "Malaysia."
} 
Carleton Macy's personal encounters with Malaysian composers, as recorded in her journal article,${ }^{25}$ is a more recent snapshot of this scene, and also provides insights into the cultural musical background of Malaysia, the composer's profession, and the current trends in the art-music scene in Malaysia.

In addition to introducing various traditional music in Malaysia, Patricia Matusky and Sooi Beng Tan—in The Music of Malaysia: The Classical, Folk and Syncretic Traditions ${ }^{26}$ also trace the development of contemporary art music in Malaysia by identifying composers active during the mid- $20^{\text {th }}$ century and their works.

On the internet, the most informative resource is the Malaysian Composers Collective's official website, Malaysiancomposers.com, which is solely dedicated to the contemporary artmusic movement in Malaysia. Not only does it provide the most recent news and updates on the contemporary art-music scene in Malaysia and other Asian regions, it also archives a wealth of past on-site postings and published articles (mostly in newspaper and magazines) about Malaysian contemporary art music. In addition, it contains a directory of Malaysian composers (some with contact information attached) and details on the premiere of new works as well as some external links to relevant websites. Information on the anthology CD entitled, "Faith, Hope \& Chaos: Malaysian Contemporary Music Vol. 1" can also be found here. This is of particular significance because it is the very first compilation of the contemporary art music written by Malaysian composers and, to an extent, it helps defines the identity of "Malaysian" art music.

To date, there are only few research studies that address contemporary art music composed by Malaysians. The earliest research is Ming Huey LAM's M.S. thesis, "Art Music

\footnotetext{
${ }^{25}$ Macy, "Tradition and Concert Music."

${ }^{26}$ Matusky and Tan, Music of Malaysia.
} 
Composition in Malaysia: A Focus on Three Composers" $(2000),{ }^{27}$ in which she discusses and provides analysis of selected works by Minni Kim Huai Ang, Cheong Jan CHAN, and Valerie Ross. The piano works included in her discussion are Ang's Miniature No. 1 and Chan's Mubarak. The analyses of these works are of particular interest, as they might serve as models for the analysis approach of this study. However, the complete dissertation is inaccessible. Other than this dissertation, Lam also published a journal article in 2001 on "Malaysian Music and Composer Valerie Ross, ${ }^{, 28}$ in which she introduces a number of Malaysian composers and discusses in particular Valerie Ross's compositional ideas and approaches to the combination of Western and Eastern instruments in a few selected works.

Amy Wai Yee Chan's Ph.D. thesis, "Composing Race and Nation: Intercultural Music and Postcolonial Identities in Malaysia and Singapore" (2005), ${ }^{29}$ also includes the analyses of two compositions by two Malaysian composers—namely, Saidah Rastam's Lapangan Ya-Ya-Ya for vocal ensemble and Sunetra Fernando's 10 -sen for mixed gamelan, rebab, ${ }^{30}$ and vocal ensemble — especially features that correlate with Malaysian culture.

A recent publication edited by HueyChing Chong, Mohd. Nasir Hashin, and YoungHwan YEO, entitled The MPO Composers Forum: And its Impact on the Performance of Contemporary Western Classical Music by Malaysian Composers in Kuala Lumpur ${ }^{31}$ provides valuable insights on the contemporary art-music scene in Malaysia. The first chapter introduces

\footnotetext{
${ }^{27}$ Ming Huey Lam, “Art Music Composition in Malaysia: A Focus on Three Composers” (MS thesis, Universiti Putra Malaysia, Malaysia, 2000).

${ }^{28}$ Lam, "Valerie Ross."

${ }^{29}$ Chan, "Composing Race and Nation."

${ }^{30}$ Rebab is a bowed string instrument.

${ }^{31}$ Chong, Hashim, and Yeo, MPO Composers Forum.
} 
the MPO and the objectives of the Forum. It also gives detailed accounts of the procedures of the event, as well as information of the participants (including biographies in the third chapter) and their works for the competitions. A list of performances of works by Malaysian composers in Kuala Lumpur between 2000 and 2008 is also provided at the end of Chapter Three. The fourth chapter discusses the impact of the Forum on the contemporary music scene in Kuala Lumpur from the perspectives of performances, composers, performers, and audiences.

Concerning the specific topic of this study, the only research that focuses extensively on the piano works by Malaysian composers is Charmaine Blythe Siagian's D.M.A. dissertation, “Selected Solo Piano Works by Contemporary Malaysian and Indonesian Composers from 1979 to 2007: An Introduction" (2007), ${ }^{32}$ which serves in many ways as a model and inspiration for this study. Siagian provides a general historical and socio-economic background for Malaysia and Indonesia, as well as information on the development of Western European art music in both countries. This study, however, gives more insights into the music education in Malaysia, the use of music as a medium to foster national unity, the search of a national identity through music, and the study of piano and its social implications.

Siagian's dissertation introduces four Malaysian composers-namely, Kee Yong Chong, Chong Lim Ng, Tazul Izan Tajuddin, and Chee-Hwa Tan — and provides stylistic analysis to the selected solo piano works by each composer. Although one of the above-mentioned composers is included in this study, a different work is selected and examined from a theoretical standpoint. In addition, this study introduces two other composers, Adeline Wong and Kah Hoe Yii, whose works have yet to be studied. The criteria for the selection of works also differ, in that the works

\footnotetext{
${ }^{32}$ Siagian, "Selected Solo Piano Works."
} 
selected by Siagian appear to be more pedagogical in nature while this study only addresses concert works.

Siagian's bibliography is particularly helpful in identifying relevant resources; however, this study includes only materials pertaining to art music and its development in Malaysia, thus adding a different set of bibliographical sources for reference by future researchers of similar topics. Siagian also includes in the appendix a "List of Known Solo Piano Pieces by Malaysian Composers," which this study builds upon. As seen in Appendix, a number of new composers and their works for solo piano have been identified. 


\section{CHAPTER THREE}

\section{Chong Lim NG}

\section{Biography}

Undoubtedly one of the most exceptional pianists in Malaysia, Chong Lim Ng has won numerous awards both locally and internationally since his youth. These include first prize of the Malaysian National Piano Competition (1993); winner of the Philip Crashaw Memorial Prize for Outstanding Overseas Musician at the Royal Overseas League Competition, UK (1994); and second prize of the AT\&T Istel Young Musician Award Piano Competition, UK (1994). ${ }^{1}$ He has also appeared as a concerto soloist with the Royal College of Music Symphony Orchestra, London, UK (1995); the Kharkov Youth Symphony Orchestra, Ukraine (1998); and the National Symphony Orchestra, Malaysia (1999 and 2003). ${ }^{2}$

$\mathrm{Ng}$ was born in 1972 in Kuala Lumpur and raised in Seremban, Negeri Sembilan, Malaysia. He grew up in a family with some musical background: his father enjoyed listening to Western music such as jazz and oldies, and his eldest sister was among the first in his family to receive an education in music. $\mathrm{Ng}$ was enrolled in the Yamaha Junior Music Course at the age of four and began playing the piano at the age of seven. A little after that, he took up the organ as well, which he continued to play for almost a decade. This was the time when he showed interest in composing, and his organ compositions earned him the privilege to represent Malaysia twice

\footnotetext{
1 “Piano \& Keyboard: Visiting Guest Artists," Allegro Music \& Arts, accessed January 18, 2013, http://www.allegromusic.info/faculty/clng.html.

${ }^{2}$ Siagian, "Selected Solo Piano Works," 34-35.
} 
at the Yamaha's International Junior Original Concert, those held in Tokyo, Japan in 1986 and $1988 .^{3}$

Between 1994 and 1997, Ng received a full scholarship to study with Frank Wibaut at the Royal College of Music, London, UK where he obtained his Postgraduate Diploma. He then went on to further his music studies in Austria for a year, enrolling at the Universität für Musik und darstellende Kunst Graz. There he studied piano under Elza Kolodin and composition under Beat Furrer. In late 2000, Ng returned to study with Furrer for a year and a half when he began to take composing "a little more seriously."4

An enthusiastic composer, $\mathrm{Ng}$ has received commissions and performance invitations around the world. The most notable of such are Rimba [Rain Forest], ...Windows ..., and Xiang [ 祥, Peace], premiered by the Malaysian Philharmonic Orchestra under the baton of Kevin Field at the MPO Forum for Malaysian Composers in 2006-7; Morning Mist for cello and piano, commissioned by the 2009 Kuala Lumpur Contemporary Music Festival and premiered by Ensemble Mosaik from Germany at the festival; Amorphous for string orchestra, commissioned by the 2010 "Streams” International New Music Festival in Brauweiler, Germany, and premiered by the Stream Festival Orchestra, conducted by Christoph Maria Wagner; and Dragonfly $(s)$ for solo piano, commissioned by the Persatuan Chopin Malaysia (Chopin Society Malaysia) as a compulsory competition piece of the $5^{\text {th }}$ ASEAN International Chopin Piano Competition in 2012.

The composer himself premiered almost all of his compositions for the piano, except for A Distant Voice of the Rain Forest (Fragments from “Rimba”...) for solo piano, which was

\footnotetext{
3 "Visiting Guest Artists" (website).

4 “On the Quiet” (website).
} 
premiered by Soo-Yeon Lim, pianist of Ensemble TIMF, at the 2009 Tongyeong International Music Festival (TIMF) in Korea. Ng was recently invited to the $40^{\text {th }}$ Annual John Donald Robb Composers' Symposium in Albuquerque, New Mexico, USA (2011) where he co-spoke in a composition seminar and performed two of his works: ...Footprints ... for solo piano (2006, revised 2011) and Morning Mist for cello and piano (2009). ${ }^{5}$

Compositionally, this classically trained pianist-composer resists using strict structure or fixed forms; rather, he prefers freedom in spirit, form, and interpretation. ${ }^{6}$ For that reason, his works have been described as "bold, experimental ... with a warmth and freedom more associated with Asian music aesthetics."7 His affection for nature and simplicity as well as his cultural heritage as a Malaysian also comes through in much of his music. ${ }^{8}$ Even though his feelings and compositional thoughts often vary before and after he writes them down, the composer still holds firm to his belief in "sharing emotions and having something to say in [his] music."9

$\mathrm{Ng}$ was a piano faculty member of the University of Malaya, Kuala Lumpur, Malaysia and the Nanyang Academy of Fine Arts, Singapore. He is currently based in Kuala Lumpur and enjoys an active solo and chamber career, which has brought him around the world to countries such as England, Austria, Germany, Spain, Ukraine, Holland, Denmark, the United States of

\footnotetext{
${ }^{5}$ John Donald Robb Composers' Symposium, program booklet, Department of Music, University of New Mexico, accessed January 18, 2013, http://music.unm.edu/media/pdfs/CompSymp2011_Program.pdf.

${ }^{6}$ Chong Lim Ng, personal message to author on Facebook, August 13, 2012.

7 "Faith, Hope \& Chaos: About the Pieces: 3 Sketches for 2 Pianos," Malaysiancomposers.com, Malaysian Composers Collective, accessed January 18, 2013, http://www.futureasia.net/malaysiancomposers/special/faith38.htm.

8 "On the Quiet" (website).

${ }^{9}$ Ibid.
} 
America, Japan, Taiwan, and Singapore. He is also frequently invited as seminar workshop speaker as well as jurist at music festivals and competitions both locally and abroad.

In the little free time he has, $\mathrm{Ng}$ gives piano lessons as well as masterclasses and composes additional uncommissioned pieces, following his personal creative agenda. A longtime passion and growing interest is writing music for the young. Concurrently, he is also very passionate about a charitable foundation named the H.E.A.R.T. Foundation, through which he has continuously contributed his musical knowledge and talents to help underprivileged children in the Southeast Asian region. ${ }^{10} \mathrm{He}$ remarked in an interview in 2007, "Doing this work has changed my life. Of course, I feel guilty occasionally that I can't do as much as I should with my music, but I'm actually very happy that I'm given the chance to work with those children. That's been my dream for a long time!"11 $\mathrm{Ng}$ still feels the same about his voluntary works but has come closer to finding balance for pursuing his multiple tasks in hand. ${ }^{12}$

\footnotetext{
10 "3 Sketches for 2 Pianos" (website).

11 "On the Quiet" (website).

${ }^{12}$ Chong Lim Ng, e-mail message to author, January 20, 2013.
} 


\section{Complete List of Works}

\section{Orchestral}

1. Xiang [祥, Peace] for orchestra (2007)

2. Amorphous for string orchestra (2009)

\section{Chamber}

1. Khatulistiwa [Equator] for two pianists and two percussionists (2001)

2. Three Sketches for two pianos (2004)

3. Rimba [Rain Forest] for fourteen musicians (2006)

4. ...Windows ... for seven musicians (2007)

5. Morning Mist for cello and piano (2009)

6. Shadows for piano, gamelan, and traditional Malay instruments (2011)

\section{Solo Instrumental}

1. Two Preludes for solo piano (1999)

2. Sonata for solo cello (2000)

3. ...Warna... [Colors] for solo piano (2001)

4. Daun [Leaves] for solo piano and electronic CD (2002)

5. A Distant Voice of the Rain Forest (Fragments from "Rimba"...) for solo piano (2008, revised 2012)

6. ...Footprints ... for solo piano (2006, revised 2011)

7. Dragonfly(s) for solo piano (2012) 


\section{Analysis of Selected Work for Piano}

\section{A Distant Voice of the Rain Forest (Fragments from “Rimba”...) for solo piano (2008, revised 2012)}

Premiere: $\quad$ March 28, 2009 at the Tongyeong International Music Festival (TIMF) in Korea. Performed by Soo-Yeon Lim, pianist of Ensemble TIMF.

Duration: Approximately 5-8 minutes.

\section{Background}

In 2006, $\mathrm{Ng}$ was selected as one of six composers to participate in the second Malaysian Philharmonic Orchestra Forum for Malaysian Composers, during which his appreciation for nature and simplicity ${ }^{13}$ led him to write Rimba [Rain Forest], a mixed chamber ensemble work for double string quartet, a flute, an oboe, a clarinet, a piano, and two percussionists. The work portrays "the earthy simplicity of a tropical rainforest" "14 and bears influences from the Malaysian tradition, particularly the gamelan. ${ }^{15}$

Two years later, A Distant Voice of the Rain Forest (Fragments from "Rimba"...) ${ }^{16}$ for solo piano was conceived by fragmenting and reconstructing musical ideas from Rimba. The composer describes his impression of the tropical rain forest in the manuscript:

\footnotetext{
13 “On the Quiet” (website).

${ }^{14}$ Chong Lim Ng, "A Distant Voice of the Rain Forest (Fragments from Rimba)," score, 2012, unpublished.

15 "On the Quiet" (website).

${ }^{16}$ Hereafter abbreviated to A Distant Voice of the Rain Forest.
} 
The murmuring of insects, birds...

rustling of falling leaves, water on rocks........

the mystical sense of stillness \& calmness........

creation of balance, at times, silent, quiet, and docile...

at times, brutal, forceful, and unpredictable.....

There are always changes in every movement, whether in a subtle or a drastic manner.....

This piece consists of eleven fragments separated in individual boxes, representing different "views" that come to the performer's mind. ${ }^{18}$ These fragments are to be played randomly in no specific order, and each such fragment may be played more than once.

Performers may also repeat any musical idea within any fragment at any time. Nevertheless, each fragment or musical idea ought to flow continuously from one to another. ${ }^{19}$ The composer uses words such as "atmospheric" and "distant" in the music score to stimulate the imagination while emphasizing the importance of "spontaneity and intuition" 20 when playing this piece. Wise use of the sustaining pedal throughout the piece is also advised. The composer's suggestions for musical expressions are indicated in green although performers are encouraged to incorporate their own interpretation.

\footnotetext{
${ }^{17} \mathrm{Ng}$, "A Distant Voice of the Rain Forest" (score). The quote is kept in its original form.

${ }^{18}$ In an e-mail correspondence with Chong Lim Ng on January 26, 2013, he clarified that the "view" does not necessary have to be a view of the rain forest; it could be a feeling or an imaginary picture.

${ }^{19}$ Chong Lim Ng, interview with author, July 17, 2013.

${ }^{20} \mathrm{Ng}$, "A Distant Voice of the Rain Forest" (score). In a personal message from Chong Lim Ng on Facebook on August 13, 2012, he also stated that he intended for the music to sound atmospheric and mystical.
} 


\section{$\underline{\text { Analysis }}$}

The analytical method used here is based on set theory. All pitch or pitch-class collections are in normal order. Unless otherwise indicated, all mention of "set" henceforth means a pitch-class set in its prime form.

\section{Fragments 1, 2, and 3}

Fragments 1, 2, and 3 (Example 3.1) bear clear resemblance to each other, in that they are constructed in the same manner: beginning with a trichord in the bass; followed by four successive whole notes in the treble, most of which are embellished with one or more grace notes; and ending with a gong-like cluster of sound in the lowest register of the keyboard, produced either by damping the strings or by striking the keys extremely quietly.
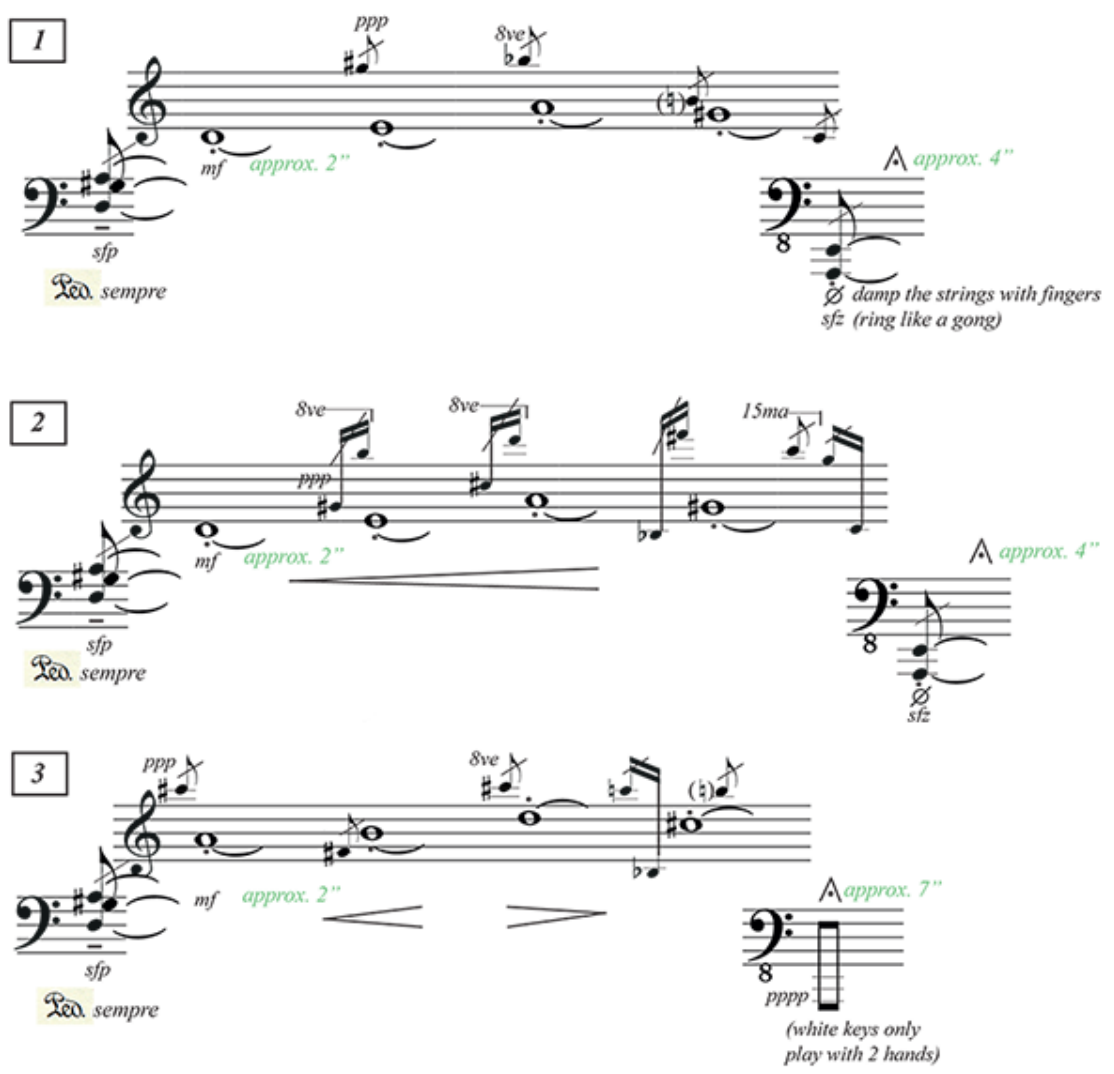

Example 3.1

Chong Lim Ng: A Distant Voice of the Rain Forest, Fragments 1-3. 
Noticed also is the similarity between the opening and ending of Fragments 1 and 2 where the D4 whole note is not preceded with any grace note, and both fragments ends with a C4 grace note. The final two grace notes in Fragments 1 and 3 also share with each other a common span of unordered pitch-class interval 1 (see Figure 3.1).

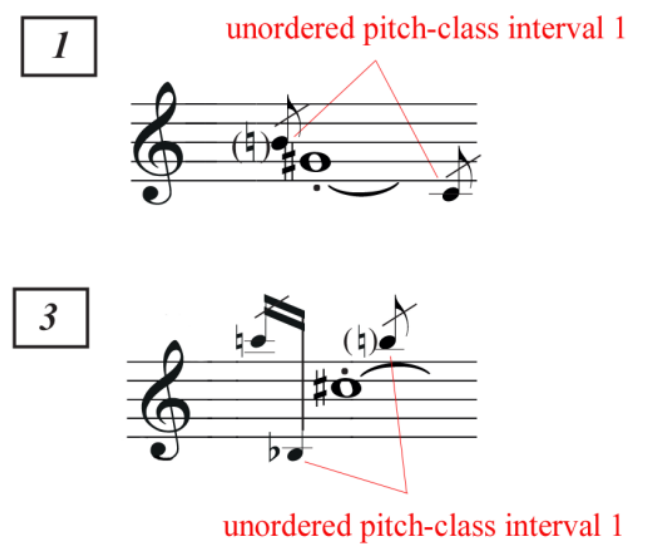

Figure 3.1 Similarity between the final two grace notes in Fragments 1 and 3.

All three fragments open with the exact same trichord: [G\#, A, D] (pitch-class set [0, 5, 6]), with all three pitches presented in the same register. Likewise, the four successive whole notes in Fragments 1 and 2 are from the same pitch collection in the same register as well (i.e., $[D, E, G \#, A]$ or set $[0,1,5,7])$. On the other hand, the whole notes $[A, B, C \#, D]$ in Fragment 3, could easily be mistaken as an exact transposition of the $[\mathrm{D}, \mathrm{E}, \mathrm{G} \#, \mathrm{~A}]$ set, judging by the similarity in contour. However, a closer look establishes that it is set $[0,1,3,5]$ (see Figure 3.2).

\begin{tabular}{|c|c|c|}
\hline \multirow{2}{*}{ Fragment } & \multicolumn{2}{|c|}{ Pitch-Class Set } \\
\cline { 2 - 3 } & Trichord & Whole Note Tetrachord \\
\hline 1 & {$[0,5,6]$} & {$[0,1,5,7]$} \\
\hline 2 & {$[0,5,6]$} & {$[0,1,5,7]$} \\
\hline 3 & {$[0,5,6]$} & {$[0,1,3,5]$} \\
\hline
\end{tabular}

Figure 3.2 Pitch content in Fragments 1-3. 
Both $[0,1,5,7]$ and $[0,1,3,5]$ sets contain pitch-class intervals 1 and 5 (i.e., the distances between 0 and 1, and between 0 and 5), thus both sets are indeed partially related by transposition: subset $[4,8,9]$ (i.e., [E, G\#, A] in integer notation) in Fragment 1 maps onto subset $[9,1,2]$ (i.e., [A, C\#, D] in integer notation) in Fragment 3 at $\mathrm{T}_{5}$. Concurrently, it could also be described in the following manner: subset $[9,1,2]$ in Fragment 3 maps onto subset [4, 8, 9] in Fragment 1 at $\mathrm{T}_{7}$ (see Figure 3.3).

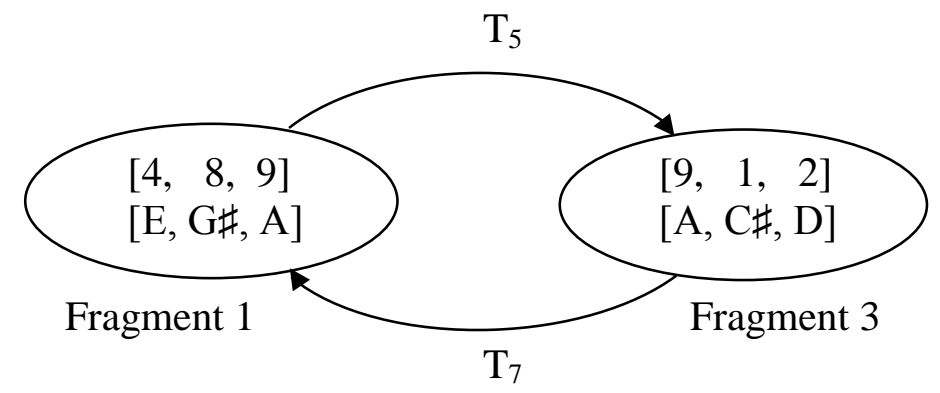

Figure 3.3 Transpositional relationships between subsets of Fragments 1 and 3.

In addition, the spanning interval of Fragments 1 and 2 (i.e., from $\mathrm{D}$ to $\mathrm{A}$ ) is inverted to form the spanning interval of Fragment 3 (i.e., from A to D). With respect to those registral extremes exemplified by the grace notes, the second pitch of the tetrachord is a major $2^{\text {nd }}$ higher than the first, and the final pitch is a minor $2^{\text {nd }}$ lower than the third. Such connections seem to be essential in this piece (see Figure 3.4). 

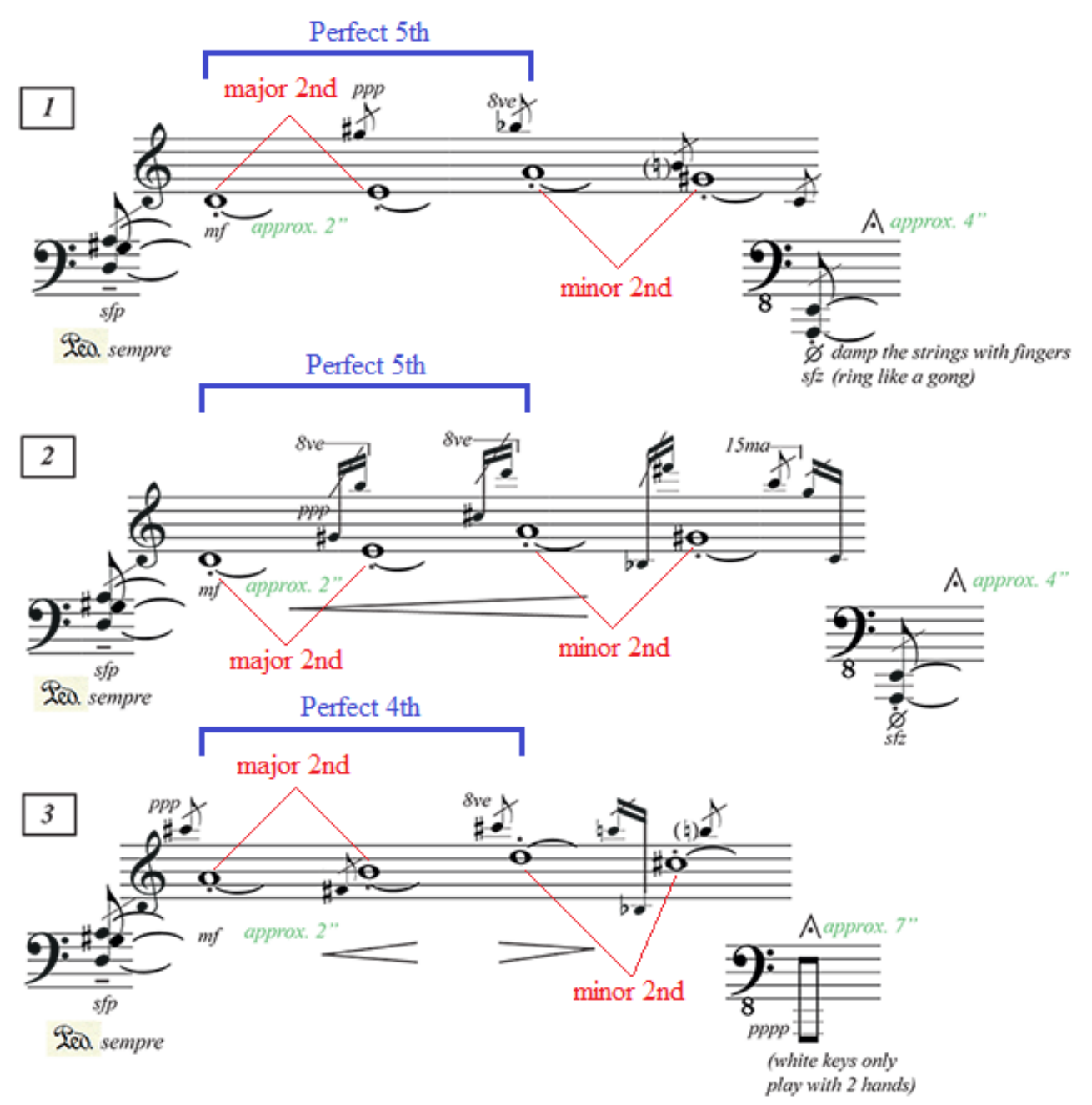

Figure 3.4 Recurrences of similar intervallic relationships between pitch-classes in Fragments 1-3.

Worthy of note is the fact that $[\mathrm{D}, \mathrm{E}, \mathrm{G} \#, \mathrm{~A}]$ is a subset of the gamelan pelog scale, or more specifically, pathet barang - the third mode of the pelog scale used by Central Javanese $\operatorname{gamelan}^{21}$ (see Figure 3.5). In the original chamber ensemble version, Rimba, this motif-as well as the $[\mathrm{A}, \mathrm{B}, \mathrm{C} \#, \mathrm{D}]$ motif-is carried by the flute and is heard throughout the composition. In $A$ Distant Voice of the Rain Forest, Fragments 1, 2, and 3 are the only fragments which contain

21 “Pelog," Wikipedia, last modified February 26, 2013, accessed March 11, 2013, http://en.wikipedia.org/wiki/Pelog. The tuning system of a gamelan is not standardized-indeed, each gamelan should have its unique tuning - and this representation of the pelog scale therefore forces the gamelan to conform to twelve-tone equal temperament. 
materials drawn from other instrumental parts in Rimba. Other than that, the remaining eight fragments are either directly quoted from the original piano part or newly composed.

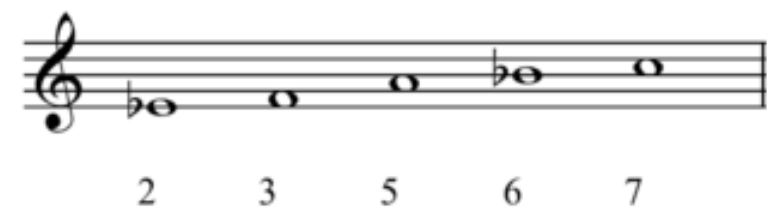

Figure 3.5 Pelog barang. Image taken from "Pelog," Wikipedia, last modified February 26, 2013, accessed March 11, 2013, http://en.wikipedia.org/wiki/Pelog.

Although Fragments 1, 2, and 3 share some common elements such as the pitch content in both the opening trichord and the four successive whole notes, some elements are slightly altered in order to make them sound different from one another. Such elements include the pitchclass selection for the grace notes as well as the number and placement of those notes, dynamic, and the sounding method of the ending gesture.

When examining the grace notes in these fragments, three possible types of relationships were considered: 1) the relationship between the grace notes and the whole notes; 2) the relationship amongst the grace notes within the same fragment; and 3) the relationship of the grace notes between one fragment and another fragment.

There is little relationship between the grace notes and the whole notes in each fragment. It is observed that each fragment includes, in its first presentation of grace notes, a use of interval class 4 above the main note. The third main note of each fragment includes a grace note representation of interval class 1: first as a span of 13 semitones, then as a span of 13 semitones between two grace notes, and finally as a span of 11 semitones (see Figure 3.6). 

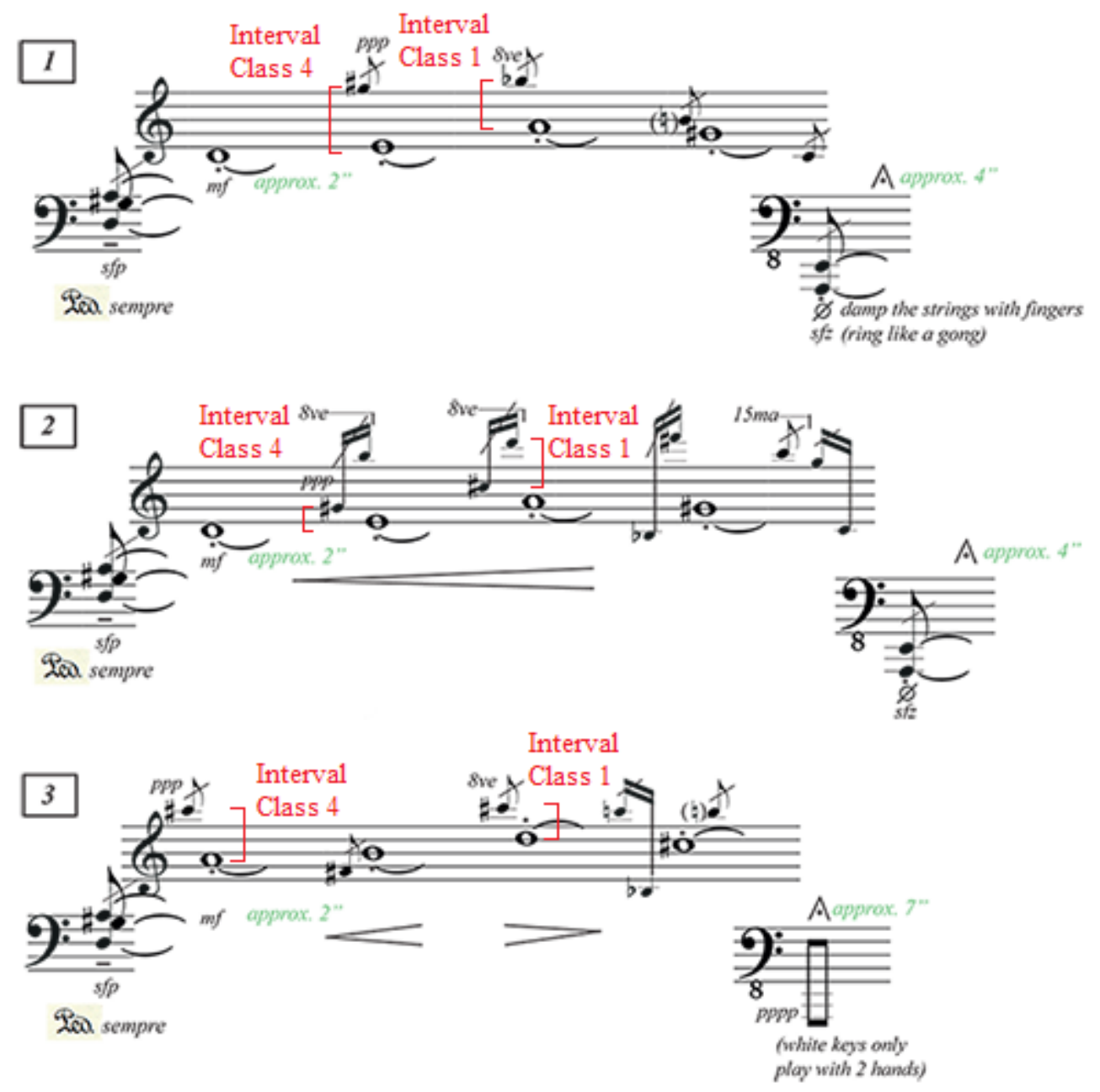

Figure 3.6 Intervallic relationships between grace notes and whole notes in Fragments 1-3.

Another notable feature is the pitch interval span of a $9^{\text {th }}$ (whether major or minor), disregarding the octave register, which continues to appear in a couple of other fragments, such as Fragments 7 and 9 (see Figure 3.7). 

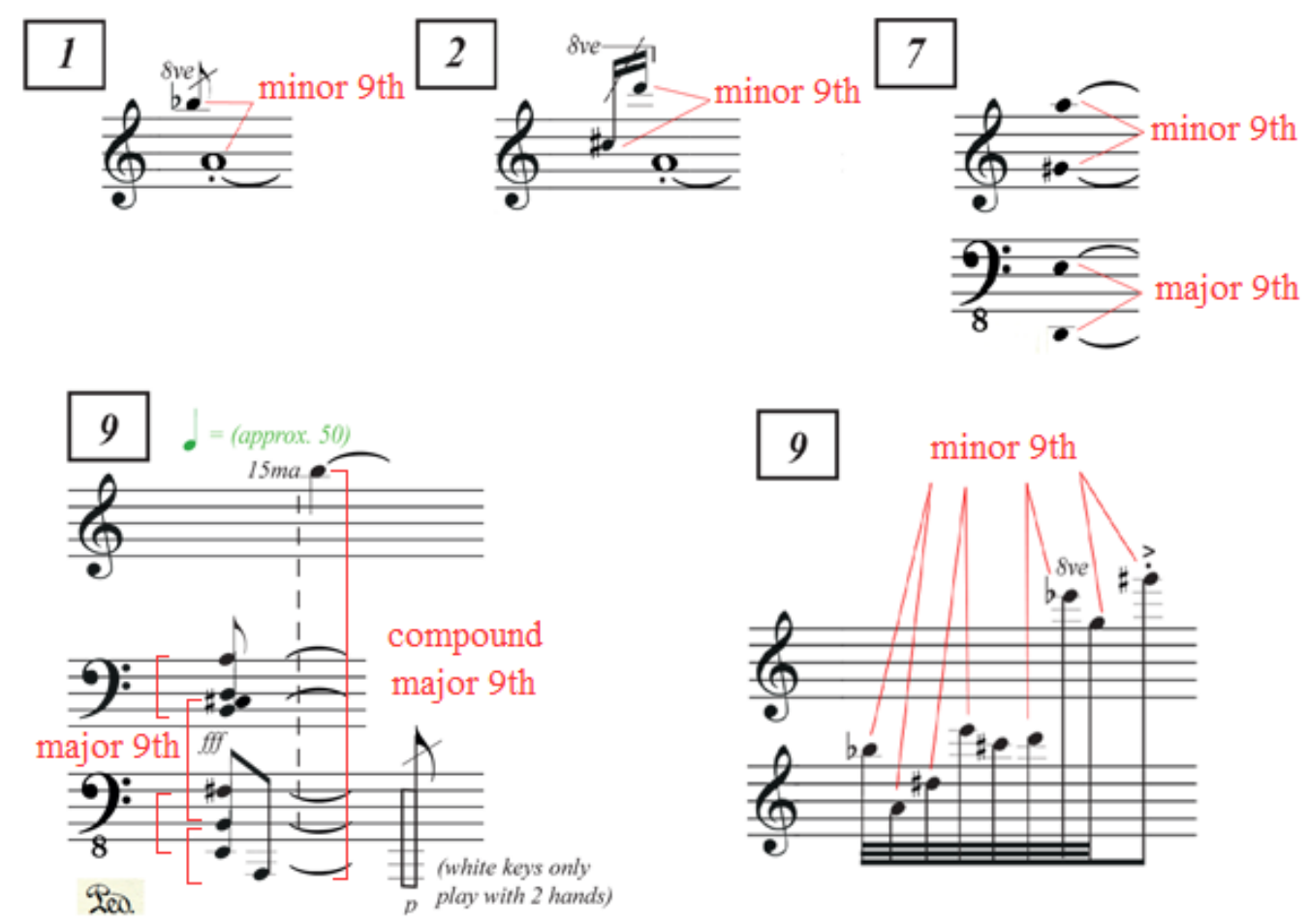

Figure 3.7 Recurrences of pitch interval span of a $9^{\text {th }}$ in Fragments 1, 2, 7, and 9.

In Fragment 2, the grace notes have a clearer relationship amongst themselves than with the whole notes. When divided into two equal sets of tetrachord, it is found that the second set is basically generated from the first set under $\mathrm{T}_{11}$. Each such tetrachord also has an instance of interval class 1 appended to the trichord: the first includes $C \#-D$ and the second includes $F \#-G$ (see Figure 3.8).

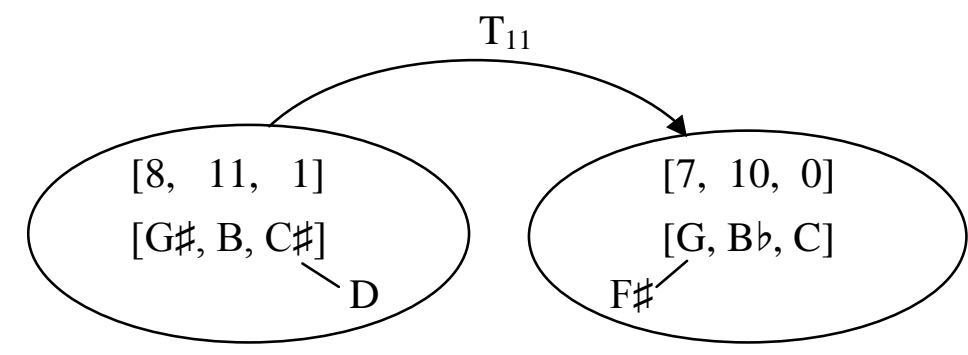

Fragment 2:

Set 1

Set 2

Figure 3.8 Relationship between grace notes in Fragment 2. 
Interestingly, the pitch-class selection for the grace notes in Fragment 3 is somewhat related to the whole notes in the same fragment: grace notes $[\mathrm{F} \#, \mathrm{~B} b, \mathrm{~B}]$ maps onto whole notes $[A, C \#, D]$ at $T_{3}$. This also means that grace notes $[F \#, B b, B]$ is $T_{2}$ of the subset of Fragment 1 , $[\mathrm{E}, \mathrm{G} \#, \mathrm{~A}]$.

It is highly likely that a system is employed when selecting the pitches for the grace notes although the reason for such selection is rather unclear. Based on how each fragment retains certain pitch-classes and adds on several other pitch-classes, it does not seem that they were randomly selected (see Figure 3.9).

\begin{tabular}{|c|c|}
\hline Fragment & \multicolumn{2}{|c|}{ Pitch Collection (Grace Notes) } \\
\hline 1 & \multicolumn{2}{|c|}{ G\#, Bb, B, C } \\
\hline 2 & F\#, G, G\#, Bb, B, C, C\#, D \\
\hline 3 & F\#, r Bb, B, C, C\# \\
\hline
\end{tabular}

Figure 3.9 Relationships between grace notes in Fragments 1-3.

\section{Fragment 4}

Fragment 4 (Example 3.2) presents a more complex texture with multiple streams of pitches intertwining with each other. More often than not, they are not in rhythm with each other, and they occasionally overlap in register. This fragment comprises two parts separated by a fermata. Each part contains repeated material within itself, shown with brackets, with minor alteration towards the end of the second part. 


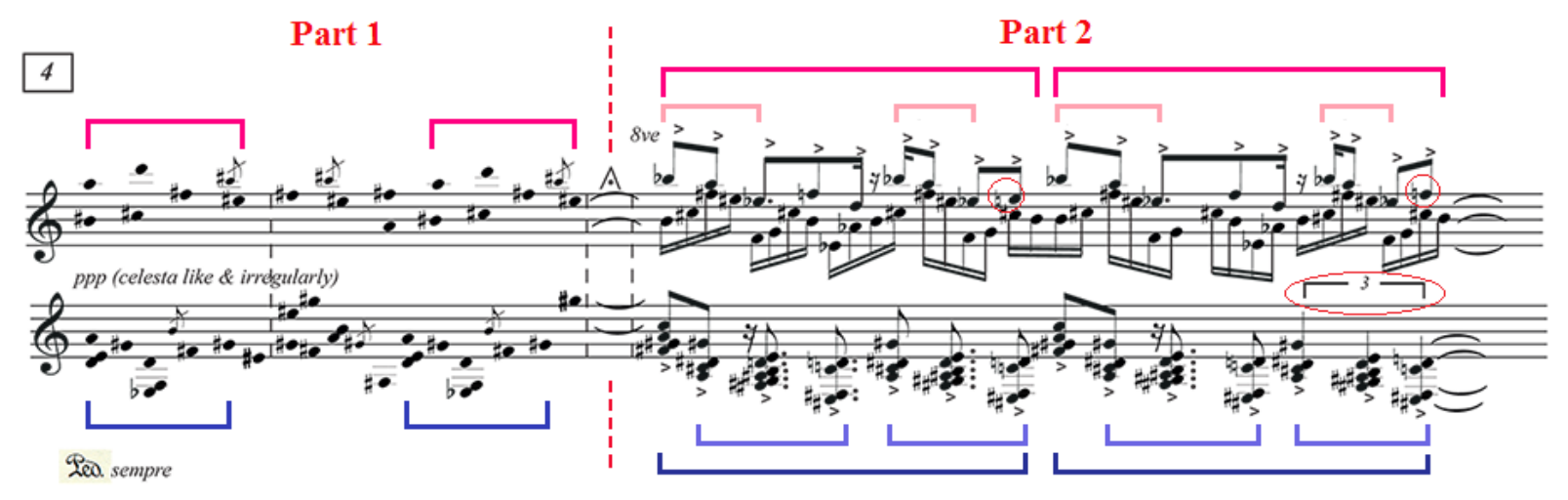

Example 3.2

Chong Lim Ng: A Distant Voice of the Rain Forest, Fragment 4.

Part 1 could be meaningfully segmented on the basis of register, hence separating the part into four possible segments (see Figures 3.10 and 3.11).

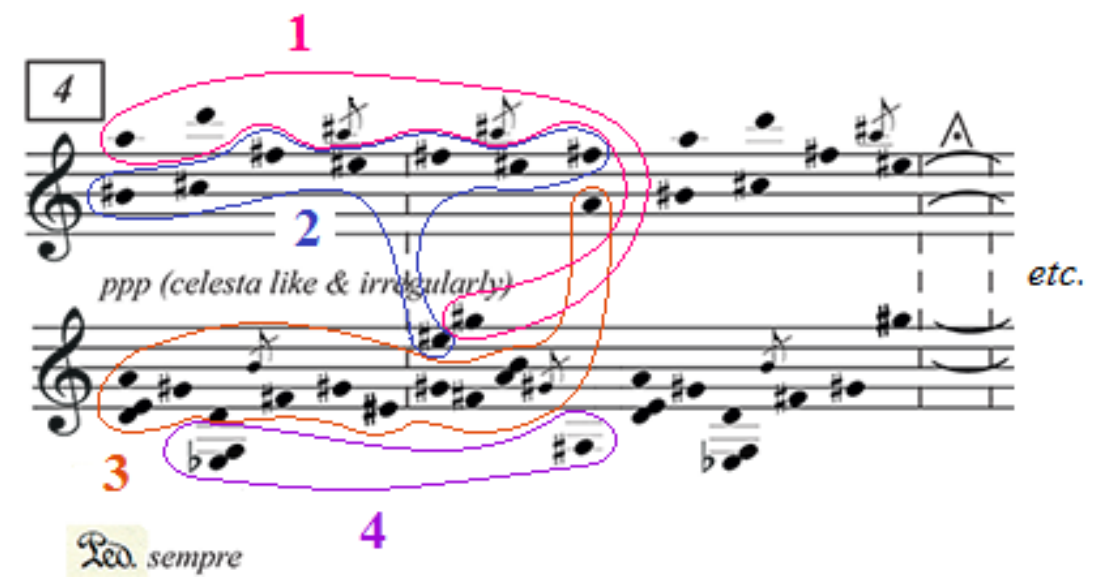

Figure 3.10

Chong Lim Ng: A Distant Voice of the Rain Forest, Fragment 4, Part 1. 


\begin{tabular}{|l|c|c|}
\hline Segment & 1 & 2 \\
\hline Pitch Collection & G\#, A, C\#, D & B\#, C\#, E\#, F\# \\
\hline Pitch-Class Set & {$[0,1,5,6]$} & {$[0,1,5,6]$} \\
\hline
\end{tabular}

\begin{tabular}{|l|c|c|c|c|}
\hline Segment & \multicolumn{3}{|c|}{3} & 4 \\
\hline Pitch Collection & D, E, G\#, A & E\#, F\#, G\#, B & F\#, G\#, A, B & Eb, F, F\# \\
\hline Pitch-Class Set & {$[0,1,5,7]$} & {$[0,3,5,6]$} & {$[0,2,3,5]$} & {$[0,1,3]$} \\
\hline
\end{tabular}

Figure 3.11 Pitch content in Fragment 4, Part 1, Segments 1-4.

It is evident that Segments 1 and 2 are related by transposition. More importantly, they are also related to the $[0,5,6]$ trichord set (i.e., $[\mathrm{G} \#, \mathrm{~A}, \mathrm{D}])$ and the $[0,1,5,7]$ whole note tetrachord set (i.e., [D, E, G\#, A]) in Fragments 1 and 2 (see Figure 3.12). It is also observed that Segment 1 contains three out of four pitch-classes from the tetrachord in Fragment 3, [A, B, C\#, D] or $[0,1,3,5]$.

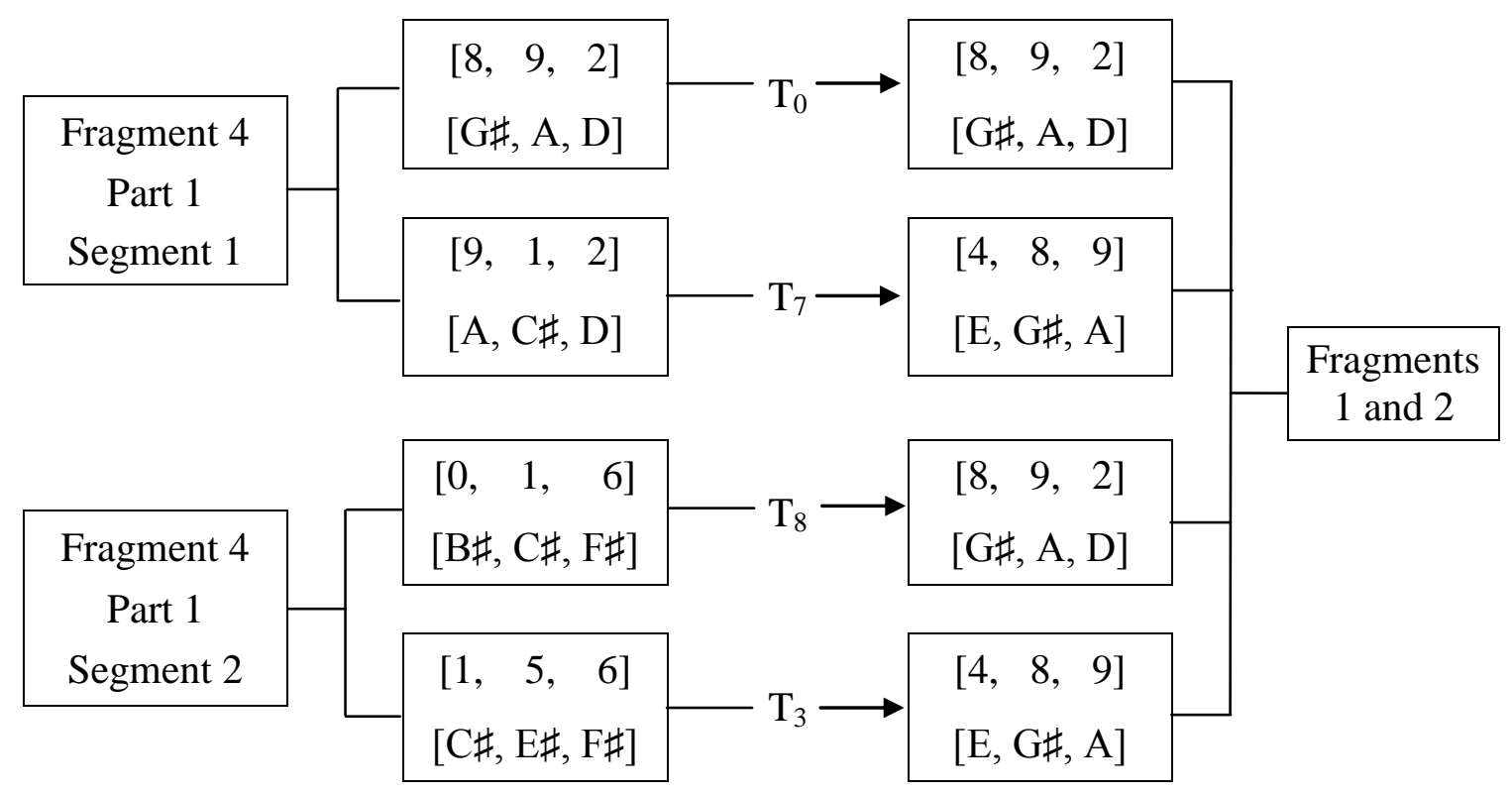

Figure 3.12 Interrelationships between pitch content in Fragment 1, 2, and 4 (Part 1). 
Segment 3 could be divided into three sets of pitches. The first set is obviously the undisguised $[0,1,5,7]$ tetrachord set from Fragments 1 and 2 in its original form. The second set when compared to the set in Segment 1 reveals that its subset, [E\#, F\#, B], is a transposed version of the $[G \#, A, D]$ trichord set from Fragment 1 under $T_{9}$.

The third set shares with the second set three common pitches-F\#, G\#, and B-while the fourth and last pitch in the third set is changed. This concept of preserving a number of pitchclasses and altering one pitch-class in the set—or, in some other places, adding one or more pitch-classes to the set—is significant and will be seen again in the half of this fragment and in other fragments. Last but not the least, subset [Eb, F, F\#] in Segment 4 is $T_{4}$ of subset [B, C\#, D] of the whole note tetrachord in Fragment 3.

In a nutshell, the pitch materials in Part 1 of Fragment 4 when broken into sets of tetrachords show close ties to that of Fragments 1,2, and 3. The relationship is based on transposition, and more often than not new tetrachordal classes are generated by transposing a trichord but changing the fourth element of the tetrachord. Such manipulations demonstrate the various developmental possibilities of a simple motivic idea.

It is apparent in Part 2 that there are three prevailing segments: 1) right hand top line, 2) right hand bottom line, and 3) left hand. Segment 1 is a perfect example of the above-mentioned concept wherein a number of pitch-classes in the set are reserved while another pitch-class is modified. The basic set here is [Eb, F, A, B b] which, again, is the [D, E, G\#, A] set in Fragments 1 and 2 transposed at $\mathrm{T}_{1}$. The first set contains all the pitches in the basic set with an additional $\mathrm{D}$ that appends to $\mathrm{E} b$ of the tetrachord, creating a span of interval class 1 as seen before in Fragment 2. The second set preserves $\mathrm{E} b, \mathrm{~A}, \mathrm{~B} b$ and alters $\mathrm{F}$ into E⿱ . The third and fourth sets 
repeat the first and second sets respectively, with the last pitch in the fourth set changed from EG to F⿹, which brings the set back to its original form (see Figure 3.13).

\begin{tabular}{|c|c|c|}
\hline St & \multicolumn{2}{|c|}{ Pitch-Class Collection } \\
\hline 1 & $\mathrm{D}, \quad \mathrm{E} b$ & $\mathrm{~F}, \mathrm{~A}, \mathrm{~B} b$ \\
\hline 2 & $\mathrm{~Eb}$ & $\mathrm{E}$, $\quad \mathrm{A}, \mathrm{Bb}$ \\
\hline 3 & $\mathrm{D}, \quad \mathrm{E} b$ & $\mathrm{~F}, \mathrm{~A}, \mathrm{~B} b$ \\
\hline 4 & $\mathrm{~Eb}$ & $\mathrm{~F}, \mathrm{~A}, \mathrm{~B} b$ \\
\hline
\end{tabular}

Figure 3.13 Pitch content in Fragment 4, Part 2, Segment 1.

It is tempting to divide Segment 2 into two equal halves. The pitches are notated in groups of four sixteenth notes, plus two sixteenths more at the end of each half. However, there is little connection found when analyzed in this manner. When separating the pitch content by register, it is discovered that there are two sets in this segment: 1) [B, C\#, E\#, F\#] and 2) [Eb, F, $\mathrm{G}, \mathrm{Ab}$ ] (see Figure 3.14). The first set is $\mathrm{T}_{9}$ of the whole note tetrachord set in Fragments 1 and 2, [D, E, G\#, A], which means it is also a $[0,1,5,7]$ set. On the other hand, the second set is $T_{6}$ of the whole note tetrachord set in Fragment 3, [A, B, C\#, D], which makes it a [0, 1, 3, 5] set.

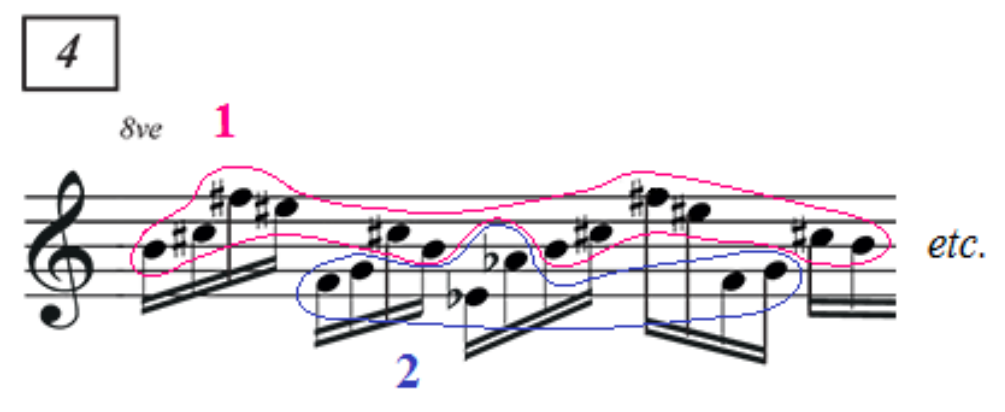

Figure 3.14

Chong Lim Ng: A Distant Voice of the Rain Forest, Fragment 4, Part 2, Segment 2. 
Segment 3 is analyzed chord by chord (see Figure 3.15). Chords 1 and 2 are related, in that the subset of Chord 1, [F\#, G\#, C], maps onto the subset of Chord 2, [A, C\#, D\#], at T9I (i.e., inverted, then transposed by interval 9). Subsequently, the same subset in Chord 2, [A, C\#, D\#], also maps onto the subset of Chord 3, [E, G\#, A\#], at T 7 . Another subset in Chord 3, [G\#, A\#, B], is transposed at $\mathrm{T}_{4}$ to form $[\mathrm{C}, \mathrm{D}, \mathrm{D} \#]$ in Chord 4 . When looped around from Chord 4 to Chord 1, [C, D, D\#] in Chord 4 maps onto [F\#, G\#, A] in Chord 1 at $T_{6}$, thus all four sets of chords become a circle of transformation.

\begin{tabular}{|l|c|c|c|c|}
\hline Chord & 1 & 2 & 3 & 4 \\
\hline Pitch Collection & F\#, G\#, A, C & G\#, A, C\#, D\# & D, E, F\#, G\#, A\#, B & C, C\#, D, D\# \\
\hline Pitch-Class Set & {$[0,3,4,6]$} & {$[0,2,6,7]$} & {$[0,1,3,5,7,9]$} & {$[0,1,2,3]$} \\
\hline
\end{tabular}

Figure 3.15 Pitch content in Fragment 4, Part 2, Segment 3.

Once again, the composer is using the same method seen in Segment 1 of this part: preserving a trichord class with the other member(s) of the set in a changing relationship. Therefore, the chords in Segment3 sound rather similar to each other even though one pitch gets changed or a couple of pitches get added because there is a cluster of intervals that gets preserved.

It is also observed that subset $[\mathrm{G} \#, \mathrm{C} \#, \mathrm{D} \#]$ in Chord 2 is a transposition of subset $[A, D$, E] in Fragments 1 and 2 at $T_{11}$ while subset [E, F\#, G\#] in Chord 3 maps onto subset [A, B, C\#] in Fragment 3 under $\mathrm{T}_{5}$. 


\section{Fragment 5}

Like Fragments 1, 2, and 3, Fragment 5 (Example 3.3) opens with the same [0, 5, 6] trichord set, but inverted from $[\mathrm{G} \#, \mathrm{~A}, \mathrm{D}]$ and transposed at $\mathrm{T}_{11}$ to become $[\mathrm{A}, \mathrm{D}, \mathrm{E} b]$. It also changes from the form of a simultaneous sounding chord into a broken figure. The rest of the fragment could be divided into two sets of pitch-classes: 1) [C, D, F] and 2) [Eb, F, G, A, Bb] (see Example 3.3). The first set could be seen as $\mathrm{T}_{3}$ of the $[\mathrm{A}, \mathrm{B}, \mathrm{C} \#, \mathrm{D}]$ tetrachord set in Fragment 3 with one pitch less. The second set is derived from [D, E, G\#, A] in Fragments 1 and 2 transposed at $T_{1}$ with an additional pitch. Yet again, the same method of manipulating a pitchclass set is employed.

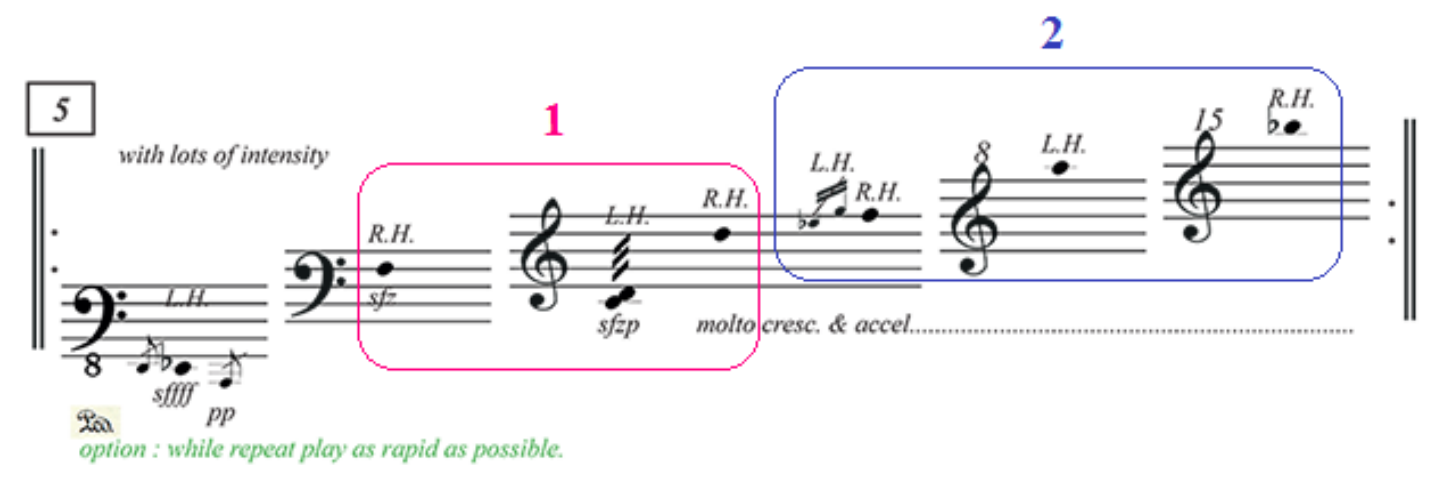

Example 3.3

Chong Lim Ng: A Distant Voice of the Rain Forest, Fragment 5.

\section{Fragment 6}

Fragment 6 (Example 3.4) presents an interesting structure, in that it is a retrograde version of Fragments 1, 2, and 3: beginning with damping the strings to resemble the sound of a gong and ending with the $[\mathrm{D}, \mathrm{G} \#, \mathrm{~A}]$ trichord in the same register with the same articulation and dynamic marking as that of Fragments 1,2, and 3. Excluding the ending trichord, this fragment could be broken into four brief segments made by four sets of pitch-classes, each of which is separated by a fermata (see Example 3.4 and Figure 3.16). 


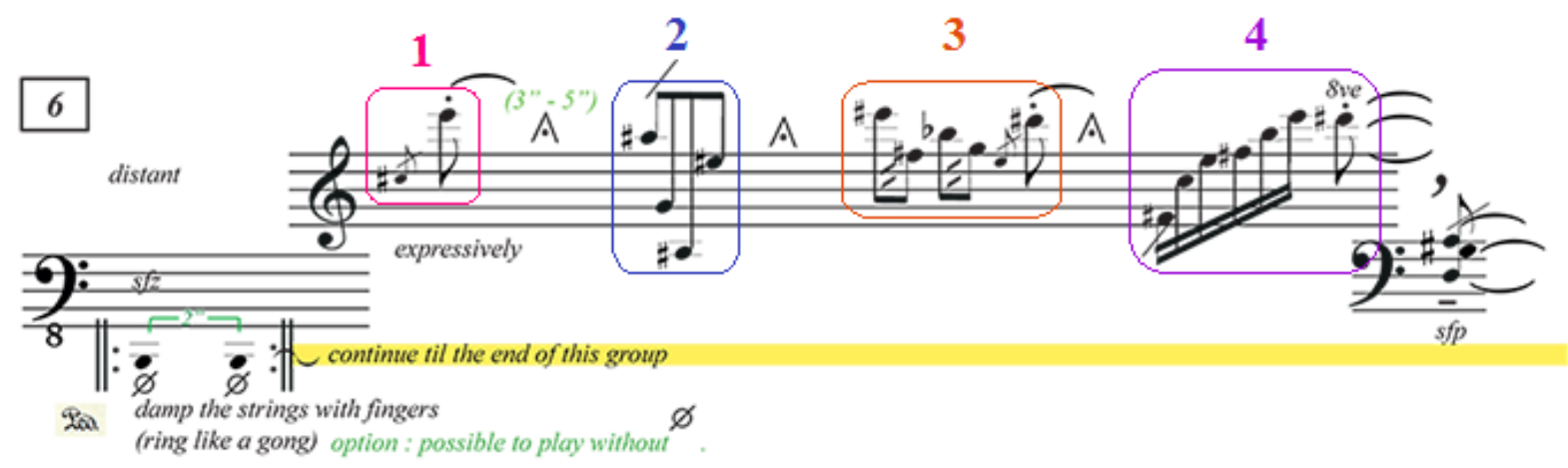

Example 3.4

Chong Lim Ng: A Distant Voice of the Rain Forest, Fragment 6.

\begin{tabular}{|l|c|c|c|c|}
\hline Segment & 1 & 2 & 3 & 4 \\
\hline Pitch Collection & C\#, E & E\#, G, A\# & D\#, E, E\#, F\#, G, Bb & B, C, D\#, E, F\# \\
\hline Pitch-Class Set & {$[0,3]$} & {$[0,3,5]$} & {$[0,3,4,5,6,7]$} & {$[0,2,3,6,7]$} \\
\hline
\end{tabular}

Figure 3.16 Pitch content in Fragment 6, Segments 1-4.

The relationship between the first three pitch-class sets is clear: the first set, $[0,3]$, develops into $[0,3,5]$ by transposition at $\mathrm{T}_{6}$ to become $[\mathrm{G}, \mathrm{A} \#]$, to which an additional pitchclass, $\mathrm{E} \#$ ([5]) is added. Then all three pitch-classes in the second set are carried over to the third set, with the difference that $A \#$ is enharmonically spelled as $\mathrm{B} b$. On top of that, three more pitchclasses are added to form the third $[0,3,4,5,6,7]$ set. These three new pitch-classes, $[\mathrm{D} \#, \mathrm{E}$, $\mathrm{F} \#$ ], also form the last set with the addition of two more pitch-classes (see Figure 3.17).

\begin{tabular}{|c|c|}
\hline Segment/Set & Pitch-Class Collection \\
\hline 1 & $\mathrm{C} \#, \mathrm{E}$ \\
\hline 2 & $\mathrm{E} \#, \quad \mathrm{G}, \mathrm{A \#}$ \\
\hline 3 & $\mathrm{D} \#, \quad \mathrm{E}, \mathrm{E} \#, \mathrm{~F} \#, \mathrm{G}, \mathrm{Bb}$ \\
\hline 4 & $\mathrm{D} \#, \quad \mathrm{E}$, \\
\hline
\end{tabular}

Figure 3.17 Interrelationships between pitch content in Fragment 6, Segments/Sets 1-4. 
At the same time, the $[0,3,5]$ set is a subset of the $[0,1,3,5]$ set in Fragment 3: [E\#, $\mathrm{G}, \mathrm{A \#}($ or $\mathrm{B} b)]$ maps onto subset $[\mathrm{A}, \mathrm{B}, \mathrm{D}]$ in Fragment 3 at $\mathrm{T}_{4}$. Besides that, $[\mathrm{E}, \mathrm{F} \#, \mathrm{G}]$ of the third set also maps onto subset $[\mathrm{B}, \mathrm{C} \#, \mathrm{D}]$ in Fragment 3 at $\mathrm{T}_{7}$. In addition to this relationship, the third set is also connected to Fragments 1 and 2: subset $[\mathrm{B} b, \mathrm{D} \#, \mathrm{E} \#]$ is $\mathrm{T}_{1}$ of the subset of Fragments 1 and 2, [A, D, E].

The fourth and final set summarizes the rest of the fragment by using a combination of transposed materials from previous segments. Subset $[B b, D \#, E]$ in Set 3 is transposed at $T_{8}$ to become subset $[F \#, B, C]$ while subset $[\mathrm{E}, \mathrm{G} \#, \mathrm{~A}]$ in Fragment 1 is transposed at $\mathrm{T}_{7}$ to become subset $[B, D \#, E]$. Besides that, subset $[D \#, E, F \#]$ is a result of inverting and transposing subset $[\mathrm{B}, \mathrm{C} \#, \mathrm{D}]$ in Fragment 3 at $\mathrm{T}_{5}$.

Up to this point, the composer has demonstrated several ways to manipulate sets of pitchclasses, including the use of inversion. It is established that all materials discussed thus far are closely connected with the pitch materials in Fragments 1, 2, and 3, except the left hand chords in Segment 2 of Fragment 4. Although these chords have no clear ties to other fragments, they do, however, have a strong connection among themselves. They also offer something different, perhaps adding contrast to the ever-so-consistent use of the same materials.

\section{Fragment 7}

Instead of opening with a trichord like the previous fragments, Fragment 7 (Example 3.5) begins with the $[0,1,5,7]$ tetrachord set, using its original pitches and stacking them on top of each other to form a chord. The wide spacing of the chord responds to the registral extremes demonstrated by the grace notes in Fragments 1, 2, and 3. The span of interval class 1 , or 13 semitones, between $\mathrm{G} \#$ and $\mathrm{A}$ in the treble staff reflects similar relationships seen, as discussed 
earlier, in Fragments 1 and 2. On the other hand, the spanning interval between $\mathrm{D}$ and $\mathrm{E}$ in the bass staff is 14 semitones, or interval class 2 .

The passage following the opening chord could be broken into two parts, each of which is separated by a breath mark. This fragment is mainly chordal wherein each chord is set in a distinctive register on the keyboard, thus making it easier to distinguish and examine the pitch content of each chord. However, some chords are played simultaneously; hence it is also possible to combine such chords into a set. It is observed that this way of grouping better informs the connection between the sets in this fragment, particularly in the first part (see Example 3.5 and Figure 3.18).

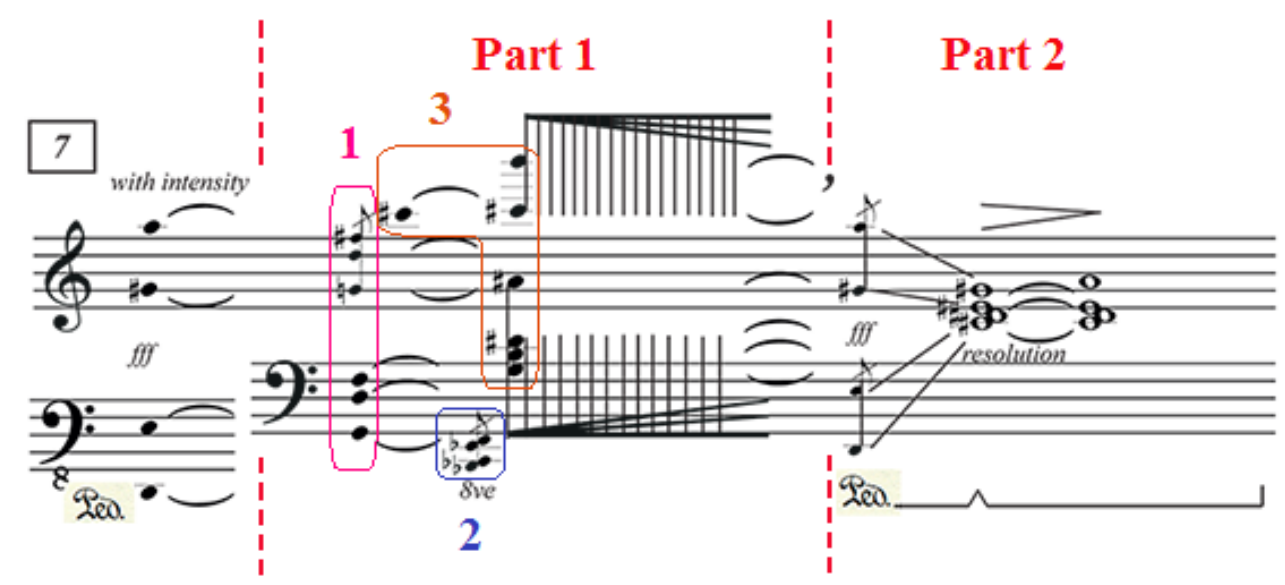

Example 3.5

Chong Lim Ng: A Distant Voice of the Rain Forest, Fragment 7.

\begin{tabular}{|l|c|c|c|}
\hline Chord & 1 & 2 & 3 \\
\hline Pitch Collection & D, F, F\#, G & B b , Cb, Eb, F & G, A\#, B, C\#, D, D\# \\
\hline Pitch-Class Set & {$[0,1,2,5]$} & {$[0,2,6,7]$} & {$[0,1,2,4,5,8]$} \\
\hline
\end{tabular}

Figure 3.18 Pitch content in Fragment 7, Part 1. 
All three pitch-class sets in Part 1 contain transposed materials from Fragments 1 and 2 (see Figure 3.19). Intriguingly, the second set is also $\mathrm{T}_{2}$ of the second set in Fragment 4, Part 2, Segment 3, [G\#, A, C\#, D\#].

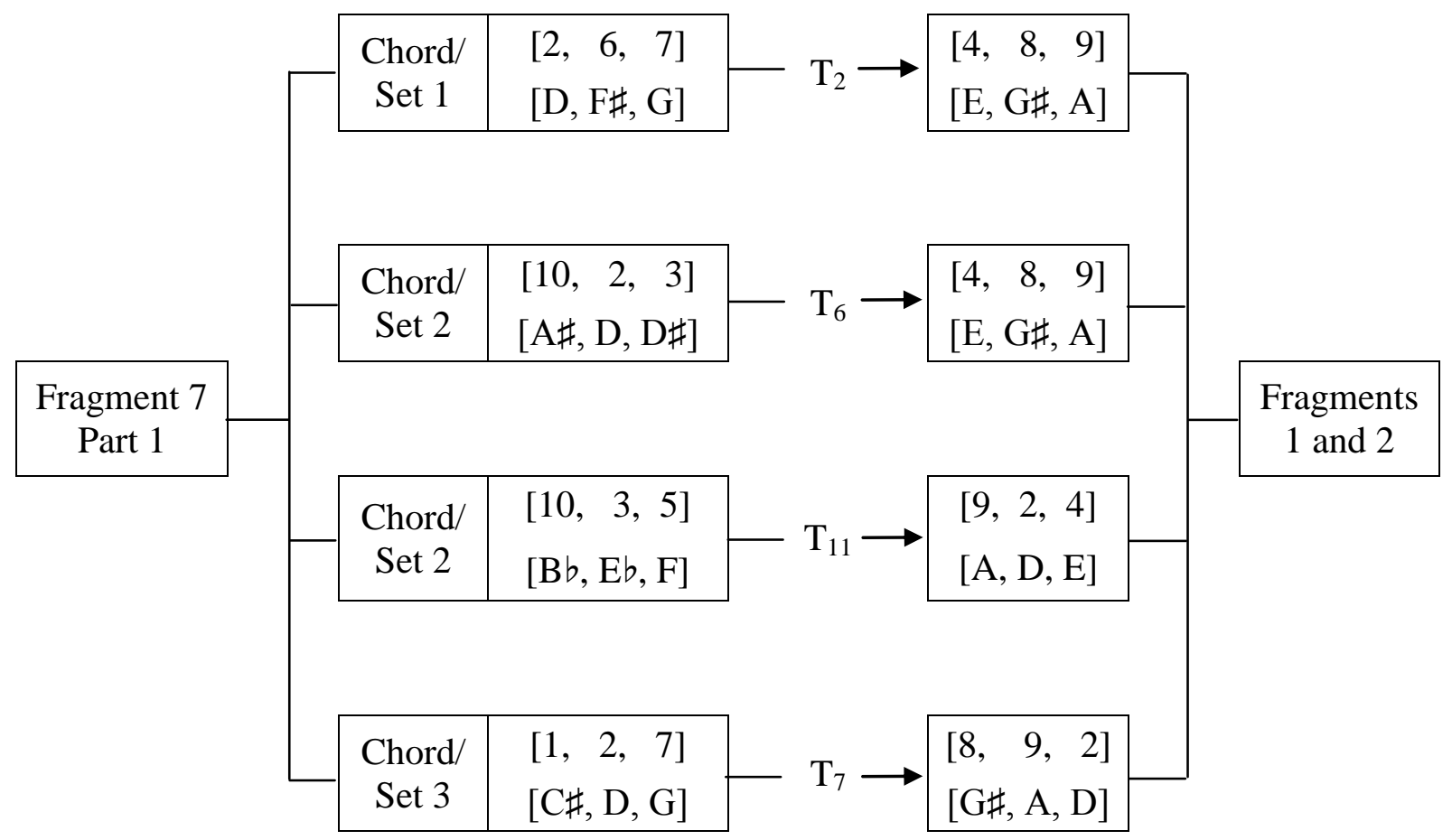

Figure 3.19 Interrelationship between pitch content in Fragments 1, 2, and 7 (Part 1).

The third pitch-class set is related to the first two pitch-class sets in many ways. Not only does it preserve three out of four pitch-classes from the second set, which are enharmonically spelled as $A \#, B$, and $D \#$, its subset $[C \#, D, G]$ is also the inversion of subset $[F, B b, C b]$ in the second set. Subset $[A \#, C \#, D, D \#]$ is also $T_{8}$ of the first set, [D, F, F\#, G].

Part 2 begins with the same tetrachord that started the fragment. This time, it is turned into a grace-note figure that proceeds quickly to the $[C \#, D \#, E \#, G \#]$ tetrachord, after which the 
last pitch, $G \#$, resolves to $A$, acting as a form of cadence. ${ }^{22}$ Therefore, the last set of pitches is examined as $[C \#, D \#, E \#, A]$ instead. This set relates to the subset $[B, C \#, D \#, G]$ in the third set of Part 1 by transposition at $T_{10}$. In addition, its subset $[\mathrm{C \#}, \mathrm{D \#}, \mathrm{E \#}]$ is also a transposition of subset $[A, B, C \#]$ in Fragment 3 under $T_{4}$.

\section{Fragment 8}

Fragment 8 (Example 3.6) is divided into three parts where each part is separated by a breath mark. The pitch material for the main notes is based heavily on the $[0,1,5,7]$ tetrachord set (see Figure 3.20). The first part reorders the [D, E, G\#, A] tetrachord in Fragments 1 and 2 in ascending and descending order, however the mirror structure is not complete until the beginning of Part 2 with D4, which at the same also begins the next part. Part 2 picks up the ascent again from $\mathrm{D}$ (preceded by a $\mathrm{C} \#$ grace note), skips $\mathrm{G} \#$ but extends the set to include $\mathrm{C} b$ and $\mathrm{F}$, and ends with a Gb grace note without any descent. The third part brings the focus back to the tetrachord but this time transposed and reordered.

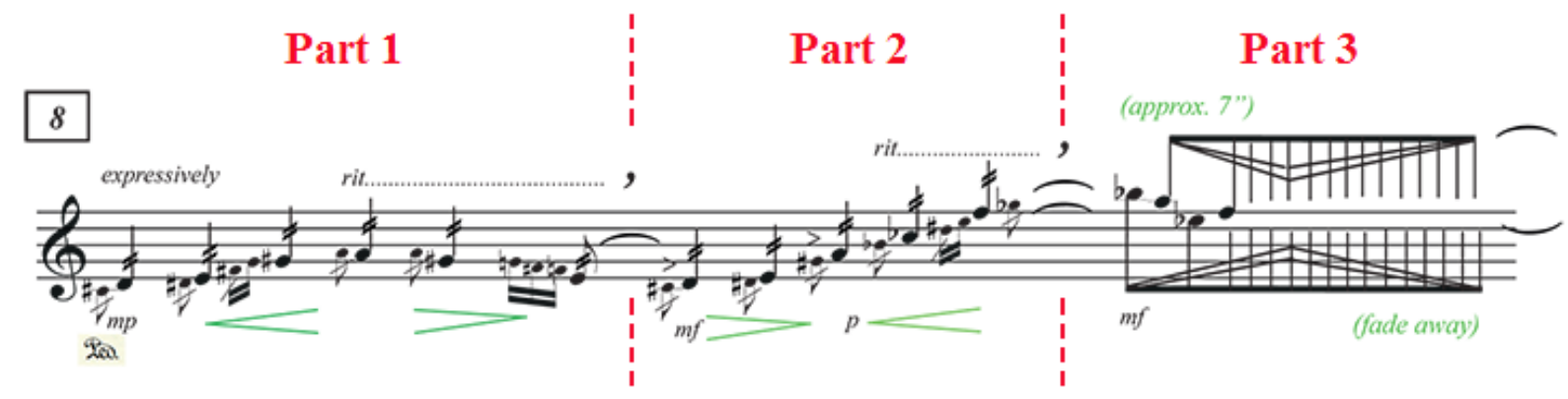

Example 3.6

Chong Lim Ng: A Distant Voice of the Rain Forest, Fragment 8.

\footnotetext{
${ }^{22}$ In a personal e-mail correspondence with Chong Lim Ng dated on January 26, 2013, he clarified that the word "resolution" bears the meaning of the resolution of sound at the end of a cadence.
} 


\begin{tabular}{|l|c|c|c|}
\hline Part & 1 & 2 & 3 \\
\hline $\begin{array}{l}\text { Pitch-Class Collection } \\
\text { (Main Notes Only) }\end{array}$ & D, E, G\#, A & A, Cb, D, E, F & Eb, F, A, B b \\
\hline Pitch-Class Set & {$[0,1,5,7]$} & {$[0,1,3,6,8]$} & {$[0,1,5,7]$} \\
\hline
\end{tabular}

Figure 3.20 Pitch content in Fragment 8, Parts 1-3.

The method applied here in manipulating the pitch-class sets is very similar to that of Fragment 6. It seems that subset [D, E, A] forms a strong link between Parts 1 and 2 (see Figure 3.21). Besides retaining subset $[\mathrm{D}, \mathrm{E}, \mathrm{A}]$ from the first set, the second set also develops it into $[\mathrm{A}, \mathrm{Cb}, \mathrm{E}]$ by transposition at $\mathrm{T}_{7}$, to which an additional pitch-class, $\mathrm{F}$ is added. Within this set, subset $[\mathrm{E}, \mathrm{F}, \mathrm{A}, \mathrm{Cb}]$ appears to be an inversion of $[\mathrm{D}, \mathrm{E}, \mathrm{G} \#, \mathrm{~A}]$ under $\mathrm{T}_{1} \mathrm{I}$.

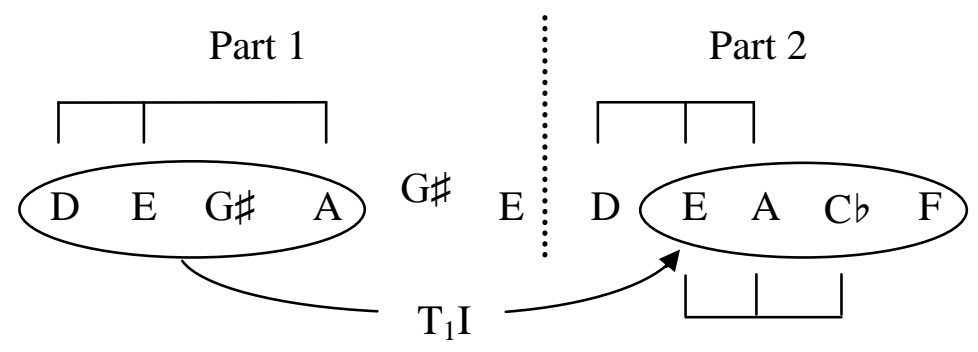

Figure 3.21 Interrelationships between pitch content in Fragment 8, Parts 1 and 2.

Then, F and A in the second set are carried over to the third set to form [Eb, F, A, $\mathrm{B} b]$ — the transposed version of [D, E, G\#, A] under $T_{1}$ which first appeared in Fragment 4,

\section{Part 2, Segment 1.}

Although it is clear throughout this piece, more so in Fragment 8, that the main notes take hierarchical priority over the grace notes, yet it is also apparent that the grace notes are not mere random filler, nor are they even just chromatic saturation. Grace notes are used extensively in Parts 1 and 2 in this fragment, mainly to fill in the gaps between the main notes in both parts, 
other times to precede the beginning main notes and to end Part 2. However, sometimes such gaps between the main notes are not completely filled.

Therefore, a closer look at their relationship with the main notes is taken by dividing the pitch-class collection into groups of four pitch-classes in a set, regardless of whether such pitchclasses are main notes or grace notes. Through this method, it is evident that these two parts consistently use pitch-class set [0, 1, 2, 3] throughout (see Figure 3.22).

\begin{tabular}{|l|c|c|c|}
\hline Part & \multicolumn{2}{|c|}{1} \\
\hline $\begin{array}{l}\text { Pitch-Class Collection } \\
\text { (Main Notes and Grace Notes) }\end{array}$ & C\#, D, D\#, E & F\#, G, G\#, A & E, F, F\#, G \\
\hline Pitch-Class Set & {$[0,1,2,3]$} & {$[0,1,2,3]$} & {$[0,1,2,3]$} \\
\hline
\end{tabular}

\begin{tabular}{|l|c|c|c|}
\hline Part & \multicolumn{2}{|c|}{2} \\
\hline $\begin{array}{l}\text { Pitch-Class Collection } \\
\text { (Main Notes and Grace Notes) }\end{array}$ & C\#, D, D\#, E & G\#, A, Bb, Cb & D\#, E, F, Gb \\
\hline Pitch-Class Set & {$[0,1,2,3]$} & {$[0,1,2,3]$} & {$[0,1,2,3]$} \\
\hline
\end{tabular}

Figure 3.22 Relationships between main notes and grace notes in Fragment 8, Parts 1 and 2.

The size of the gaps between these tetrachord sets is also examined. However, in contrast to the constant use of set $[0,1,2,3]$, the gaps appear to be rather irregular in size (see Figure $3.23)$. 


\section{Part 1}

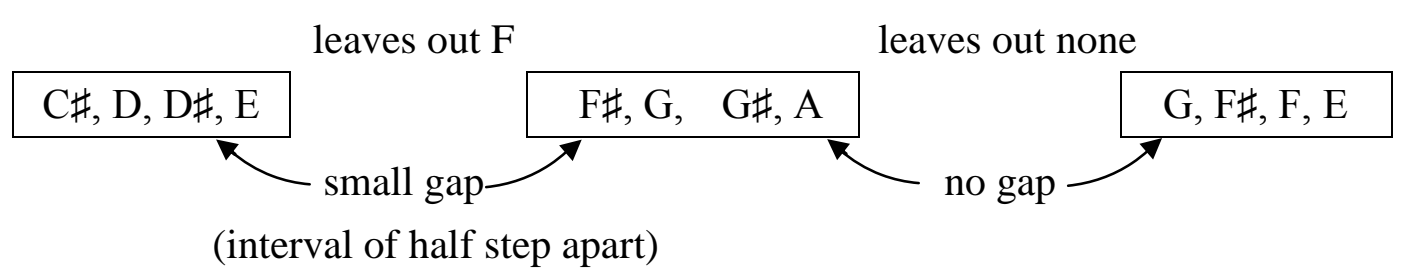

\section{Part 2}

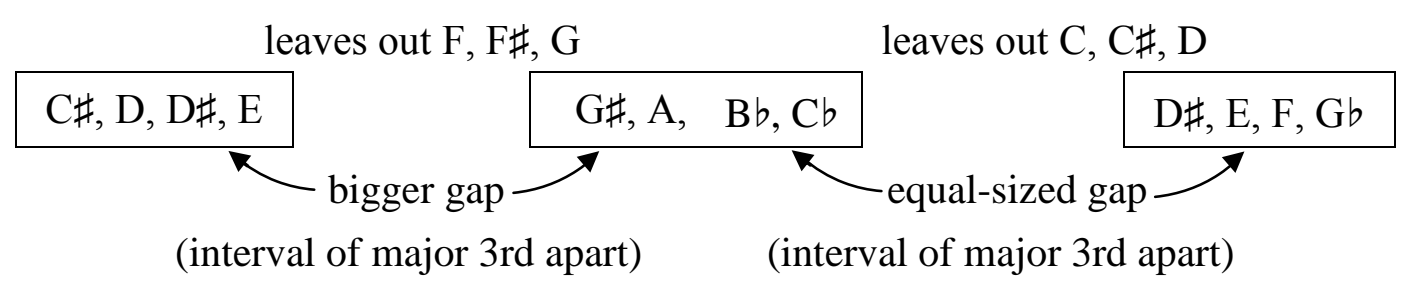

Figure 3.23 Gaps between tetrachord sets in Fragment 8, Parts 1 and 2.

\section{Fragment 9}

Fragment 9 (Example 3.7) could be divided into four segments. The beginning chord in Segment 1 resembles that at the beginning of Fragment 7, particularly in that the left hand spans fourteen semitones between $\mathrm{E}$ and $\mathrm{F} \#$. The chord is followed by an A at the very bottom of the keyboard, then a B at the very high end of the keyboard. This extreme span surpasses any other wide interval span seen in the entire piece. After that, a quiet gong-like cluster in the lower range of the keyboard separates Segments 1 and 2 . 


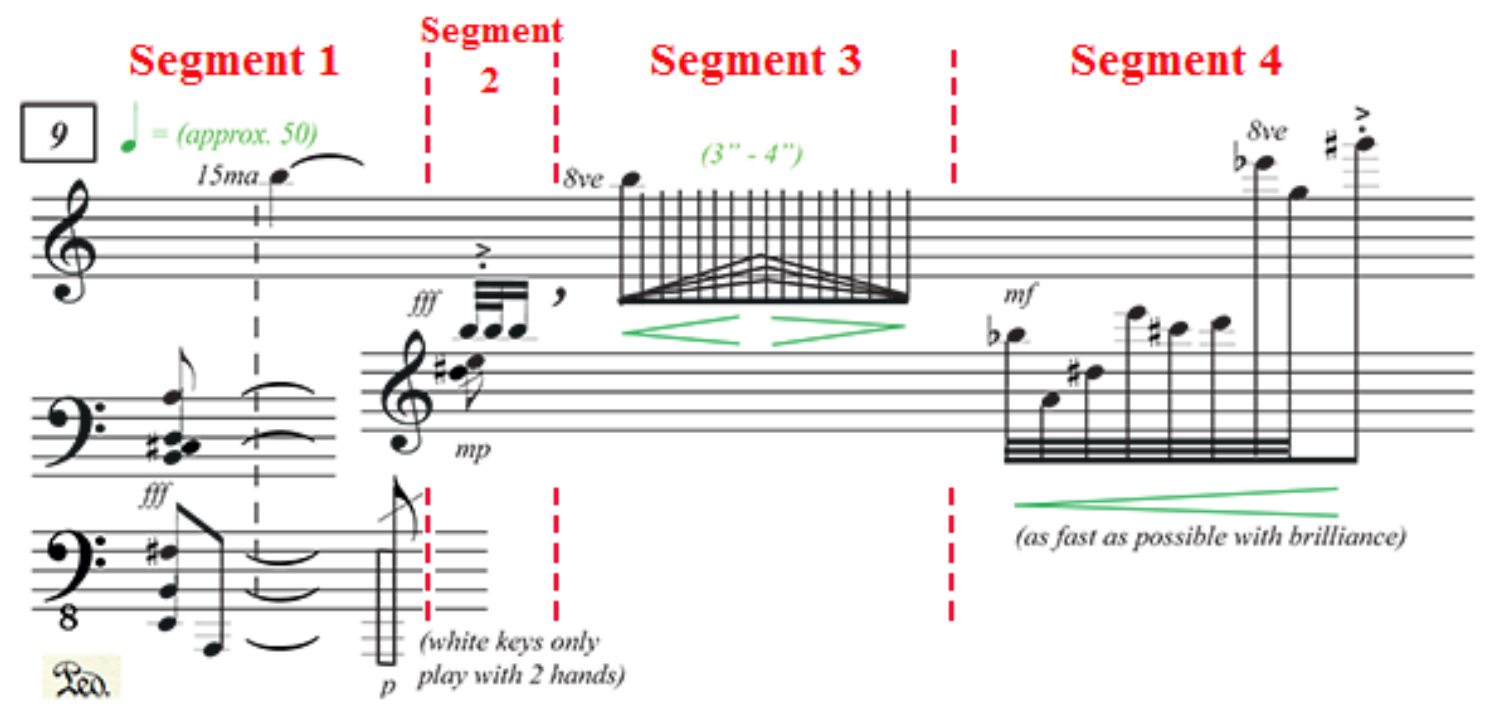

Example 3.7

Chong Lim Ng: A Distant Voice of the Rain Forest, Fragment 9.

There are several ways to look at the pitch collection in Segment 1. Firstly, it is apparent that there are a lot of stacked $5^{\text {th }} \mathrm{s}$ in this segment, in this case, perfect $5^{\text {th }} \mathrm{s}$; and when they stack up on top of each other, they result in the interval of a $9^{\text {th }}$, in this case, a major $9^{\text {th }}$ (see Figure 3.24a). Once again, it is evident that the intervallic span of a $9^{\text {th }}$ (or a $2^{\text {nd }}$ ) seems to be an important element in this piece (see also Figures 3.4 and 3.7). Not only does it occur here in Segment 1 , the interval of a $9^{\text {th }}$ also governs the majority of Segment 4 (see Figure $3.25 \mathrm{a}$ ).

Another way to examine the pitch collection is by dividing them into two sets of four pitch-classes: 1) [E, F\#, A, B], or [0, 2, 5, 7]; and 2) [A, B, C\#, D], or [0, 1, 3, 5] (see Figure 3.24b). The first set is closely related to the [D, E, G\#, A] tetrachord set in Fragments 1 and 2, merely transposed at $\mathrm{T}_{2}$, with the third pitch-class altered to a semitone lower. The second set is the whole note tetrachord set in Fragment 3 in its original form. 
a)

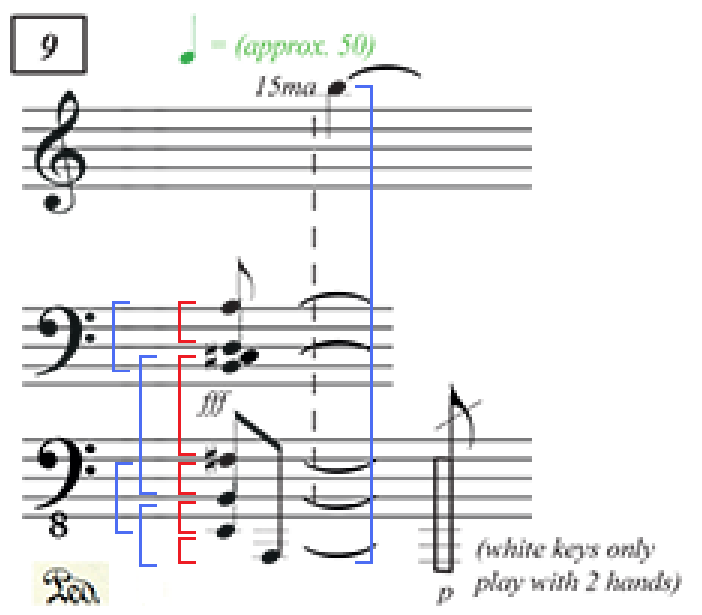

- Perfect 5th

- (Compound) Major 9th b)

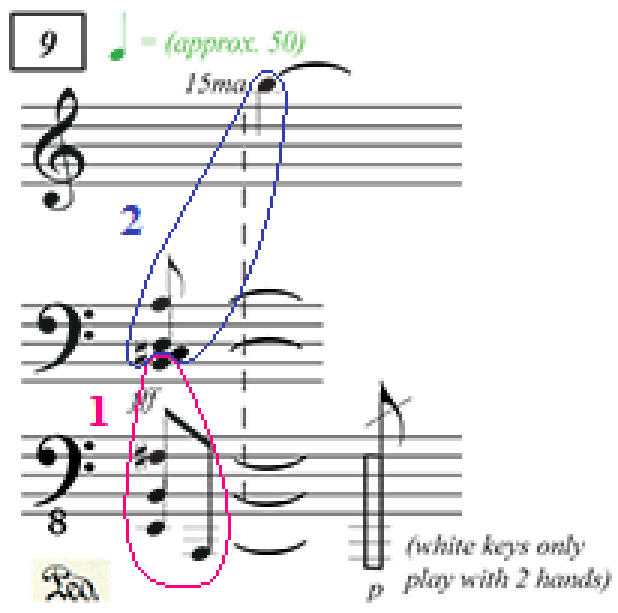

Figure 3.24

Chong Lim Ng: A Distant Voice of the Rain Forest, Fragment 9, Segment 1.

Segment 2 is made of $[B, D \#, E]$ set, which is the subset of the tetrachord set in Fragments 1 and 2, [E, G\#, A], transposed at $\mathrm{T}_{7}$. Other than that, it could also be connected to the tetrachord set in Fragment 3, in that $[B, D \#, E]$ is subset $[A, C \#, D]$ transposed at $T_{2}$. At the same time, it is also related to subset $[\mathrm{A}, \mathrm{C} \#, \mathrm{D}]$ from Set 2 of Segment 1 by transposition at $\mathrm{T}_{2}$.

On the other hand, Segment 3 is an echo of the repeated B's in Segment 2, only an octave higher and extending the duration of the repeat. It is apparent that pitch-class B is the element that ties Segments 1, 2, and 3 together. It seems that the pitch collection gradually gets reduced from two pitch-class sets in Segment 1, to one pitch-class set in Segment 2, and finally to a single pitch-class, B, in Segment 3.

In relation to Segment 1 , the interval of a $9^{\text {th }}$ is seen throughout Segment 4 (see Figure 3.25a). Similarly, this segment could also be separated into two pitch-class sets: 1) [D\#, E, A, $\mathrm{Bb}]$, or $[0,1,6,7]$; and 2) [C\#, D, Eb, G, G\#], or [0, 1, 5, 6, 7] (see Figure 3.25b). Like the first 
set in Segment 1, the first set in Segment 4 is also a transposition of the [D, E, G\#, A] tetrachord set in Fragments 1 and 2, but at $\mathrm{T}_{1}$. This time, instead of altering the third pitch-class in the set, it is the second pitch-class that gets altered to a semitone lower.

The second set is very much related to the first set in that its subset, [C\#, D, G, G\#], is $T_{10}$ of the first set. This set could also be seen as a combination of the $[0,5,6]$ and $[0,1,5,7]$ sets in Fragments 1 and 2: Subset [C\#, D, G] is the trichord set, [G\#, A, D], transposed at $T_{5}$ while subset $[C \#, E b, G, G \#]$ is the tetrachord set, $[D, E, G \#, A]$, transposed at $T_{11}$. Concurrently, subset $[\mathrm{D}, \mathrm{Eb}, \mathrm{G}, \mathrm{G} \#]$ is also a transposition of the $[0,1,5,6]$ sets seen in Part 1 of Fragment 4.

a)

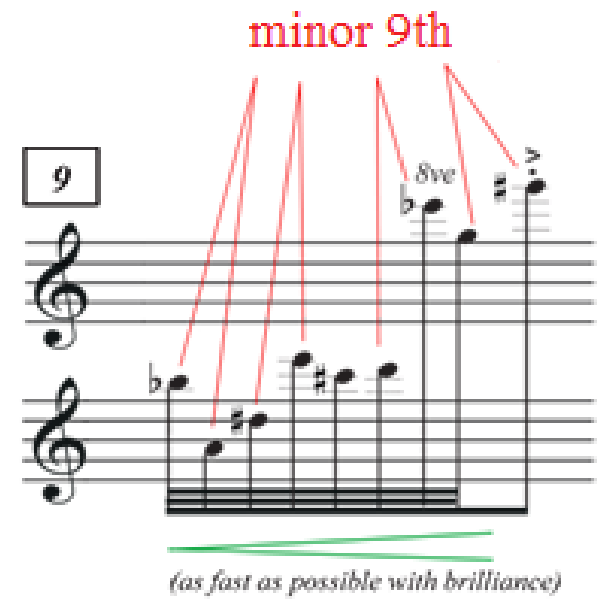

b)

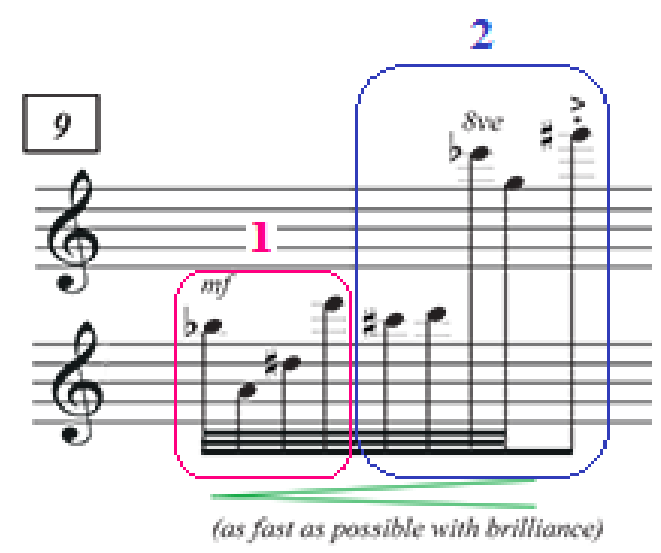

Figure 3.25

Chong Lim Ng: A Distant Voice of the Rain Forest, Fragment 9, Segment 4. 


\section{Fragment 10}

Separated by the breath mark into two parts, Fragment 10 (Example 3.8) is constructed by reusing and reworking materials from Fragment 9, particularly that of Segments 1 and 4 .

Part 1 of Fragment 10 could be divided into three segments. The first segment makes use of the pitch-class collection in Segment 1 of Fragment 9 by reordering them and breaking them into arpeggiated figures in ascending order. However, the lowest pitch, A, is altered to become A\# in Fragment 10. This changes the first pitch-class set from [0, 2, 5, 7] ([E, F\#, A, B]), to [0, 1, $5,7]$ ([E, F\#, A\#, B]), which strongly connects it to the tetrachord set in Fragments 1 and 2.

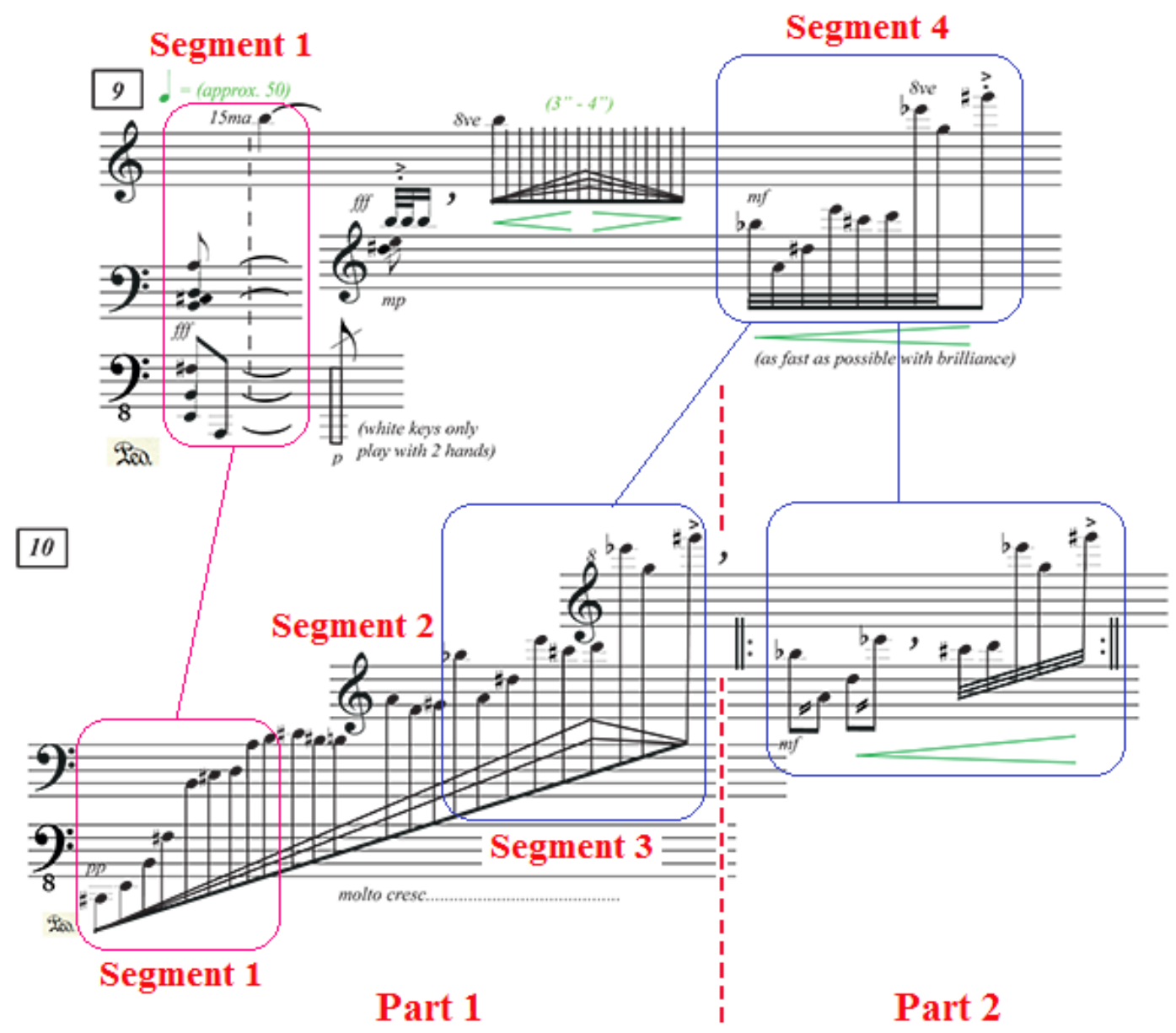

Example 3.8

Chong Lim Ng: A Distant Voice of the Rain Forest, Fragments 9 and 10. 
The second segment is made of [F, G\#, A, B, B\#, C\#], or [0, 1, 2, 4, 5, 8]. This pitchclass collection, when broken down into sets of trichords, could be related to several sets in other fragments. For example, its subset, $[\mathrm{G} \#, B \#, C \#]$ maps onto $[B, D \#, E]$ in Fragment 9, Segment 2 under $T_{3}$. This connection also ties the $[\mathrm{G} \#, B \#, C \#]$ set to the subset of the tetrachord set in Fragment 1, [E, G\#, A], and the subset of the tetrachord set in Fragment 3, [A, C\#, D]. In addition, subset $[\mathrm{A}, \mathrm{B}, \mathrm{C} \#]$ is also directly derived from the tetrachord set in Fragment 3 .

On the other hand, this segment could somewhat be related to Segment 2 of Fragment 9, in that the first two notes and the last note of the former segment outline the chord in the latter segment when transposed at $\mathrm{T}_{9}$ (see Figure 3.26). However, there does not seem to be any other connection that could tie the rest of the pitches in this segment to that of Fragment 9.

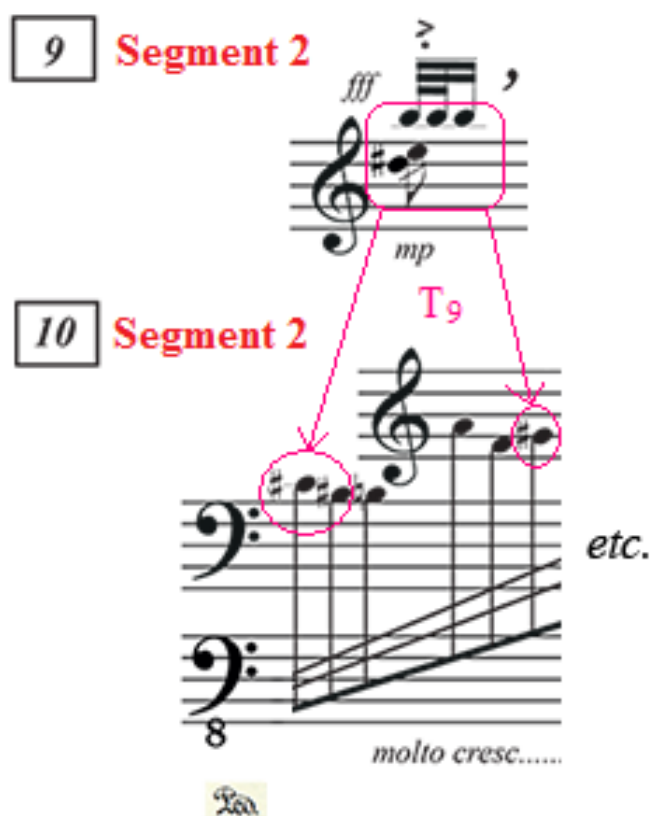

Figure 3.26

Chong Lim Ng: A Distant Voice of the Rain Forest, Fragment 9, Segment 2 and Fragment 10, Segment 2. 
Nevertheless, the strongest connection is discovered when the entire pitch-class collection is compared with that of Fragment 6, Segment 3, [D\#, E, E\#, F\#, G, Bb] (see Figure 3.27). It is evident that both sets are related by inversion, with the only difference being the intervallic span between $\mathrm{A}-\mathrm{B}$ in the former set and $\mathrm{E} \#-\mathrm{F} \#$ in the latter set (see Figure 3.28).

\begin{tabular}{|l|c|c|}
\cline { 2 - 3 } \multicolumn{1}{c|}{} & $\begin{array}{c}\text { Pitch-Class Set } \\
\text { (Integer Notation) }\end{array}$ & Interval Succession \\
\hline Fragment 10, Segment 2 & {$[5,8,9,11,0,1]$} & $3-1-2-1-1$ \\
\hline Fragment 6, Segment 3 & {$[3,4,5,6,7,10]$} & $1-1-1-1-3$ \\
\hline
\end{tabular}

Figure 3.27 Pitch content in Fragment 10, Segment 2 and Fragment 6, Segment 3.

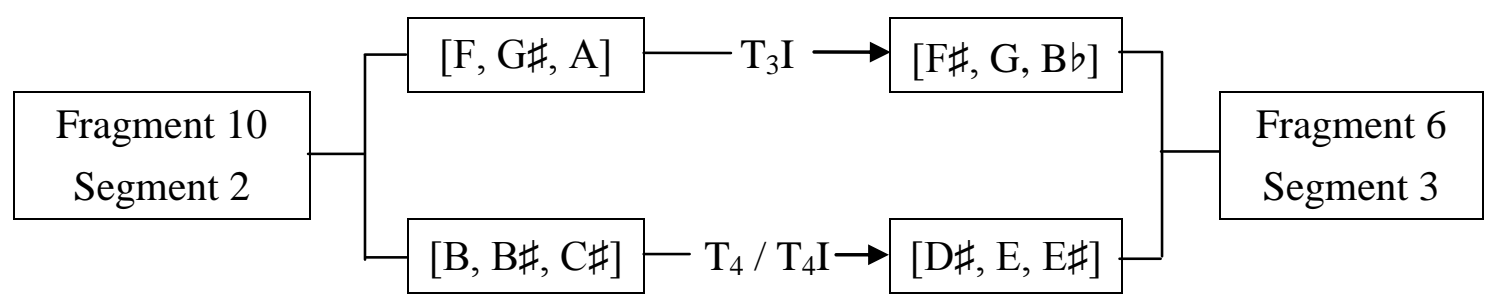

Figure 3.28 Relationship between pitch content in Fragment 10, Segment 2 and Fragment 6, Segment 3.

It is apparent that Segment 3 of Part 1, Fragment 10 is a direct quote of the pitch material from Segment 4 of Fragment 9. Meanwhile, Part 2 of Fragment 10 reuses the same material but with two alterations in the first set of tetrachord: changing $\mathrm{D} \#$ into $\mathrm{D}$, and $\mathrm{E}$ into $\mathrm{E} b$. Thus, the first set becomes $[\mathrm{A}, \mathrm{B} b, \mathrm{D}, \mathrm{E} b]$, or $[0,1,5,6]$-a set that first appeared in Part 1 of Fragment 4 -while the second set remains as [C\#, D, Eb, G, G\#], or [0, 1, 5, 6, 7]. The first set is now related to the subset of the second set, [D, Eb, G, G $\sharp]$, by transposition at $T_{5}$. At the same time, its subset, [A, Bb, Eb], is also $\mathrm{T}_{1}$ of the trichord set in Fragments 1, 2, and 3, [G\#, A, D]. 
Thus far, it is reasonable to conclude that all ten fragments are in most part closely related to each other, with the exception of the left hand chords in Segment 2 of Fragment 4, and Parts 1 and 2 of Fragment 8, when including both grace notes and main notes in the discussion of pitch-class collection. Occasionally, the pitch-class sets are preserved in their original formsometimes reordered — but more often than not they are manipulated — in parts or in its entiretyand made complicated by transposition, inversion, as well as by adding or removing one or more pitch-classes to the sets.

\section{Fragment 11}

The final and largest fragment, Fragment 11, could be treated as a movement of its own. Unlike other fragments which present one or two ideas, this fragment comprises a number of different ideas within itself, some of which are borrowed from earlier fragments. The composer includes the use of dotted bar lines; however, this fragment is utterly meant to be unmeasured, hence accidentals do not get carried over to subsequent occurrences of the same pitch. ${ }^{23}$ In other words, each pitch is as it is notated in the score, with or without accidentals. Nevertheless, to assist in the discussion of the analysis here, the measures are numbered on the basis of the dotted barlines, as seen in Example 3.9.

Based on the texture and the amount of activity in the music, Fragment 11 could be divided into three sections: 1) mm. 1-15, 2) mm. 16-19, and 3) m. 20. Like Fragment 4, the pitch content in these sections is segmented on the basis of register. However, in the case of the first section where both hands are mostly kept in the same register, the pitch content is initially examined hand by hand, and within each hand, register by register. Applying the same method

\footnotetext{
${ }^{23}$ Chong Lim Ng, e-mail message to author, January 11, 2013.
} 
used in previous fragments, the pitch content in this fragment is grouped in units typically of four pitches - in some cases, more than four - to see if they are in any way related to previous materials. Where no such connection could be drawn, they are compared with materials within the same fragment or the same part.

Section 1 (Example 3.9) comprises two parts that share some similarity in structure, in that both parts contain repeated materials within themselves, especially towards the end of each part. Therefore, the discussion of the analysis will not include repeated materials as such.

\begin{tabular}{ll}
\hline III Section 1 & Part 1
\end{tabular}
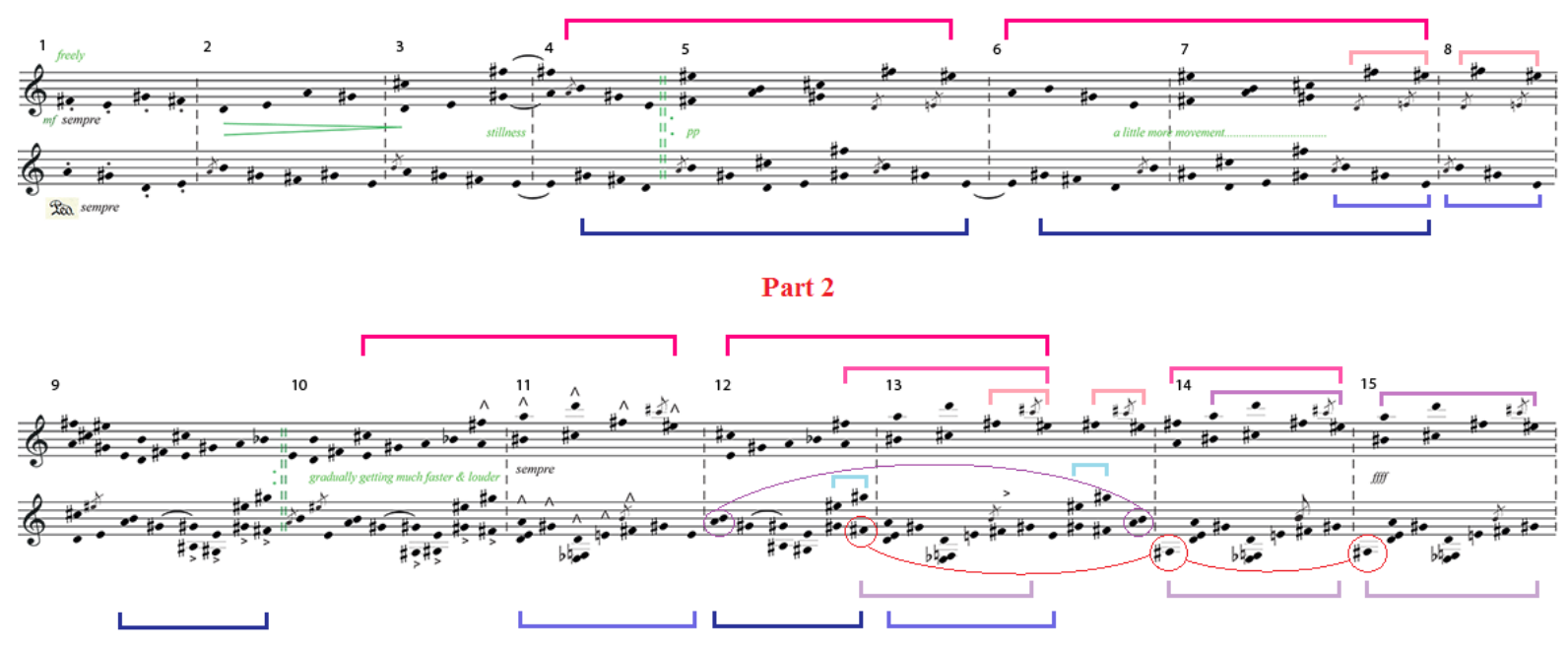

Example 3.9

Chong Lim Ng: A Distant Voice of the Rain Forest, Fragment 11, Section 1, mm. 1-15.

Part 1 (mm. 1-8) contains four streams of pitches: two in the right hand and another two in the left hand. These are labeled as Segments 1 thru 4, within which the pitches are grouped in sets of tetrachords, following the same manner seen in the main notes in Fragments 1 thru 3, as the first four notes in the left hand clearly outline the $[\mathrm{D}, \mathrm{E}, \mathrm{G} \#, \mathrm{~A}]$ tetrachord with the same exact pitches (see Figure 3.29). Some of the pitches overlap between segments; for instance, the 
B between Segments 1 and 2 in m. 4, as well as between Segments 3 and 4 in m. 5. Therefore, such pitches will be included in the discussion of both segments.

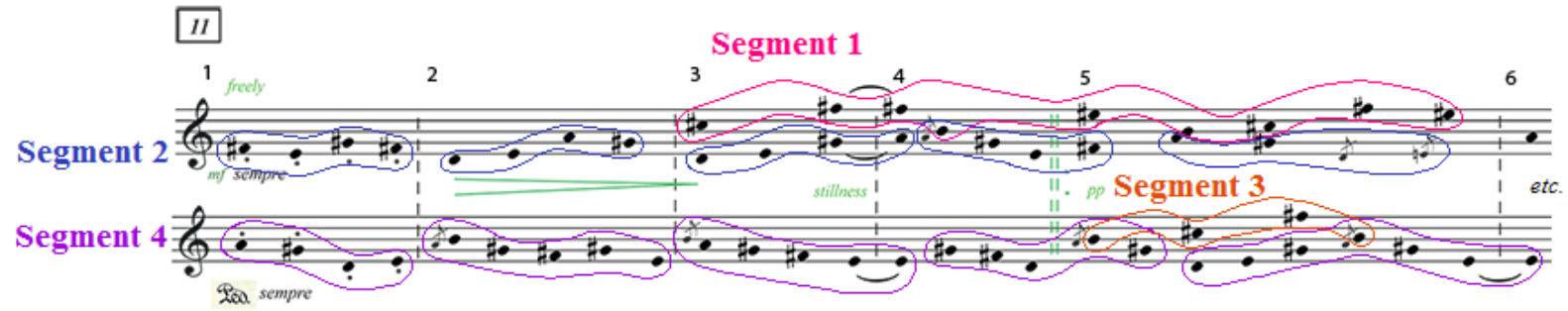

Figure 3.29

Chong Lim Ng: A Distant Voice of the Rain Forest, Fragment 11, Section 1, Part 1, mm. 1-6.

The pitch content in Part 1 is based heavily on the tetrachord set in Fragments 1 and 2, [D, E, G\#, A], seen in its original form in Segments 2 and 4, and in its transposed version at level 9, [B, C\#, E\#, F\#], in Segments 1 and 3. Meanwhile, Segments 2 and 4 contain some additional pitches which seem to correlate with adjacent sets within each respective segment. To better demonstrate the relationship between the sets in these segments, all sets in Part 1 are retained in their original order as they appear in the music.

Segment 2 contains five pitch-class sets, most of which are tetrachords, with the exception of the fourth, a pentachord (see Figure 3.30). On one level, the relationship between these sets is demonstrated by the final two pitches in each set-all of which outline the interval of a second-which rises from $\mathrm{G} \#-\mathrm{F} \#$ to $\mathrm{A}-\mathrm{G} \#$, and falls from $\mathrm{G} \#-\mathrm{A}$ to $\mathrm{E}-\mathrm{F} \#$, and later to $\mathrm{D}-\mathrm{E}$. Noticed also is how the order between those pitches are switched from descending to ascending seconds. 


\begin{tabular}{|c|ccc|cc|}
\hline Set & \multicolumn{4}{|c|}{ Pitch Collection } \\
\hline 1 & F\# & E & G\# & F\# \\
\hline 2 & D & E & A & G\# \\
\hline 3 & D & E & G\# & A \\
\hline 4 & A & B & G\# & E & F\# \\
\hline 5 & A & G\# & & D & E \\
\hline
\end{tabular}

Figure 3.30 Pitch content in Fragment 11, Section 1, Part 1, Segment 2.

Subsequently, among the five sets, there are two groups of sets that exemplify close connection to one another. The two groups are Sets 1 and 4 (see Figure 3.31a), and Sets 2, 3, and 5 (see Figure 3.31b).

a)

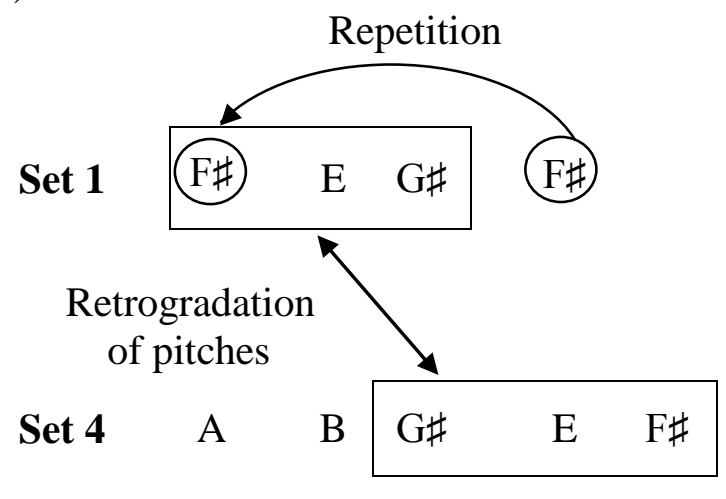

b)

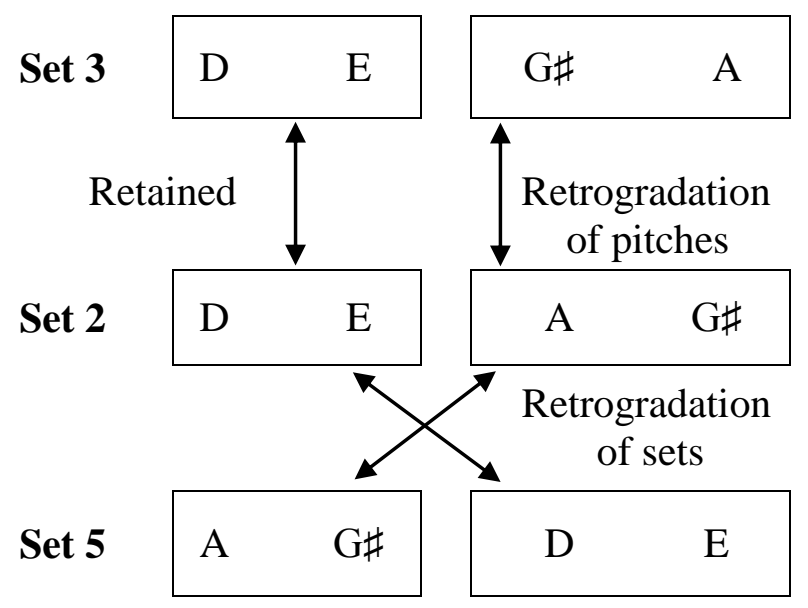

Figure 3.31 Interrelationships between sets in Fragment 11, Section 1, Part 1, Segment 2. 
All five sets are essentially related to one another. As demonstrated in Figure 3.30, all sets contain $\mathrm{E}$ and $\mathrm{G} \#$ while certain other pitches get preserved in each set. Some subsets are preserved in its original order; some of the pitches within the same subset undergo retrogradation; and sometimes the subsets' positions get switched. On a different note, Sets 1 and 4 also show connection to another fragment: they are both $T_{7}$ of the tetrachord set in Fragment 3 , $[\mathrm{A}, \mathrm{B}, \mathrm{C} \#, \mathrm{D}]$.

When grouped in a way that conforms to the grouping of pitches in Segment 3 (see Figure 3.29), Segment 4 also contains five pitch-class sets, but this time most of the sets are pentachords; only the first set is a tetrachord (see Figure 3.32, grace notes are indicated in parenthesis). Similarly to Segment 2, the relationship between sets in Segment 4 could also be seen through the preservation, repetition, and retrogradation of certain pitches in the sets (see Figures 3.33 and 3.34).

\begin{tabular}{|c|ccccccc|}
\hline Set & \multicolumn{7}{|c|}{ Pitch Collection } \\
\hline 1 & A & G\# & D & E & & & \\
\hline 2 & (A) & B & G\# & F\# & G\# & E & \\
\hline 3 & (B) & A & G\# & F\# & E & & \\
\hline 4 & G\# & F\# & D & (A) & B & G\# & \\
\hline 5 & D & E & G\# & (A) & B & G\# & E \\
\hline
\end{tabular}

Figure 3.32 Pitch content in Fragment 11, Section 1, Part 1, Segment 4.

Sets 1, 2, and 3 show some progressive development from one set to another set (see Figure 3.33). First of all, main note $\mathrm{A}$ in Set 1 becomes a grace note in Set 2 and later gets shifted back to being a main note again in Set 3. Similarly, pitches A and B switch from being a main note to a grace note and vice versa in Sets 2 and 3. 
Next, Set 2 is a transformation of Set 1: it retains A, G\#, and E, from Set 1 while adding $\mathrm{B}$ and $\mathrm{F} \#$; meanwhile, its subset $[\mathrm{B}, \mathrm{F} \#, \mathrm{E}]$ is the transposition and reordering of subset $[\mathrm{A}, \mathrm{D}, \mathrm{E}]$ in Set 1. To say the least, the connection between Sets 2 and 3 are the clearest among all three sets.

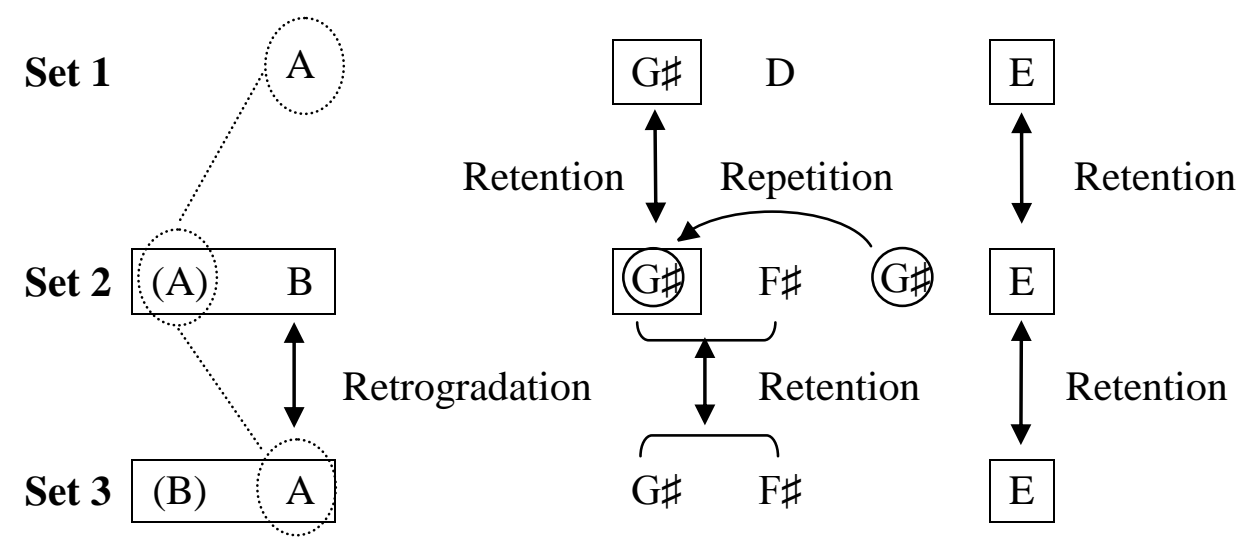

Figure 3.33 Interrelationships between Sets 1-3 in Fragment 11, Section 1, Part 1, Segment 4.

Set 4 shows a close tie to Set 2, in that five out of six pitch-classes get preserved (see Figure 3.34). The relationship is strengthened when the pitch content in each set is grouped into two sets of trichords: $[A, B, G \#]$ and $[F \#, G \#, E]$ in Set 2; [G\#, F\#, D] and [A, B, G\#] in Set 4. It is as though subsets $[A, B, G \#]$ and $[F \#, G \#, E]$ are switched in position, with some alteration in the latter set: subset $[\mathrm{F} \#, \mathrm{G} \#]$ is retrograded and $\mathrm{E}$ is changed to $\mathrm{D}$. Subsets $[\mathrm{A}, \mathrm{B}, \mathrm{D}]$ and $[\mathrm{F} \#$, G\#, B] are also related to the tetrachord set in Fragment 3.

On the other hand, Set 5 retains subset $[A, B, G \sharp]$ from Set 4, and retains [D, E, G\#] from Set 1 but reorders the pitches. Like Set 4, it also contains subsets that are related to the tetrachord set in Fragment 3: [A, B, D] and [E, G\#, A]. 


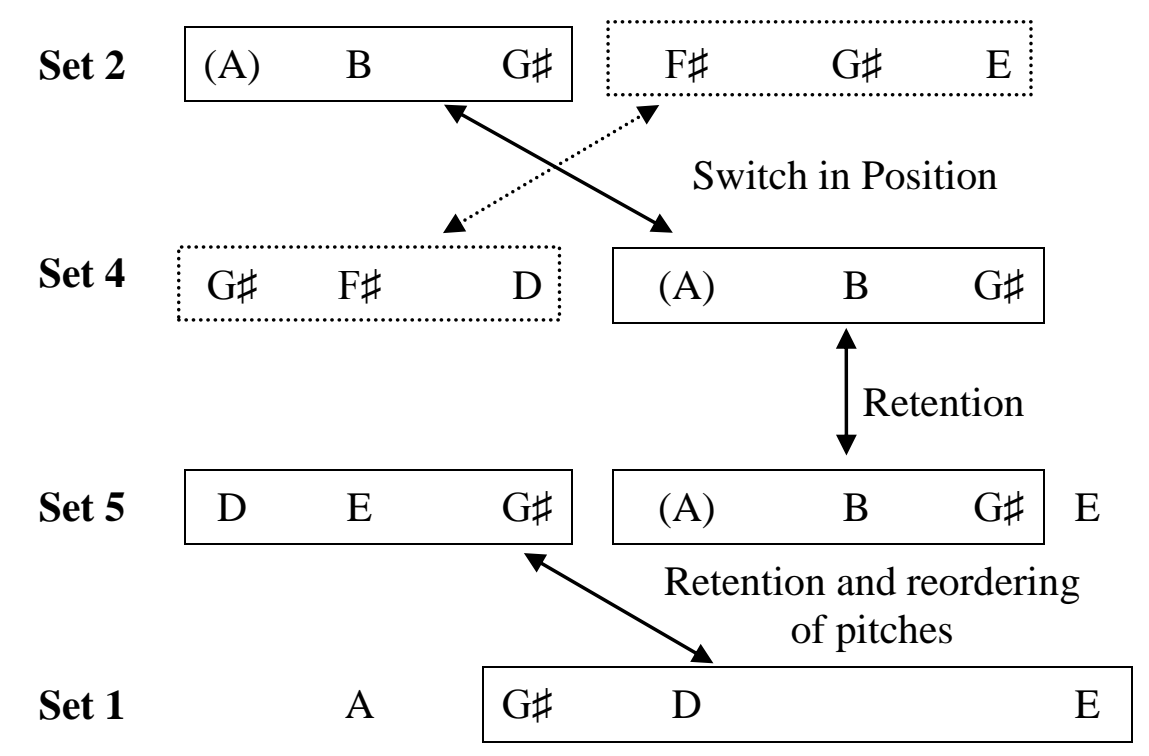

Figure 3.34 Interrelationships between Sets 1, 2, 4, and 5 in Fragment 11, Section 1, Part 1, Segment 4.

Likewise, Part 2 of Section 1 (mm. 9-15) continues to utilize the [D, E, G\#, A] and [B, $\mathrm{C \#}, \mathrm{E \#}, \mathrm{F} \#]$ tetrachord sets but add to the sets some other pitches. This part contains six streams or segments of pitches separated by register and articulation (see Figure 3.35). Within each segment, the pitch collection is examined in groups of four or five pitch-classes in order to investigate relationships with previous materials. Some are grouped in accordance to articulations (e.g., Segments 5 and 6), and others are segmented in a way that best relate them to the $[0,1,5,7]$ and $[0,5,6]$ sets, or to other sets found elsewhere within that segment. Again, due to the fact that some pitches overlap between segments, such as F\# and E\# between Segments 1 and 2 in $\mathrm{m} .11$, such pitches are included in the discussion of both segments. 


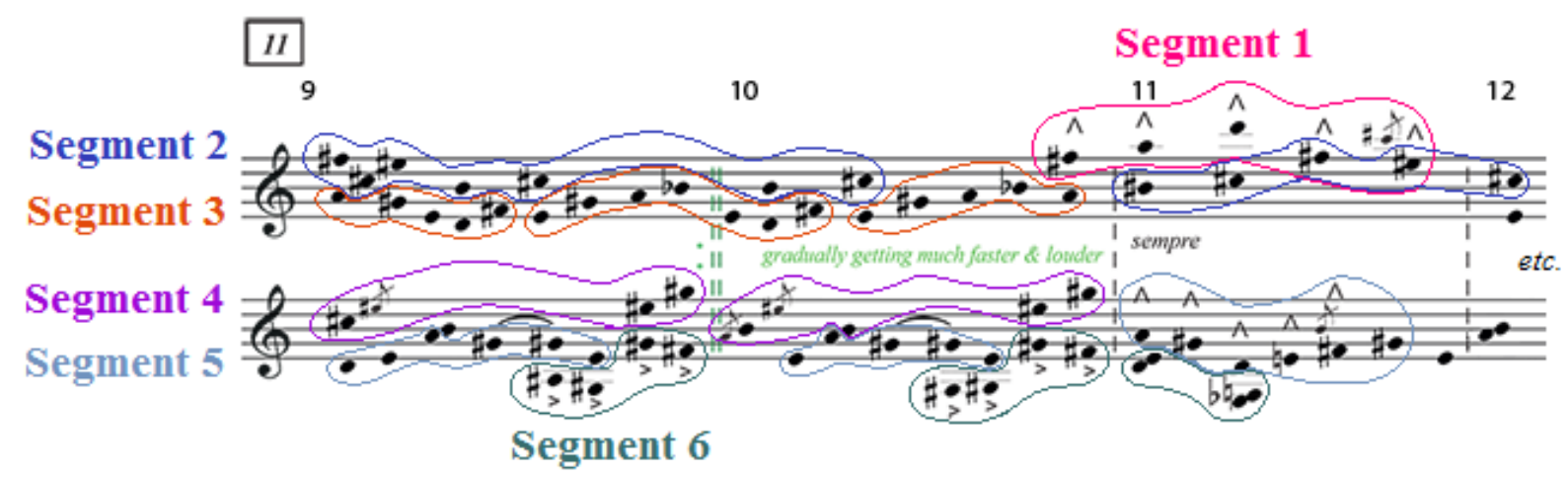

Figure 3.35

Chong Lim Ng: A Distant Voice of the Rain Forest, Fragment 11, Section 1, Part 2, mm. 9-12.

Segment 1 is made of a single pentachord set, [C\#, D, E\#, F\#, A], within which all pitches are punctuated by marcato marks $(\wedge)$ during its first appearance in $\mathrm{mm} .10-11$. This set combines subsets of $[\mathrm{D}, \mathrm{E}, \mathrm{G} \#, \mathrm{~A}]$ and $[\mathrm{B}, \mathrm{C} \#, \mathrm{E} \#, \mathrm{~F} \#]$. In addition, its subset, $[\mathrm{C} \#, \mathrm{E} \#, \mathrm{~F} \#]$, is not only $\mathrm{T}_{9}$ of subset $[\mathrm{E}, \mathrm{G} \#, \mathrm{~A}]$, it is also related to the subset of the tetrachord set in Fragment 3, [A, C\#, D], by transposition at level 4. Notably, [A, C\#, D], which is present within this set, is also $T_{5}$ of subset $[\mathrm{E}, \mathrm{G} \#, \mathrm{~A}]$.

Segment 2 comprises two tetrachords: 1) [B, C\#, E\#, F\#] and 2) [B\#, C\#, E\#, F\#]. Both of these sets preserve subset $[\mathrm{C} \#, \mathrm{E} \#, \mathrm{~F} \#]$ from Segment 1, hence both sets are related to the [E, $\mathrm{G} \#$, A] subset of the [D, E, G\#, A] set by transposition at level 9. Set 2 changes the B in Set 1 to B\#, thus becomes a $[0,1,5,6]$ set which first appeared in Part 1 of Fragment 4, and later on in Segment 4 of Fragment 9 and Part 2 of Fragment 10. This set could be seen as a combination as well as transformation of the $[0,1,5,7]$ and $[0,5,6]$ sets, both of which are the foundation of this piece.

The third segment could be broken into three sets that retains from one another certain pitches (see Figure 3.36). The direct connection to the [D, E, G\#, A] set in Fragments 1 and 2 is apparent in all three sets, except the last set removes the first pitch in the set, D. Subset [E, 
$\mathrm{F} \#, \mathrm{~B} b]$ in Sets 2 and 3 are also related to the above-mentioned tetrachord set by transposition at level 2. On the other hand, subset [E, F\#, G\#, A] is also $T_{7}$ of the tetrachord set in Fragment 3, [A, B, C\#, D], with the exception that Set 3 removes the second pitch in the set, F\#.

a)

\begin{tabular}{|c|cccccc|}
\hline Set & \multicolumn{6}{|c|}{ Pitch Collection } \\
\hline 1 & D & E & F\# & G\# & A & \\
\hline 2 & D & E & F\# & G\# & A & Bb \\
\hline 3 & & E & & G\# & A & Bb \\
\hline
\end{tabular}

b)

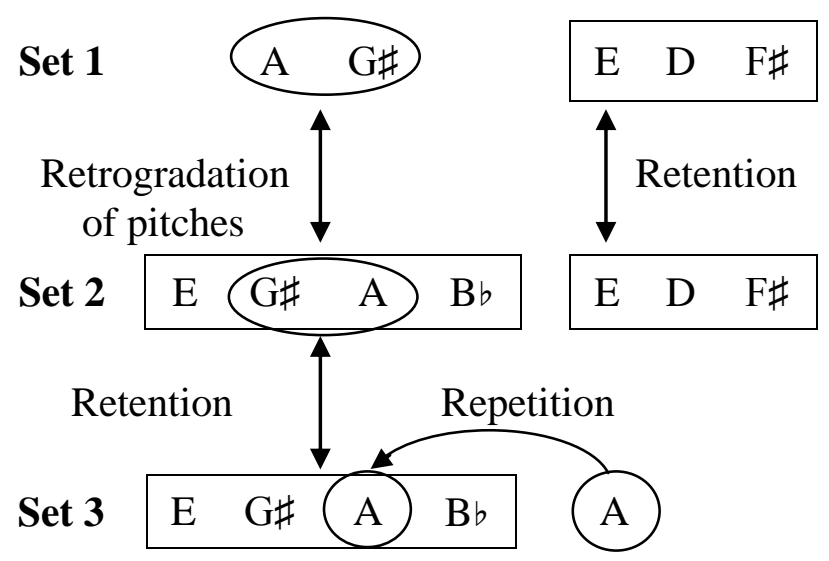

Figure 3.36 Pitch content and interrelationships between sets in Fragment 11, Section 1, Part 2, Segment 3.

The two tetrachord sets in Segment 4, [E\#, G\#, B, C\#] and [E\#, G\#, A, B], share two pitches in common, $\mathrm{E} \#$ and $\mathrm{G} \#$, while the second set transposes the other two pitches in Set 1, B and $C \#$, to $A$ and $B$. The entire of Set 2 also maps onto the subset of Set 4 in Fragment 6, [C, D\#, $E, F \#]$, at $T_{7}$. Set 1 could also be connected to the $[B, C \#, E \#, F \#]$ set in Segment 2, in that it retains three pitches from the set and changes the $\mathrm{F} \#$ to $\mathrm{G} \#$. For that reason, its subset, $[\mathrm{B}, \mathrm{C} \#$, E\#], also maps onto subset [D, E, G\#] of the tetrachord set in Fragments 1 and 2 at $T_{3}$.

Segment 5 is rather similar to Segment 3 in that both segments contain three sets of pitchclass collections, in which five out of six pitches-D, E, F\#, G\#, and A-are held in common in both segments, while the last pitch changes from B b in Segment 3 to B in Segment 5. The sets are also related each other by retention and retrogradation of certain pitches, and it is clear that all three sets have a connection with the [D, E, G\#, A] tetrachord set in Fragments 1 and 2 (see 
Figure 3.37). In addition, the subset of Set 3, [F\#, G\#, B], is also related to the subset of the tetrachord set in Fragment 3, [A, B, D], by transposition at level 3.

a)

\begin{tabular}{|c|cccccc|}
\hline Set & \multicolumn{5}{|c|}{ Pitch Collection } \\
\hline 1 & D & E & G\# & A & \\
\hline 2 & & E & & G\# & A & \\
\hline 3 & D & E & F\# & G\# & A & B \\
\hline
\end{tabular}

b)

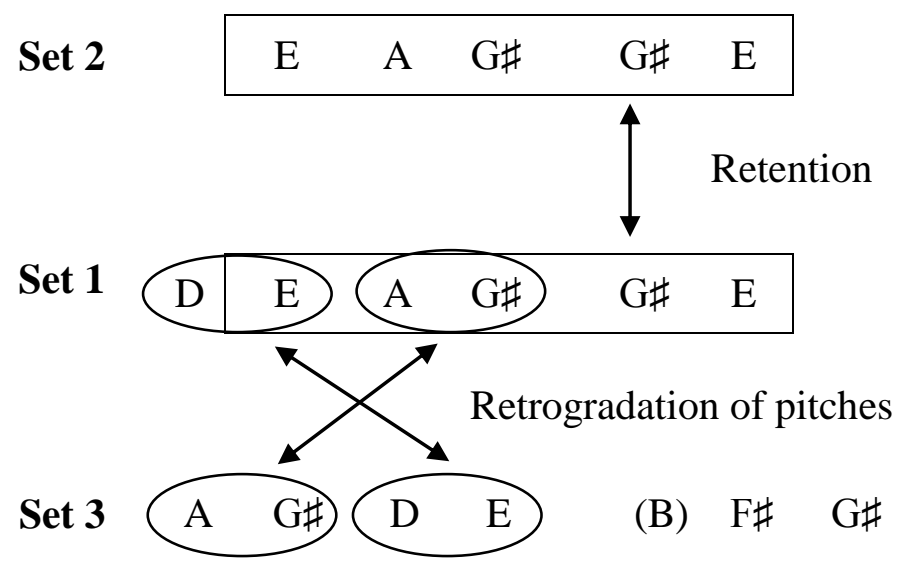

Figure 3.37 Pitch content and interrelationships between sets in Fragment 11, Section 1, Part 2, Segment 5.

The sixth and last segment is unlike any other sets within Part 2 in terms of the organization of the pitches, and to an extent, its pitch content. It contains three sets of pitches that are more often than not lower in register, some of which are also marked by accents $(>)$. Each set comprises two sets of dyads a tone apart with a relationship either by transposition or by retrogradation (see Figure 3.38). Both subsets $F \#-G \#$ in Sets 1 and 2 as well as D-E in Set 3 have already been seen in Segments 3 and 5. The $A \sharp-G \#$ subset in Set 1 could be treated as a transposition of the subsequent subset $\mathrm{G} \#-F \#$ while the $\mathrm{E} b-\mathrm{F}$ subset in Set 3 could be treated as a transposition of the D-E subset that precedes it. 


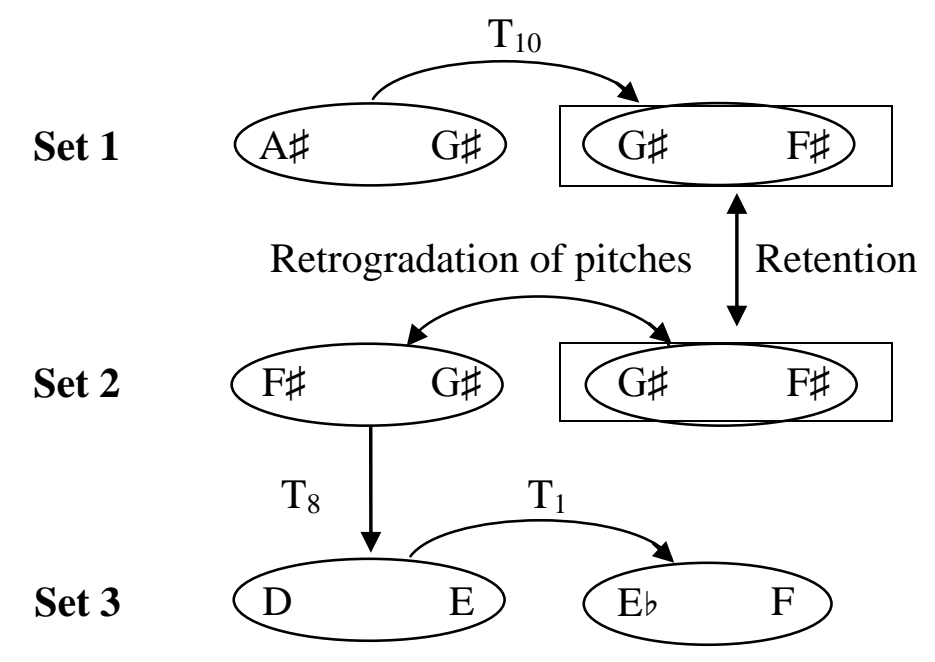

Figure 3.38 Pitch content and interrelationships between sets in Fragment 11, Section 1, Part 2, Segment 6.

Section 2 (Example 3.10) could be separated into three distinctive parts based on texture and rhythm. Both Parts 1 and 2 contains repeated materials; in fact, Part 2 quotes directly from Fragment 4. Again, previously discussed materials and repeated materials will be omitted from the discussion below. 

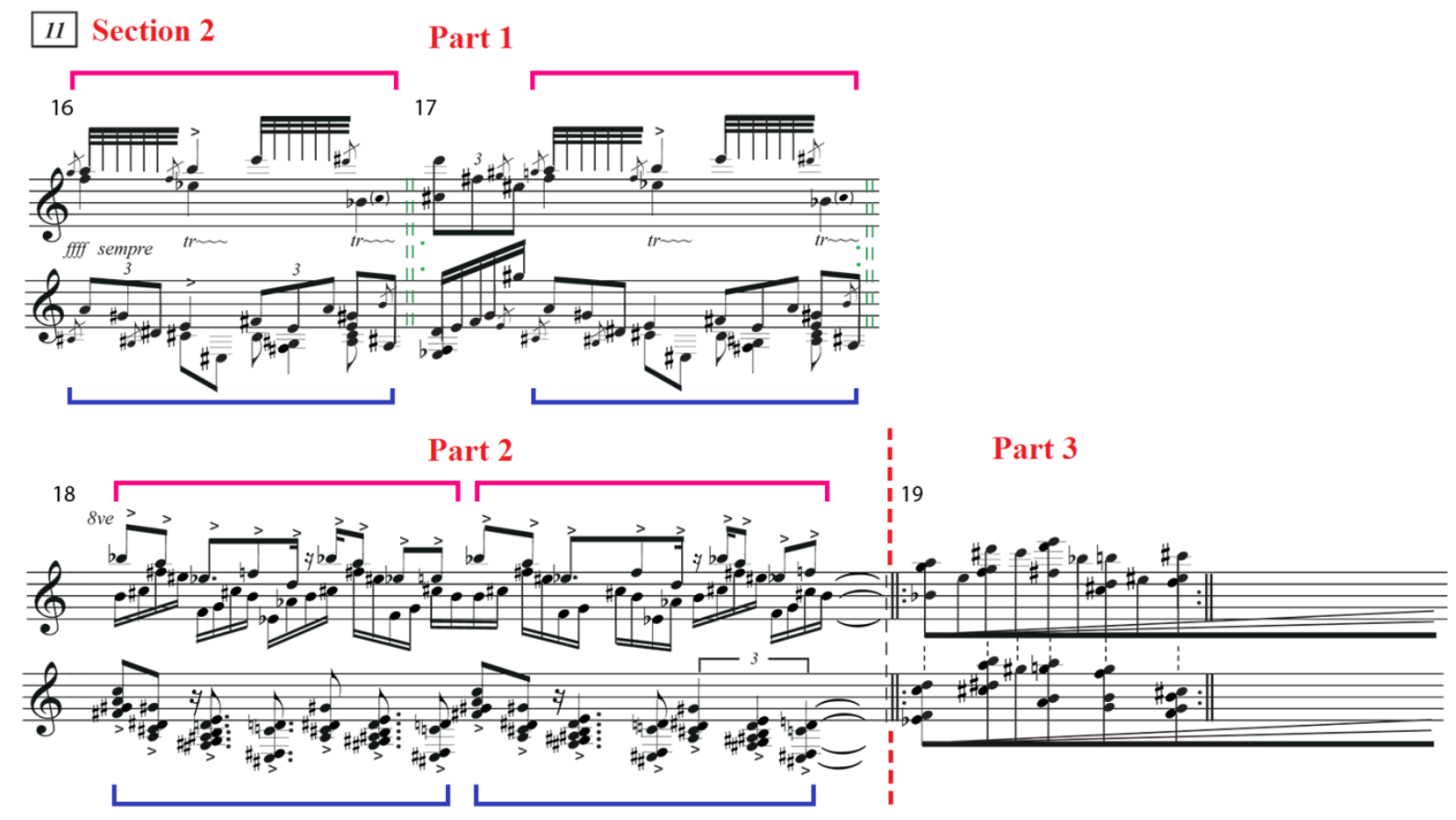

Example 3.10

Chong Lim Ng: A Distant Voice of the Rain Forest, Fragment 11, Section 2, mm. 16-19.

In Part 1, it is evident that there are two types of rhythmic groupings that separate the pitch materials, particularly that of $\mathrm{m} .16$ and $\mathrm{m}$. 17. Therefore, having taken consideration the register distribution and rhythmic grouping of the pitch content — which includes indications such as repeated-note figure, trill, ${ }^{24}$ as well as the beaming of the pitches-Part 1 is further broken into two parts in which the first part is repeated (see Figure 3.39), and each of the parts are segmented accordingly (see Figures 3.40a and 3.40b).

\footnotetext{
${ }^{24}$ Where trills are indicated, both sets of main notes and trill notes are treated as equally important, as are the grace notes found elsewhere in this piece.
} 


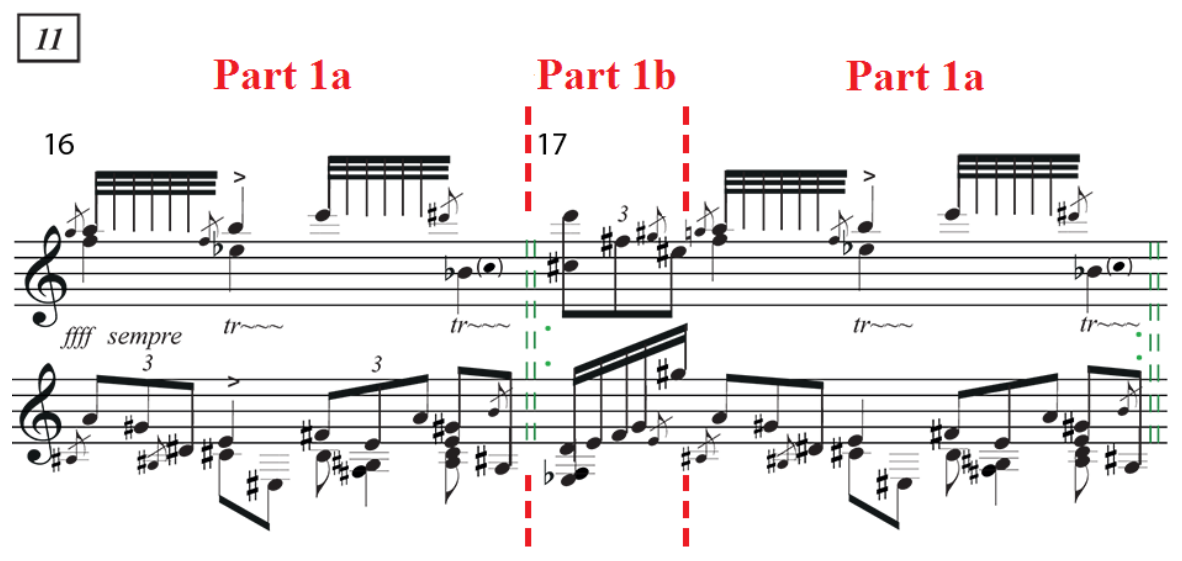

Figure 3.39

Chong Lim Ng: A Distant Voice of the Rain Forest, Fragment 11, Section 2, Part 1, mm. $16-17$.

a)

\section{Part 1a}

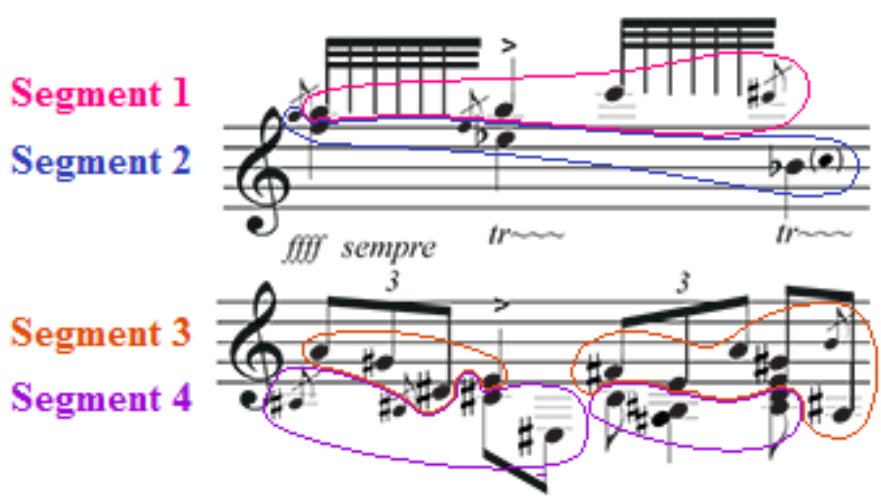

b)
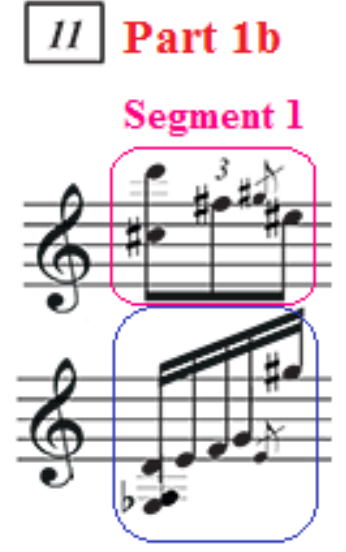

Segment 2

Figure 3.40

Chong Lim Ng: A Distant Voice of the Rain Forest, Fragment 11, Section 2, Part 1a (m. 16) and Part 1b (m. 17).

The first segment of Part 1a is made of a single pitch-class set, $[A, B, D \#, E]$, which is $T_{7}$ of the tetrachord set in Fragments 1 and 2, [D, E, G\#, A]. The second segment comprises three sets of dyads a tone apart which altogether form the pitch-class set, [Eb, F, G, B b, C] (or [0, 2, 5, 7, 9]). This set correlates to the tetrachord sets in Fragments 1, 2, and 3 in a few ways. Its subset, $[\mathrm{B} b, \mathrm{C}, \mathrm{F}]$, is $\mathrm{T}_{8}$ of $[\mathrm{D}, \mathrm{E}, \mathrm{A}]$, subset of the tetrachord set in Fragments 1 and 2 . At the same time, 
its subsets, $[\mathrm{E} b, \mathrm{~F}, \mathrm{G}],[\mathrm{F}, \mathrm{G}, \mathrm{B} b]$, and $[\mathrm{B} b, \mathrm{C}, \mathrm{E} b]$ are also transpositionally related to the tetrachord set in Fragment 3.

Segment 3 could be grouped into two pitch-class sets based on rhythm and the beaming of the pitches: 1) [D\#, E, G\#, A], or [0, 1, 5, 6]; and 2) [E, F\#, G\#, A, B], or [0, 2, 3, 5, 7]. As mentioned before, the first $[0,1,5,6]$ set could be treated as a combination of pitch-class sets $[0$, $5,6]$ and $[0,1,5,7]$. Meanwhile, the second set preserves [E, G\#, A] from the first set and add to the set $\mathrm{F} \#$ and $\mathrm{B}$ to become a $[0,2,3,5,7]$ set. This set also connects to the tetrachord sets in Fragments 1, 2, and 3 in several ways. Its subsets, [E, F\#, B] [E, G\#, A], and [A, B, E] are subsets of the tetrachord set in Fragments 1 and 2 by transposition. On the other hand, its subset, [E, F\#, G\#, A] is $T_{7}$ of the tetrachord set in Fragment 3, [A, B, C\#, D], while subset [F\#, G\#, B] also maps onto subset $[\mathrm{A}, \mathrm{B}, \mathrm{D}]$ under $\mathrm{T}_{9}$.

Worthy of note is the fact that these two sets in Segment 3 are constructed in a way that is somewhat similar to Section 1, Part 2, Segment 5 (m. 11), and to an extent, Section 1, Part 1, Segment 4 (mm. 1-2) (see Figure 3.41).

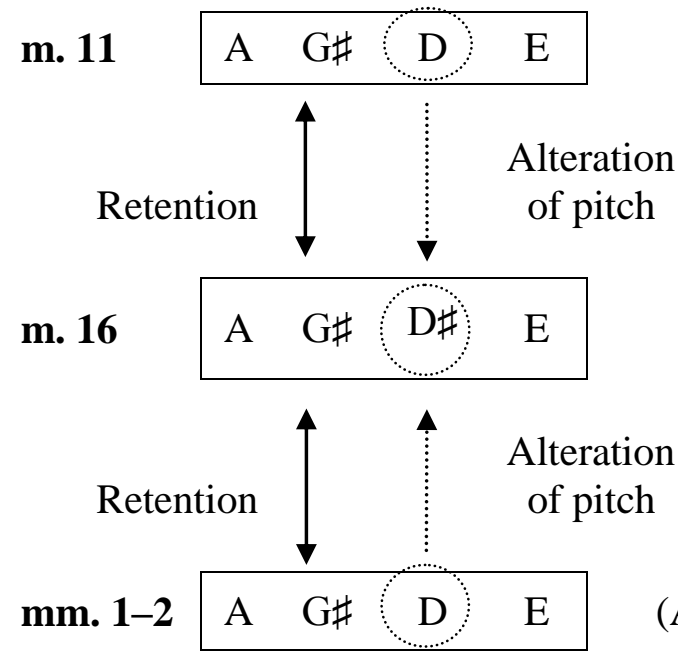

(A)
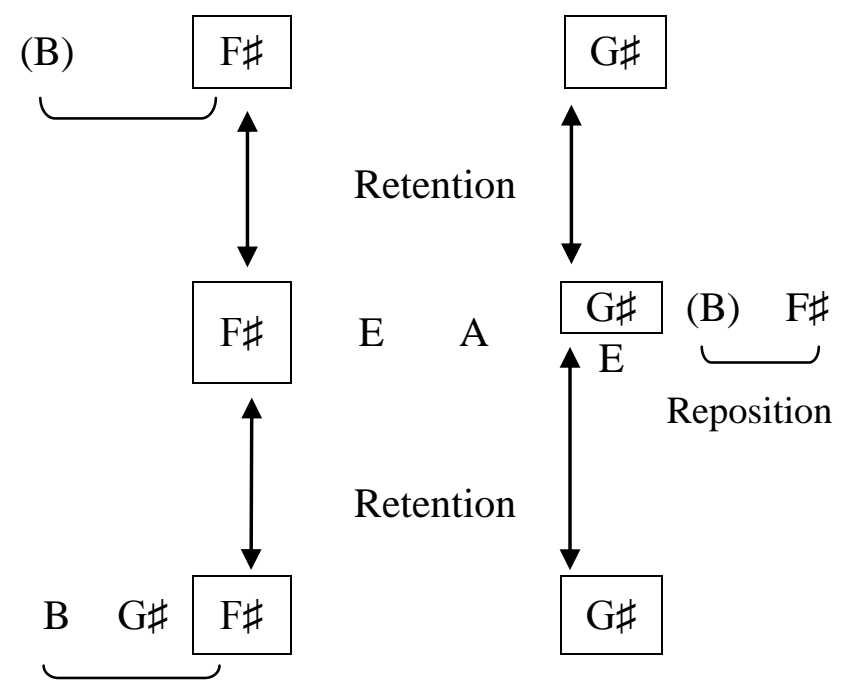

Figure 3.41

Similarities between pitch content in Fragment 11, Section 2, Part 1a, Segment 3 (m. 16); Section 1, Part 2, Segment 5 (m. 11); and Section 1, Part 1, Segment 4 (mm. 1-2). 
Like Segment 3, the fourth segment could also be grouped into two pitch-class sets. The first set, [G\#, $A \#, C \#]$ (or $[0,3,5]$ ) is unmistakably a subset of the tetrachord set in Fragment 3. The second set, $[\mathrm{F} \#, \mathrm{G} \#, \mathrm{~A}, \mathrm{~B}, \mathrm{C}]$ (or $[0,1,3,4,6]$ ) preserves the trichord class $[0,3,5]$ from the first set but transposes the set to $[F \#, G \#, B]$ and adds to the set $A$ and $C$. Its subset $[F \#, G \#, C]$ is also $\mathrm{T}_{4}$ of a subset of the tetrachord set in Fragments 1 and 2.

Unlike Part 1a, Part 1b (Figure 3.40b) poses a challenge to registral segmentation; it is found most ideal to group them by the beaming of the pitches. The first segment is made of pitch-class set [C\#, D, E\#, F\#, G\#] (or [0, 2, 3, 6, 7]), wherein its subset [C\#, E\#, F\#], is transpositionally related to the tetrachord sets in Fragments 1, 2, and 3. Concurrently, its subset $[\mathrm{F} \#, \mathrm{G} \#, \mathrm{C} \#]$ is also $\mathrm{T}_{4}$ of a subset of the tetrachord set in Fragments 1 and 2.

The second segment consists of pitch-class set $[D, E b, E, F, G, G \#]($ or $[0,1,3,4,5,6])$, which makes a chromatic cluster set with one pitch less $(\mathrm{F} \#)$. This set also contains elements that correlate with the tetrachord sets in Fragments 1, 2, and 3. First, its subsets, [D, E, G\#] and [G\#, $\mathrm{D}, \mathrm{E} b]$ are subsets of the tetrachord set in Fragments 1 and 2 by transposition. In addition, subsets $[D, E, G]$ and $[E b, F, G, G \sharp]$ are also transpositionally related to the tetrachord set in Fragment 3.

Like Part 1, the texture and the registral distribution of the pitches in Part 3 (see Example 3.10 and Figure 3.44) also offer several possible ways to examine the pitch materials. The trichords on the upper staff consistently form a relationship among themselves (see Figure 3.42), while the single pitches in both staves when grouped as a set also correlate to previous materials (see Figure 3.43). 


\begin{tabular}{|l|c|c|c|}
\hline Pitch-Class Collection (Trichords) & G, A, B b & F, F\#, G & F, F\#, G \\
\hline Pitch-Class Set & {$[0,1,3]$} & {$[0,1,2]$} & {$[0,1,2]$} \\
\hline
\end{tabular}

\begin{tabular}{|l|c|c|}
\hline Pitch-Class Collection (Trichords) & B, C\#, D & C\#, D, E \\
\hline Pitch-Class Set & {$[0,1,3]$} & {$[0,2,3]$} \\
\hline
\end{tabular}

Figure 3.42 Pitch content of the trichords in the upper staff of Fragment 11, Section 2, Part 3.

\begin{tabular}{|l|c|}
\hline Pitch-Class Collection (Single Pitch) & $\mathrm{E}, \mathrm{E} \#, \mathrm{G} \#, \mathrm{~B} b$ \\
\hline Pitch-Class Set & {$[0,2,5,6]$} \\
\hline
\end{tabular}

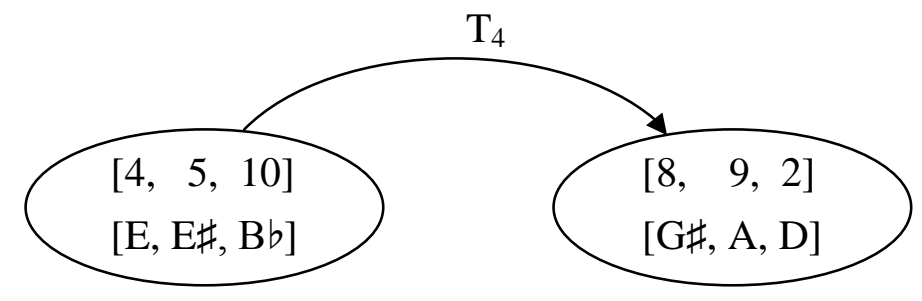

Fragment 11, Section 2, Part $3 \quad$ Fragments 1, 2, 3

Figure 3.43 Collection of single pitches in Fragment 11, Section 2, Part 3 and its relationship to the pitch content in Fragments 1-3.

On the lower staff, the dyads in the bottom form a familiar whole-tone scale, but the dyads on top appear to have connection to neither of the materials in this part nor materials seen elsewhere strongly suggesting that this material is organized in some other way. This leads to an alternative method to investigate the chords vertically, which includes the trichords on the upper staff and the tetrachords on the bottom staff as one set of pitch-class collection (see Figure 3.44 and 3.45). 


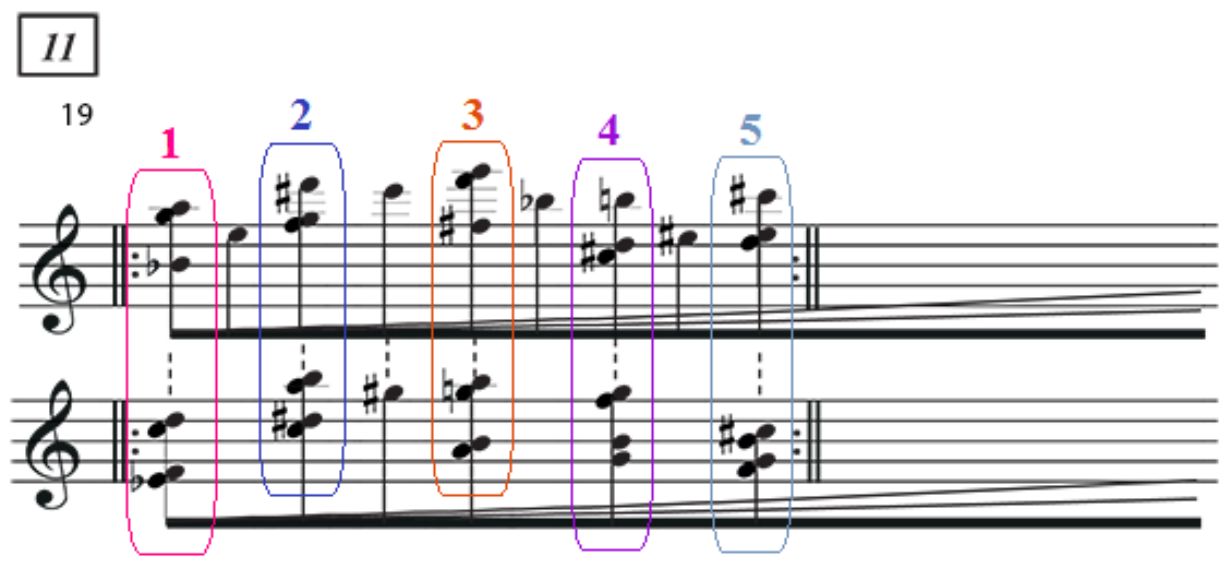

Figure 3.44

Chong Lim Ng: A Distant Voice of the Rain Forest, Fragment 11, Section 2, Part 3 (m. 19).

\begin{tabular}{|l|c|c|}
\hline Chord/Set & 1 & 2 \\
\hline Pitch-Class Collection & A, B b, C, D, Eb, F, G & C\#, D\#, F, F\#, G, A, B \\
\hline Pitch-Class Set & {$[0,2,4,5,7,9,10]$} & {$[0,2,4,5,6,8,10]$} \\
\hline
\end{tabular}

\begin{tabular}{|l|c|c|c|}
\hline Chord/Set & 3 & 4 & 5 \\
\hline Pitch-Class Collection & F, F\#, G, A, B & B, C\#, D, F, G & B, C\#, D, E, F, G \\
\hline Pitch-Class Set & {$[0,2,4,5,6]$} & {$[0,2,5,6,8]$} & {$[0,2,3,5,6,8]$} \\
\hline
\end{tabular}

Figure 3.45 Pitch content of the vertical chords in Fragment 11, Section 2, Part 3.

Through this method, it is found that Sets $1-2,2-3,2-4$, and 4-5 have a relationship respectively by preserving a certain pitch-class set or set class. The first and second sets are transpositionally related because subset $[A, D, E b, F, G]$ in Set 1 maps onto subset $[C \#, F \#, G, A$, B] in Set 2 at $\mathrm{T}_{4}$. On the other hand, Set 3 is a subset of Set 2 in that it retains the exact pitchclass set, [F, F\#, G, A, B]. Similarly, Set 5 also retains from Set 4, [B, C\#, D, F, G]. At the same 
time, Set 4 is also a subset of Set 2 by transposing subset [D\#, F, F\#, A, B] eight semitones higher.

Sets $1,2,4$, and 5 are also related to each other by transposition, in that each of these set contains the interval succession of 4-6-7: [Eb, G, A, Bb] in Set 1; [B, D\#, F, F\#] in Set 2; and $[\mathrm{G}, \mathrm{B}, \mathrm{C \#}, \mathrm{D}]$ in Sets 4 and 5. Meanwhile, subset $[\mathrm{F}, \mathrm{A}, \mathrm{B}]$ in Set 3 has partial connection to the sets mentioned above, but is one pitch short. Nevertheless, these chords are in fact closely related to one another, more so than they might appear to be on the music score. In addition, these five sets could also be connected to the $[0,5,6],[0,1,5,7]$, and $[0,1,3,5]$ sets in Fragments 1, 2, and 3 (see Figure 3.46).

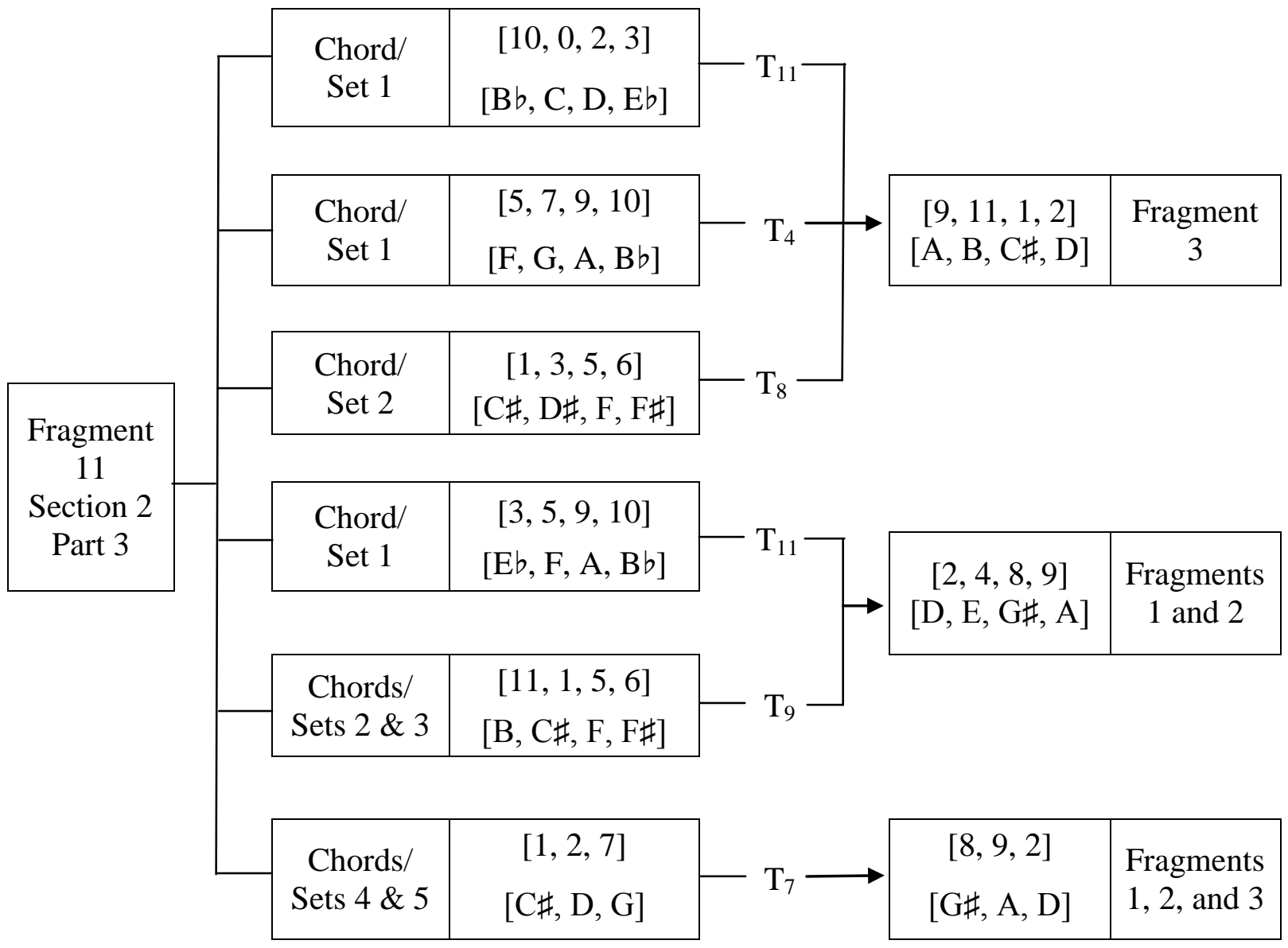

Figure 3.46 Interrelationships between sets in Fragment 11, Section 2, Part 3, and sets in Fragments 1,2, and 3. 
The final section of Fragment 11 (Example 3.11) consists of four segments. The first segment is the white key cluster that resembles the evocation of the sound of gongs which has already been seen in Fragments 3 and 9, though each such occurrence of the cluster is given a different dynamic marking. The second segment is a direct quotation of Segment 4 of Fragment 9, and the third segment is the $[\mathrm{D}, \mathrm{E}, \mathrm{G} \#, \mathrm{~A}]$ motif in an alternating-hand figure that is somewhat similar to Part 3 of Fragment 8. The fragment closes with a silent cluster of the [D, E, G\#, A] motif.

\section{Section 3}

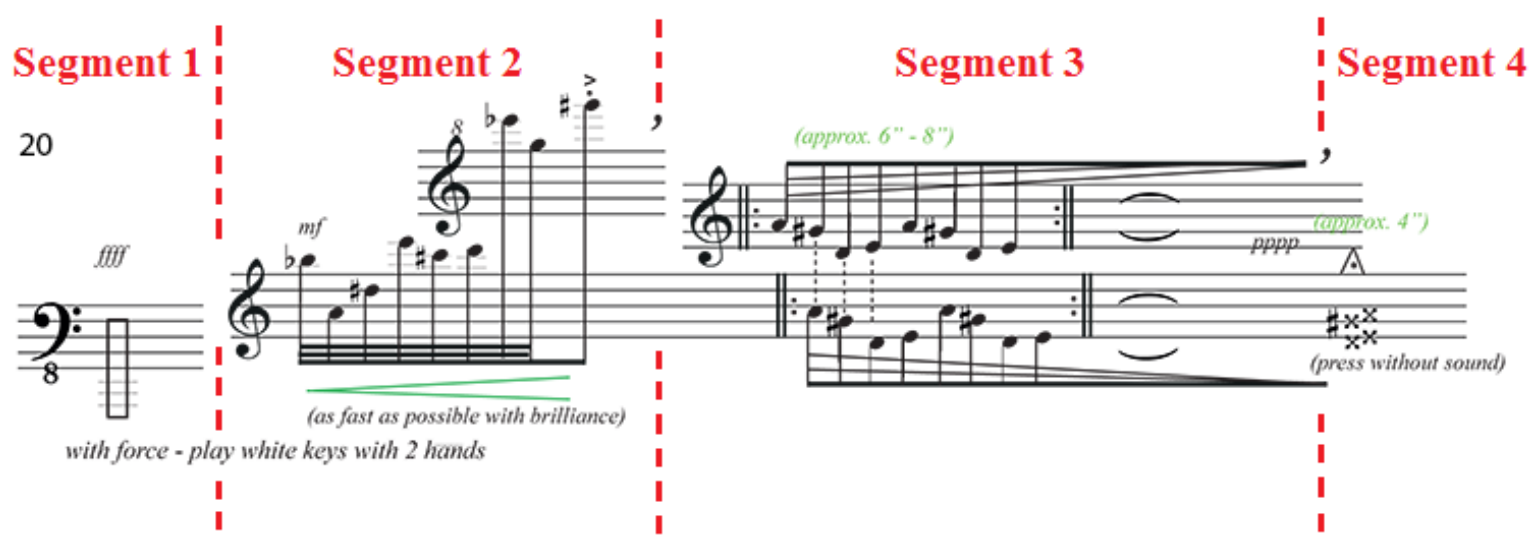

Example 3.11

Chong Lim Ng: A Distant Voice of the Rain Forest, Fragment 11, Section 3, m. 20.

\section{Conclusion}

Despite the fact that A Distant Voice of the Rain Forest is divided into fragments, there are certain places that connect between one place in a fragment and another place within the same fragment, and between one fragment and another fragment. Some of them are closely related in terms of structure and to an extent, pitch content, such as Fragments 1, 2, and 3, as well as Fragment 6 which is the above-mentioned fragments in retrogradation. 
There are a limited number of pitch-class sets that are prominent in this piece and which unite the fragments together as a whole. These sets include the $[0,5,6]$ trichord set, the $[0,1,5$, 7] whole note tetrachord set in Fragments 1 and 2, and the [0, 1, 3, 5] whole note tetrachord set in Fragment 3, all of which are present throughout this piece.

When such connections are established between one fragment and another fragment, more often than not the very same pitches are used. For instance, Fragments 4 (left hand), 7, and 11 (left hand) start with the same specific $[0,1,5,7]$ set (that is, [D, E, G\#, A]), while Fragment 8 reorders and expands the set. At times, the pitches in the set are even preserved in the same registral distribution, as seen in Fragments 4 (left hand), 8, and 11.

Other times these pitch-class sets are transformed in a complicated way: more often than not, by transposition and inversion. For instance, Fragments 5 and 10 have a relationship at the beginning that recalls that of Fragments 1,2 , and 3, in that they start with the same $[0,5,6]$ trichord set. This relationship is clearly audible, even though the set is confusingly manipulated. Also apparent in a number of fragments is the strategy of preserving a number of pitch-classes, pitch-class sets, or set classes and altering the final pitch-class in the set-whether by adding one or more pitch-classes to the set, or by changing or removing a pitch-class from the set. Specifically, this is seen in Fragments 4, 5, 6, 7, 8, 9, and 11.

However, some of the fragments contain materials that have little connection with other fragments, such as that of Fragment 4, Part 2, Segment 3, as well as Parts 1 and 2 of Fragment 8. On the contrary, the materials within such fragments have a stronger connection among themselves instead. These materials are perhaps intended to have rather loose connections with the other fragments in order to create diversity in this piece. 
To conclude, the success of this piece lies in the combination of a few components: simplicity, complexity, and diversity—all derived and expanded from a limited number of pitchclass sets. Although the compositional technique of this piece owes much to modern Western European compositional styles, there is an unmistaken sound and trait of a Javanese gamelan, specifically pitch-classes that are subsets of the pelog scale, and the evocation of the sound of gongs. The combination of Western influences, such as the use of the piano, with non-Western influences—-specifically, from the Southeast Asian region—makes this piece a significant example of syncretism.

This piece is technically challenging to play but the writing is very pianistic, which is hardly surprising, given that the composer himself is a master of the instrument. The elements of chance and spontaneity — as demonstrated by the random choice of order in which each fragment and/or musical idea is played, the improvisatory-like character in a lot of the passages, and the duration of pauses which determine the flow between passages and segments—also add freshness to the music each time it is performed. 


\section{CHAPTER FOUR}

\section{Adeline WONG}

\section{Biography}

Born in 1975 in Kuala Lumpur, Malaysia, Adeline Wong is among the most acclaimed Malaysian composers of her generation. This has been demonstrated by the Cameronian Arts Awards, which gave her the Malaysia's Most Promising Artist Award (2005) as well as the prize for Best Original Composition (2003 and 2005).

Since she was young, Wong's parents have been very supportive of her music education. Her mother, who plays elementary piano, encouraged her to begin taking piano lessons at the age of five, and later flute lessons at the age of nine. She started composing at the age of eight, and twice represented Malaysia at the Yamaha Music Foundation's International Junior Original Concert (IJOC) held in Tokyo in 1984 and 1986.

While working on her Diploma of Music at La Salle College of Arts in Singapore between 1992 and 1995, Wong had the opportunity to study for two years with American composer John Sharpley, who broadened her compositional horizon. "Before studying with John, I had only been exposed to traditional scores. He exposed me to new music, scores, sounds, and ideas." 1

In 1995, Wong went to the United States of America to pursue her Bachelor of Music degree at the Eastman School of Music. For the next three years she studied piano with Nelita True and composition with Joseph Schwantner, Christopher Rouse, Augusta Read Thomas, and David Liptak. In 2001-2 she was granted a scholarship to further her music education at the

\footnotetext{
${ }^{1}$ Adeline Wong, e-mail message to author, March 1, 2013.
} 
Royal College of Music London, where she also received the Cobbett and Hurlstone Composition Prize and was awarded a Master of Music degree in composition, under the tutelage of Edwin Roxburgh.

Wong's compositional output includes works for orchestra, chamber ensembles, solo instruments, and voice, as well as music for film, theater, and multi-media. Her works have been performed by the Tasmanian Symphony Orchestra; the Belgian National Orchestra; Orkest de ereprijs, The Netherlands; Minensemblet, Norway; Bang on A Can, USA; The Song Company, Australia; the T'ang Quartet, Singapore; the New Zealand Symphony Orchestra; and the Malaysian Philharmonic Orchestra. She has worked with conductors Matthias Bamert, Pascal Rophé, Kevin Field, James Wood, Brad Lubman, Roland Peelman, and Kenneth Young.

A prolific composer, Wong maintains an international presence through composition and new music festivals. She has received invitations to the Berlinale Talent Campus of the Berlin Film Festival (2003); The Australian Composers Orchestral Forum, Hobart, Tasmania (2004); TACTUS Young Composers Forum, Brussels (2004); 11th International Young Composers' Meeting, Apeldoorn, The Netherlands (2005); Bang on A Can Summer Music Festival, Massachusetts, USA (2006); and the Asian Composers League-Asia Pacific Festival, New Zealand (2007).

Early recognition was reached in 2002-3, when Wong was among 66 international composers who were commissioned by British pianist, Thalia Myers, to compose a miniature for solo piano. The compilation of these works was then published by the Associated Board of the Royal Schools of Music, UK, in Spectrum 4 (2005).

In 2004, Wong emerged as one of the four finalists in the Malaysian Philharmonic Orchestra (MPO) Forum for Malaysian Composers. One of her competition submissions, 
Synclastic Illuminations (2003), originally written for chamber ensemble, was later performed by the New Zealand Symphony Orchestra in 2007. The following year, the recording of the full orchestral performance was included in the Malaysia's first anthology CD of contemporary art music, "Faith, Hope \& Chaos: Malaysian Contemporary Music Vol. 1."2

The relationship with the MPO continued when Wong was commissioned by MPO cellist, Steve Retallick, to write a concerto for cello and chamber orchestra, Snapshots. Subsequently, Wong was specially commissioned by the MPO in 2007 to compose two prestigious works. The first, Empunya yang beroleh Sita Dewi [For He Who Owns Sita Dewi], was a collaboration between the MPO and wayang kulit (shadow puppet) ensemble in celebration of the MPO's $10^{\text {th }}$-year Anniversary, and the second, Ria! [Joy!], a fanfare for the inaugural gala opening of the Malaysian Philharmonic Youth Orchestra (MPYO).

In the same year, Wong's film score, Chermin [Mirror], was premiered and featured at the Udine Far East Film Festival in Italy, the Puchon International Fantastic Film Festival in Korea, and the Australian Malaysian Film Festival in Melbourne. Her most recent work, Lengt [Longing] (2010) is a commissioned multi-media work for solo cello with string quartet, electronics, digital art, and dancer in collaboration with Norwegian visual artist, Are Andreassen. Lengt was premiered by the MiNensemblet (Norway) at the Nordland Musikkfestuke, Bod $\varnothing$, Norway in August 2010. The work was also recently performed by the T'ang Quartet (Singapore) at the Kuala Lumpur Performing Arts Center, Malaysia in February 2012. Influenced by such great composers as Witold Lutoslawski, György Ligeti, John Adams, Steve Reich, and George Crumb, Wong describes her compositional style as a "combination of

\footnotetext{
${ }^{2}$ Faith, Hope \& Chaos: Malaysian Contemporary Music Vol. 1, Edge Communications, Petaling Jaya, Malaysia, 2008, compact disc. Produced by Hardesh Singh and CH Loh. Released with the February 2008 issue of Off The Edge magazine.
} 
harmonic and textural energy [with] kaleidoscopic colors, and lyricism"3 and believes in "[writing] what you feel that is honest and represents your creativity.",

Also successful as an educator, Wong has taught at Akademi Seni Kebangsaan (now known as Akademi Seni Budaya \& Warisan Kebangsaan [ASWARA]) and University College Sedaya International (UCSI), both located in Kuala Lumpur, Malaysia. She currently lectures at the Yong Siew Toh Conservatory of Music, National University of Singapore.

\footnotetext{
${ }^{3}$ Adeline Wong, e-mail message to author, March 1, 2013.

${ }^{4}$ Ibid.
} 


\section{Complete List of Works}

\section{Orchestral}

1. Steel Sky (2004)

2. Starburst (2004)

3. Snapshots - Concerto for cello and chamber orchestra (2005)

4. Ria! [Joy!] - Fanfare for orchestra (2007)

5. Empunya yang beroleh Sita Dewi [For He Who Owns Sita Dewi] for orchestra and wayang kulit (shadow puppet) ensemble (2007)

\section{Chamber}

1. Time - Duo for voice and harp, or voice and piano (1997)

2. Dream Labyrinths - Duo for flutes and percussion (1998)

3. Metamorphosis - Quintet for cor anglais, clarinet, violin, viola, and cello (1998)

4. Shock Wave for 3 horns, 2 trumpets, trombone, bass trombone, tuba, 3 percussion instruments, harp, and piano (1998)

5. Variations - Quartet for Bb clarinet, violin, viola, and cello (2002)

6. Fractured Images - Trio for violin, flute, and piano (2002)

7. Cahaya [Light] for strings and woodwinds (2002)

8. Sojourn for flute, clarinet, bassoon, horn in F, violin, viola, cello, and double bass (2002)

9. Synclastic Illuminations for woodwinds, brass, harp, piano, 2 percussion, and strings (2003)

10. Voices for soprano, alto, tenor, bass, clarinet, saxophone, piano, horn, trumpet, trombone, and percussion (2005)

11. Waktu [Time] for clarinet, marimba, vibraphone, soprano, piano, violin, and cello (2006)

\section{Solo Instrumental}

3. Sphere for solo clarinet (1997)

4. Penang for solo marimba (1998)

5. Alternative Current for solo piano (2000)

6. Pierced for solo cello and electronics (2004)

7. Mind the Gap for solo piano (2005)

8. Paces for solo piano and electronics (2005) 


\section{Film Score}

1. Unheimliche Geschichten [Five Mysterious Stories] (2003)

Commissioned by Goethe Institut Kuala Lumpur to compose new music for this classic German silent film, 1919.

Director: Richard Oswald

Instrumentation: violin, cello, piano, prepared piano, and electronics

2. Anybody Home? in Visits: Hungry Ghost Anthology (2004)

Director: Ho YuHang

Instrumentation: electronics

3. Chermin [Mirror] (2006)

Director: Zarina Abdullah

Instrumentation: strings, voices, piano, rebab, gendang, and electronics

\section{Music for Theater}

1. Five Letters from an Eastern Empire (2004)

Instrumentation: boy soprano, cello and electronics

\section{Music for Multi-media}

1. Lengt [Longing] (2010)

Instrumentation: solo cello with string quartet, electronics, digital art, and dancer 


\section{Analysis of Selected Work for Piano}

\section{Paces for solo piano and electronics (2005)}

I. Construction/Industrial

II. Metal Grating

III. Piano Solo

IV. Gameboy/Digital

Premiere: $\quad$ August 10, 2005 at the HSBC Classics Piano Festival in Kuala Lumpur, Malaysia. Performed by Chong Lim Ng.

Duration: $\quad$ Approximately 9 minutes 30 seconds.

\section{$\underline{\text { Background }}$}

Set in four sections, Paces is "a fun and showy work for piano" that portrays life in a modern city and how one copes with it. ${ }^{6}$ This work features a live solo piano part, accompanied by an audio recording that is produced beforehand. The audio recording is a combination of electronics and sound samples that were put together to produce sounds commonly heard in an urban area—construction noises generated by machines and electrical equipments; "sequences of traffic ... [and] blaring car horns;",7 fragments of various musical genres, both modern and traditional, ranging from techno music to ethnic music and Western European art music; as well as digital sounds of mobile ring tones and gaming devices - all of which indicates the inevitable use of technology in present day lives. ${ }^{8}$

\footnotetext{
${ }^{5}$ CH Loh, "Young Malaysians - Adeline Wong Offers Snapshots," Malaysiancomposers.com, Malaysian Composers Collective. August 31, 2010, access March 24, 2013, http://www.futureasia.net/malaysiancomposers/focus/focus32_adeline.htm. Originally published in Off The Edge September, 2005.

6 "We Built This City: Malaysian Voices and Their Songs of the City," KL Contemporary Music Festival '09, Malaysiancomposers.com, Malaysian Composers Collective, accessed March 24, 2013, http://www.futureasia.net/malaysiancomposers/klcmf09/concert27.htm.

${ }^{7}$ CH Loh, "Adeline Wong Offers Snapshots."

8 "We Built This City" (website).
} 
On the other hand, the piano represents an "individual coping and integrating with city life." ${ }^{9}$ Sometimes it plays simultaneously with the electronics, occasionally competes with it, and "at times intervening and being part of the electronic sounds."10 Towards the end of this work, the piano — or, the individual—is joined by the sound of children's voices, "which signifies the future generation who would determine the sounds and pace of city life to come."11

Wong remarks in an interview, "This work is a departure from my normal style. Since the first MPO Forum [in 2003-4], I've always wanted to explore the area of electronics and I'm glad I finally have the opportunity to do so... I've always enjoyed the music of Bjork, Aphex Twin, [and] Orbital, and you can hear their subtle influences in this work." ${ }^{12}$

\footnotetext{
9 "We Built This City" (website).

${ }^{10}$ Ibid.

${ }^{11}$ Ibid.

${ }^{12}$ CH Loh, "Adeline Wong Offers Snapshots."
} 


\section{$\underline{\text { Analysis }}$}

\section{Construction/Industrial}

Marked as "menacing and nerve-wrecking," this opening section of thirty-three measures (Example 4.1) is filled with construction sounds. On top of that, the cimbalom carries a series of short melodic figures, joined at first in unison by the piano for fourteen measures, before the latter carries on with the development of such figures on its own.

In general, it is clear that a rhythmic motif comprising three $16^{\text {th }}$ notes dominates the entire section. This is seen in mm. 9, 10, 23, and 26-29, and is especially apparent through the rhythmic grouping seen in m. 30 to the end of Section I (see Example 4.1). Sometimes the motif appears in groups of four $16^{\text {th }}$ notes, as seen in mm. 3, 5, 14, 17, 19-22 and so forth, yet it is evident from the melodic aspect that more often than not they are made of a series of three $16^{\text {th }}$ note cells (see Figure 4.1).

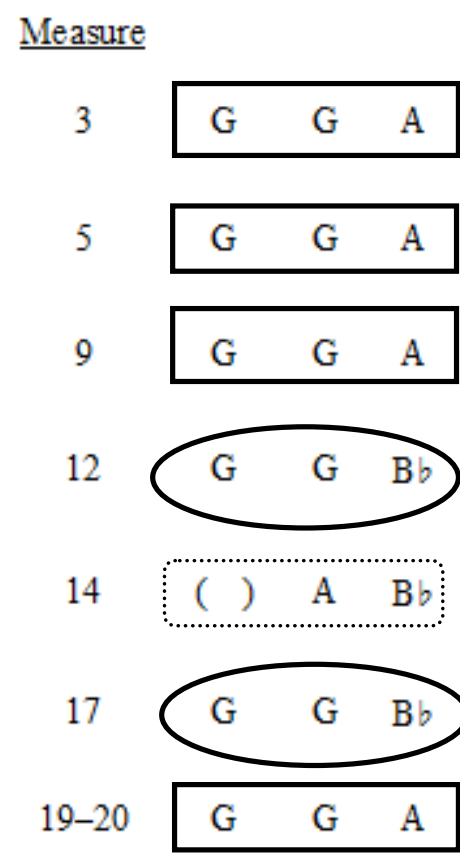

\section{$\underline{\text { Pitch-Class Collection }}$}
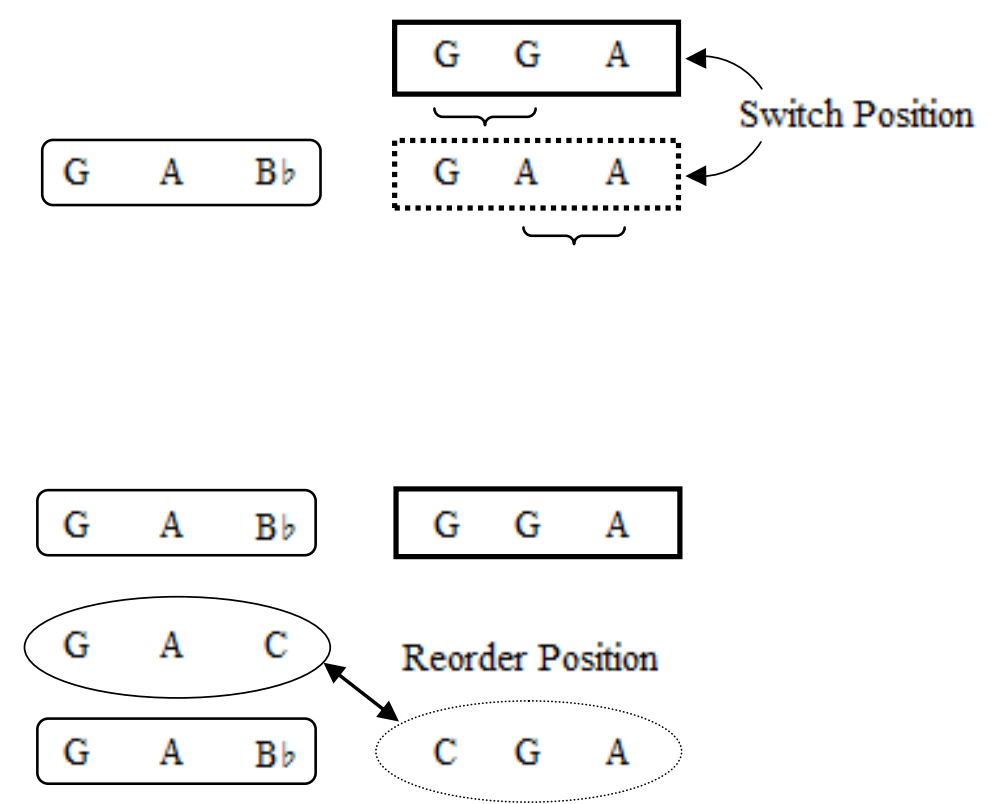

Figure 4.1 Derivation of three-16 ${ }^{\text {th }}$-note cells in Section I, "Construction/Industrial," mm. 3-20. 
P A C E S

(I. CONSTRUCTION/INDUSTRIAL)
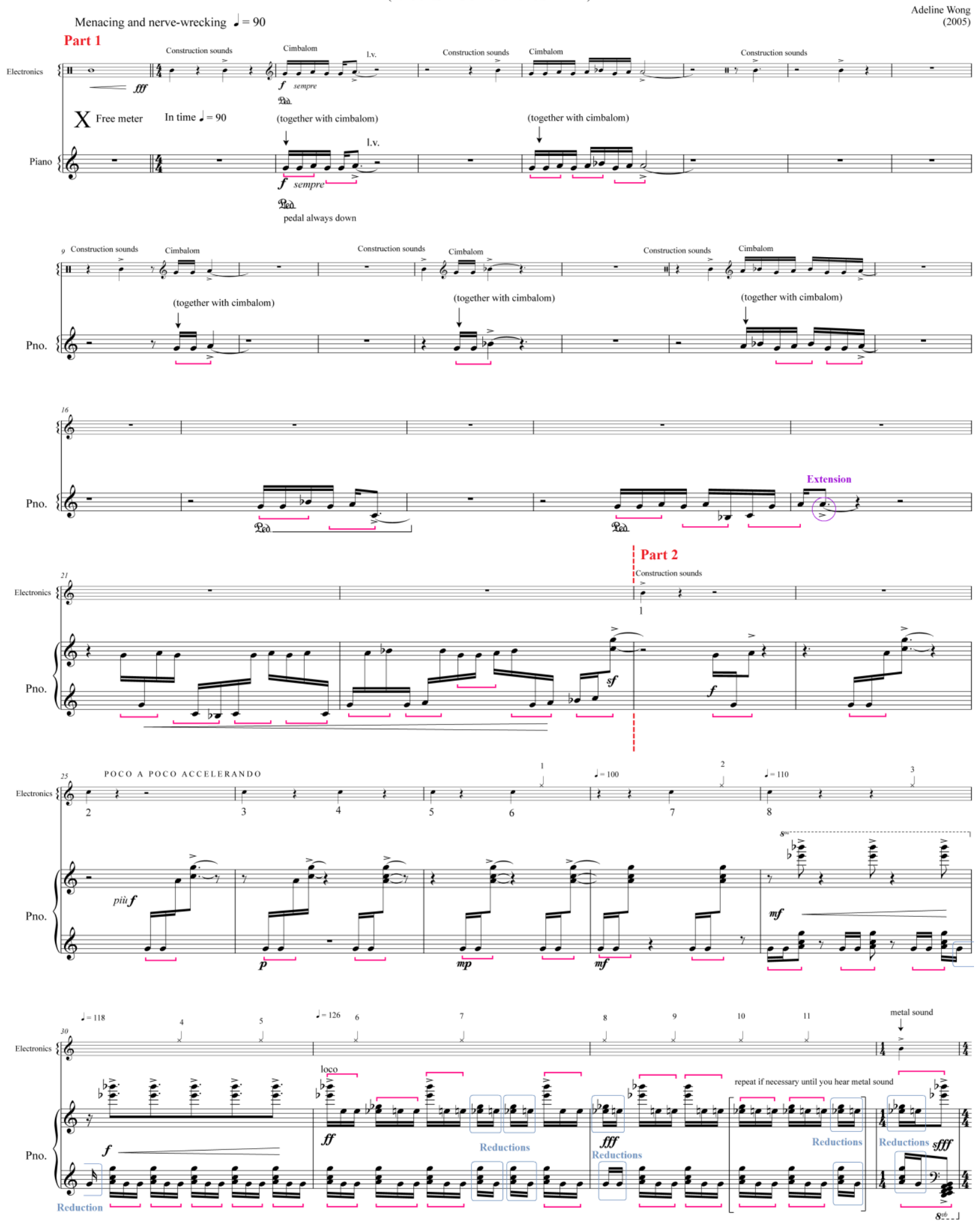

Example 4.1

Adeline Wong: Paces, Section I, “Construction/Industrial,” mm. 1-33. 
The melodic figure in $\mathrm{m} .3$ consists of two identical three-note cells, [G-G-A]. This cell begins the next melodic figure in $\mathrm{m} .5$; however, instead of being repeated, a new cell with a new pitch, $[\mathrm{G}-\mathrm{A}-\mathrm{B} b]$, is introduced. The third cell in this figure reuses both $\mathrm{G}$ and $\mathrm{A}$ from the first cell, but changes the order from two G's and one A to one G and two A's. The [G-G-A] cell recurs again in $\mathrm{m} .9$, and later in $\mathrm{m} .12$, with the A changed to the new pitch introduced earlier, $\mathrm{B} b$.

There are several melodic figures that could be connected to that of $\mathrm{m}$. 5. First of all, $\mathrm{m}$. 14 could be seen as a retrogradation of $\mathrm{m} .5$, although the first cell in $\mathrm{m} .14$ is not at all related to the last cell in m. 5, [G-A-A]. Rather, it could be treated as a subset of the $[\mathrm{G}-\mathrm{A}-\mathrm{B} b]$ cell, with the G missing. Subsequently, m. 17 contains two three-note cells that are somewhat similar to the first two cells in $\mathrm{m}$. 5, except for the fact that the third pitch-classes of both cells are changed to a step higher, plus an octave displacement of the final C, in $\mathrm{m} .17$. On the other hand, mm. 19-20 begins with the same pitch-classes as the first two cells in $\mathrm{m} .5$, and ends with a third cell that reorders the pitches of the second cell in m. 17.

In short, all of these melodic figures are connected to one another, particularly through the recurrence of the three-note cell, $[\mathrm{G}-\mathrm{G}-\mathrm{A}]$. The pitches in this cell are then varied by the alteration of a certain pitch, and by the addition of new pitches to form such new cells as $[\mathrm{G}-\mathrm{G}-\mathrm{B} b],[\mathrm{G}-\mathrm{A}-\mathrm{B} b]$, and $[\mathrm{G}-\mathrm{A}-\mathrm{C}]$. It seems as though the composer is in the process of building a scale.

While the melodic figures seen so far are rather short, the next two measures (mm. 21-22) contain a longer figure, which is also made of a series of three-note cells (see Figure 4.2). Within this figure, all of the above-mentioned cells, except $[\mathrm{G}-\mathrm{G}-\mathrm{B} b]$, are used. These cells are further the use of reordering and of octave displacement. 


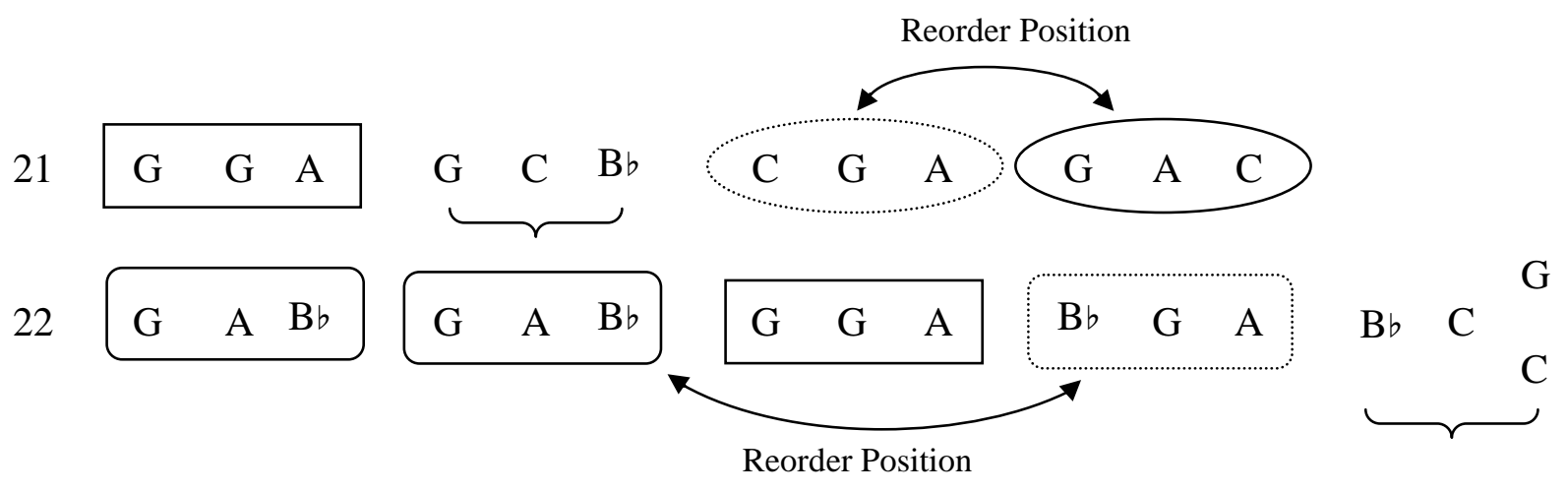

Figure 4.2 Derivation of three- $16^{\text {th }}$-note cell motives in Section I, "Construction/Industrial," mm. 20-21.

At the very end of the melodic figure in m. 22, a change in texture occurs when G5 is added on top of $\mathrm{C} 5$ to form an open $5^{\text {th }}$ dyad. From the subsequent measure all through the rest of Section I, it seems that the focus has shifted to the vertical permutation of the three-note cells, which is exemplified by the progressive addition of new pitches to the stacked $5^{\text {th }}$ (see Example 4.1). Such a textural change perhaps suggests a division in Section I into two parts: the first part (mm. 1-22) concentrates on the linear treatment of the cells, while the second part (mm. 23-33) deals with the vertical aspects of such treatment.

Part 2 of Section I begins in $\mathrm{m} .23$ by recalling the three-note cell that started the section, [G-G-A] (see Figure 4.3). This cell is then followed by the open $5^{\text {th }}$ dyad that ended Part 1, sounding through the next three measures until $\mathrm{m}$. 26, where the open $5^{\text {th }}$ dyad merges with the last note of the three-note cell, A, to form a trichord. This expands the three-note cell into five notes, although the rhythmic grouping of three $16^{\text {th }}$ notes remains unchanged. This rhythmic motif will henceforth be named three-16 $6^{\text {th }}$-note cell. 


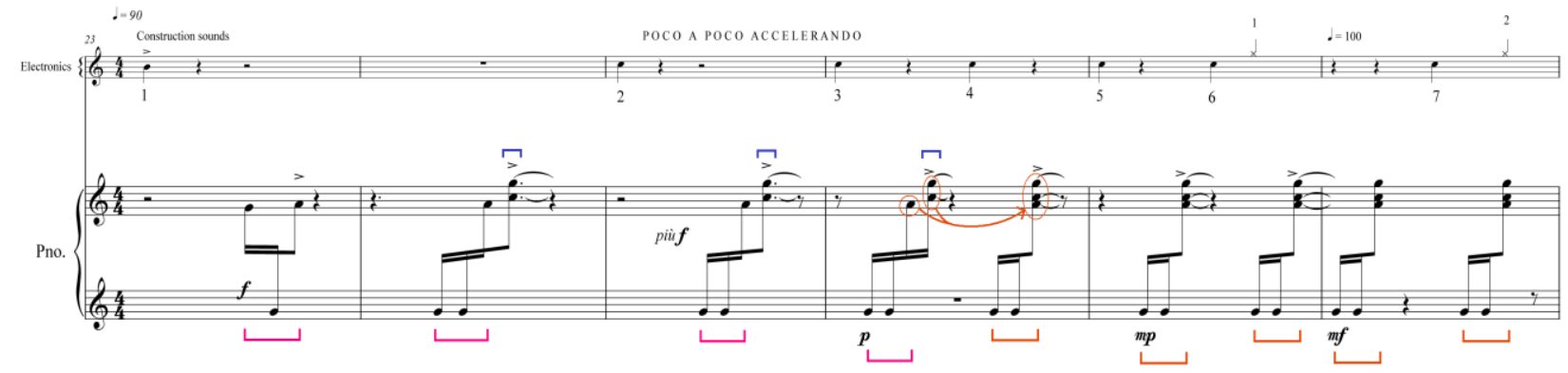

Figure 4.3

Adeline Wong: Paces, Section I, “Construction/Industrial,” Part 2, mm. 23-28.

This newly formed cell is repeated for two measures, and then starting from m. 29 two more pitches, $\mathrm{E} b 7$ and $\mathrm{B} b 7$, are added on top of the trichord (see Figure 4.4). At the end of m. 29 and the beginning of m. 30, the G4's are perhaps a reduction of such a cell-with the pentachord, [A-C-G-Eb-Bb], being left out-as the beamings in $\mathrm{m} .30$ clearly suggest that the first G4 in the measure is not part of such rhythmic groups. Note also the retrogradation of this previous cell from m. 30 onwards.

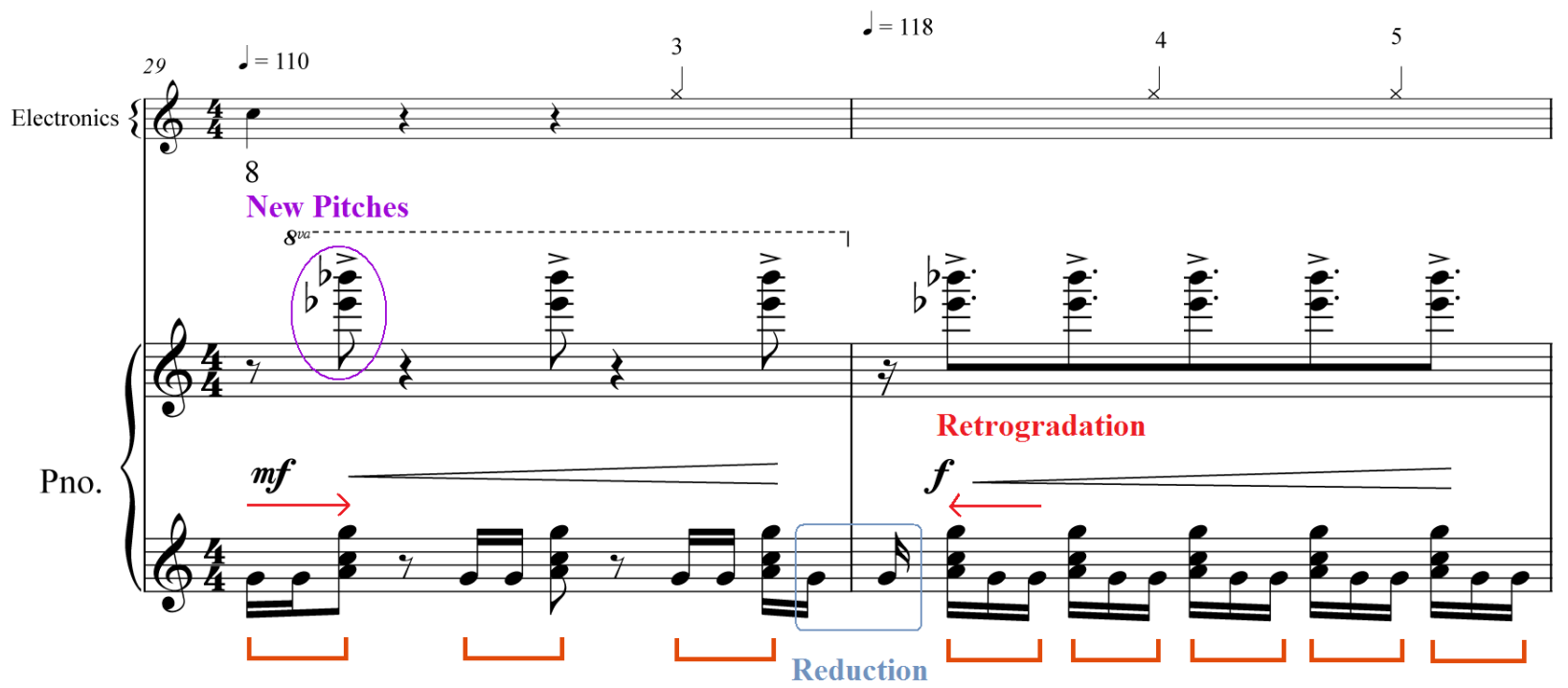

Figure 4.4

Adeline Wong: Paces, Section I, “Construction/Industrial,” Part 2, mm. 29-30. 
In the last three measures of Section I, mm. 31-33, yet another two new pitches, E5 and Gb5, are added to the right hand (see Figure 4.5). Thus far, the pitch-class collection for this section consists of, in ascending order, $\mathrm{E} b, \mathrm{E}, \mathrm{G} b, \mathrm{G}, \mathrm{A}, \mathrm{B} b$, and $\mathrm{C}$, which all together forms a familiar octatonic scale, with one pitch, $\mathrm{D} b$ omitted.

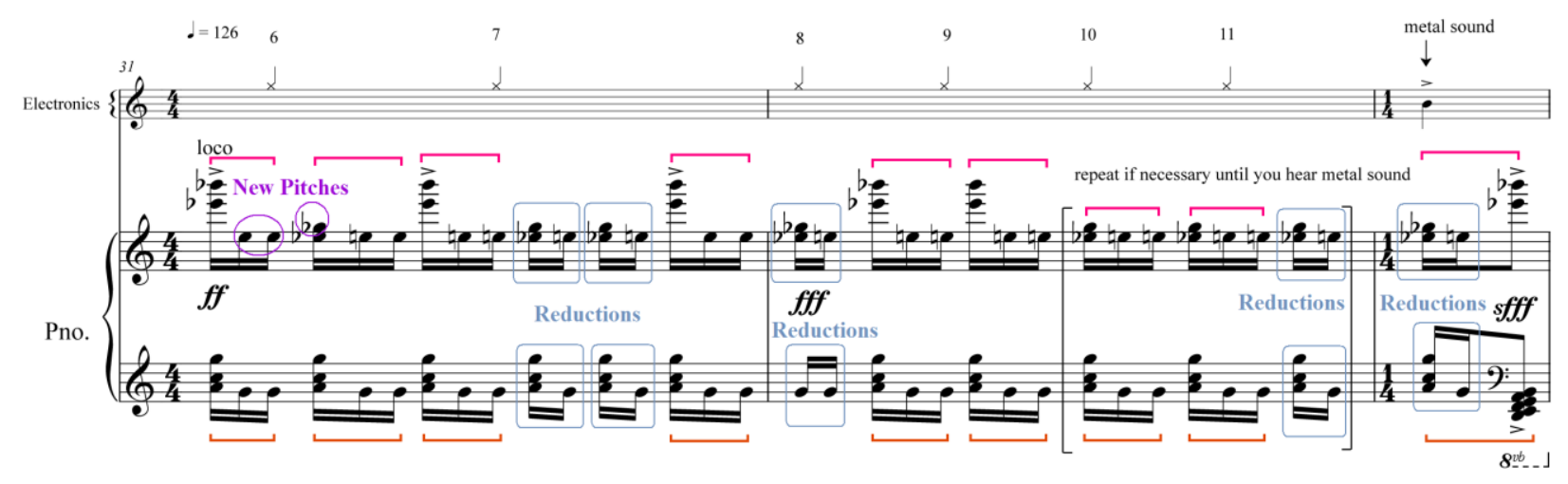

Figure 4.5

Adeline Wong: Paces, Section I, "Construction/Industrial," Part 2, mm. 31-33.

At times, the three- $16^{\text {th }}$-note cell is reduced to two $16^{\text {th }}$ notes by leaving out pitches on the third $16^{\text {th }}$ note. Such irregularity in rhythmic grouping, in addition to the gradual increase of density in texture as well as the poco a poco accelerando that started back in $\mathrm{m}$. 25 , creates a sense of urgency and heightens the intensity in the music. In fact, there are more spaces between each melodic figure in the first part of this section; whereas in the second part, the distance between figures is gradually shortened, and the motion of such figures becomes more perpetual, eventually leaving no space between figures.

The final chord that ends this section consists of $\mathrm{E} b 7$ and $\mathrm{B} b 7$ in the right hand, and a white key cluster ranging from D1 to B1 in the left hand, which is played simultaneously with a loud metal sound from the audio recording. 
To summarize, this first section demonstrates the permutation of a three-note cell in several ways: 1) by altering the pitch-classes of the cell; 2) by reordering such pitch-classes; 3) by adding more pitch-classes to the cell, but keeping the same rhythm, achieved through stacking the pitch-classes; and 4) by modifying the rhythm of such cell—expanding the grouping of three $16^{\text {th }}$ notes into four $16^{\text {th }}$ notes, or reducing them to two $16^{\text {th }}$ notes. It seems that in this section, the composer works her way through short motives to form a pitch-class collection that comprises an incomplete octatonic scale, [Eb, E, Gb, G, A, Bb, C]. The rhythmic motif of three $16^{\text {th }}$ notes is also prominent throughout this section.

\section{Metal Grating}

Immediately following the loud metallic sound that ended Section I, the sound of sand from tipper opens the second section of this piece (Example 4.2) - the shortest section of all, only twenty four measures in length—and slowly transits into a series of techno-like dance beats made by drums and some percussion, which continues all through this section.

The piano part has minimal playing, hence having a somewhat less important role in this section. However, it repeatedly plays, with muted strings, a rhythmic motif of three $16^{\text {th }}$ notes, which was seen throughout the first section. Where the piano is assigned such motives, it seems to be emphasizing the drum kicks in the audio recording, which makes it an additional supportive percussive instrument in this section.

Therefore, Section II could be treated as purely rhythmic, highlighting the rhythmic aspect of the three-note cell that governs Section I. In a way, it also serves as a rhythmic transition from the relatively interruptive first section to the more flowing third section, which will be discussed next. 
II. Metal Grating
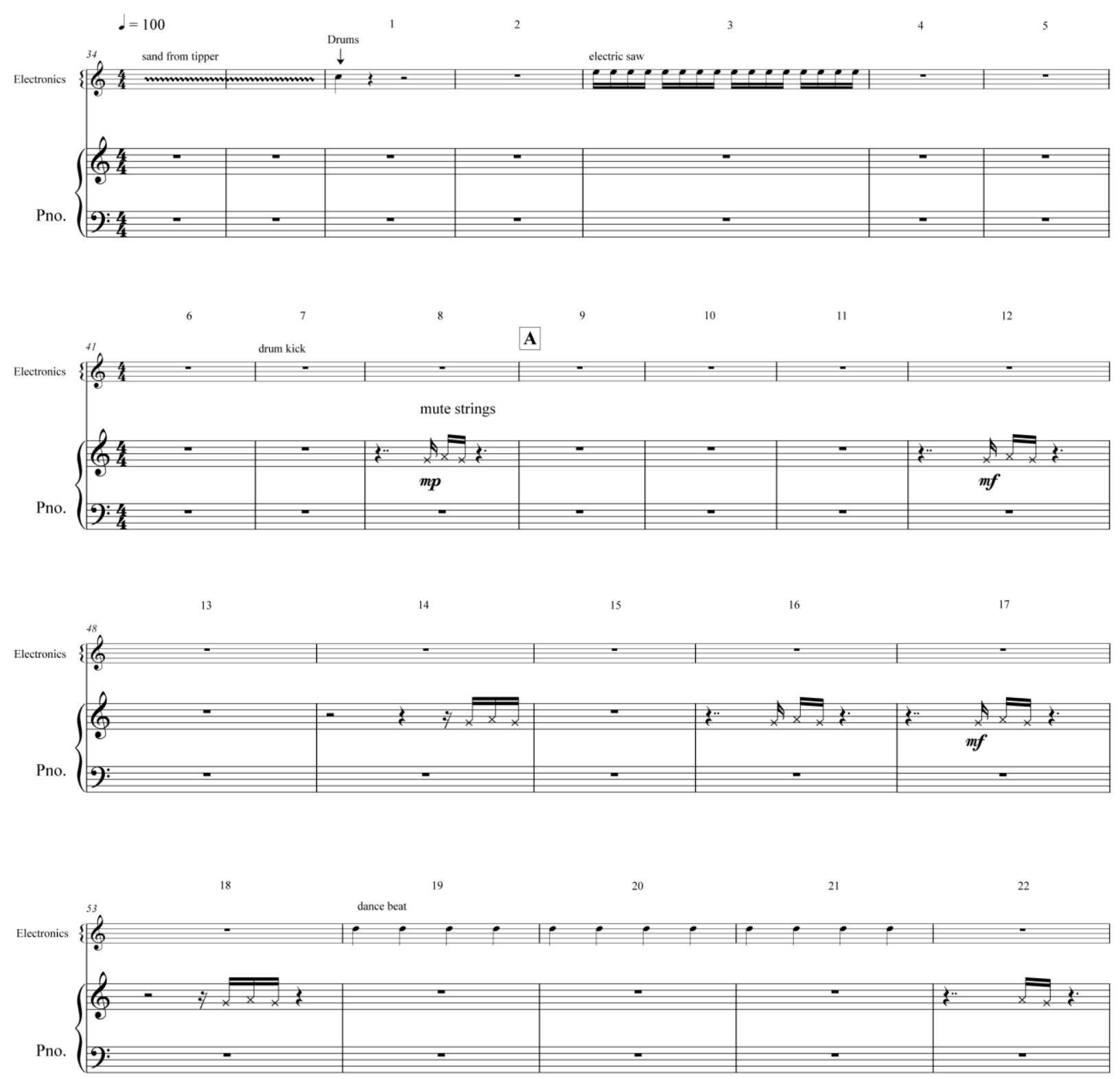

Example 4.2

Adeline Wong: Paces, Section II, "Metal Grating," mm. 34-57. 


\section{Piano Solo}

This third section is the longest section, lasting for a hundred measures. The dance beats in Section II fuse into the sounds of gamelan orchestra at the beginning of this section. This continues for approximately thirty five seconds before the piano blends in with the gamelan in $\mathrm{m}$. 60 with a string of $16^{\text {th }}$ notes in groups of four in the left hand, and a bell-like perfect $5^{\text {th }}$ figure in the right hand that echoes the gamelan. Soon after, the piano takes over entirely until the end of the section, where the audio recording comes in again with the sound of car horn.

The texture in the piano part is generally homophonic: the melody is often carried in the top voice, accompanied by alternating chords in $16^{\text {th }}$ note rhythm, with occasional counterpoint in other voices. The density in texture also resembles such $19^{\text {th }}$ century pianistic writing as that of Brahms, but the tonality is both neo-romantic and contemporary: the melodic and bass lines are for the most part diatonic, but the harmony often contains non-harmonic tones, and becomes more and more chromatic as this section progresses.

The constant $16^{\text {th }}$-note perpetual motion in the accompaniment creates a sense of stability. In contrast, such irregularities as the frequent change of meter, tempo, dynamics, and articulations - less often at the beginning and ending, but more rapid in the middle of this section-makes the music highly driving.

Based on all of the above-mentioned elements and characters, this section could be divided into six parts: 1) Brief Introduction (mm. 60-63), 2) Part A (mm. 64-87), 3) Part B (mm. 88-106), 4) Part A' (mm. 107-128), 5) Part C (mm. 129-149), and 6) Coda (mm. 150-160).

Within Parts A, B, and C, there are two contrasting ideas, or characters: the first is relatively lyrical, calm, and expressive; while the second is more abrupt and aggravated. Although both Parts A and B contain similar melodic materials, the character and sound of such 
materials are very distinctive in both parts, as a result of a combination of several aspects such as tempo, meter, articulation, the use of pedal or the lack of such use, and - to an extent - dynamics and phrase structure. Hence, for the ease of further discussion, Part B is not treated as a variant of Part A, but rather a different part with a contrasting character. In other words, the characterization of these parts is based on such contrast in the character of the melodic materials, not so much the contrast of melodic ideas.

Due to the complexity presented in Section III, the discussion of the analysis will therefore be broken into several aspects: 1) Phrase Structure; 2) Pitch Content; and 3) Interrelationship between Harmonic Rhythm, Tempo, Meter, Dynamics, and Articulation.

\section{Phrase Structure}

The division of phrases is clearly defined by the melodic and harmonic structure, as well as changes in tempo and the use of pedal. Although Section III opens with the sounds of gamelan orchestra that last for approximately thirty five seconds - which, on the music score, are conveniently given two empty measures (mm. 58-59) - the discussion of phrase structure and pitch-content in this section only concern the piano part, which begins in $\mathrm{m}$. 60 . For that reason, mm. 58-59 is treated as a transition between Sections II and III, hence is labeled as Transition I.

The four measures where the piano blends with the audio track serve as an Introduction (mm. 60-63, Example 4.3). This is followed by Part A (mm. 64-87, Example 4.4), which comprises three phrases of equal eight-measure length. The second and third phrases are variants of the first. Since the third phrase shows less variation from the model than does the second, and also is untransposed, the three phrases form an ABA pattern. 


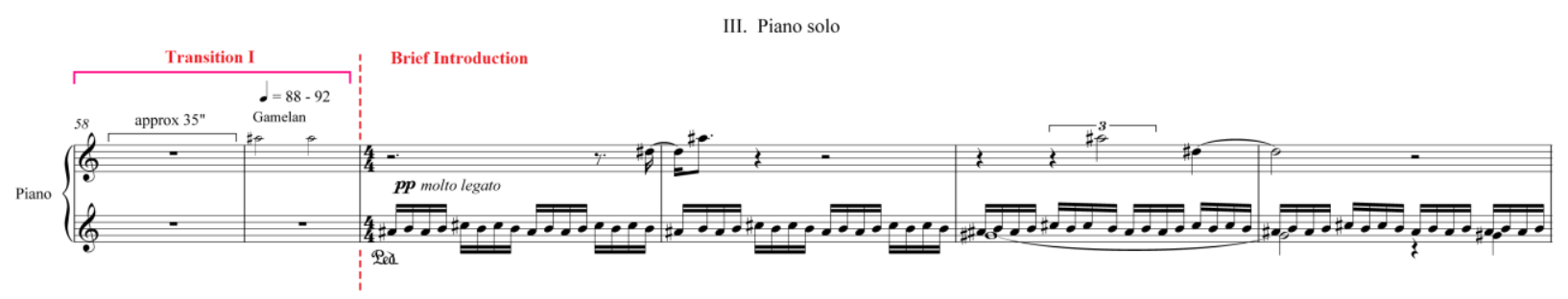

Example 4.3

Adeline Wong: Paces, Transition I, mm. 58-59, and

Section III, "Piano Solo," Brief Introduction, mm. 60-63.

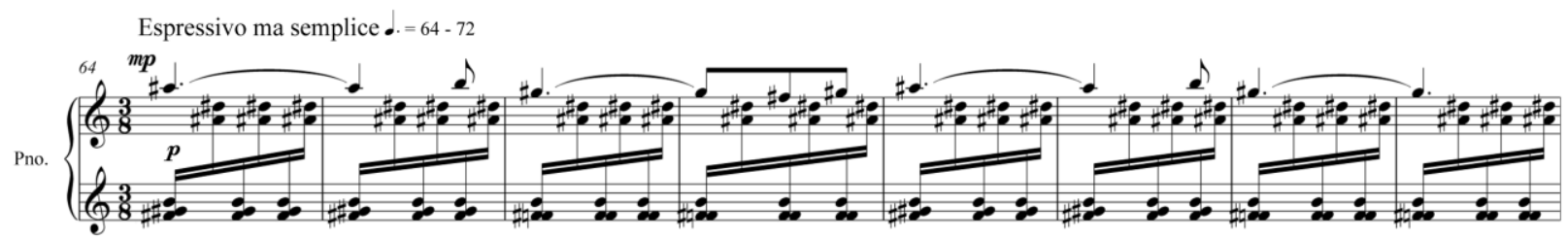

Qed sempre
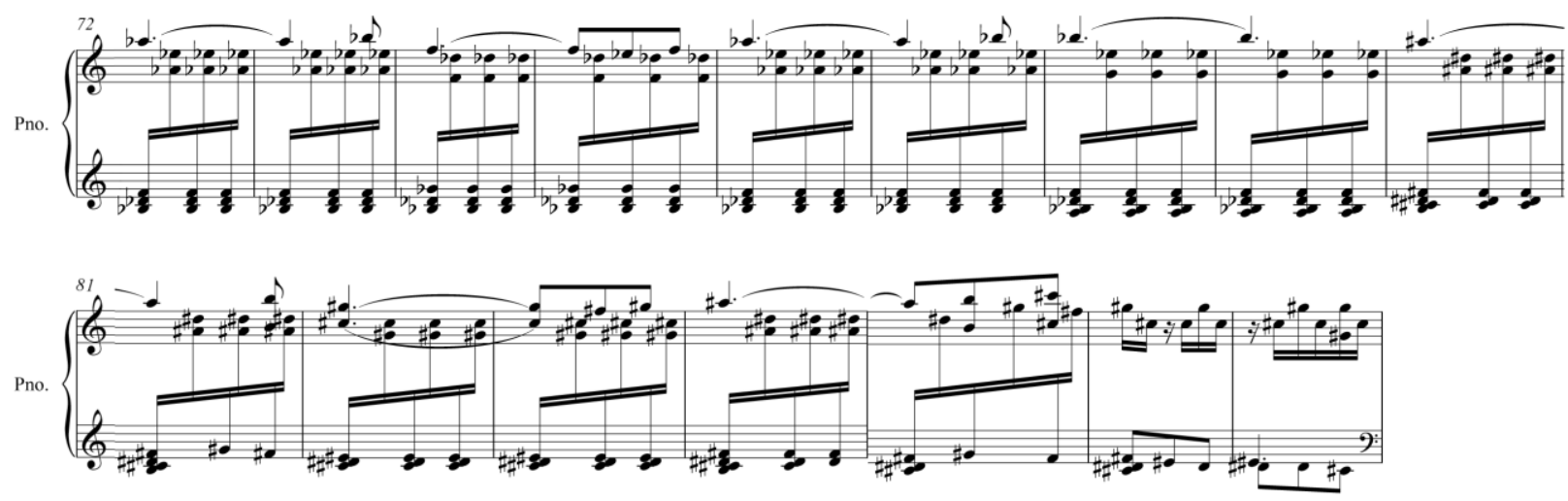

Example 4.4

Adeline Wong: Paces, Section III, "Piano Solo," Part A, mm. 64-87.

Part B (mm. 88-106, Example 4.5) uses similar melodic material to Part A, but further develops and extends such material. Unlike Part A, the phrase structure of Part B is rather irregular. There are two large phrases of different length: $(8)+(4+4+2+1)$ measures. 

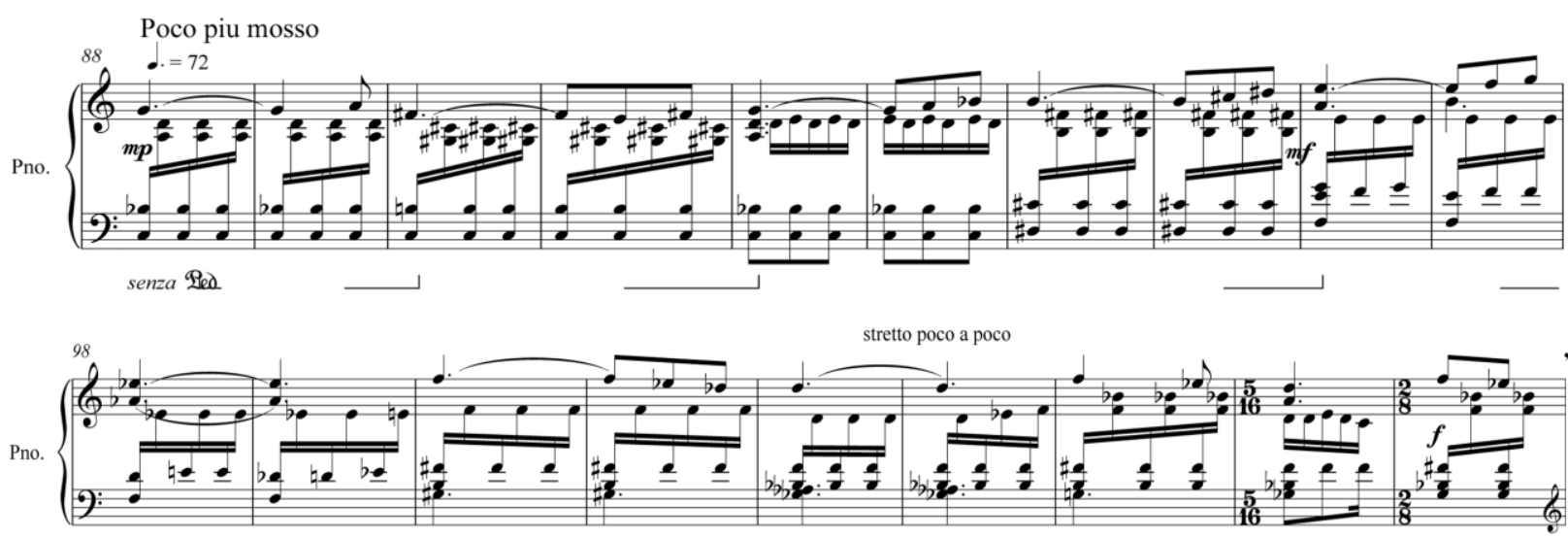

$\longrightarrow$

Example 4.5

Adeline Wong: Paces, Section III, "Piano Solo," Part B, mm. 88-106.

The next part, labeled as Part A' (mm. 107-128, Example 4.6), is a variant of Part A: most of the melodic and harmonic materials in this part are derived from Part A, but transposed to a key a whole step lower. Other than some modification in the harmony, the first phrase is very much like that of Part A. The second phrase maintains the same melodic and harmonic materials from that of Part A, though there is an additional counter-melody in the left hand. However, this phrase is incomplete as it is reduced to only six measures long.

Subsequently, the structure of the next phrase is rather subjective. It is clear that the sixmeasure phrase (mm. 121-126) is a variant of the first phrase with a counter-melody in the top voice. However, it is interrupted by a two-measure phrase, which bears the characteristic of Part B - set in a faster tempo where the notes are much separated, presumably played without pedal.

Given that this part is a variant of Part A, which means that this third phrase could possibly be an eight-measure long phrase, it could be treated as having a $6+2$ measure phrase structure.

Therefore, the only irregular phrase in this Section A' is the second phrase, which only has six measures. 

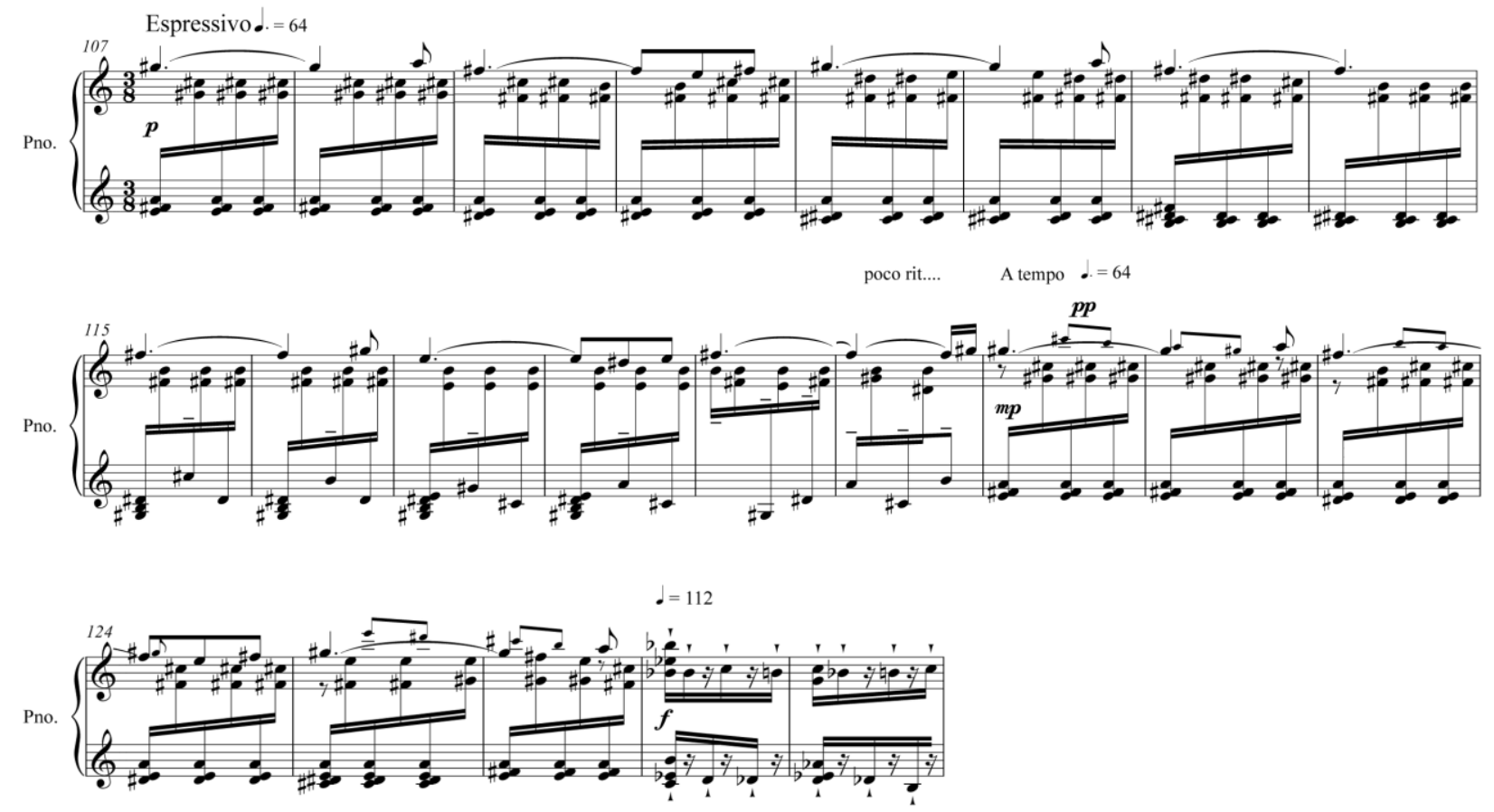

Example 4.6

Adeline Wong: Paces, Section III, “Piano Solo,” Part A', mm. 107-128.

The next measure (m. 129) recalls a simplified version of m. 121-almost like an attempt to restart the third phrase of Part $\mathrm{A}^{\prime}$ - but is immediately interrupted again by the contrasting material. This time, this material is further extended and developed into a new idea that is separate from Parts A and B-especially with the absence of the melodic material that ties the latter parts together-hence, it is characterized as Part C (mm. 129-149, Example 4.7). 

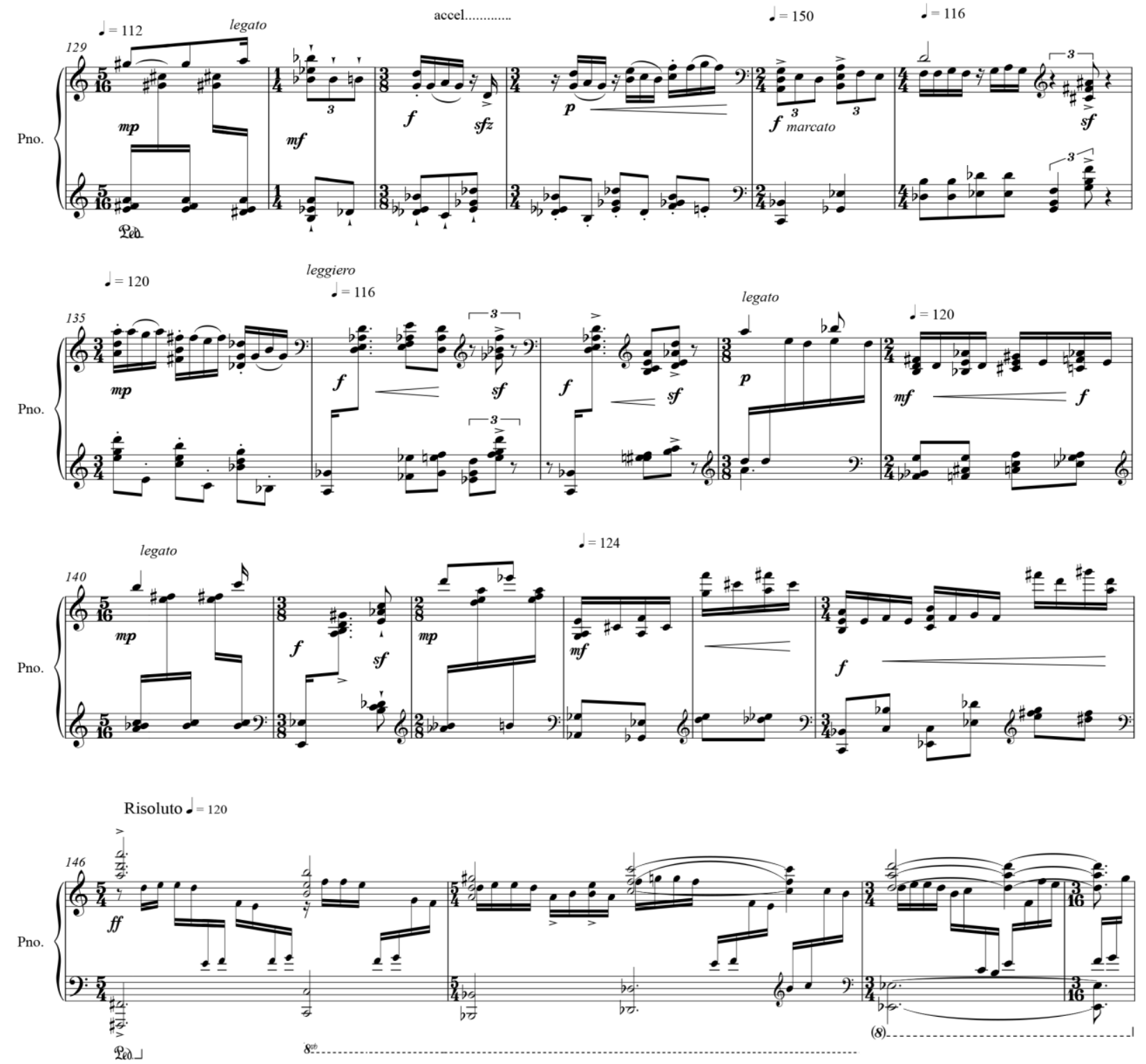

Example 4.7

Adeline Wong: Paces, Section III, “Piano Solo,” Part C, mm. 129-149.

In this part, there are several rapid changes in tempo, meter, dynamics, and articulations.

Such changes are, more often than not, abrupt instead of gradual. Occasionally, there are also insertions of fragments of Part A. Therefore, the phrase structure is highly irregular:

$[(1)+(2+3)+(2+1)]+[(1+1)+(1+1)+(1+3)]+[4]$ measures phrase structure (see Example 4.7). 
The final part in Section III is a coda (Example 4.8) that lasts for ten measures, with materials that are rather through-composed. The method used in building the climax is somewhat similar to the ending of Section I, achieved through thickening of texture by gradually introducing more pitches in the top voice (see Example 4.1). Similarly, the piano stops playing at the tenth measure mark (with optional repeat of the tenth measure) when the audio recording comes in again, this time transiting this section into the next section with the sound of car horn that gradually turns into footsteps and chattering voices, and later Western orchestral music —a change of scene from the busy streets to the concert hall.
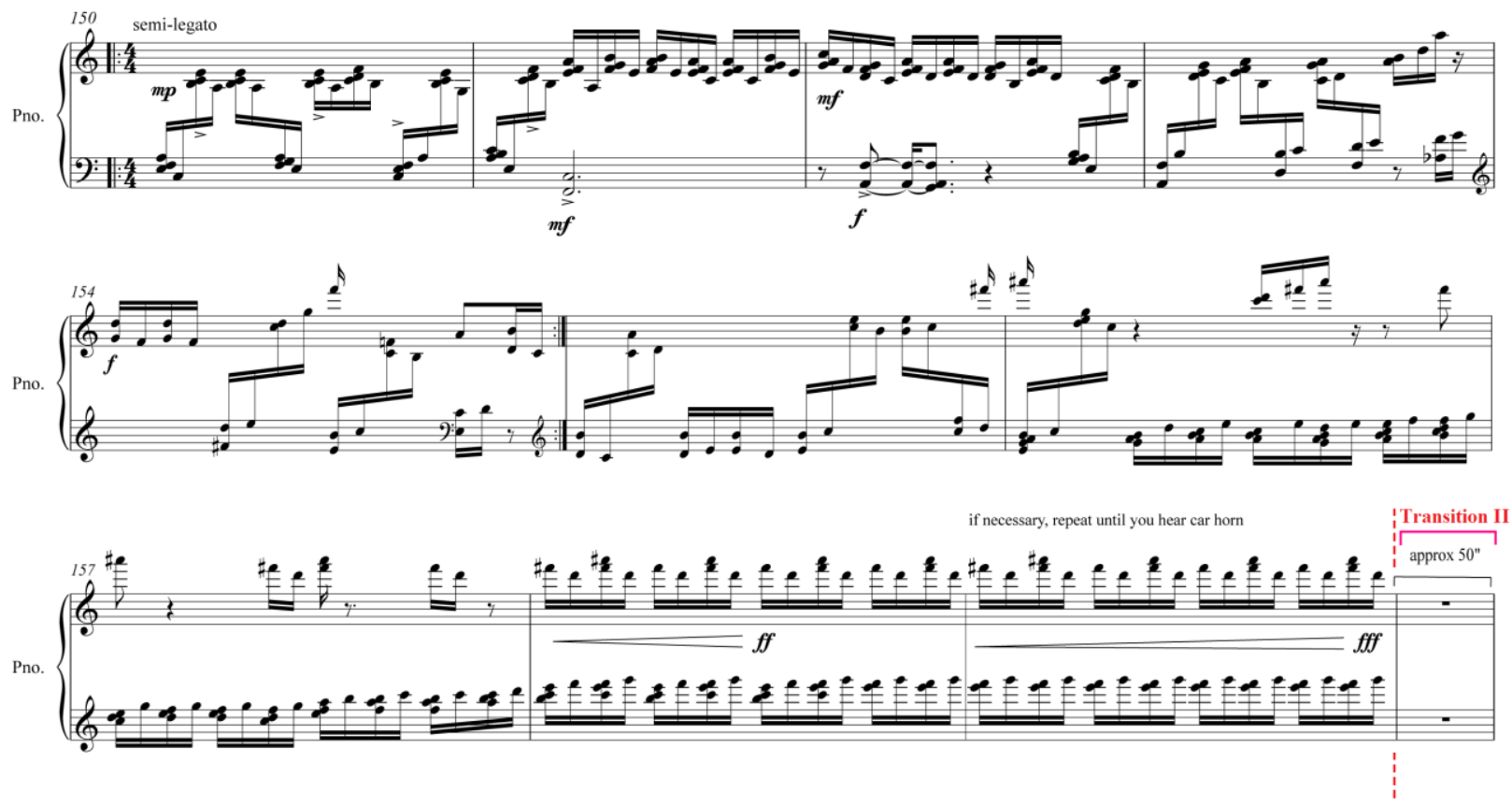

Example 4.8

Adeline Wong: Paces, Section III, “Piano Solo," Coda, mm. 150-159, and Transition II, m. 160. 


\section{Pitch Content}

In general, the pitch content of Section III is examined in pairs of measures, particularly in the Brief Introduction, Part A, Part B, and Part A', where the phrase structure is more regular, and more often than not the harmony changes every two measures. However, due to the fact that Part $\mathrm{C}$ is made of many smaller units of phrases that are often irregular in length, and the fact that the harmony changes at a quicker rate, most of the pitch materials in this part are examined chord by chord, and at times beat by beat. In contrast, the Coda is one big phrase on its own, within which the development of pitch materials shall be traced.

Since musical excerpts of each individual part of Section III have been given during the previous discussion, "Phrase Structure," no such musical examples will be provided here, with the exception of the Coda (with new annotation). The discussion of pitch content in each partone that is based on set theory—will begin with an illustration of the pitch-class collections and the pitch-class sets found in such parts. All pitch or pitch-class collections are in normal order. Unless otherwise indicated, all mention of "set" henceforth means a pitch-class set in its prime form.

These presentations are followed by further observations, where appropriate, particularly concerning the interrelationships between sets or parts, or both. These pitch-class collections and pitch-class sets are also given specific labels that demonstrate which section they are from and to which set they are related. These labels will be used extensively, and at times, interchangeably with the actual sets, in order to make the discussion of pitch content easier to comprehend. 


\section{Brief Introduction}

\begin{tabular}{|c|c|c|c|}
\hline Measure & Pitch-Class Collection & Pitch-Class Set & Label \\
\hline $60-61$ & A\#, B, C\#, D\# & {$[0,2,4,5]$} & I1 \\
\hline $62-63$ & G\#, A\#, B, C\#, D\# & {$[0,2,4,5,7]$} & I2 \\
\hline
\end{tabular}

Figure 4.6 Pitch content in Brief Introduction.

As illustrated in Figure 4.6, the Introduction of Section III solely focuses on pitch-class set $[0,2,4,5]$ (Set I1), and the expansion of the set into [0, 2, 4, 5, 7] (Set I2). Due to the fact that these two sets serve as the basis for permutation and further development throughout Section III, Set I2 is given separate label, instead of being labeled as a superset of Set I1, such as I1a. For the same reason, it seems that the function of the Introduction is more than structural; it also introduces the main ideas - in this case, the main pitch-class sets - that unite the entire section as a whole. 


\section{$\underline{\text { Part A }}$}

\begin{tabular}{|c|c|c|c|c|}
\hline & Measure & Pitch-Class Collection & Pitch-Class Set & Label \\
\hline \multirow{4}{*}{ Phrase 1} & $64-65$ & $\mathrm{D} \#, \mathrm{~F} \#, \mathrm{G} \#, \mathrm{~A} \#, \mathrm{~B}$ & {$[0,1,3,5,8]$} & A1.1 \\
\hline & $66-67$ & $\mathrm{D} \#, \mathrm{~F}, \mathrm{~F} \#, \mathrm{G} \#, \mathrm{~A} \#, \mathrm{~B}$ & {$[0,1,3,5,6,8]$} & A1.2 \\
\hline & $68-69$ & $\mathrm{D} \#, \mathrm{~F} \#, \mathrm{G} \#, \mathrm{~A} \#, \mathrm{~B}$ & {$[0,1,3,5,8]$} & A 1.1 \\
\hline & $70-71$ & $\mathrm{D} \#, \mathrm{~F}, \mathrm{~F} \#, \mathrm{G} \#, \mathrm{~A} \#, \mathrm{~B}$ & {$[0,1,3,5,6,8]$} & A 1.2 \\
\hline \multirow{4}{*}{ Phrase 2} & $72-73$ & $\mathrm{~A} b, \mathrm{~B} b, \mathrm{D} b, \mathrm{E} b, \mathrm{~F}$ & {$[0,2,4,7,9]$} & A 2.1 \\
\hline & $74-75$ & $\mathrm{~B} b, \mathrm{D} b, \mathrm{E} b, \mathrm{~F}, \mathrm{G} b$ & {$[0,1,3,5,8]$} & A 1.1 \\
\hline & $76-77$ & $\mathrm{~A} b, \mathrm{~B} b, \mathrm{D} b, \mathrm{E} b, \mathrm{~F}$ & {$[0,2,4,7,9]$} & A 2.1 \\
\hline & $78-79$ & $\mathrm{D} b, \mathrm{E} b, \mathrm{~F}, \mathrm{G}, \mathrm{A}, \mathrm{B} b$ & {$[0,1,3,5,7,9]$} & A3 \\
\hline \multirow{4}{*}{ Phrase 3} & $80-81$ & $\mathrm{~F} \#, \mathrm{G} \#, \mathrm{~A} \#, \mathrm{~B}, \mathrm{C} \#, \mathrm{D} \#$ & {$[0,2,4,5,7,9]$} & $\mathrm{A} 2.2$ \\
\hline & $82-83$ & $\mathrm{C} \#, \mathrm{D} \#, \mathrm{E} \#, \mathrm{~F} \#, \mathrm{G} \#$ & {$[0,2,3,5,7]$} & A 2.3 \\
\hline & $84-85$ & $\mathrm{~F} \#, \mathrm{G} \#, \mathrm{~A} \#, \mathrm{~B}, \mathrm{C} \#, \mathrm{D} \#$ & {$[0,2,4,5,7,9]$} & A 2.2 \\
\hline & $86-87$ & $\mathrm{C} \#, \mathrm{D} \#, \mathrm{E} \#, \mathrm{~F} \#, \mathrm{G} \#$ & {$[0,2,3,5,7]$} & A 2.3 \\
\hline
\end{tabular}

Figure 4.7 Pitch content in Part A.

Figure 4.7, as shown above, illustrates the pitch content in Part A. Each pitch-class set is given a label in order to aid in the discussion of pitch content. The labeling system adopted here shows the connection between pitch-class sets within the same part, regardless of which phrase such sets fall under. The labeling of A1, A2, and A3 group sets of the same origin together. This system only applies to the Introduction, Parts A, B, and A', as well as the Coda. It is not applied to Parts $\mathrm{C} 1, \mathrm{C} 2$, and $\mathrm{C} 3$ due to the fact that some pitch-class sets of different origin share common subsets; hence, a different labeling system is required.

There are three primary sets in Part A: 1) Set A1.1, which then expands into Set A1.2; 2) Set A2.1, which later expands into Sets A2.2 and A2.3; and 3) Set A3 (see Figure 4.7). 
The first set and its superset, Set A1.1 and A1.2, are related to Set I1 in the Introduction in that subset, $[0,1,3,5]$, maps onto $[0,2,4,5]$ when inverted and transposed at $\mathrm{T}_{5}$. It is clear that the second pair of sets, Sets A2.1 and A2.2, is also directly connected to Set I 2 in the Introduction because they share common subsets. At the same time, the second pair of sets is related to the first pair of sets by transposition as well (see Figure 4.8a). In addition, subset [2, 4, $5,7,9]$ in Set A2.2 becomes Set A2.3 when transposed at $\mathrm{T}_{10}$. When inverted and transposed at $\mathrm{T}_{9}$, Set A2.3 becomes subset $[0,2,4,5,7]$ of Set A2.2 (see Figure 4.8b).

a)

\begin{tabular}{|c|c|c|c|c|}
\hline Set & Subset & Relationship & Subset & Set \\
\cline { 1 - 4 } A2.1, A2.2 & {$[0,2,4,7]$} & Transposition & {$[1,3,5,8]$} & \multirow{2}{*}{ A1.1, A1.2 } \\
\cline { 1 - 4 } A2.2 & {$[0,4,5,7,9]$} & Transposition & {$[8,0,1,3,5]$} & \\
\hline
\end{tabular}

b)

\begin{tabular}{|c|c|c|c|c|}
\hline Set & Subset & Relationship & Pitch-Class Set & Set \\
\hline \multirow{2}{*}{ A2.2 } & {$[2,4,5,7,9]$} & Transposition & \multirow{2}{*}[0,2,3,5,7]{} & A2.3 \\
\cline { 2 - 3 } & {$[0,2,4,5,7]$} & $\begin{array}{c}\text { Inversion \& } \\
\text { Transposition }\end{array}$ & \\
\hline
\end{tabular}

Figure 4.8 Interrelationships between the three primary sets in Part A.

On the other hand, the third set, Set A3, could be seen as a combination of both Sets A1 and A2. Subset $[0,1,3,5]$ is also a subset of Sets A1.1 and A1.2, while subset $[0,1,3,7]$ is the subset of Set A1.2, [5, 6, 8, 0], transposed at $\mathrm{T}_{7}$. Meanwhile, subset $[0,5,7,9]$ is a subset of Set A2.2, which at the same time is also a transposition of subset $[8,1,3,5]$ in Sets A1.1 and A1.2. In addition, Set A3 also shares a common subset with Set A2.3 (see Figure 4.9). 


\begin{tabular}{|c|c|c|c|c|}
\hline Set & Subset & Relationship & Subset & Set \\
\hline \multirow{4}{*}{ A3 } & {$[0,1,3,5]$} & Exact Form & {$[0,1,3,5]$} & A1.1, A1.2 \\
\cline { 2 - 5 } & {$[0,1,3,7]$} & Transposition & {$[5,6,8,0]$} & A1.2 \\
\cline { 2 - 5 } & \multirow{2}{*}[0,5,7,9]{} & Exact Form & {$[0,5,7,9]$} & A2.2 \\
\cline { 2 - 5 } & & Transposition & {$[8,1,3,5]$} & A1.1, A1.2 \\
\cline { 2 - 5 } & {$[0,3,5,7]$} & Exact Form & {$[0,3,5,7]$} & A2.3 \\
\hline
\end{tabular}

Figure 4.9 Derivation of Set A3 from Sets A1 and A2.

In short, all of these pitch-class sets in Part A are related to one another. Most importantly, they are all fundamentally transformations, through subset/superset relationships, of sets $[0,2,4,5]$ (Set I1) and [0, 2, 4, 5, 7] (Set I2) from the Introduction.

Firstly, subset $[0,1,3,5]$ of Sets A1.1, A1.2, and A3, as well as subset $[4,5,7,9]$ of Set 2.2 are all inversions of Set I1 transposed at $\mathrm{T}_{5}$ and $\mathrm{T}_{9}$ respectively (see Figure 4.10a). Meanwhile, Set I2 is directly found in Set A2.2. At the same time, subset $[2,4,5,7,9]$ of Set A2.2, and pitch-class set A2.3, $[0,2,3,5,7]$, are both inversions of Set $I 2$ transposed at $\mathrm{T}_{7}$ and $\mathrm{T}_{9}$ respectively. On the other hand, Sets I2 and A2.1 also share common subset (see Figure 4.10b).

\begin{tabular}{|c|c|c|c|c|}
\hline Set & Pitch-Class Set & Relationship & Subset & Set \\
\hline \multirow{2}{*}{ I1 } & \multirow{2}{*}[0,2,4,5]{} & $\begin{array}{l}\text { Inversion \& } \\
\text { Transposition }\end{array}$ & {$[0,1,3,5]$} & $\mathrm{A} 1.1, \mathrm{~A} 1.2, \mathrm{~A} 3$ \\
\hline & & $\begin{array}{l}\text { Inversion \& } \\
\text { Transposition }\end{array}$ & {$[4,5,7,9]$} & A 2.2 \\
\hline
\end{tabular}

Figure 4.10a Derivation of Sets A1, A2, and A3 from Set I1. 


\begin{tabular}{|c|c|c|c|c|}
\hline Set & $\begin{array}{c}\text { Pitch-Class Set/ } \\
\text { Subset }\end{array}$ & Relationship & $\begin{array}{c}\text { Pitch-Class Set/ } \\
\text { Subset }\end{array}$ & Set \\
\hline \multirow{3}{*}{ I2 } & \multirow{2}{*}[0,2,4,5,7]{} & Exact Form & {$[0,2,4,5,7]$} & A2.2 \\
\cline { 3 - 5 } & & $\begin{array}{c}\text { Inversion \& } \\
\text { Transposition }\end{array}$ & {$[2,4,5,7,9]$} & A2.2 \\
\cline { 3 - 5 } & $\begin{array}{c}\text { Inversion \& } \\
\text { Transposition }\end{array}$ & {$[0,2,3,5,7]$} & A2.3 \\
\cline { 3 - 6 } & {$[0,2,4,7]$} & Exact Form & {$[0,2,4,7]$} & A2.1 \\
\hline
\end{tabular}

Figure 4.10b Derivation of Set A2 from Set I2.

\section{$\underline{\text { Part B }}$}

\begin{tabular}{|c|c|c|c|c|}
\hline & Measure & Pitch-Class Collection & Pitch-Class Set & Label \\
\hline \multirow{4}{*}{ Phrase 1} & $88-89$ & $\mathrm{G}, \mathrm{A}, \mathrm{B} b, \mathrm{C}, \mathrm{D}$ & {$[0,2,4,5,7]$} & B1.1 \\
\hline & $90-91$ & $\mathrm{~B}, \mathrm{C}, \mathrm{C} \#, \mathrm{E}, \mathrm{F} \#, \mathrm{G} \#$ & {$[0,2,4,7,8,9]$} & B1.2 \\
\hline & $92-93$ & $\mathrm{G}, \mathrm{A}, \mathrm{B} b, \mathrm{C}, \mathrm{D}, \mathrm{E}$ & {$[0,2,4,6,7,9]$} & B1.3 \\
\hline & $94-95$ & $\mathrm{~B}, \mathrm{C} \#, \mathrm{D} \#, \mathrm{~F} \#$ & {$[0,3,5,7]$} & B2.1 \\
\hline \multirow{7}{*}{ Phrase 2} & $96-97$ & $\mathrm{E}, \mathrm{F}, \mathrm{G}, \mathrm{A}, \mathrm{B}$ & {$[0,2,4,6,7]$} & B1.4 \\
\hline & 98-99 & $\mathrm{D} b, \mathrm{D}, \mathrm{E} b, \mathrm{E}, \mathrm{F}, \mathrm{A} b$ & {$[0,3,4,5,6,7]$} & B2.2 \\
\hline & $100-101$ & $\mathrm{~B}, \mathrm{D} b, \mathrm{E} b, \mathrm{~F}, \mathrm{~F} \#, \mathrm{G} \#$ & {$[0,2,3,5,7,9]$} & B2.3 \\
\hline & $102-103$ & $\mathrm{D}, \mathrm{E} b, \mathrm{~F}, \mathrm{G} b, \mathrm{~A} b, \mathrm{~B} b$ & {$[0,2,4,5,7,8]$} & B1.5 \\
\hline & 104 & $\mathrm{E} b, \mathrm{~F}, \mathrm{~F} \#, \mathrm{G}, \mathrm{B} b, \mathrm{~B}$ & {$[0,1,4,5,6,8]$} & B3.1 \\
\hline & 105 & $\mathrm{~A}, \mathrm{~B} b, \mathrm{C}, \mathrm{D}, \mathrm{E}, \mathrm{F}, \mathrm{G} b$ & {$[0,1,2,4,6,8,9]$} & B3.2 \\
\hline & 106 & $\mathrm{E} b, \mathrm{~F}, \mathrm{~F} \#, \mathrm{G}, \mathrm{B} b$ & {$[0,3,4,5,7]$} & B2.4 \\
\hline
\end{tabular}

Figure 4.11 Pitch content in Part B. 
Figure 4.11, from the previous page, shows the pitch-class sets used in Part B. Even at first glance, Part B clearly contains several pitch-class sets that are directly derived from Part A. These sets are either subsets or transpositions of those of Part A, or vice versa. Figure 4.12, as follows, illustrates the most significant relationships, as measured through largest common subset.

\begin{tabular}{|c|c|c|c|c|c|}
\hline & \multicolumn{2}{|r|}{ Part B } & \multirow{2}{*}{ Relationship } & \multicolumn{2}{|c|}{ Part A } \\
\hline & Label & Pitch-Class Set & & Pitch-Class Set & Label \\
\hline \multirow{6}{*}{ Phrase 1} & B 1.1 & {$[0,2,4,5,7]$} & Subset & {$[0,2,4,5,7,9]$} & A 2.2 \\
\hline & B1.2 & {$[0,2,4,7,8,9]$} & Subset & {$[0,2,4,7,9]$} & A2.1 \\
\hline & \multirow{2}{*}{ B 1.3} & \multirow{2}{*}[0,2,4,6,7,9]{} & Subset & {$[0,2,4,5,7,9]$} & A 2.2 \\
\hline & & & $\begin{array}{c}\text { Subset \& } \\
\text { Transposition }\end{array}$ & {$[0,1,3,5,7,9]$} & A3 \\
\hline & \multirow{2}{*}{ B2.1 } & \multirow{2}{*}[0,3,5,7]{} & Subset & {$[0,2,3,5,7]$} & A 2.3 \\
\hline & & & Subset & {$[0,1,3,5,7,9]$} & A3 \\
\hline \multirow{11}{*}{ Phrase 2} & \multirow[b]{2}{*}{ B 1.4} & \multirow{2}{*}[0,2,4,6,7]{} & Subset & {$[0,2,4,7,9]$} & A 2.1 \\
\hline & & & $\begin{array}{c}\text { Subset \& } \\
\text { Transposition }\end{array}$ & {$[0,1,3,5,7,9]$} & A3 \\
\hline & \multirow{2}{*}{$\mathrm{B} 2.2$} & \multirow{2}{*}[0,3,4,5,6,7]{} & Subset & {$[0,2,4,5,7,9]$} & A 2.2 \\
\hline & & & Subset & {$[0,1,3,5,7,9]$} & A3 \\
\hline & \multirow{2}{*}{ B2.3 } & \multirow{2}{*}[0,2,3,5,7,9]{} & $\begin{array}{c}\text { Subset \& } \\
\text { Transposition }\end{array}$ & {$[0,2,4,5,7,9]$} & A 2.2 \\
\hline & & & Subset & {$[0,2,3,5,7]$} & A 2.3 \\
\hline & B 1.5 & {$[0,2,4,5,7,8]$} & Subset & {$[0,2,4,5,7,9]$} & A 2.2 \\
\hline & \multirow[b]{2}{*}{ B3.1 } & \multirow[b]{2}{*}[0,1,4,5,6,8]{} & Subset & {$[0,1,3,5,6,8]$} & A 1.2 \\
\hline & & & $\begin{array}{c}\text { Subset \& } \\
\text { Transposition }\end{array}$ & {$[0,1,3,5,7,9]$} & A3 \\
\hline & B3.2 & {$[0,1,2,4,6,8,9]$} & $\begin{array}{c}\text { Subset \& } \\
\text { Transposition }\end{array}$ & {$[0,1,3,5,7,9]$} & A3 \\
\hline & B2.4 & {$[0,3,4,5,7]$} & Subset & {$[0,1,3,5,7,9]$} & A3 \\
\hline
\end{tabular}

Figure 4.12 Interrelationships between pitch content of sets in Parts A and B. 
In addition, there are three core components that construct the pitch content in Part B. The first component is pitch-class set $[0,2,4,7]-$ which is a subset of Set $\mathrm{I} 2,[0,2,4,5,7]$, from the Introduction - and the second is $[0,3,5,7]$, which is the inversion of $[0,2,4,7]$ at $\mathrm{T}_{7}$. This first set expands into several forms: in Phrase 1, these are Sets B1.1 (which is also Set I2), B1.2, and B1.3; and in Phrase 2, these are Sets B1.4 and B1.5. Note in Set B1.3 that subset [2, 4, 6, 7, 9] is a transposition of $[0,2,4,5,7]$ at $\mathrm{T}_{2}$.

The second source for Part B, set [0, 3, 5, 7], is set forth directly in mm. 94-95 of Phrase 1. Labeled as Set B2, this set is then expanded to become Sets B2.2, B2.3, and B2.4. Of particular note are the additional significant relationships that Set B2.3, [0, 2, 3, 5, 7, 9], has with sets $[0,2,4,7]$ and $[0,3,5,7]$ : subset $[2,5,7,9]$ is a transposition of $[0,3,5,7]$ at $\mathrm{T}_{2}$; subset $[0$, $5,7,9]$ is also the transposition and re-ordering of $[0,2,4,7]$ at $\mathrm{T}_{2}$; and subset $[0,2,3,5,7]$ becomes Set B1.1, $[0,2,4,5,7]$ - or, Set $\mathrm{I} 2$ - when inverted and transposed at $\mathrm{T}_{7}$, as was the case with Set A2.3 (see Figure 4.8b).

The remaining two sets, Sets B3.1 and B3.2, are interrelated in that both sets contain subset $[0,1,4,6,8]$. On a deeper level, the former is also a subset of the latter when transposed at level 8 and re-ordered (i.e., $\left.\mathrm{T}_{8}[0,1,4,5,6,8]=[8,9,0,1,2,4]\right)$. These two sets also have significant relationships with sets $[0,2,4,7]$ and $[0,3,5,7]$ : subset $[1,4,6,8]$ is a transposition of $[0,3,5,7]$ at $\mathrm{T}_{1}$, which also means that it is related to $[0,2,4,7]$ by inversion and transposition at $\mathrm{T}_{8}$. Based on this connection, Sets B3.1 and B3.2 are intimately connected to the other sets in Part B. For instance, subset [1, 4, 5, 6, 8] becomes Set B2.4, [0, 3, 4, 5, 7], when transposed at level 11; and subset $[0,2,4,6,9]$ becomes subset $[0,3,5,7,9]$ of Set B2.3 under T9I. 
To summarize, the pitch-class sets from the Introduction, [0, 2, 4, 5] (Set I1) and [0, 2, 4, 5, 7] (Set I2), are present throughout Part B, just as they are in Part A, although Part B focuses more on the permutation of subset $[0,2,4,7]$, where such permutation also forms a circle of transformation (see Figure 4.13).

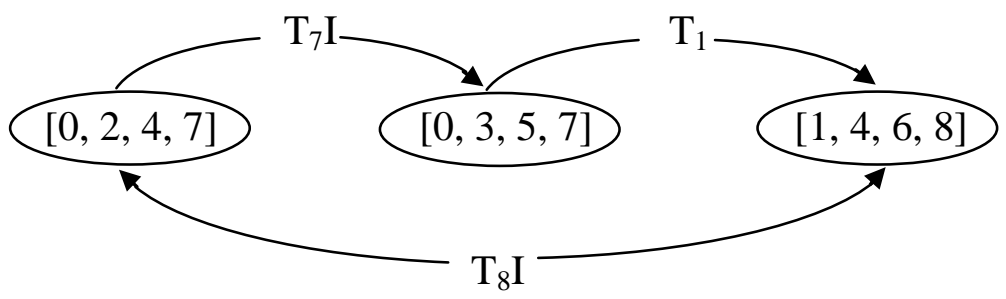

Figure 4.13 Circle of tetrachordal transformations in Part B.

\section{$\underline{\text { Part } \mathrm{A}^{\prime}}$}

\begin{tabular}{|c|c|c|c|c|}
\hline & Measure & Pitch-Class Collection & Pitch-Class Set & Label \\
\hline \multirow{4}{*}{ Phrase 1} & $107-108$ & $\mathrm{C} \#, \mathrm{E}, \mathrm{F} \#, \mathrm{G} \#, \mathrm{~A}$ & {$[0,1,3,5,8]$} & $\mathrm{A}^{\prime} 1.1$ \\
\hline & $109-110$ & $\mathrm{~A}, \mathrm{~B}, \mathrm{C} \#, \mathrm{D} \#, \mathrm{E}, \mathrm{F} \#$ & {$[0,2,3,5,7,9]$} & $\mathrm{A}^{\prime} 2.1$ \\
\hline & $111-112$ & $\mathrm{C} \#, \mathrm{D} \#, \mathrm{E}, \mathrm{F} \#, \mathrm{G} \#, \mathrm{~A}$ & {$[0,1,3,5,6,8]$} & $\mathrm{A}^{\prime} 1.2$ \\
\hline & $113-114$ & $\mathrm{~B}, \mathrm{C} \#, \mathrm{D} \#, \mathrm{~F} \#$ & {$[0,3,5,7]$} & $\mathrm{A}^{\prime} 2.2$ \\
\hline \multirow{3}{*}{ Phrase 2} & $115-116$ & $\mathrm{~B}, \mathrm{C} \#, \mathrm{D} \#, \mathrm{~F} \#, \mathrm{G} \#$ & {$[0,2,5,7,9]$} & $\mathrm{A}^{\prime} 2.3$ \\
\hline & $117-118$ & $\mathrm{G} \#, \mathrm{~A}, \mathrm{~B}, \mathrm{C} \#, \mathrm{D} \#, \mathrm{E}$ & {$[0,1,3,5,7,8]$} & $\mathrm{A}^{\prime} 1.3$ \\
\hline & $119-120$ & $\mathrm{C} \#, \mathrm{D} \#, \mathrm{E}, \mathrm{F} \#, \mathrm{G} \#, \mathrm{~A}, \mathrm{~B}$ & {$[0,2,3,5,7,8,10]$} & $\mathrm{A}^{\prime} 2.4$ \\
\hline \multirow{4}{*}{ Phrase 3} & $121-122$ & $\mathrm{E}, \mathrm{F} \#, \mathrm{G} \#, \mathrm{~A}, \mathrm{~B}, \mathrm{C} \#$ & {$[0,2,4,5,7,9]$} & $\mathrm{A}^{\prime} 2.5$ \\
\hline & $123-124$ & $\mathrm{G} \#, \mathrm{~A}, \mathrm{~B}, \mathrm{C} \#, \mathrm{D} \#, \mathrm{E}, \mathrm{F} \#$ & {$[0,2,3,5,7,9,10]$} & $A^{\prime} 2.6$ \\
\hline & $125-126$ & $\mathrm{G} \#, \mathrm{~A}, \mathrm{~B}, \mathrm{C} \#, \mathrm{D} \#, \mathrm{E}, \mathrm{F} \#$ & {$[0,2,3,5,7,9,10]$} & $A^{\prime} 2.6$ \\
\hline & $127-128$ & $\mathrm{G}, \mathrm{A} b, \mathrm{~B} b, \mathrm{~B}, \mathrm{C}, \mathrm{D} b, \mathrm{D}, \mathrm{E} b$ & {$[0,1,2,3,4,5,7,8]$} & $\mathrm{A}^{\prime} 1.4$ \\
\hline
\end{tabular}

Figure 4.14 Pitch content in Part A'. 
Figure 4.14, shown in the previous page, illustrates the set content of Part A'. Just as much of the pitch materials in Part B are related to Part A, the pitch content in Part $\mathrm{A}^{\prime}$ is also connected to Part A, as it is a variation of the latter (see Figure 4.15). However, some of the pitch materials are also directly derived from Part B. Therefore, the pitch content of Part $\mathrm{A}^{\prime}$ is rather a combination of that of Parts A and B.

Again, Figure 4.15 lists only those connections that best demonstrate the relationships between the pitch materials in the above-mentioned parts. The focus of this comparison is to determine how much of Part $\mathrm{A}^{\prime}$ is similar to that of Parts A and B.

We see that the pitch content in Part $\mathrm{A}^{\prime}$ is borrowed alternatively, and roughly equally, from Parts A and B. The relationships between the pitch materials of these parts are rather straightforward: all of the pitch-class sets in Part A' are either the exact forms or subsets of some sets in Parts A and B. As such, they are necessarily also connected to the sets in the Introduction. In addition to obvious repetition of previous sets, in mm. 119-120, subset $[0,3,5,7,8$, 10] maps onto $[0,2,4,5,7,9]$ in Part A (mm. 80-81 and 84-85) when transposed at $\mathrm{T}_{3}$. As for the final set, $[0,1,2,3,4,5,7,8]$, as one would predict with a large set, there are various ways to connect its subsets with other sets in Parts A and B, as demonstrated in Figure 4.15. In a nutshell, it is clear that the pitch materials in Part A' exemplify a strong connection to that of the Introduction. 


\begin{tabular}{|c|c|c|c|c|c|}
\hline & \multicolumn{2}{|r|}{ Part $A^{\prime}$} & \multirow{2}{*}{ Relationship } & \multicolumn{2}{|c|}{ Previous Parts } \\
\hline & Label & Pitch-Class Set & & Pitch-Class Set & Label \\
\hline \multirow{4}{*}{$\begin{array}{c}\text { Phrase } \\
1\end{array}$} & $\mathrm{~A}^{\prime} 1.1$ & {$[0,1,3,5,8]$} & Exact Form & {$[0,1,3,5,8]$} & A1.1 \\
\hline & $\mathrm{A}^{\prime} 2.1$ & {$[0,2,3,5,7,9]$} & Exact Form & {$[0,2,3,5,7,9]$} & $\mathrm{B} 2.3$ \\
\hline & $\mathrm{A}^{\prime} 1.2$ & {$[0,1,3,5,6,8]$} & Exact Form & {$[0,1,3,5,6,8]$} & A 1.2 \\
\hline & $\mathrm{A}^{\prime} 2.2$ & {$[0,3,5,7]$} & Exact Form & {$[0,3,5,7]$} & B2.1 \\
\hline \multirow{3}{*}{$\begin{array}{c}\text { Phrase } \\
2\end{array}$} & $\mathrm{~A}^{\prime} 2.3$ & {$[0,2,5,7,9]$} & Subset & {$[0,2,3,5,7,9]$} & B2.3 \\
\hline & $\mathrm{A}^{\prime} 1.3$ & {$[0,1,3,5,7,8]$} & Subset & {$[0,1,3,5,8]$} & A 1.1 \\
\hline & $\mathrm{A}^{\prime} 2.4$ & {$[0,2,3,5,7,8,10]$} & $\begin{array}{c}\text { Subset \& } \\
\text { Transposition }\end{array}$ & {$[0,2,4,5,7,9]$} & $\mathrm{A} 2.2$ \\
\hline \multirow{13}{*}{$\begin{array}{c}\text { Phrase } \\
3\end{array}$} & $\mathrm{~A}^{\prime} 2.5$ & {$[0,2,4,5,7,9]$} & Exact Form & {$[0,2,4,5,7,9]$} & A 2.2 \\
\hline & $\mathrm{A}^{\prime} 2.6$ & {$[0,2,3,5,7,9,10]$} & Subset & {$[0,2,3,5,7,9]$} & B2.3 \\
\hline & $\mathrm{A}^{\prime} 2.6$ & {$[0,2,3,5,7,9,10]$} & Subset & {$[0,2,3,5,7,9]$} & $\mathrm{B} 2.3$ \\
\hline & \multirow{10}{*}{$\mathrm{A}^{\prime} 1.4$} & \multirow{10}{*}[0,1,2,3,4,5,7,8]{} & Subset & {$[0,1,3,5,8]$} & A1.1 \\
\hline & & & Subset & {$[0,2,4,5,7,9]$} & A 2.2 \\
\hline & & & Subset & {$[0,2,3,5,7]$} & $\mathrm{A} 2.3$ \\
\hline & & & Subset & {$[0,1,3,5,7,9]$} & A3 \\
\hline & & & Subset & {$[0,2,4,5,7]$} & B1.1 \\
\hline & & & Subset & {$[0,2,4,7,8,9]$} & B1.2 \\
\hline & & & Subset & {$[0,3,4,5,6,7]$} & $\mathrm{B} 2.2$ \\
\hline & & & Subset & {$[0,2,3,5,7,9]$} & $\mathrm{B} 2.3$ \\
\hline & & & Subset & {$[0,1,4,5,6,8]$} & B3.1 \\
\hline & & & Subset & {$[0,1,2,4,6,8,9]$} & B3.2 \\
\hline
\end{tabular}

Figure 4.15 Interrelationships between sets in Part $\mathrm{A}^{\prime}$ and in previous parts. 


\section{$\underline{\text { Part C }}$}

As mentioned earlier, most of the pitch materials in Part $\mathrm{C}$ are examined chord by chord or beat by beat due to the complexity in meter and the rapid change in harmony. Because of the irregular phrase structure, each phrase will be discussed separately. As such, Figure 4.16 only presents the pitch content of the first phrase in Part C.

Again, the labeling system of the pitch-class sets in Part $\mathrm{C}$ is different from that used in the Introduction, Parts A, B, and A', as well as the Coda. This system does not reflect the origin of each pitch-class set, because the two main sets from which all other sets are generated are so closely related that they bound to generate common sets. This can be seen, for example, with sets such as C1.k, C1.n, and C1.p.

The first phrase, marked as Part C1 (mm. 129-137), consists of a [(1)+(2+3)+(2+1)] measure phrase structure, within which most of the measures - all but the first two measurescomprise more than one chord (see Figure 4.16). Unlike any of the previous parts, only two pitch-class sets are repeated here in Part $\mathrm{C} 1$, each of which is only repeated once. 


\begin{tabular}{|c|c|c|c|c|c|}
\hline & Measure & Beat & Pitch-Class Collection & Pitch-Class Set & Label \\
\hline \multirow{22}{*}{$\begin{array}{c}\text { Part C } \\
\text { Phrase } 1 \\
\text { (Part C1) }\end{array}$} & 129 & & $\mathrm{C} \#, \mathrm{D} \#, \mathrm{E}, \mathrm{F} \#, \mathrm{G} \#, \mathrm{~A}$ & {$[0,1,3,5,6,8]$} & C1.a \\
\hline & 130 & & $\mathrm{~A}, \mathrm{~B} b, \mathrm{~B}, \mathrm{D} b, \mathrm{E} b$ & {$[0,2,4,5,6]$} & C1.b \\
\hline & \multirow{2}{*}{131} & $1 \& 2$ & $\mathrm{G}, \mathrm{A}, \mathrm{B} b, \mathrm{C}, \mathrm{D} b, \mathrm{D}, \mathrm{E} b$ & {$[0,1,2,3,5,6,8]$} & C1.c \\
\hline & & 3 & $\mathrm{D} b, \mathrm{D}, \mathrm{E} b, \mathrm{G} b$ & {$[0,3,4,5]$} & C1.d \\
\hline & \multirow{3}{*}{132} & 1 & $\mathrm{G}, \mathrm{A}, \mathrm{B} b, \mathrm{~B}, \mathrm{D} b, \mathrm{D}, \mathrm{E} b$ & {$[0,1,2,4,5,6,8]$} & C1.e \\
\hline & & 2 & $\mathrm{~B}, \mathrm{C}, \mathrm{D} b, \mathrm{E} b, \mathrm{E}, \mathrm{G} b$ & {$[0,2,3,5,6,7]$} & C1.f \\
\hline & & 3 & $\mathrm{E}, \mathrm{F}, \mathrm{G} b, \mathrm{G}, \mathrm{B} b, \mathrm{C}$ & {$[0,2,5,6,7,8]$} & C1.g \\
\hline & \multirow{2}{*}{133} & 1 & $\mathrm{G}, \mathrm{A}, \mathrm{B} b, \mathrm{C}, \mathrm{D}, \mathrm{E}$ & {$[0,2,4,6,7,9]$} & C1.h \\
\hline & & 2 & $\mathrm{E} b, \mathrm{E}, \mathrm{F}, \mathrm{G} b, \mathrm{~A}, \mathrm{~B}$ & {$[0,2,5,6,7,8]$} & C1.g \\
\hline & \multirow{3}{*}{134} & 1 & $\mathrm{~B}, \mathrm{D} b, \mathrm{D}, \mathrm{F}, \mathrm{G}$ & {$[0,2,5,6,8]$} & C1.i \\
\hline & & 2 & $\mathrm{D} b, \mathrm{D}, \mathrm{E} b, \mathrm{G}, \mathrm{A}$ & {$[0,2,6,7,8]$} & C1.j \\
\hline & & 3 & $\mathrm{~F}, \mathrm{~F} \#, \mathrm{G}, \mathrm{A} \#, \mathrm{~B}, \mathrm{C} \#$ & {$[0,2,3,6,7,8]$} & C1.k \\
\hline & \multirow{3}{*}{135} & 1 & $\mathrm{~F}, \mathrm{G}, \mathrm{A}, \mathrm{B}, \mathrm{D}$ & {$[0,3,5,7,9]$} & C1.1 \\
\hline & & 2 & $\mathrm{~B}, \mathrm{D}, \mathrm{E}, \mathrm{F} \#, \mathrm{G}$ & {$[0,1,3,5,8]$} & $\mathrm{C} 1 . \mathrm{m}$ \\
\hline & & 3 & $\mathrm{~F}, \mathrm{G}, \mathrm{B}, \mathrm{D} b$ & {$[0,2,6,8]$} & C1.n \\
\hline & \multirow{4}{*}{136} & 1 & $\mathrm{~A} b, \mathrm{~B} b, \mathrm{C}, \mathrm{D}, \mathrm{E}$ & {$[0,2,4,6,8]$} & C1.o \\
\hline & & $\begin{array}{l}2 \text {, first } \\
8^{\text {th }} \text { beat }\end{array}$ & $\mathrm{E}, \mathrm{F}, \mathrm{G} b, \mathrm{~A} b$ & {$[0,2,3,4]$} & C1.p \\
\hline & & $\begin{array}{c}2, \text { second } \\
8^{\text {th }} \text { beat }\end{array}$ & $\mathrm{G}, \mathrm{A} b, \mathrm{~A}, \mathrm{~B} b, \mathrm{D}$ & {$[0,4,5,6,7]$} & C1.q \\
\hline & & 3 & $\mathrm{~F}, \mathrm{G} b, \mathrm{G}, \mathrm{A}, \mathrm{B} b, \mathrm{~B}$ & {$[0,1,2,4,5,6]$} & C1.r \\
\hline & \multirow{3}{*}{137} & $\begin{array}{c}1 \& 2 \text {, first } \\
8^{\text {th }} \text { beat }\end{array}$ & $\mathrm{A} b, \mathrm{~B} b, \mathrm{C}, \mathrm{D}, \mathrm{E}$ & {$[0,2,4,6,8]$} & C1.o \\
\hline & & $\begin{array}{c}2, \text { second } \\
8^{\text {th }} \text { beat }\end{array}$ & $\mathrm{E}, \mathrm{G}, \mathrm{G} \#, \mathrm{~A}, \mathrm{~B}, \mathrm{C}$ & {$[0,1,3,4,5,8]$} & C1.s \\
\hline & & 3 & $\mathrm{~A} b, \mathrm{~B}, \mathrm{C}, \mathrm{D}, \mathrm{E}$ & {$[0,2,4,5,8]$} & C1.t \\
\hline
\end{tabular}

Figure 4.16 Pitch content in Part C, Phrase 1 (Part C1). 
Many of the pitch-class sets in this phrase are essentially subsets of the closely related sets $[0,1,2,3,5,6,8]$ (Set C1.c) and $[0,1,2,4,5,6,8]$ (Set C1.e), as exemplified in Figures 4.17 and 4.18 respectively. Some of the pitch-class sets are subsets of Sets C1.c and C1.e, while others are subsets of Sets C1.c and C1.e that undergo such transformations as transposition, inversion, or both. Figure 4.17c in particular illustrates a more complex interrelationship between Sets C1.c, C1.h, and C1.1. It shows that Set C1.c shares a common subset with Set C1.h, which contains a subset that forms Set C1.1 after being inverted and transposed at $\mathrm{T}_{9}$. On the other hand, Sets C1.1 and C1.c also share a common subset.

\begin{tabular}{|c|c|c|c|c|}
\hline \multicolumn{5}{|c|}{ Direct Relationships with Set C1.c } \\
\hline Label & Pitch-Class Set & Relationship & Pitch-Class Set & Label \\
\hline \multirow{3}{*}{ C1.c } & & & {$[0,1,3,5,6,8]$} & C1.a \\
\cline { 4 - 5 } & & \multirow{2}{*}{ Exact Form $1,2,3,5,6,8]$} & {$[0,1,3,5,8]$} & C1.m \\
\cline { 4 - 5 } & & & {$[0,2,6,8]$} & C1.n \\
\hline
\end{tabular}

Figure 4.17a Sets with direct relationships with Set C1.c.

\begin{tabular}{|c|c|c|c|c|}
\hline \multicolumn{5}{|c|}{ Transformative Relationships with Set C1.c } \\
\hline Label & Subset & Relationship & Pitch-Class Set & Label \\
\hline \multirow{4}{*}{ C1.c } & {$[1,2,3,5,6,8]$} & $\mathrm{T}_{8} \mathrm{I}$ & {$[0,2,3,5,6,7]$} & C1.f \\
\cline { 2 - 5 } & {$[0,1,2,3,6,8]$} & $\mathrm{T}_{8} \mathrm{I}$ & {$[0,2,5,6,7,8]$} & C1.g \\
\cline { 2 - 5 } & {$[0,1,2,6,8]$} & $\mathrm{T}_{8} \mathrm{I}$ & {$[0,2,6,7,8]$} & C1.j \\
\cline { 2 - 5 } & {$[0,1,2,5,6,8]$} & $\mathrm{T}_{8} \mathrm{I}$ & {$[0,2,3,6,7,8]$} & C1.k \\
\cline { 2 - 5 } & {$[1,2,3,5]$} & $\mathrm{T}_{5} \mathrm{I}$ & {$[0,2,3,4]$} & C1.p \\
\cline { 2 - 5 } & {$[8,0,1,2,3]$} & $\mathrm{T}_{4}$ & {$[0,4,5,6,7]$} & C1.q \\
\hline
\end{tabular}

Figure 4.17b Sets with transformative relationships with Set C1.c. 


\begin{tabular}{|c|c|c|}
\hline$\frac{\text { Pitch-Class Set }}{\text { C1.c }}$ & $\frac{\text { Pitch-Class Set }}{\text { C1.h }}$ \\
{$[0,1,2,3,5,6,8]$} & {$[0,2,4,6,7,9]$} \\
\hline
\end{tabular}$\quad \begin{gathered}\frac{\text { Pitch-Class Set }}{\text { C1.1 }} \\
{[0,3,5,7,9]}\end{gathered}$

$\underline{\text { Subset }}$

$[3,5,6,8,0]$

\section{$\underline{\text { Subset }}$}

$$
\begin{aligned}
& {[0,4,6,7,9]} \\
& {[0,2,4,6,9] \longrightarrow \mathrm{T}_{9} \mathrm{I} \longrightarrow \frac{\text { Pitch-Class Set }}{[0,3,5,7,9]}}
\end{aligned}
$$

$\underline{\text { Subset }}$

$[1,3,5,8]$

$\underline{\text { Subset }}$

$[0,3,5,7]$

Figure 4.17 c Other transformative relationships with Set C1.c.

\begin{tabular}{|c|c|c|c|c|}
\hline \multicolumn{5}{|c|}{ Direct Relationships with Set C1.e } \\
\hline Label & Pitch-Class Set & Relationship & Pitch-Class Set & Label \\
\hline \multirow{3}{*}{ C1.e } & \multirow{3}{*}{} & & {$[0,2,4,5,6]$} & C1.b \\
\cline { 4 - 5 } & \multirow{3}{*}{} & \multirow{3}{*}{ Exact Form } & {$[0,2,5,6,8]$} & C1.i \\
\cline { 4 - 5 } & & & {$[0,2,6,8]$} & C1.n \\
\cline { 4 - 5 } & & & {$[0,2,4,6,8]$} & C1.o \\
\cline { 4 - 5 } & & & {$[0,1,2,4,5,6]$} & C1.r \\
\hline
\end{tabular}

Figure 4.18a Sets with direct relationships with Set C1.e.

\begin{tabular}{|c|c|c|c|c|}
\hline \multicolumn{5}{|c|}{ Transformative Relationships with Set C1.e } \\
\hline Label & Subset & Relationship & Pitch-Class Set & Label \\
\hline \multirow{3}{*}{ C1.e } & {$[0,1,2,5,6,8]$} & $\mathrm{T}_{8} \mathrm{I}$ & {$[0,2,3,6,7,8]$} & C1.k \\
\cline { 2 - 5 } & {$[0,1,2,4]$} & $\mathrm{T}_{4} \mathrm{I}$ & {$[0,2,3,4]$} & C1.p \\
\cline { 2 - 5 } & {$[1,4,5,6]$} & $\mathrm{T}_{11}$ & {$[0,3,4,5]$} & C1.d \\
\hline
\end{tabular}

Figure 4.18b Sets with transformative relationships with Set C1.c. 
A close examination of Figures 4.17 and 4.18 also shows that both Sets C1.c and C1.e share some common sets, such as Sets C1.n, C1.k, and C1.p (in red). This is not unusual, especially because these two sets only differ by one integer. In another instance, as illustrated in Figure 4.19, the combination of Sets C1.c and C1.e forms a new pitch-class set, Set C1.s. Its subset, [0, 3, 4, 5] (Set C1.d), is also found in Set C1.e (in red). Evidently, all of the pitch-class sets in Part C1 are interrelated in one way or another.

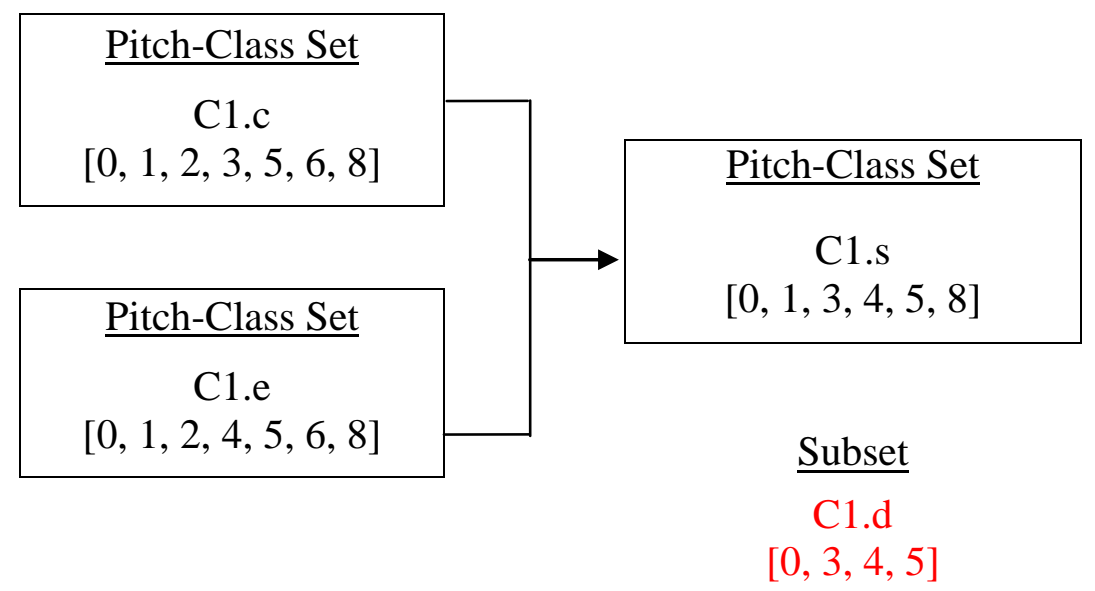

Figure 4.19 Sets formed through the combination of Sets C1.c and C1.e.

Also noteworthy is the fact that set $[0,1,2,4,5,6,8]$ (Set C1.e) could be seen as a combination of sets $[0,1,4,5,6,8]$ (Set B3.1) and [0, 1, 2, 4, 6, 8, 9] (Set B3.2) from Part B. All of these sets share subset $[0,1,4,6,8]$, which is a transformation of subset $[0,2,4,7]$ from Set I2 in the Introduction, as illustrated earlier in Figure 4.13. Once again, this comes to show the importance of Set I2 throughout Section III.

Having established the relationship between sets within Part C1, the pitch-class sets can then be compared with those of the Introduction, as well as Parts A, B, and A', to further determine the relationship between sets in a larger context - that is, the relationship between 
parts (see Figure 4.20). As before, Figure 4.20 displays only the connection that best describes the relationships between the pitch materials in the above-mentioned parts.

For the most part, Part C1 shows a balance of derivation of pitch materials from Parts A and $\mathrm{B}$, with a few connections to Part $\mathrm{A}^{\prime}$ and the Introduction. While most of the connections are rather direct, some are more complicated, as the sets are permutated and disguised under transpositions and inversions. 


\begin{tabular}{|c|c|c|c|c|c|}
\hline \multicolumn{3}{|c|}{ Part C Phrase 1 (Part C1) } & \multirow{2}{*}{ Relationship } & \multicolumn{2}{|c|}{ Previous Parts } \\
\hline Measure & Label & Pitch-Class Set & & Pitch-Class Set & Label \\
\hline 129 & C1.a & {$[0,1,3,5,6,8]$} & Exact Form & {$[0,1,3,5,6,8]$} & A 1.2 \\
\hline \multirow{2}{*}{130} & \multirow{2}{*}{ C1.b } & \multirow{2}{*}[0,2,4,5,6]{} & Subset & {$[0,2,4,5]$} & $\mathrm{I} 1$ \\
\hline & & & Subset & {$[0,1,4,5,6,8]$} & B3.1 \\
\hline \multirow{2}{*}{131} & C1.c & {$[0,1,2,3,5,6,8]$} & Subset & {$[0,1,3,5,6,8]$} & A 1.2 \\
\hline & C1.d & {$[0,3,4,5]$} & Subset & {$[0,3,4,5,7]$} & B2.4 \\
\hline \multirow{5}{*}{132} & \multirow{3}{*}{ C1.e } & \multirow{3}{*}[0,1,2,4,5,6,8]{} & Subset & {$[0,1,4,5,6,8]$} & B3.1 \\
\hline & & & Subset & {$[0,1,2,4,6,8,9]$} & B3.2 \\
\hline & & & Subset & {$[0,1,2,3,4,5,7,8]$} & $\mathrm{A}^{\prime} 1.4$ \\
\hline & C1.f & {$[0,2,3,5,6,7]$} & $\begin{array}{c}\text { Subset \& } \\
\text { Transposition }\end{array}$ & {$[0,1,2,3,4,5,7,8]$} & $\mathrm{A}^{\prime} 1.4$ \\
\hline & C1.g & {$[0,2,5,6,7,8]$} & Subset & {$[0,2,4,5,7,8]$} & B1.5 \\
\hline \multirow{2}{*}{133} & C1.h & {$[0,2,4,6,7,9]$} & Exact Form & {$[0,2,4,6,7,9]$} & B1.3 \\
\hline & C1.g & {$[0,2,5,6,7,8]$} & Subset & {$[0,2,4,5,7,8]$} & B1.5 \\
\hline \multirow{3}{*}{134} & C1.i & {$[0,2,5,6,8]$} & $\begin{array}{c}\text { Subset \& } \\
\text { Transposition }\end{array}$ & {$[0,1,3,5,7,9]$} & A3 \\
\hline & $\mathrm{C} 1 . \mathrm{j}$ & {$[0,2,6,7,8]$} & $\begin{array}{l}\text { Subset, Inversion } \\
\& \text { Transposition }\end{array}$ & {$[0,1,2,4,6,8,9]$} & B3.2 \\
\hline & C1.k & {$[0,2,3,6,7,8]$} & $\begin{array}{l}\text { Subset, Inversion } \\
\& \text { Transposition }\end{array}$ & {$[0,1,3,5,7,9]$} & A3 \\
\hline \multirow{4}{*}{135} & \multirow{2}{*}{ C1.1 } & \multirow{2}{*}[0,3,5,7,9]{} & Subset & {$[0,1,3,5,7,9]$} & $\mathrm{A} 3$ \\
\hline & & & Subset & {$[0,2,3,5,7,9]$} & $\mathrm{B} 2.3$ \\
\hline & C1.m & {$[0,1,3,5,8]$} & Exact Form & {$[0,1,3,5,8]$} & A1.1 \\
\hline & C1.n & {$[0,2,6,8]$} & Subset & {$[0,1,2,4,6,8,9]$} & B3.2 \\
\hline \multirow{5}{*}{136} & C1.o & {$[0,2,4,6,8]$} & Subset & {$[0,1,2,4,6,8,9]$} & B3.2 \\
\hline & C1.p & {$[0,2,3,4]$} & Subset & {$[0,1,2,3,4,5,7,8]$} & $\mathrm{A}^{\prime} 1.4$ \\
\hline & $\mathrm{C} 1 . \mathrm{q}$ & {$[0,4,5,6,7]$} & Subset & {$[0,3,4,5,6,7]$} & $\mathrm{B} 2.2$ \\
\hline & \multirow{2}{*}{ C1.r } & \multirow{2}{*}[0,1,2,4,5,6]{} & Subset & {$[0,1,4,5,6,8]$} & B3.1 \\
\hline & & & Subset & {$[0,1,2,4,6,8,9]$} & B3.2 \\
\hline \multirow{4}{*}{137} & C1.o & {$[0,2,4,6,8]$} & Subset & {$[0,1,2,4,6,8,9]$} & B3.2 \\
\hline & $\mathrm{C} 1 . \mathrm{s}$ & {$[0,1,3,4,5,8]$} & Subset & {$[0,1,3,5,8]$} & A1.1 \\
\hline & \multirow[b]{2}{*}{ C1.t } & \multirow[b]{2}{*}[0,2,4,5,8]{} & Subset & {$[0,2,4,5]$} & I1 \\
\hline & & & $\begin{array}{l}\text { Subset, Inversion } \\
\text { \& Transposition }\end{array}$ & {$[0,1,3,5,7,9]$} & A3 \\
\hline
\end{tabular}

Figure 4.20 Interrelationships between sets in Part C1 and in previous parts. 
The second phrase of Part C, labeled as Part C2 (mm. 138-145), is made of a $[(1+1)+(1+1)+(1+3)]$ measure phrase structure. With the exception of mm. 138 and 140 , the pitch-content is examined in accordance to the harmonic changes, which more often than not occur every other $8^{\text {th }}$ beat (see Figure 4.21 ).

\begin{tabular}{|c|c|c|c|c|c|}
\hline & Measure & Beat & Pitch-Class Collection & Pitch-Class Set & Label \\
\hline \multirow{17}{*}{$\begin{array}{c}\text { Part C } \\
\text { Phrase } 2 \\
\text { (Part } \\
\text { C2) }\end{array}$} & 138 & & $\mathrm{~A}, \mathrm{~B} b, \mathrm{D}, \mathrm{E}$ & {$[0,2,6,7]$} & C2.a \\
\hline & \multirow{4}{*}{139} & $\begin{array}{l}1, \text { first } \\
8^{\text {th }} \text { beat }\end{array}$ & $\mathrm{F} \#, \mathrm{G}, \mathrm{A} b, \mathrm{~B} b, \mathrm{~B}, \mathrm{D}$ & {$[0,3,4,6,7,8]$} & C2.b \\
\hline & & $\begin{array}{l}1, \text { second } \\
8^{\text {th }} \text { beat }\end{array}$ & $\mathrm{G}, \mathrm{A} b, \mathrm{~A}, \mathrm{~B} b, \mathrm{C} \#, \mathrm{D}, \mathrm{E}$ & {$[0,2,3,6,7,8,9]$} & C2.c \\
\hline & & $\begin{array}{l}2, \text { first } \\
8^{\text {th }} \text { beat }\end{array}$ & $\mathrm{G} \#, \mathrm{~A}, \mathrm{C}, \mathrm{C} \#, \mathrm{E}$ & {$[0,3,4,7,8]$} & C2.d \\
\hline & & $\begin{array}{l}2, \text { second } \\
8^{\text {th }} \text { beat }\end{array}$ & $\mathrm{E} b, \mathrm{E}, \mathrm{F}, \mathrm{G} b, \mathrm{~A} b, \mathrm{~A}, \mathrm{C}$ & {$[0,3,4,6,7,8,9]$} & C2.e \\
\hline & 140 & & $\mathrm{E}, \mathrm{F} \#, \mathrm{~A}, \mathrm{~B} b, \mathrm{~B}, \mathrm{C}$ & {$[0,1,2,3,6,8]$} & C2.f \\
\hline & \multirow{2}{*}{141} & $1 \& 2$ & $\mathrm{G} \#, \mathrm{~A}, \mathrm{~B}, \mathrm{D}, \mathrm{E} b, \mathrm{E}$ & {$[0,1,2,5,7,8]$} & C2.g \\
\hline & & 3 & $\mathrm{~A} b, \mathrm{~B}, \mathrm{C}, \mathrm{D} b, \mathrm{E}$ & {$[0,3,4,5,8]$} & C2.h \\
\hline & \multirow{2}{*}{142} & 1 & $\mathrm{~A} b, \mathrm{~A}, \mathrm{~B} b, \mathrm{D}, \mathrm{E}$ & {$[0,2,6,7,8]$} & $\mathrm{C} 2 . \mathrm{i}$ \\
\hline & & 2 & $\mathrm{E} b, \mathrm{E}, \mathrm{F}, \mathrm{A}, \mathrm{B}$ & {$[0,2,6,7,8]$} & $\mathrm{C} 2 . \mathrm{i}$ \\
\hline & \multirow{2}{*}{143} & 1 & $\mathrm{C} \#, \mathrm{E}, \mathrm{G} b, \mathrm{G}, \mathrm{A} b, \mathrm{~A}$ & {$[0,1,2,3,5,8]$} & $\mathrm{C} 2 . \mathrm{j}$ \\
\hline & & 2 & $\mathrm{C} \#, \mathrm{E} b, \mathrm{~F}, \mathrm{G} b, \mathrm{~A}$ & {$[0,3,4,6,8]$} & $\mathrm{C} 2 . \mathrm{k}$ \\
\hline & \multirow{2}{*}{144} & 1 & $\mathrm{C} \#, \mathrm{D}, \mathrm{E}, \mathrm{F}, \mathrm{G}$ & {$[0,2,3,5,6]$} & $\mathrm{C} 2.1$ \\
\hline & & 2 & $\mathrm{C} \#(\mathrm{D} b), \mathrm{E} b, \mathrm{~F} \#, \mathrm{~A}$ & {$[0,3,6,8]$} & $\mathrm{C} 2 . \mathrm{m}$ \\
\hline & \multirow{3}{*}{145} & 1 & $\mathrm{~A}, \mathrm{~B} b, \mathrm{~B}, \mathrm{C}, \mathrm{E}, \mathrm{F}$ & {$[0,1,5,6,7,8]$} & C2.n \\
\hline & & 2 & $\mathrm{~B}, \mathrm{C}, \mathrm{D} b, \mathrm{E} b, \mathrm{~F}, \mathrm{G}$ & {$[0,2,4,6,7,8]$} & $\mathrm{C} 2.0$ \\
\hline & & 3 & $\mathrm{D}, \mathrm{D} \#, \mathrm{E}, \mathrm{F} \#, \mathrm{G}, \mathrm{G} \#, \mathrm{~A}$ & {$[0,1,2,3,5,6,7]$} & C2.p \\
\hline
\end{tabular}

Figure 4.21 Pitch content in Part C, Phrase 2 (Part C2). 
Part C2 is similar to Part C1 in many ways. Like Part C1, most of the pitch-class sets do not get re-used. Here, only one pitch-class set, Set C2.1, is repeated, and only once. Likewise, the pitch-class sets within Part $\mathrm{C} 2$ are fundamentally subsets of two closely related sets, $[0,2,3,6,7$, 8, 9] (Set C2.c) and [0, 3, 4, 6, 7, 8, 9] (Set C2.e). As with Part C1, a comparison is made among the pitch-class sets within Part C2 in order to establish the relationships between sets (see Figure 4.22).

There are basically three main sets in Part C2: 1) $[0,2,3,6,7,8,9]$ (Set C2.c), 2) $[0,3,4$, 6, 7, 8, 9] (Set C2.e), and 3) [0, 1, 2, 3, 5, 6, 7] (Set C2.p). As mentioned above, the first two sets are closely related because they both share subset $[0,3,6,7,8,9]$. However, they are treated as two distinctive sets as they both generate many other sets, whether directly or through some form of transformation.

Figures 4.22 and 4.23 demonstrate the direct connection and transformations of those pitch-class sets associated with Sets C2.c and C2.e respectively. Note that Set C2.m is shared by these two sets (in red). The subset of Set C2.e, [3, 4, 6, 7, 8, 9], is an inversion and transposition of subset $[0,1,2,3,5,6]$ from Set C2.p under $\mathrm{T}_{9} \mathrm{I}$ (see Figure 4.23c). Set C2.p is also important in Part C2, as it generates three other pitch-class sets in this part—namely, Sets C2.g, C2.j, and C2.n - through inversion and transposition of subsets. As shown in Figure 4.24, the combination of the subsets of Sets C2.c and C2.e also forms a new pitch-class set, Set C2.o. Again, these show that all of the pitch-class sets in Part C2, like those of Part C1, are interrelated with one another. 


\begin{tabular}{|c|c|c|c|c|}
\hline \multicolumn{5}{|c|}{ Direct Relationships with Set C2.c } \\
\hline \multirow{2}{*}{ Label } & Pitch-Class Set & Relationship & Pitch-Class Set & Label \\
\hline \multirow{3}{*}{ C2.c } & & & {$[0,2,6,7]$} & C2.a \\
\cline { 4 - 5 } & & \multirow{2}{*}{ Exact Form } & {$[0,2,6,6,7,8,9]$} & C2.i \\
\cline { 4 - 5 } & & & {$[0,3,6,8]$} & C2.m \\
\hline
\end{tabular}

Figure 4.22a Sets with direct relationships with Set C2.c.

\begin{tabular}{|c|c|c|c|c|}
\hline \multicolumn{5}{|c|}{ Transformative Relationships with Set C2.c } \\
\hline Label & Subset & Relationship & Pitch-Class Set & Label \\
\hline C2.c & {$[6,7,8,9,0,2]$} & $\mathrm{T}_{6}$ & {$[0,1,2,3,6,8]$} & C2.f \\
\hline
\end{tabular}

Figure 4.22b Sets with transformative relationships with Set C2.c.

\begin{tabular}{|c|c|c|c|c|}
\hline \multicolumn{5}{|c|}{ Direct Relationships with Set C2.e } \\
\hline Label & Pitch-Class Set & Relationship & Pitch-Class Set & Label \\
\hline \multirow{3}{*}{ C2.e } & & & {$[0,3,4,6,7,8]$} & C2.b \\
\cline { 4 - 5 } & \multirow{2}{*}[0,3,4,6,7,8,9]{} & \multirow{2}{*}{ Exact Form } & {$[0,3,4,7,8]$} & C2.d \\
\cline { 4 - 5 } & & & {$[0,3,4,6,8]$} & C2.k \\
\cline { 4 - 5 } & & & {$[0,3,6,8]$} & C2.m \\
\hline
\end{tabular}

Figure 4.23a Sets with direct relationships with Set C2.e.

\begin{tabular}{|c|c|c|c|c|}
\hline \multicolumn{5}{|c|}{ Transformative Relationships with Set C2.e } \\
\hline \multirow{2}{*}{ Label } & Subset & Relationship & Pitch-Class Set & Label \\
\hline \multirow{2}{*}{ C2.e } & {$[0,1,2,5,6,8]$} & $\mathrm{T}_{0} \mathrm{I}$ & {$[3,4,5,8,0]$} & C2.h \\
\cline { 2 - 5 } & {$[0,1,2,4]$} & $\mathrm{T}_{9} \mathrm{I}$ & {$[0,2,3,5,6]$} & C2.1 \\
\hline
\end{tabular}

Figure 4.23b Sets with transformative relationships with Set C2.e. 


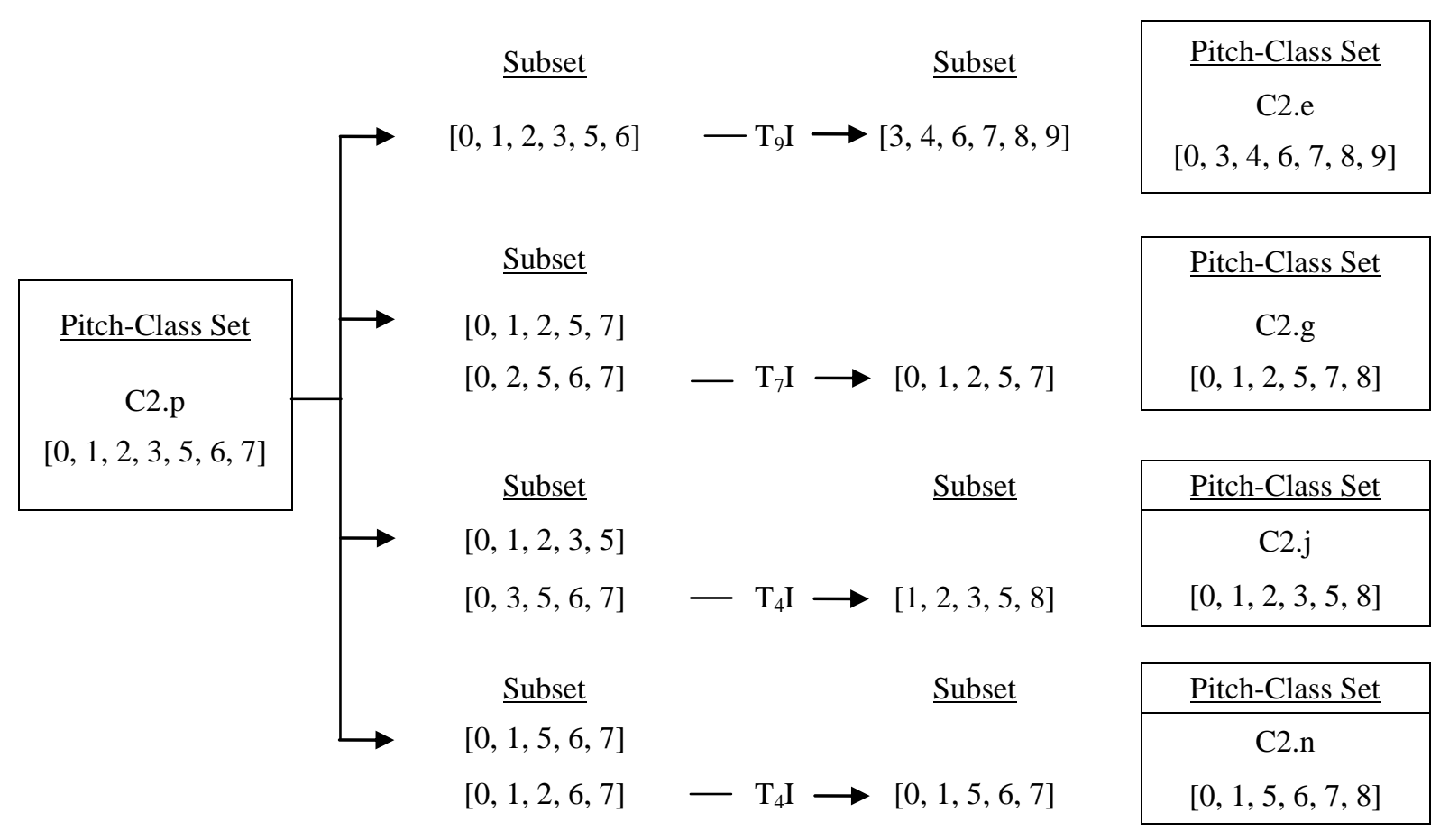

Figure 4.23c Other transformative relationships with Set C2.p.

\begin{tabular}{|c|}
\hline$\frac{\text { Pitch-Class Set }}{\text { C2.c }}$ \\
{$[0,2,3,6,7,8,9]$} \\
\hline
\end{tabular}

$\underline{\text { Subset }}$

$[0,2,6,7,8]$

\section{$\underline{\text { Pitch-Class Set }}$ \\ C2.e \\ $[0,3,4,6,7,8,9]$}

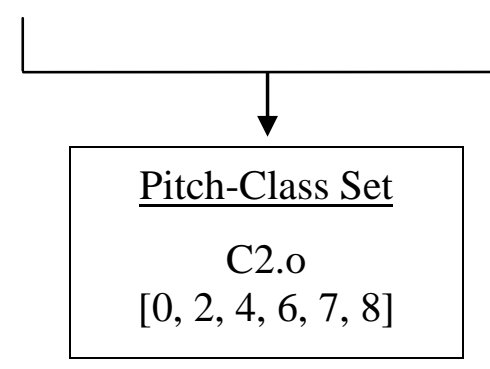

Figure 4.24 Set formed through the combination of Sets C2.e and C2.p. 
Having established the relationship between sets within Part C2, a comparison with sets in other parts is made. However, priority of such comparison is given to that of Part C1 in order to establish a connection among sets within Part C, before comparing such sets with other parts (see Figure 4.25). Direct relationships where sets appear in the exact form of previous sets, or where sets are subsets of or share subsets with previous sets, are listed. When no such connection is found, or when there seems to be too many possible connections, transformations of such sets are considered and further examined. Again, where a set occurs more than once, only its first occurrence is listed.

As shown in Figure 4.25, most of the pitch-class sets in Part C2 are indeed related to that of Part C1 in one way or another, while the rest of the sets show connections to those of Parts A, B, and A'. Further examination on the three main sets in Part C2-Sets C2.c, C2.e, and C2.palso shows some connection to sets $[0,2,4,5]$ (Set I1) and $[0,2,4,5,7]$ (Set I2) from the Introduction. First of all, subset [4, 6, 8, 9] of Set C2.e maps onto [0, 2, 4, 5] when transposed at level 8. On the other hand, subset $[0,2,3,5,7]$ of Set C2.p maps onto $[0,2,4,5,7]$ under inversion and transposition at $\mathrm{T}_{7}$. Lastly, as mentioned before, the combination of Sets C2.c and C2.e forms Set C2.o, [0, 2, 4, 6, 7, 8] (see Figure 4.24), within which subset $[2,4,6,7]$ also maps onto $[0,2,4,5]$ when transposed at level 8 . This shows, again, the direct and indirect presence of Sets I1 and I2 throughout Section III. 


\begin{tabular}{|c|c|c|c|c|c|}
\hline \multicolumn{3}{|c|}{ Part C Phrase 2 (Part C2) } & \multirow{2}{*}{ Relationship } & \multicolumn{2}{|c|}{ Previous Parts } \\
\hline Measure & Label & Pitch-Class Set & & Pitch-Class Set & Label \\
\hline \multirow{2}{*}{138} & \multirow{2}{*}{$\mathrm{C} 2 . \mathrm{a}$} & \multirow{2}{*}[0,2,6,7]{} & Subset & {$[0,2,4,6,7]$} & B 1.4 \\
\hline & & & Subset & {$[0,2,6,7,8]$} & C1.j \\
\hline \multirow{8}{*}{139} & \multirow{3}{*}{$\mathrm{C} 2 . \mathrm{b}$} & \multirow{3}{*}[0,3,4,6,7,8]{} & Subset & {$[0,3,4,5,6,7]$} & B2.2 \\
\hline & & & Subset & {$[0,1,2,3,4,5,7,8]$} & $\mathrm{A}^{\prime} 1.4$ \\
\hline & & & Subset & {$[0,2,3,6,7,8]$} & C1.k \\
\hline & $\mathrm{C} 2 . \mathrm{c}$ & {$[0,2,3,6,7,8,9]$} & Subset & {$[0,2,3,6,7,8]$} & C1.k \\
\hline & \multirow{2}{*}{ C2.d } & \multirow{2}{*}[0,3,4,7,8]{} & Subset & {$[0,1,2,3,4,5,7,8]$} & $\mathrm{A}^{\prime} 1.4$ \\
\hline & & & Subset & {$[0,1,3,4,5,8]$} & C1.s \\
\hline & \multirow{2}{*}{ C2.e } & \multirow{2}{*}[0,3,4,6,7,8,9]{} & $\begin{array}{l}\text { Subset, Inversion } \\
\& \text { Transposition }\end{array}$ & {$[0,1,2,3,4,5,7,8]$} & $\mathrm{A}^{\prime} 1.4$ \\
\hline & & & $\begin{array}{l}\text { Subset, Inversion } \\
\& \text { Transposition }\end{array}$ & {$[0,1,2,4,5,6,8]$} & C1.e \\
\hline 140 & C2.f & {$[0,1,2,3,6,8]$} & Subset & {$[0,1,2,3,5,6,8]$} & C1.c \\
\hline \multirow{3}{*}{141} & $\mathrm{C} 2 . \mathrm{g}$ & {$[0,1,2,5,7,8]$} & Subset & {$[0,1,2,3,4,5,7,8]$} & $\mathrm{A}^{\prime} 1.4$ \\
\hline & \multirow{2}{*}{$\mathrm{C} 2 . \mathrm{h}$} & \multirow{2}{*}[0,3,4,5,8]{} & Subset & {$[0,1,2,3,4,5,7,8]$} & $\mathrm{A}^{\prime} 1.4$ \\
\hline & & & Subset & {$[0,1,3,4,5,8]$} & C1.s \\
\hline \multirow{2}{*}{142} & C2.i & {$[0,2,6,7,8]$} & Exact Form & {$[0,2,6,7,8]$} & $\mathrm{C} 1 . \mathrm{j}$ \\
\hline & $\mathrm{C} 2 . \mathrm{i}$ & {$[0,2,6,7,8]$} & Exact Form & {$[0,2,6,7,8]$} & $\mathrm{C} 1 . \mathrm{j}$ \\
\hline \multirow{3}{*}{143} & \multirow{2}{*}{$C 2 . j$} & \multirow{2}{*}[0,1,2,3,5,8]{} & Subset & {$[0,1,2,3,4,5,7,8]$} & $\mathrm{A}^{\prime} 1.4$ \\
\hline & & & Subset & {$[0,1,2,3,5,6,8]$} & C1.c \\
\hline & $\mathrm{C} 2 . \mathrm{k}$ & {$[0,3,4,6,8]$} & $\begin{array}{l}\text { Inversion \& } \\
\text { Transposition }\end{array}$ & {$[0,2,4,5,8]$} & C1.t \\
\hline \multirow[t]{2}{*}{144} & $\mathrm{C} 2.1$ & {$[0,2,3,5,6]$} & Subset & {$[0,2,3,5,6,7]$} & C1.f \\
\hline & $\mathrm{C} 2 . \mathrm{m}$ & {$[0,3,6,8]$} & Subset & {$[0,1,3,5,6,8]$} & A 1.2 \\
\hline \multirow{4}{*}{145} & $\mathrm{C} 2 . \mathrm{n}$ & {$[0,1,5,6,7,8]$} & $\begin{array}{c}\text { Subset \& } \\
\text { Transposition }\end{array}$ & {$[0,1,2,3,4,5,7,8]$} & $\mathrm{A}^{\prime} 1.4$ \\
\hline & $\mathrm{C} 2 . \mathrm{o}$ & {$[0,2,4,6,7,8]$} & $\begin{array}{l}\text { Subset, Inversion } \\
\& \text { Transposition }\end{array}$ & {$[0,1,2,4,6,8,9]$} & B 3.2 \\
\hline & \multirow{2}{*}{ C2.p } & \multirow{2}{*}[0,1,2,3,5,6,7]{} & Subset & {$[0,1,2,3,5,6,8]$} & C1.c \\
\hline & & & Subset & {$[0,2,3,5,6,7]$} & C1.f \\
\hline
\end{tabular}

Figure 4.25 Interrelationships between sets in Part C2 and in previous parts. 
The third and last phrase in Part C, labeled as C3 (mm. 146-149), has a four-measure phrase structure. The pitch content in this part is grouped in accordance to the pentachords which last for two or three quarter notes (see Figure 4.26). Mm. 148 and 149 are treated as one unit due to the tying of the last pentachord across bar.

\begin{tabular}{|c|c|c|c|c|c|}
\hline & Measure & Beat & Pitch-Class Collection & Pitch-Class Set & Label \\
\hline \multirow{5}{*}{$\begin{array}{c}\text { Part C } \\
\text { Phrase } 3 \\
\text { (Part } \\
\text { C3) }\end{array}$} & \multirow{2}{*}{146} & $1,2 \& 3$ & $\mathrm{D}, \mathrm{E}, \mathrm{F}, \mathrm{F} \#, \mathrm{G}, \mathrm{A}$ & {$[0,2,3,4,5,7]$} & C3.a \\
\hline & & $4 \& 5$ & $\mathrm{E}, \mathrm{F}, \mathrm{G}, \mathrm{B}, \mathrm{C}$ & {$[0,1,5,7,8]$} & C3.b \\
\hline & \multirow{2}{*}{147} & $1 \& 2$ & $\mathrm{G} \#, \mathrm{~A}, \mathrm{~B} b, \mathrm{~B}, \mathrm{D}, \mathrm{E}$ & {$[0,2,5,6,7,8]$} & C3.c \\
\hline & & $3,4 \& 5$ & $\mathrm{~B}, \mathrm{C}, \mathrm{D} b, \mathrm{E}, \mathrm{F}, \mathrm{G}$ & {$[0,2,3,6,7,8]$} & C3.d \\
\hline & $148-149$ & & $\mathrm{D}, \mathrm{E} b, \mathrm{E}, \mathrm{F}, \mathrm{G}, \mathrm{A}, \mathrm{B}, \mathrm{C}$ & {$[0,1,3,5,7,8,9,10]$} & C3.e \\
\hline
\end{tabular}

Figure 4.26 Pitch content in Part C, Phrase 3 (Part C3).

An examination of the relationship between sets within Part C3 shows that all of the sets are related to Set C3.e either directly or through some form of transformation (see Figure 4.27a). Interestingly, Set C3.b (in red) is not only a subset of the above-mentioned set, it is also a subset of Set C3.d when the latter set is transposed at level 5 (see Figure 4.27b). Meanwhile, Set C3.e is also related to set $[0,2,4,5,7]$ (Set I2) from the Introduction, in that its subsets, $[3,5,7,8,10]$ and $[5,7,9,10,0]$, are transpositions of Set $\mathrm{I} 2$ at $\mathrm{T}_{3}$ and $\mathrm{T}_{5}$ respectively.

\begin{tabular}{|c|c|c|c|c|}
\hline \multicolumn{5}{|c|}{ Interrelationships with Set C3.e } \\
\hline Label & Subset & Relationship & Pitch-Class Set & Label \\
\hline \multirow{4}{*}{ C3.e } & {$[0,1,5,7,8]$} & Exact Form & {$[0,1,5,7,8]$} & C3.b \\
\cline { 2 - 5 } & {$[5,7,8,9,10]$} & $\mathrm{T}_{7}$ & {$[0,2,3,4,5,7]$} & C3.a \\
\cline { 2 - 5 } & {$[7,8,9,10,1,3]$} & $\mathrm{T}_{3} \mathrm{I}$ & {$[0,2,5,6,7,8]$} & C3.c \\
\cline { 2 - 5 } & {$[7,8,9,0,1,3]$} & $\mathrm{T}_{3} \mathrm{I}$ & {$[0,2,3,6,7,8]$} & C3.d \\
\hline
\end{tabular}

Figure 4.27a Sets related to Set C3.e. 


\begin{tabular}{|c|}
\hline Pitch-Class Set \\
C3.d \\
{$[0,2,3,6,7,8]$} \\
\hline
\end{tabular}

$\underline{\text { Subset }}$

$[7,8,0,2,3]$

\section{$\underline{\text { Pitch-Class Set }}$ \\ C3.e \\ $[0,1,3,5,7,8,9$, \\ 10]}

\section{Pitch-Class}

$\underline{\text { Set }}$

$\underline{\text { Subset }}$

$[0,1,5,7,8] \quad$ or $\quad$ Set C3.b

Figure 4.27b Derivation of Set C3.b from Sets C3.d and C3.e.

The pitch content in Part C3 can be compared with that of other parts using the same criteria as previous comparisons. A majority of the pitch materials in this part show a close tie to that of Part A' and some connection to that of Parts $\mathrm{C} 1$ and $\mathrm{C} 2$ (see Figure 4.28).

\begin{tabular}{|c|c|c|c|c|c|}
\hline \multicolumn{3}{|c|}{ Part C Phrase 3 (Part C3) } & \multirow{2}{*}{ Relationship } & \multicolumn{2}{|c|}{ Previous Parts } \\
\hline Measure & Label & Pitch-Class Set & & Pitch-Class Set & Label \\
\hline \multirow{5}{*}{146} & C3.a & {$[0,2,3,4,5,7]$} & Subset & {$[0,1,2,3,4,5,7,8]$} & $\mathrm{A}^{\prime} 1.4$ \\
\hline & \multirow{4}{*}{ C3.b } & \multirow{4}{*}[0,1,5,7,8]{} & Subset & {$[0,1,3,5,7,8]$} & $\mathrm{A}^{\prime} 1.3$ \\
\hline & & & Subset & {$[0,1,2,3,4,5,7,8]$} & $\mathrm{A}^{\prime} 1.4$ \\
\hline & & & Subset & {$[0,1,2,5,7,8]$} & $\mathrm{C} 2 . \mathrm{g}$ \\
\hline & & & Subset & {$[0,1,5,6,7,8]$} & $\mathrm{C} 2 . \mathrm{n}$ \\
\hline \multirow{2}{*}{147} & C3.c & {$[0,2,5,6,7,8]$} & Exact Form & {$[0,2,5,6,7,8]$} & C1.g \\
\hline & C3.d & {$[0,2,3,6,7,8]$} & Exact Form & {$[0,2,3,6,7,8]$} & C1.k \\
\hline \multirow{5}{*}{$\begin{array}{c}148- \\
149\end{array}$} & \multirow{5}{*}{ C3.e } & \multirow{5}{*}[0,1,3,5,7,8,9,10]{} & Subset & {$[0,1,3,5,7,9]$} & A3 \\
\hline & & & Subset & {$[0,1,3,5,7,8]$} & $\mathrm{A}^{\prime} 1.3$ \\
\hline & & & Subset & {$[0,2,3,5,7,8,10]$} & $\mathrm{A}^{\prime} 2.4$ \\
\hline & & & Subset & {$[0,2,3,5,7,9,10]$} & $\mathrm{A}^{\prime} 2.6$ \\
\hline & & & Subset & {$[0,1,2,3,4,5,7,8]$} & $\mathrm{A}^{\prime} 1.4$ \\
\hline
\end{tabular}

Figure 4.28 Interrelationships between sets in Part C3 and in previous parts. 
In short, the pitch content in Part $\mathrm{C}$ is loosely based on the two main pitch-class sets that are present in every other preceding parts, $[0,2,4,5]$ (Set I1) and [0, 2, 4, 5, 7] (Set I2). Many of the sets in Part $\mathrm{C}$ have direct connections with other sets in previous parts, in that they are either exact form or subset of sets that have been previously used. Meanwhile, some sets reveal more complicated relationships, such as inversion and transposition, to other sets. Besides that, a combination of sets also generates some other new sets. Nevertheless, Part C, as a whole, is still a cohesive body in terms of its pitch-class selection.

\section{$\underline{\text { Coda }}$}

The final part in Section III, the Coda, is made of a single phrase of eleven measures, within which the pitch materials could be grouped into several smaller groups of phrases according to melodic contour and recurring patterns (see Figure 4.29). Even though there appears to be different streams of lines or counterpoints in this section, in the interest of the pitch-class selection, simultaneously sounding pitch-classes are grouped as a collection (see Figure 4.30).

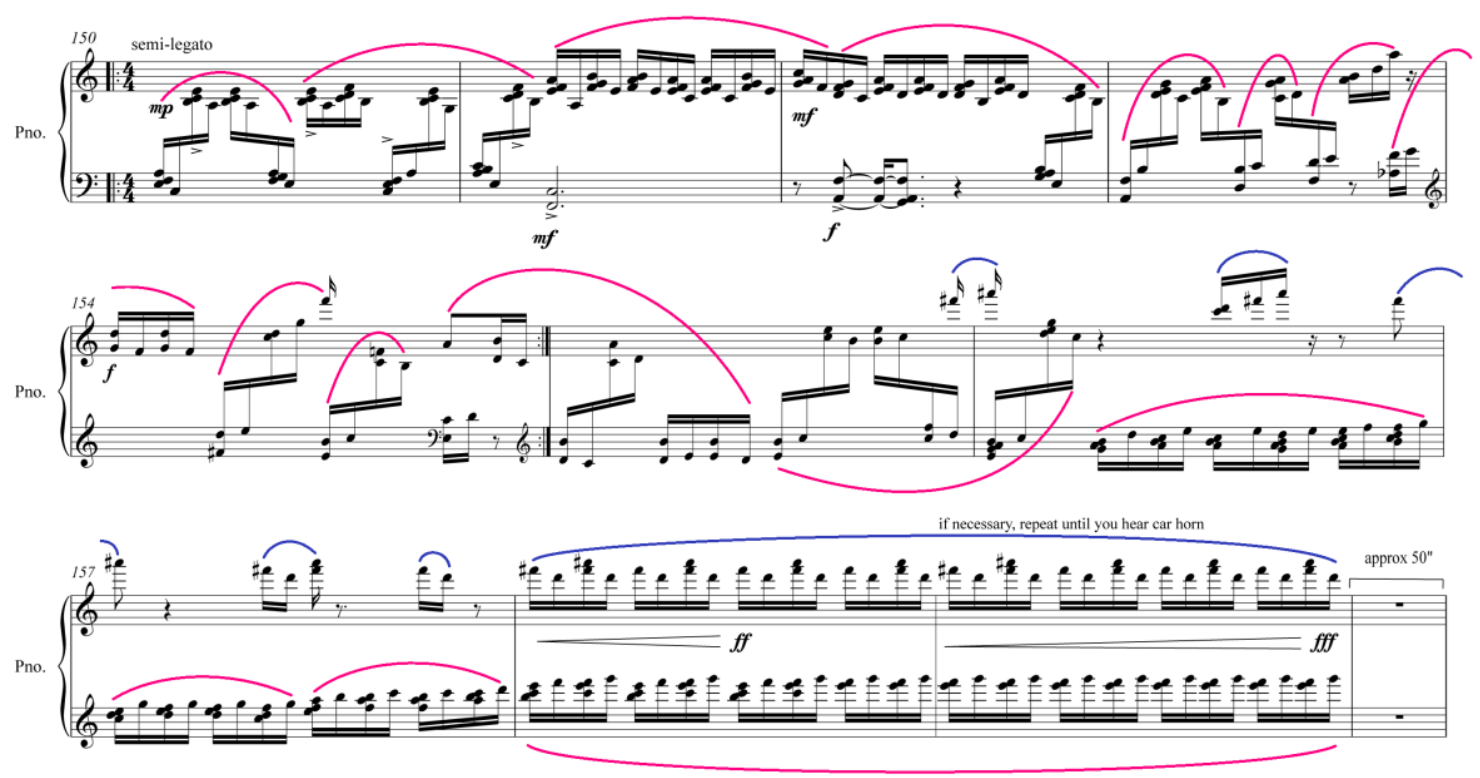

Figure 4.29

Adeline Wong: Paces, Section III, “Piano Solo,” Coda, mm. 150-159. 


\begin{tabular}{|c|c|c|c|c|}
\hline Measure & Beat & Pitch-Class Collection & Pitch-Class Set & Label \\
\hline 150 & $1 \& 2$ & $\mathrm{E}, \mathrm{F}, \mathrm{G}, \mathrm{A}, \mathrm{B}, \mathrm{C}$ & {$[0,1,3,5,7,8]$} & Cd.a \\
\hline 150 & $3 \& 4$ & \multirow{2}{*}{$\mathrm{B}, \mathrm{C}, \mathrm{D}, \mathrm{E}, \mathrm{F}, \mathrm{G}, \mathrm{A}$} & \multirow{2}{*}[0,2,4,5,7,9,10]{} & \multirow{2}{*}{ Cd.b } \\
\hline 151 & 1 & & & \\
\hline 151 & $2,3, \& 4$ & \multirow{2}{*}{$\mathrm{E}, \mathrm{F}, \mathrm{G}, \mathrm{A}, \mathrm{B}, \mathrm{C}$} & \multirow{2}{*}[0,1,3,5,7,8]{} & \multirow{2}{*}{ Cd.a } \\
\hline 152 & 1 , first $8^{\text {th }}$ beat & & & \\
\hline \multirow{2}{*}{152} & 1 , second $8^{\text {th }}$ beat & \multirow{2}{*}{$\mathrm{B}, \mathrm{C}, \mathrm{D}, \mathrm{E}, \mathrm{F}, \mathrm{G}, \mathrm{A}$} & \multirow{2}{*}[0,2,4,5,7,9,10]{} & \multirow{2}{*}{ Cd.b } \\
\hline & $2,3,4$ & & & \\
\hline 153 & $1 \& 2$, first $8^{\text {th }}$ beat & $\mathrm{B}, \mathrm{C}, \mathrm{D}, \mathrm{E}, \mathrm{F}, \mathrm{G}, \mathrm{A}$ & {$[0,2,4,5,7,9,10]$} & Cd.b \\
\hline \multirow{4}{*}{153} & 2 , second $8^{\text {th }}$ beat & \multirow{2}{*}{$\mathrm{G}, \mathrm{A}, \mathrm{B}, \mathrm{C}, \mathrm{D}$} & \multirow{2}{*}[0,2,3,5,7]{} & \multirow{2}{*}{ Cd.c } \\
\hline & 3 , first $8^{\text {th }}$ beat & & & \\
\hline & 3 , second $8^{\text {th }}$ beat & \multirow{2}{*}{$\mathrm{A}, \mathrm{B}, \mathrm{D}, \mathrm{E}, \mathrm{F}$} & \multirow{2}{*}[0,1,3,6,8]{} & \multirow{2}{*}{ Cd.d } \\
\hline & 4 (upper staff) & & & \\
\hline 153 & 4 (lower staff) & \multirow{2}{*}{$\mathrm{D}, \mathrm{F}, \mathrm{G}, \mathrm{A} b$} & \multirow{2}{*}[0,1,3,6]{} & \multirow{2}{*}{ Cd.e } \\
\hline 154 & 1 & & & \\
\hline \multirow{2}{*}{154} & $\begin{array}{l}2 \& 3 \text {, first } 16^{\text {th }} \\
\text { note (upper staff) }\end{array}$ & $\mathrm{C}, \mathrm{D}, \mathrm{E}, \mathrm{F}, \mathrm{F} \#, \mathrm{G}$ & {$[0,1,2,3,5,7]$} & Cd.f \\
\hline & 3 (lower staff) & $\mathrm{B}, \mathrm{C}, \mathrm{E}, \mathrm{F}$ & {$[0,1,5,6]$} & Cd.g \\
\hline 154 & 4 & \multirow{2}{*}{$\mathrm{A}, \mathrm{B}, \mathrm{C}, \mathrm{D}, \mathrm{E}$} & \multirow{2}{*}[0,2,4,5,7]{} & \multirow{2}{*}{ Cd.h } \\
\hline 155 & $1 \& 2$ & & & \\
\hline 155 & 3,4 & \multirow{2}{*}{$\mathrm{E}, \mathrm{F}, \mathrm{F} \#, \mathrm{G}, \mathrm{A}, \mathrm{A} \#, \mathrm{~B}, \mathrm{C}, \mathrm{D}$} & \multirow{2}{*}[0,2,3,4,5,7,8,9,10]{} & \multirow{2}{*}{ Cd.i } \\
\hline 156 & 1 & & & \\
\hline 156 & $2,3 \& 4$ & $\mathrm{E}, \mathrm{F}, \mathrm{F} \#, \mathrm{G}, \mathrm{A}, \mathrm{A} \#, \mathrm{~B}, \mathrm{C}, \mathrm{D}$ & {$[0,2,3,4,5,7,8,9,10]$} & Cd.i \\
\hline \multirow{2}{*}{157} & $1 \& 2$ & $\mathrm{~A} \#, \mathrm{C}, \mathrm{D}, \mathrm{E}, \mathrm{F}, \mathrm{F} \#, \mathrm{G}$ & {$[0,1,2,3,5,7,9]$} & Cd.j \\
\hline & $3 \& 4$ & $\mathrm{~A}, \mathrm{~A} \#, \mathrm{~B}, \mathrm{C}, \mathrm{D}, \mathrm{E}, \mathrm{F}, \mathrm{F} \#$ & {$[0,1,2,4,6,7,8,9]$} & Cd.k \\
\hline 158 & $1,2 \& 3$ & $\mathrm{~A} \#, \mathrm{~B}, \mathrm{C}, \mathrm{D}, \mathrm{E}, \mathrm{F}, \mathrm{F} \#, \mathrm{G}$ & {$[0,1,2,3,5,7,8,9]$} & Cd.1 \\
\hline 158 & 4 & \multirow{2}{*}{$\mathrm{D}, \mathrm{E}, \mathrm{F}, \mathrm{F} \#, \mathrm{G}, \mathrm{A \#}$} & \multirow{2}{*}[0,3,4,5,6,8]{} & \multirow{2}{*}{ Cd.m } \\
\hline 159 & & & & \\
\hline
\end{tabular}

Figure 4.30 Pitch content in Coda. 
The pitch content in the Coda is mainly derived from Set Cd.i, $[0,2,3,4,5,7,8,9,10]$ (see Figure 4.31). With reference to Figure 4.30, the pitch selection in the first four measures of the Coda are drawn from Set Cd.b, $[0,2,4,5,7,9,10]$, or [B, C, D, E, F, G, A]. From m. 154 onwards, F\# and $\mathrm{A} \#$ are gradually introduced to complete the set. As a result, the labeling system employed in the Coda follows that used in Part C, because all of the pitch-class sets fundamentally originate from Set Cd.i.

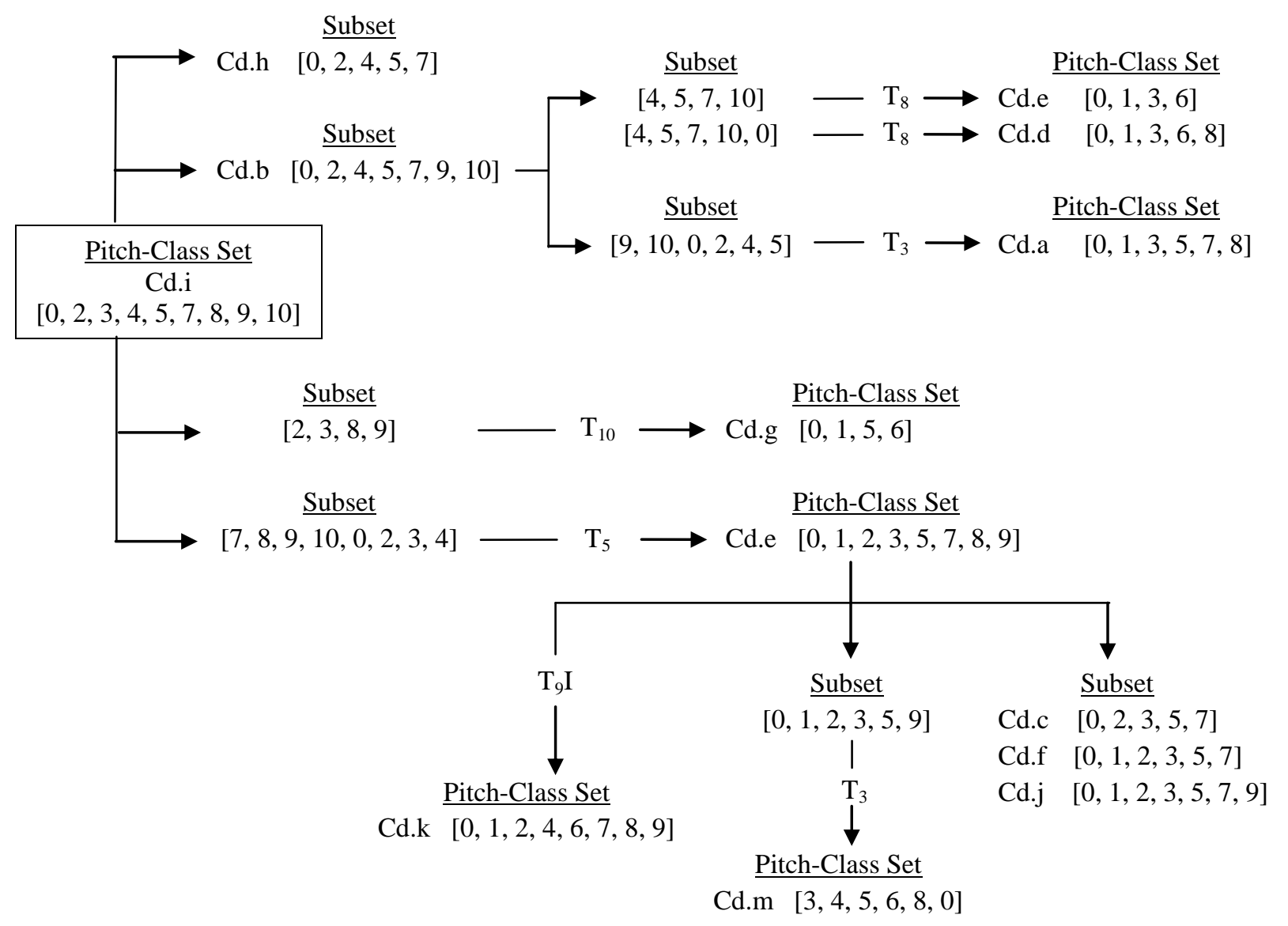

Figure 4.31 Derivation of sets from Set Cd.i.

The Coda ties the entire Section III together through the use of a pitch-class set that has a strong connection to the pitch content in other parts of this section (see Figure 4.32). Most importantly, its pitch content is obviously connected to the two main sets in the Introduction by 
sharing subset $[0,2,4,5,7]$. This strong connection between the Introduction and the Coda, as with the connection shared between the Coda and other parts in Section III, further exemplifies unity and cohesiveness in the pitch content in Section III.

\begin{tabular}{|c|c|c|c|c|}
\hline \multicolumn{3}{|c|}{ Previous Parts } & \multirow[b]{2}{*}{ Relationship } & \multirow{2}{*}{$\begin{array}{c}\text { Coda } \\
\text { Subset of Set Cd.i, } \\
{[0,2,3,4,5,7,8,9,10]}\end{array}$} \\
\hline Part & Label & $\begin{array}{c}\text { Main Pitch-Class Set/ } \\
\text { Subset }\end{array}$ & & \\
\hline \multirow{2}{*}{ Intro } & I1 & {$[0,2,4,5]$} & Exact Form & {$[0,2,4,5]$} \\
\hline & I2 & {$[0,2,4,5,7]$} & Exact Form & {$[0,2,4,5,7]$} \\
\hline \multirow{5}{*}{ A } & \multirow{3}{*}{ A1.1 } & \multirow{3}{*}[0,1,3,5,8]{} & $\begin{array}{c}\text { Subset \& } \\
\text { Transposition }\end{array}$ & {$[2,3,5,7,10]$} \\
\hline & & & $\begin{array}{c}\text { Subset \& } \\
\text { Transposition }\end{array}$ & {$[4,5,7,9,0]$} \\
\hline & & & $\begin{array}{c}\text { Subset \& } \\
\text { Transposition }\end{array}$ & {$[9,10,0,2,5]$} \\
\hline & A2.1 & {$[0,2,4,7,9]$} & Exact Form & {$[0,2,4,7,9]$} \\
\hline & $\mathrm{A} 3$ & {$[0,1,3,5,7,9]$} & $\begin{array}{c}\text { Subset \& } \\
\text { Transposition }\end{array}$ & {$[7,8,10,0,2,4]$} \\
\hline \multirow{3}{*}{ B } & B1.1 & {$[0,2,4,(5) 7]$,} & Exact Form & {$[0,2,4,7]$} \\
\hline & B2.1 & {$[0,3,5,7]$} & Exact Form & {$[0,3,5,7]$} \\
\hline & B3.1 & {$[0,1,4,(5) 6,8]$,} & $\begin{array}{c}\text { Subset \& } \\
\text { Transposition }\end{array}$ & {$[4,5,8,10,0]$} \\
\hline \multirow{2}{*}{$\mathrm{A}^{\prime}$} & $\mathrm{A}^{\prime} 1.4$ & {$[0,1,2,3,4,5,7,8]$} & Shared Subset & {$[0,2,3,4,5,7,8]$} \\
\hline & $\mathrm{A}^{\prime} 2.4$ & {$[0,2,3,5,7,8,10]$} & Shared Subset & {$[0,3,5,7,8,10]$} \\
\hline \multirow{2}{*}{$\mathrm{C} 1$} & C1.c & {$[0,1,2,3,5,6,8]$} & $\begin{array}{c}\text { Subset \& } \\
\text { Transposition }\end{array}$ & {$[2,3,4,5,7,8,10]$} \\
\hline & C1.e & {$[0,1,2,4,5,6,8]$} & Shared Subset & {$[0,2,4,5,8]$} \\
\hline \multirow{3}{*}{$\mathrm{C} 2$} & $\mathrm{C} 2 . \mathrm{c}$ & {$[0,2,3,6,7,8,9]$} & Shared Subset & {$[0,2,3,7,8,9]$} \\
\hline & C2.e & {$[0,3,4,6,7,8,9]$} & Shared Subset & {$[0,3,4,7,8,9]$} \\
\hline & C2.p & {$[0,1,2,3,5,6,7]$} & $\begin{array}{c}\text { Subset \& } \\
\text { Transposition }\end{array}$ & {$[2,3,4,5,7,8,9]$} \\
\hline $\mathrm{C} 3$ & C3.e & {$[0,1,3,5,7,8,9,10]$} & $\begin{array}{l}\text { Subset \& } \\
\text { Transposition }\end{array}$ & {$[7,8,10,0,2,3,4,5]$} \\
\hline
\end{tabular}

Figure 4.32 Interrelationships between sets in Coda and in previous parts. 


\section{Interrelationship between Harmonic Rhythm, Tempo, Meter, Dynamics, and Articulation}

Previous discussions of phrase structure and pitch content demonstrate a close tie

between these two musical elements. Other elements presented in Section III, such as the

harmonic rhythm, tempo, meter, dynamics, and articulation, are also interrelated. These

interrelationships are laid out and best described in Figure 4.33, as follows. Again, due to the fact

that musical excerpts of each individual part of Section III have been given during the previous

discussion, "Phrase Structure," no such musical examples will be provided here.

\begin{tabular}{|c|c|c|c|c|c|c|}
\hline & Introduction & Part A & Part B & Part $A^{\prime}$ & Part C & Coda \\
\hline Measure & $60-63$ & $64-87$ & $88-106$ & $107-113$ & $114-149$ & $150-159$ \\
\hline $\begin{array}{l}\text { Harmonic } \\
\text { Rhythm }\end{array}$ & Stable. & Stable. & $\begin{array}{l}\text { Mostly stable, } \\
\text { intensify towards } \\
\text { the end. }\end{array}$ & Stable. & Highly unstable. & Stable. \\
\hline Tempo & $\begin{array}{l}\text { Stable, with } \\
\text { no change: } \\
-=88-92\end{array}$ & $\begin{array}{l}\text { Stable, } \\
\text { with no } \\
\text { change: } \\
\text { Espressivo } \\
\text { ma } \\
\text { semplice, } \\
\text { - = }=64-72\end{array}$ & $\begin{array}{l}\text { Mostly stable at } \\
\text { the beginning } \\
\text { (poco piu } \\
\text { mosso, } \\
\text { gradually gets } \\
\text { faster towards } \\
\text { the end. }\end{array}$ & $\begin{array}{l}\text { Stable at the } \\
\text { beginning } \\
\text { (Espressivo } \\
\text { poco rit. } \\
\text { followed } \\
\text { immediately by } \\
\text { a tempo in the } \\
\text { middle, changes } \\
\text { tempo at the } \\
\text { very end } \\
(d=112) \text {. }\end{array}$ & $\begin{array}{l}\text { Highly unstable, } \\
\text { rapid changes. }\end{array}$ & $\begin{array}{l}\text { Stable, } \\
\text { with no } \\
\text { change: } \\
\text { Risoluto } \\
\downarrow=120\end{array}$ \\
\hline Meter & $\begin{array}{l}\text { Stable, with } \\
\text { no change: } \mathbf{4}\end{array}$ & $\begin{array}{l}\text { Stable, } \\
\text { with no } \\
\text { change: } \mathbf{3}\end{array}$ & $\begin{array}{l}\text { Mostly stable ( } \\
\text { ),82 meter } \\
\text { changes towards } \\
\text { the end. }\end{array}$ & $\begin{array}{l}\text { Stable, with no } \\
\text { change: } \mathbf{3}\end{array}$ & $\begin{array}{l}\text { Highly unstable, } \\
\text { frequent irregular } \\
\text { meter changes. }\end{array}$ & $\begin{array}{l}\text { Stable, } \\
\text { with no } \\
\text { change: } \mathbf{4}\end{array}$ \\
\hline Dynamics & $p p$ & $p$ & $\begin{array}{l}\text { Gradually } \\
\text { changes from } m p \\
\text { to } m f \text {, then to } f \text {. }\end{array}$ & $\begin{array}{l}p \text { throughout } \\
\text { Phrases } 1 \text { and } 2 ; \\
m p / p p \text { in Phrase } \\
3(\mathrm{~mm} .121- \\
126) \text { and } f \text { in } \\
\text { mm. } 127-128 .\end{array}$ & $\begin{array}{l}\text { Wide dynamic range } \\
(p-f f) ; \text { rapidly } \\
\text { changes throughout; } \\
\text { mixture of gradual } \\
\text { and subito changes. }\end{array}$ & $\begin{array}{l}\text { Wide } \\
\text { dynamic } \\
\text { range ( } m p- \\
\text { fff); gradual } \\
\text { changes } \\
\text { throughout. }\end{array}$ \\
\hline Articulation & $\begin{array}{l}\text { molto legato, } \\
\text { with pedal. }\end{array}$ & $\begin{array}{l}\text { No } \\
\text { indication } \\
\text { of } \\
\text { changes. }\end{array}$ & $\begin{array}{l}\text { Mostly without } \\
\text { pedal. }\end{array}$ & $\begin{array}{l}\text { Presumably } \\
\text { legato, with } \\
\text { pedal; } \\
\text { staccatissimo in } \\
\text { mm. 127-128). }\end{array}$ & $\begin{array}{l}\text { Various articulations: } \\
\text { legato, staccato, } \\
\text { staccatissimo, } \\
\text { slurring, marcato, } \\
\text { accent. }\end{array}$ & $\begin{array}{l}\text { semi- } \\
\text { legato. }\end{array}$ \\
\hline
\end{tabular}

Figure 4.33 Interrelationship between harmonic rhythm, tempo, meter, dynamics, and articulation in Section III, "Piano Solo." 


\section{1) Harmonic Rhythm, Tempo, and Meter}

The discussion of the harmonic rhythm in Section III is not one that is based on the concept of tonal harmony; rather, it is based on the rate at which the pitch content, in this case, the pitch-class collection, changes. Therefore, the term "harmony," and any term related to it, henceforth refers to the pitch-class collection.

In reference to Figure 4.33 , there is generally a consistent structure or pattern in terms of the changes in harmonic rhythm, tempo, and meter throughout Section III. The Introduction and Part A are very stable in all of these aspects: the harmony changes every two measures, with no changes in tempo and meter. Part B is mostly stable with a regular one-harmony-per-twomeasure rhythm. However, the harmony changes in each of the last three measures (mm. 104106). The tempo also speeds up in the last five measures (mm. 102-106), and there are two consecutive changes in meters in the last two measures (mm. 106-107). Subsequently, Part A' recalls Part A in similar manner, except for a poco rit. gesture halfway through, and a change in tempo at the end.

On the other hand, Part $\mathrm{C}$ presents a distinctive contrast to the previous parts. It is highly unstable in every aspect. First of all, the harmonic rhythm quickly changes from one harmony per measure (mm. 129-131) to one harmony per every quarter note (mm. 132-136), and gradually switches to every $8^{\text {th }}$ note (mm. 136-139). Occasionally, it returns to one harmony per measure (mm. 138 and 140), and then switches back to every quarter note (mm. 139, and 141145). The last few measures are relatively more stable, with two harmonies per measure (mm. 146-147) and one harmony per two measures (mm. 148-149).

In addition to the unstable harmonic rhythm, the tempo also rapidly changes within Part C. In the first half of this part (mm. 129-135), almost every measure is marked with a different 
tempo, or an indication of change in tempo (i.e., accel.). Halfway through Part C, the tempo changes every three to four measures (mm. 136-149). Similarly, the meter also frequently changes in an irregular manner, mostly at the rate of one measure per meter, except in mm. 135137, 142-144, and 146-147.

The stability is restored in the Coda, where the harmonic changes are not nearly as rapid as those in Part C. There are only two main harmonic regions in the Coda (mm. 150-153 and mm. 154-159), while the tempo and meter remains unchanged throughout.

\section{2) Dynamics}

Section III presents a wide range of dynamics, growing from pianissimo $(\mathrm{pp})$ to fortississimo ( fff ). The dynamics change gradually and at a slower rate at the beginning, and change more rapidly and irregularly in the middle. At the end of this section, the changes become gradual again, but they occur at a faster rate. Section III begins with pianissimo $(p p)$ in the Introduction and remains very soft until Part $\mathrm{A}$, where it becomes piano $(p)$ and remains the same throughout Part A.

In Part B, there are three different levels of dynamics: mezzo piano $(\mathrm{mp})$ in Phrase $1(\mathrm{~mm}$. 88-95), mezzo forte ( $\mathrm{mf}$ ) in the majority of Phrase 2 (mm. 121-126), and forte $(f)$ in the very last measure of Phrase 2 (m. 106). Similarly, Part A' also presents three different dynamic levels: piano $(p)$ throughout Phrases 1 and 2 (mm. 106-120), mezzo piano ( $m p$ ) with a pianissimo ( $p p)$ counter-melody in the majority of Phrase 3 (mm. 121-126), and changes to forte $(f)$ in the very last two measures of Phrase 3 (mm. 127-128). This manner of gradual dynamic change-from soft to moderately soft or moderately loud, to loud — is not only seen in Parts B and A'. On a larger scale, it is also evident from part to part: from pianissimo $(p p)$ in the Introduction, to piano ( $p$ ) Part A, and then to mezzo piano $(m p)$ in Part B. The consistency in such gradual 
changes therefore aligns with the stabilities in harmonic rhythm, tempo, and meter. Hence, the Introduction, Parts A, B, and A' can be grouped as a "stable region."

Contrastingly, Part $\mathrm{C}$ shows a wide range of dynamics from piano $(p)$ to fortissimo $(f f)$. The dynamics change rapidly throughout, at times in a gradual manner, and at times suddenly. Even though Part $\mathrm{C}$ retains the characteristic of changing from a softer dynamic level to a louder level, as seen in previous parts, such changes occur very swiftly. Moreover, the occasional punctuations from the accents and sforzandi abruptly interrupt the flow of such dynamic changes. Therefore, Part C is comparatively more interrupted or less stable than previous parts, and is thus labeled as an "unstable region."

The Coda, on the other hand, preserves the gradual change of dynamics from mezzo piano ( $m p)$ to mezzo forte $(m f)$, forte $(f)$, fortissimo $(f f)$, and later to fortississimo $(f f f)$. Such changes occur gradually over the course of ten measures, which is considerably quicker than that seen in the Introduction, Parts A, B, and A', but is significantly more moderate than that in Part C. For this reason, the Coda is considered as a "stable region."

\section{3) Articulation}

The articulations seen in Section III can be divided into two types: legato and non-legato. The Introduction and Part A are both to be played with pedal, hence creating a very smooth texture. On the other hand, Part B contains a mixture of pedaling and lack of pedaling, but most of the time it is played without the pedal.

There is no indication of articulation in most of Part A'. It is presumably legato, mainly due to the fact that it is very similar to Part A in terms of melody and texture until the last two measures, where staccatissimo signs appear. This leads to a variety of articulations in Part C, 
where legato, staccato, staccatissimo, slurring, marcato, and accents are seen throughout. Even though such indications are rather irregular, there is a distinctive characteristic of the sequence of these articulations: they often alternate between legato and detached. For example, m. 129 is marked legato and mm. 130-132 contains a mixture of staccatissimo, staccato, and slurring; and mm. 133-134 is presumably legato while m. 135 is, again, marked with a mixture of staccato and slurring.

Lastly, the Coda is marked semi-legato, which in a way serves as a happy medium between the smooth passages and the more interruptive passages.

To conclude, Section III presents an ABA pattern in terms of stability-A being a more stable region, while $\mathrm{B}$ is a less stable region. It starts in a simple and stable manner all through Part A', and changes radically in character and the overall mood in Part C. The intensity is built up by the frequent—and more often than not, irregular—changes in harmonic rhythm, tempo, meter, dynamics, as well as articulation, which also coincides with the relatively more complex pitch content in Part C. The music reaches its first climax at the end of this part, but is abruptly interrupted by a sudden change in dynamic and articulation which marks the beginning of the Coda, before the texture and dynamics quickly build up again, bringing the entire section to a new, greater height. 


\section{Gameboy/Digital}

At the end of Section III: Solo Piano, where the solo piano repeatedly plays a string of high-pitched clusters, the audio recording merges in with the sounds of blaring car horns, marking the end of the section and the beginning of the transitional passage, labeled as Transition II, into Section IV: Gameboy/Digital.

Transition II lasts for approximately fifty seconds, during which the audience is carried on an audio journey from a busy street (sounds of car horns and pedestrians) into a building (sounds of people chattering), and later on into a concert hall (sounds of various orchestral instruments and the piano). These sounds fade away when a digital sound - a mobile phone ringtone $^{13}$, to be exact-enters from a distance, marking the beginning of the Section IV.

A clear sectional division is well-marked by an "X" at the beginning of m. 224.

Combined with other structural elements, such as melodic structure, texture, and tempo change, a three-part structure emerges: 1) Part A (mm. 161-201), 2) Part B (mm. 202-223), and 3) Part C (mm. 224-243).

The mobile phone ringtone takes the lead in Part A (Example 4.9), playing short motives that are highly rhythmic. These motives are repeated throughout Part A, which is rather similar to the treatment of the three-note cells seen in Section I: Construction/Industrial. The piano blends in fourteen measures later, playing the exact motive as the ringtone does, but a fifth higher in the right hand and, shortly afterwards, a fifth lower in the left hand. The ringtone and piano parts gradually grow apart but remain related in an imitative way. The texture is contrapuntal throughout.

\footnotetext{
${ }^{13}$ In an e-mail correspondence on February 27, 2013, Wong clarified that the ringtone is not derived from an actual ring tone; rather, it is a combination of computer game music and digital ringtones that she has heard over the years.
} 
IV. Gameboy/Digital
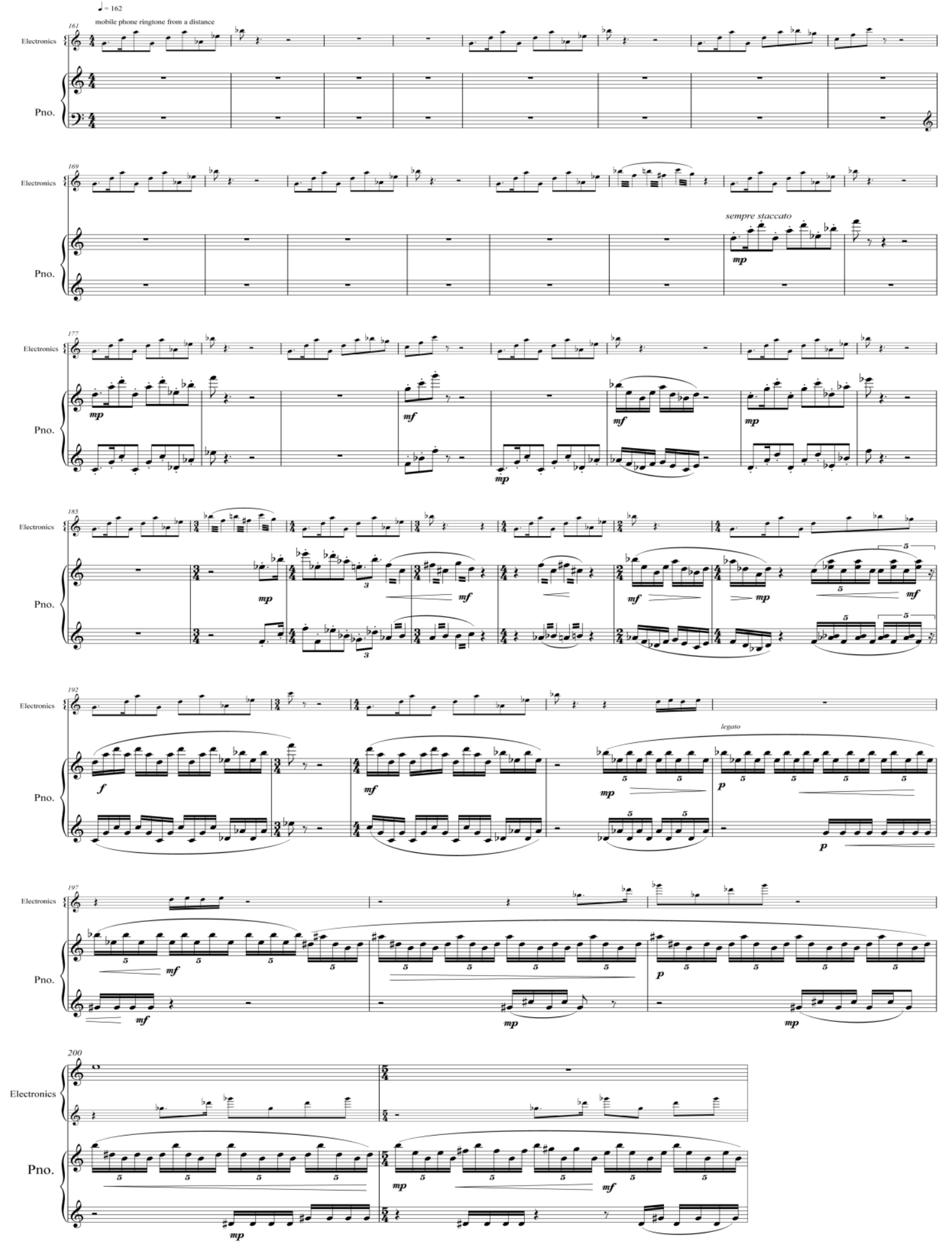

Example 4.9

Adeline Wong: Paces, Section IV, "Gameboy/Digital," Part A, mm. 161-201. 
Marked by a change in tempo, Part B (Example 4.10) is rather homophonic in texture, in that the piano plays strings of repeated pitches, acting as echoes, under a cloud of electronic sounds, which altogether creates a dreamy impression. At half the tempo of Part A, these repeated notes also create a delaying effect-perhaps, one that is similar to a slow motion visual effect in movies. Concurrently, another high-pitched electronic sound plays fragments of short, faint melodic motives. This is followed by a series of pedal tones in the bass, both in the electronics and the piano, which slowly fades away and bringing an end to Part B.
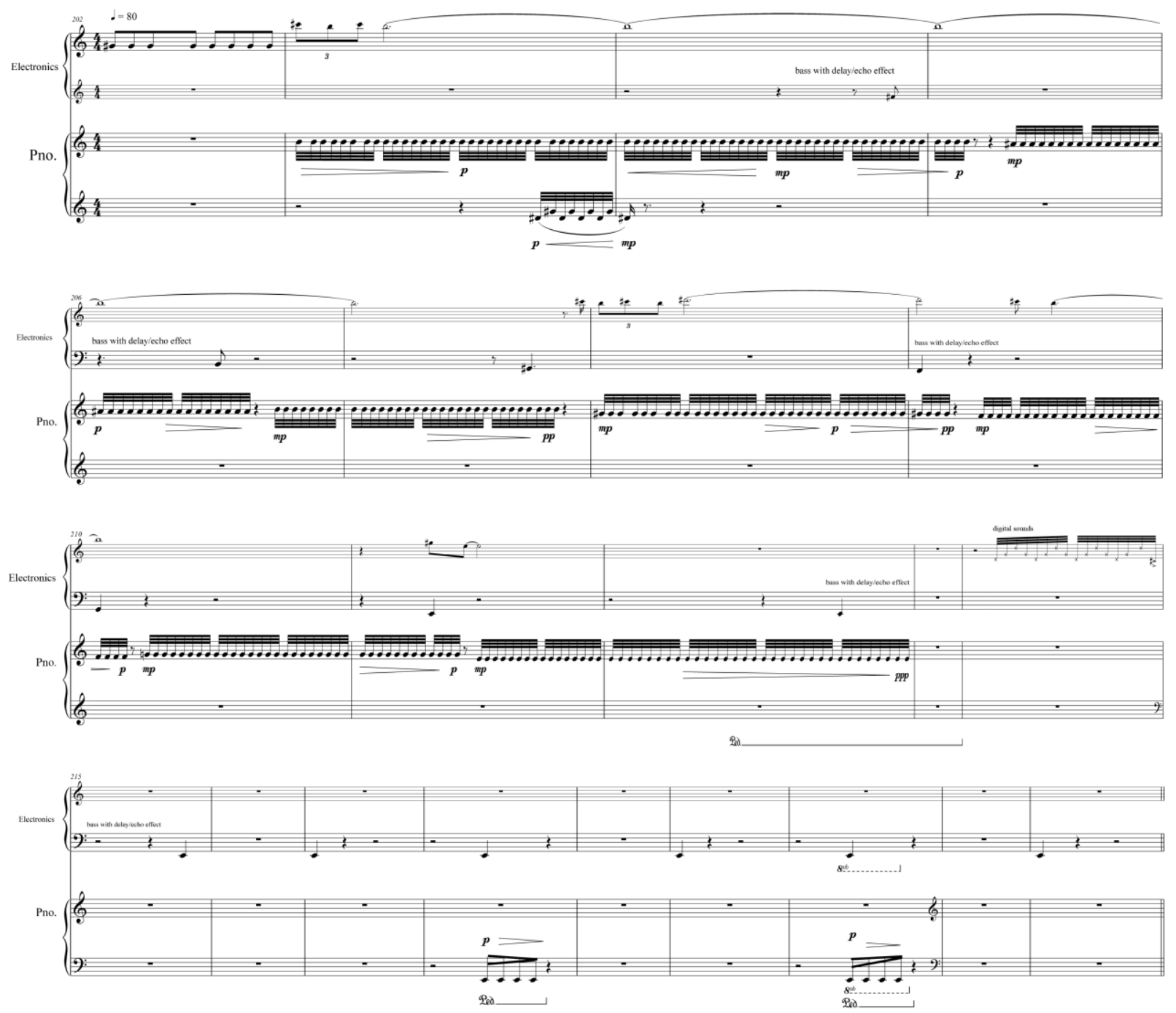

Example 4.10

Adeline Wong: Paces, Section IV, “Gameboy/Digital,” Part B, mm. 202-223. 
The last part, Part C (Example 4.11), is marked at a slower tempo. It begins with the piano solo, where the left hand part presses a tetrachord silently, while the right hand part attacks a series of dyads in open fifths and fourths, creating harmonics. This is followed by a change in meter and tempo, where a short melodious phrase set in a chordal texture recalls the main theme in Section III: Piano Solo. The audio recording surfaces again, adding voices of children to the last few chords in the piano, bringing Section III to a peaceful close.
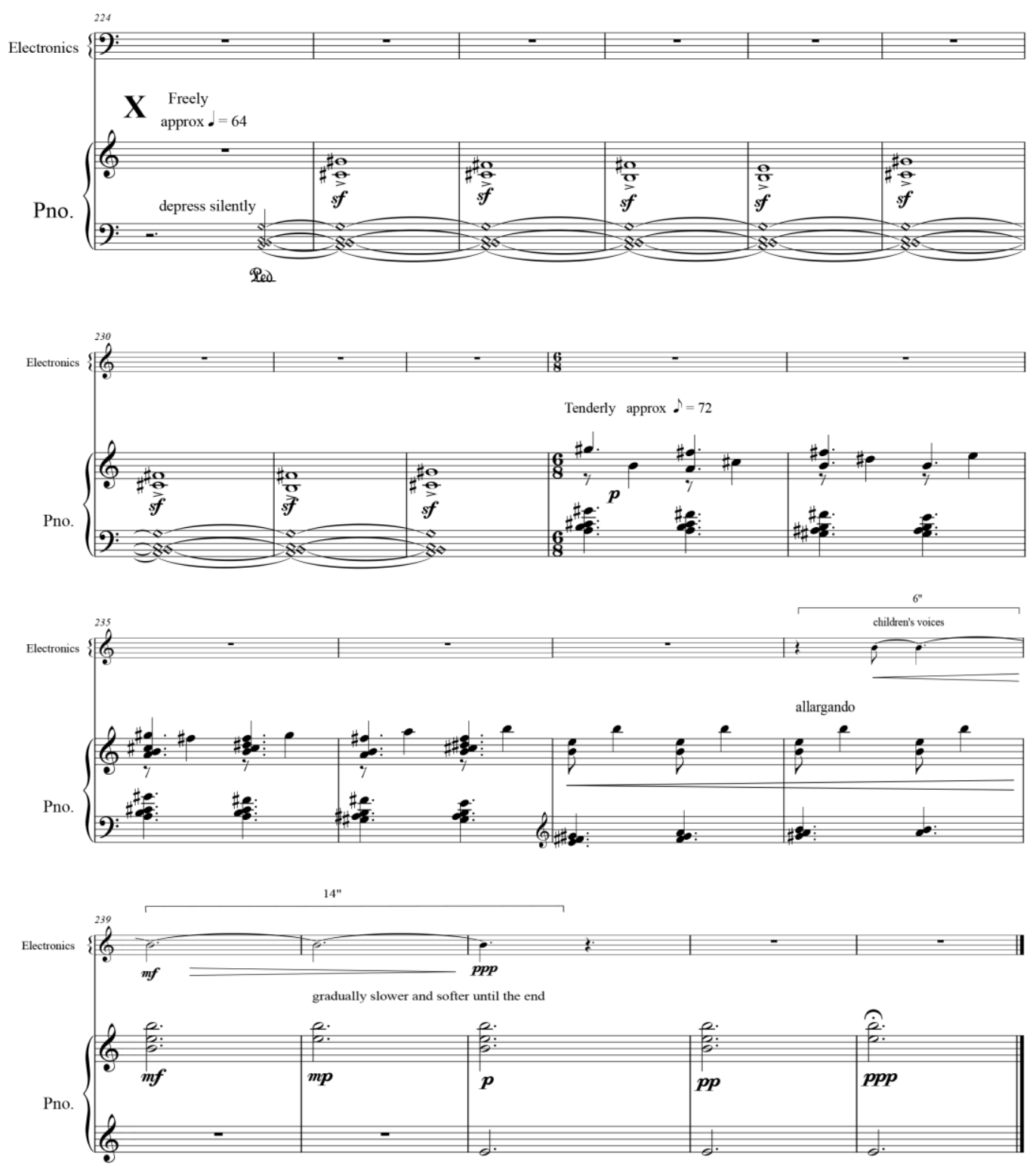

Example 4.11

Adeline Wong: Paces, Section IV, “Gameboy/Digital,” Part C, mm. 224-243. 
Thus far, each section in Paces seems to focus on one or two musical ideas. In this fourth section, the concept of three-note cells from Section I is still prevalent, with some alterations in rhythm. It is also interesting to trace the development of such cells throughout this section.

Another idea that stands out in Section IV is the concept of spaces between pitches, and between parts - which includes the counterpoint between the electronics ${ }^{14}$ and the piano parts: how they play together and gradually move away from each other. These two concepts require discussion. To assist in such discussion, other musical elements such as phrase structure, rhythm, and pitch relationship must also be examined.

\section{$\underline{\text { Part A }}$}

Part A opens with a short motif in the electronics, labeled as Motif 1, which comprises three sets of three-note cells that are interrelated (see Figures 4.34a and 4.34b). Unlike Section I which presents all of the cells in strict $16^{\text {th }}$ note rhythms, the dotted rhythm in the first cell adds a playful character to this motif.

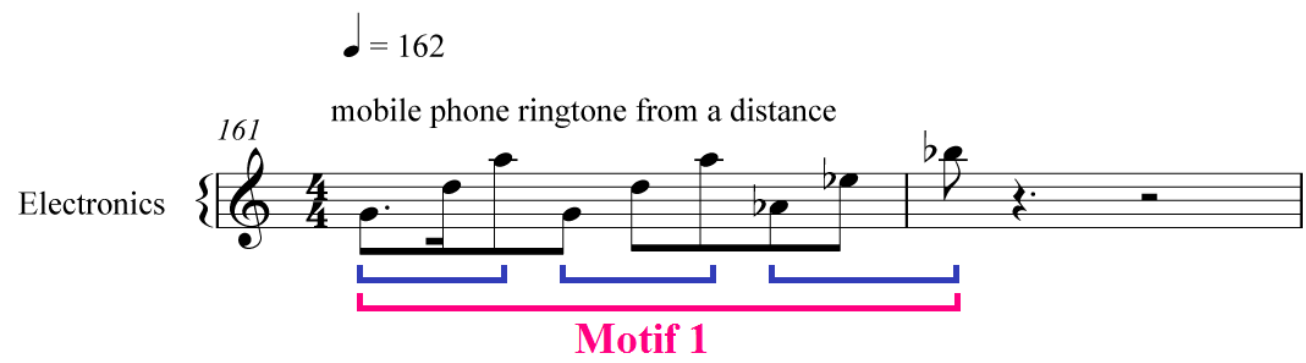

Figure 4.34a Motif 1.

\footnotetext{
${ }^{14}$ For the convenience of labeling and future references, the various sound samples in the audio recording will henceforth be labeled as electronics.
} 


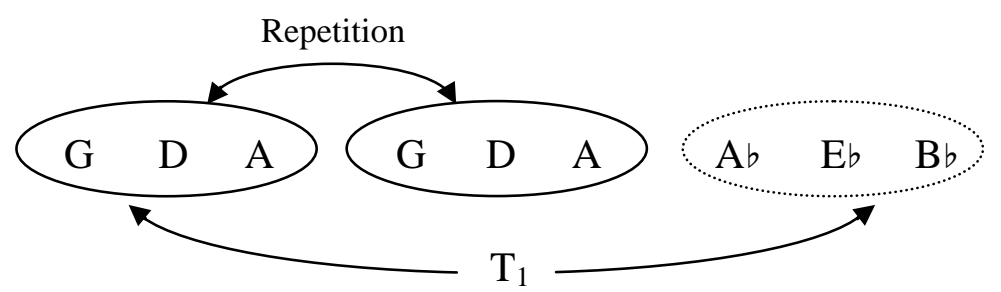

Figure 4.34b Three sets of three-note cells, Motif 1.

Motif 1 is present throughout Part A: at times it is presented in exact repetition ( $\mathrm{mm}$. 165-166); at times it is altered and extended at the end (mm. 167-168); and at times it expands into a new motif, Motif 2 (mm. 173-174) (see Figure 4.35). These motives, when grouped in sets of three, form two phrases that are for the most part identical in pitch and rhythm, except at the end of each phrase. Hence, they are labeled as Phrases 1a and 1a'.

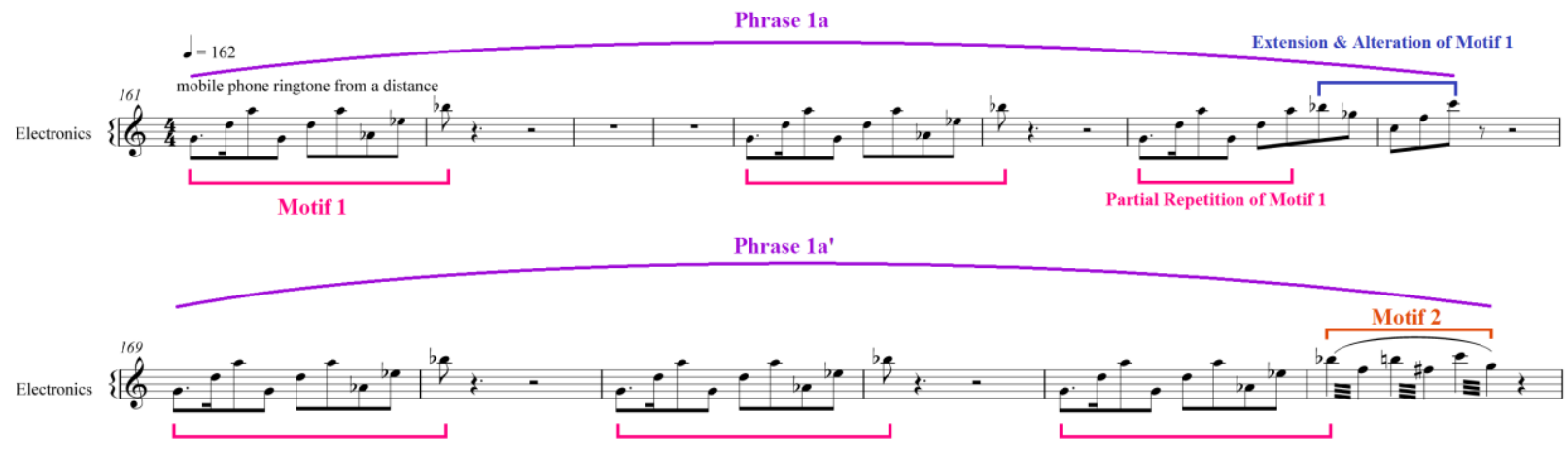

Figure 4.35 Recurrences of Motif 1 and the introduction of Motif 2 in Part A, Phrases 1a and 1a'.

These two phrases are repeated in mm. 175-186 almost in their entire exact form, except there are some minor alterations to the duration of silence between motives (see Figure 4.36, differences are shown by pink arrows). These phrases are labeled as Phrases $2 \mathrm{a}$ and $2 \mathrm{a}^{\prime}$, in that Phrase 2a is related to Phrase 1a, while Phrase 2a' is related to Phrase 1a'. At the beginning of Phrase 2a, the two empty measures seen in Phrase 1a are eliminated. Meanwhile, at the end of 
Phrase 2a', the last quarter rest is dropped and the meter is changed, leaving no space before the next phrase, Phrase 3a, begins.

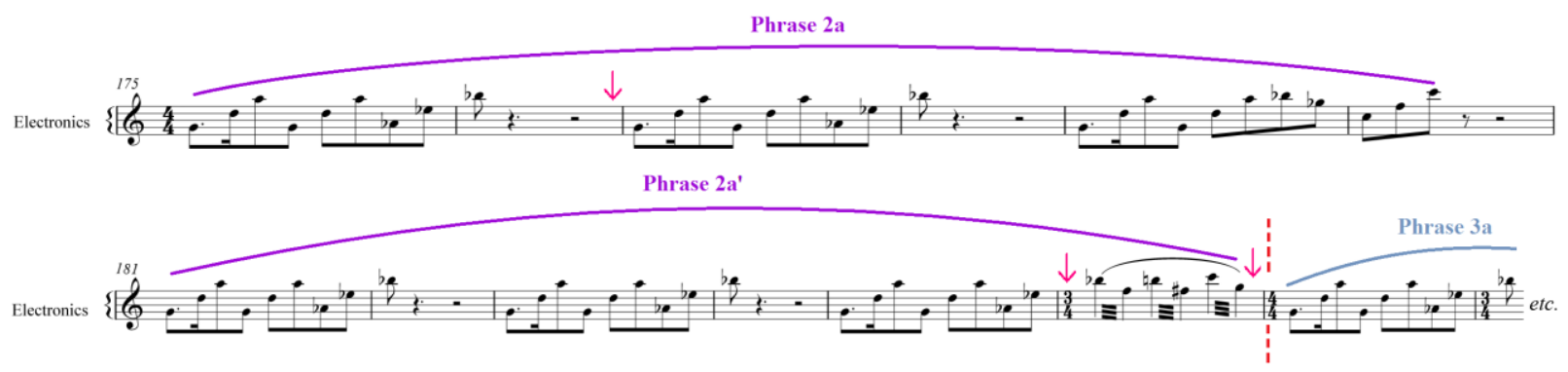

Figure 4.36 Part A, Phrases 2a and 2a'.

Phrase 3a (mm. 187-191) is a repetition of Phrase 2a, but with some slight modifications: the duration of silence between motives is shortened through meter changes, and the ending is incomplete (see Figure 4.37a, differences are shown by pink arrows). This is immediately followed by Phrase 3a' (mm. 192-197), which quotes the first four measures of Phrase 3a, but with an alteration in pitch in the second measure and without a change in meter in the fourth measure (see Figure 4.37a). The last group of Motif 1 in Phrase 3a is replaced by yet another short motivic idea, labeled as Motif 3, which is repeated a measure later. Arguably a variant of Motif 2, this motif is also clearly related to the gamelan motif seen at the beginning of Section III, in the Brief Introduction (see Figure 4.37b).

Phrase 3a

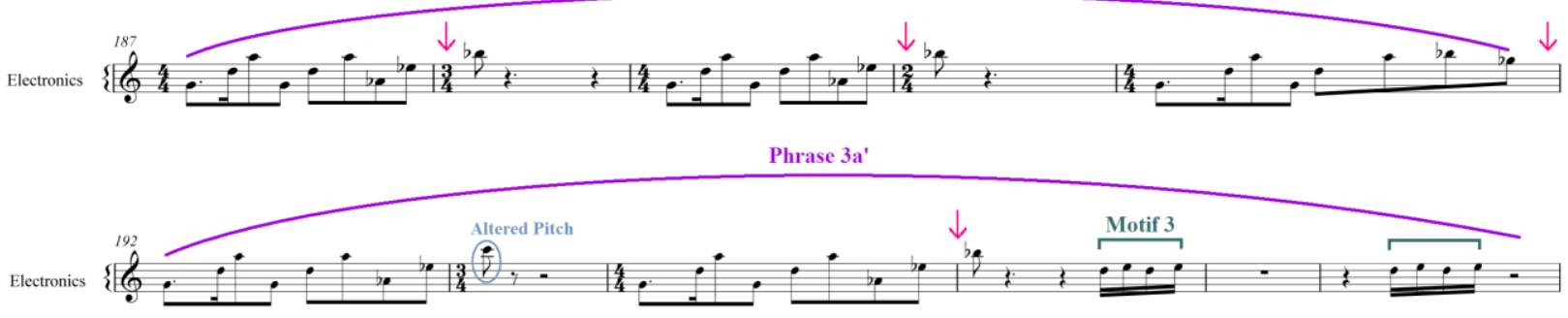

Figure 4.37a Part A, Phrases 3a and 3a'. 


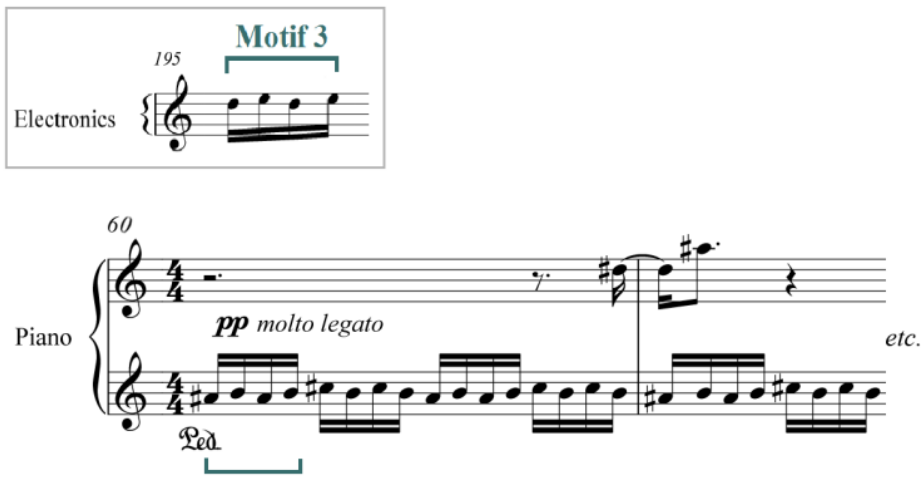

Figure 4.37b Similarities between Motif 3 and the gamelan motif in Brief Introduction, m. 60 .

Subsequently, the last phrase in this part, Phrase 4 (mm. 198-201), is made of three repeated sets of incomplete motives derived from Motif 1 (see Figure 4.38a). To be exact, they are transpositions of the piano counterparts which double the electronics in Phrase 2a, mm. 175 and 177 (see Figure 4.38b).

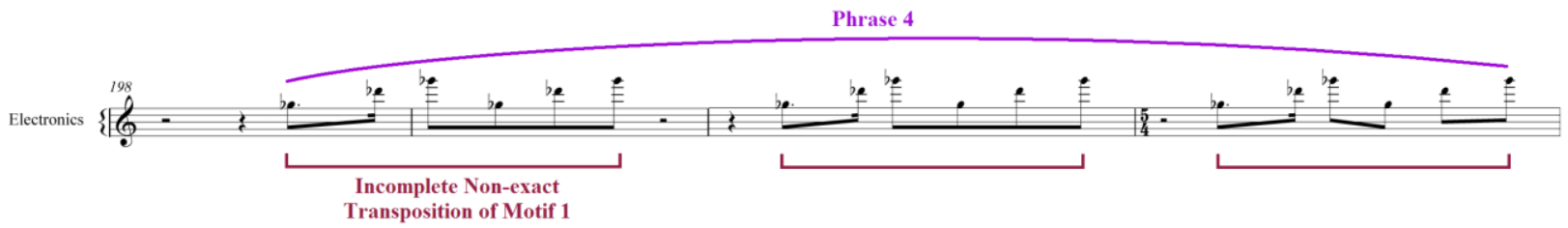

Figure 4.38a Partial recurrences of Motif 1 in Part A, Phrase 4.
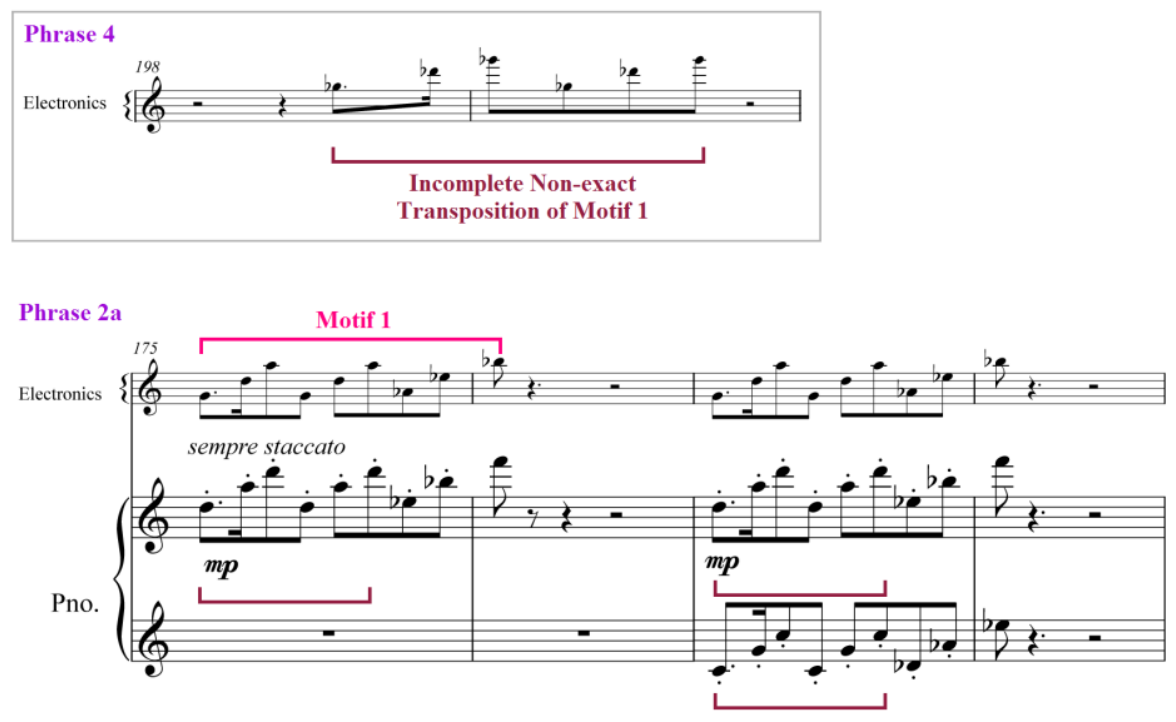

Figure 4.38b Derivation of the incomplete Motif 1 from the piano parts in Part A, Phrase 2a. 

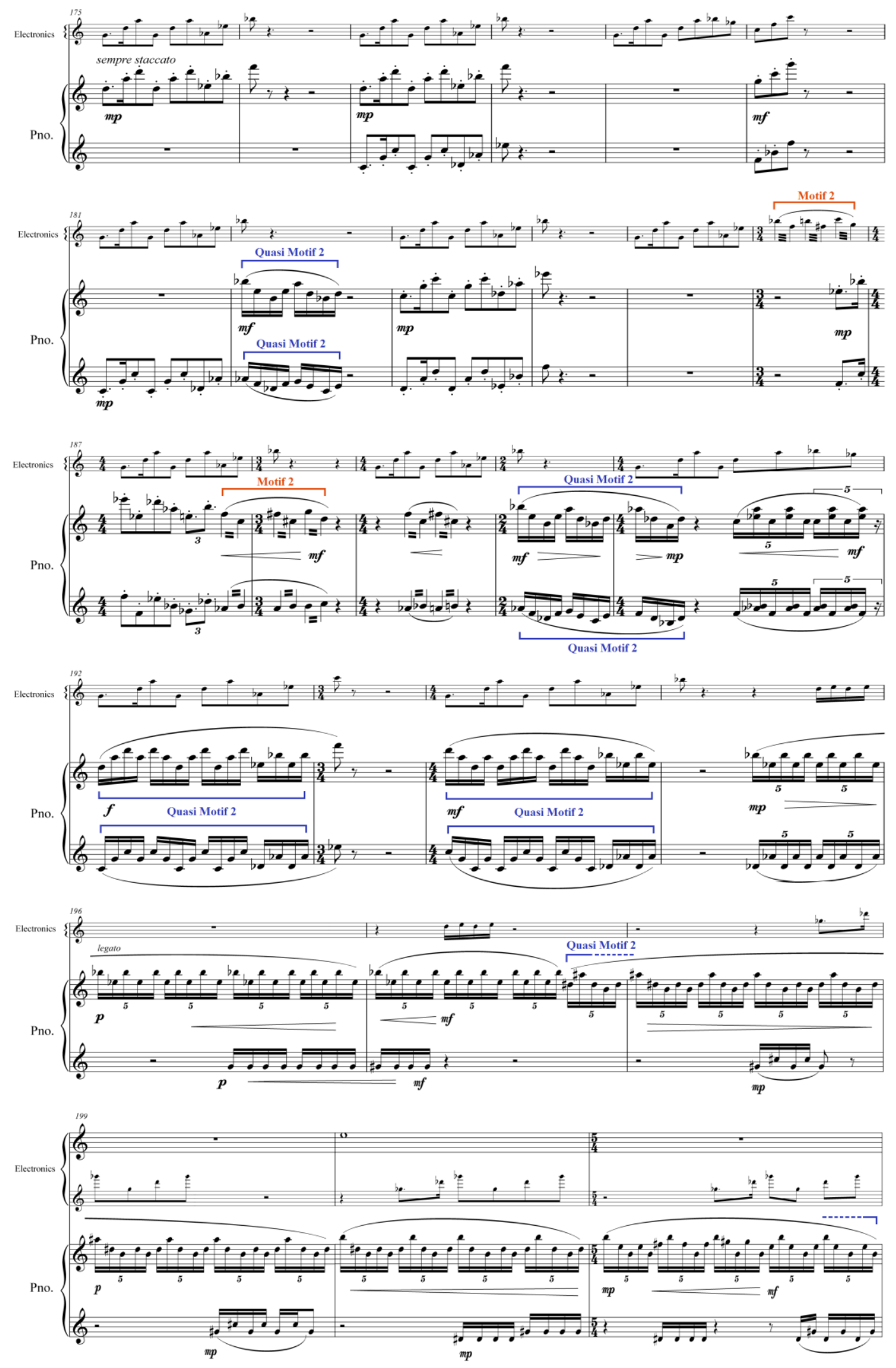

Figure 4.39 Counterpoint between electronics and piano parts; and traces of Motif 2 in Part A, mm. 175-201. 
As seen in Figure 4.39, the piano parts begin by doubling the electronics in an imitative manner (mm. 175-178). All three counterparts are generally transpositionally related, but not entirely so. Sometimes, one or both of the piano parts drop(s) out and only play(s) parts of the motives with the electronics (mm. 179-181, 194-195). At times, the rhythm of the motives in the piano parts are varied into a pattern somewhat like that of Motif 2 (mm. 182, 190-192, 194, and 197-201). Occasionally, the piano parts start the motives a few beats later than the electronics (mm. 185-188), and sometimes they insert different motives — particularly, variants of Motif 2that do not coincide with the electronics (mm. 182, 189-191, 195-201).

As mentioned earlier, one of the key features in Section IV is the development of the three-note cells, especially the development of Motif 2. This motif is first seen in the electronics in m. 174 as an extension of Motif 1 (see Figure 4.40). It consists of two sets of rising 3-note cells, in which each note is a semitone apart, separated under a tremolo gesture (see Figure 4.41a). Both cells, when lined up vertically, create the interval of a perfect $4^{\text {th }}$ (or, unordered pitch-class interval 5).

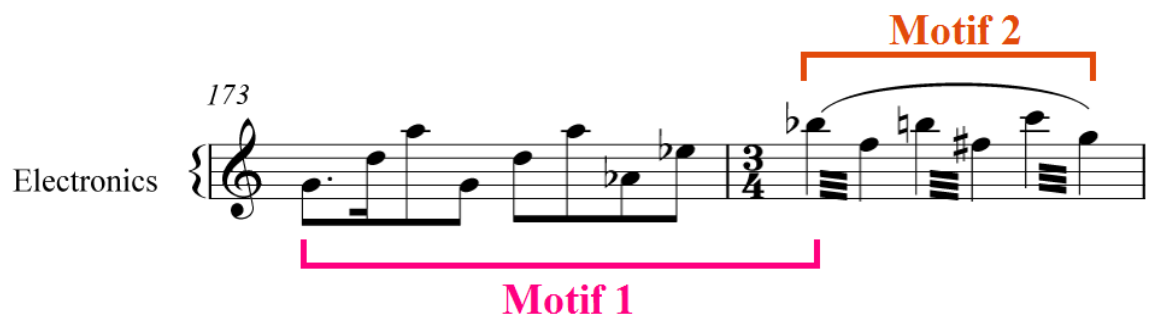

Figure 4.40 Extension of Motif 1 into Motif 2. 
a)

\section{Motif 2}

Electronics

c)

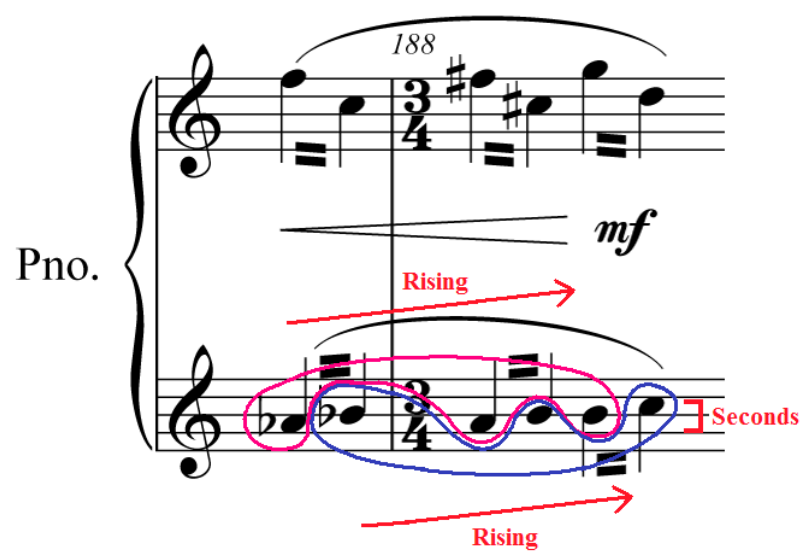

b)

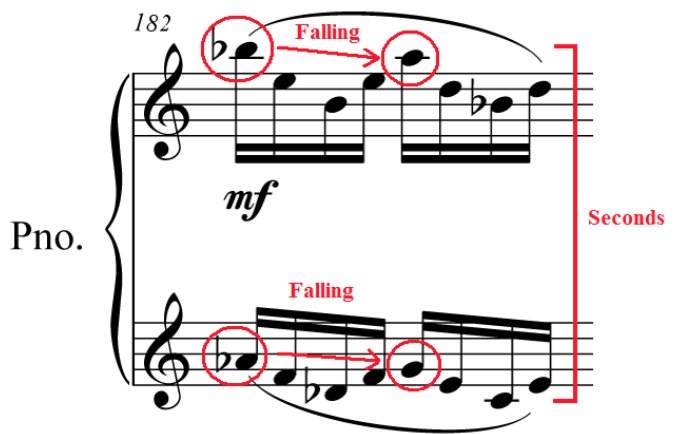

d)

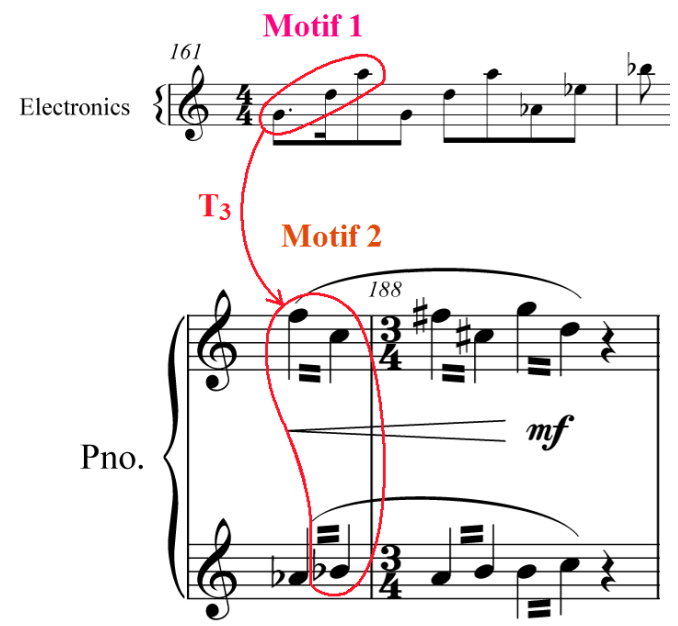

e)

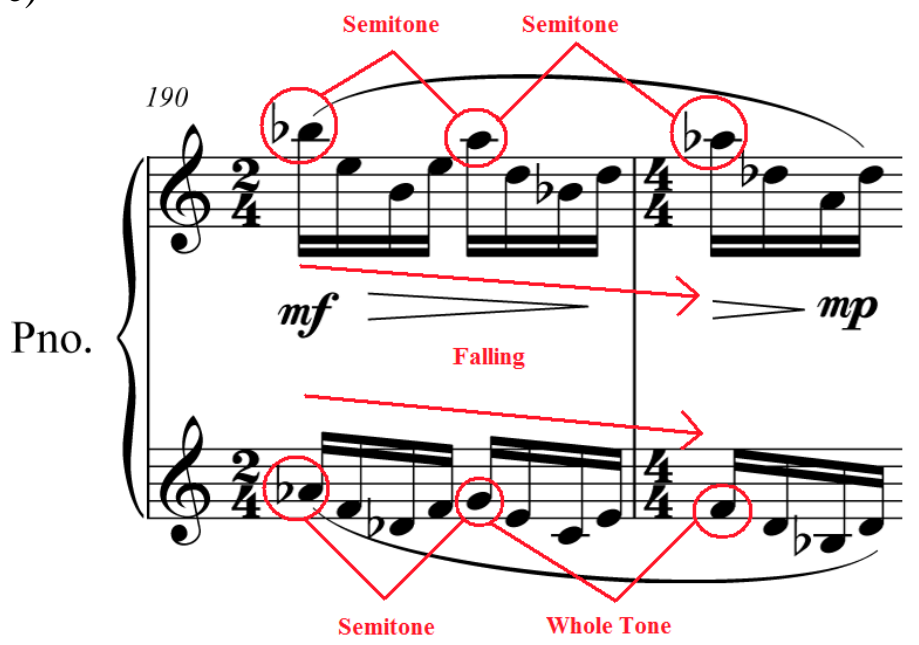

Figure 4.41 Motif 2 and its variants. 
When Motif 2 first appears in the piano parts in $\mathrm{m} .182$, it is transformed into two groups of broken chord figures instead, which results in the motif being incomplete (see Figure 4.41b). The main metric notes in each hand remain a semitone apart, but this time they are in descending order. Meanwhile, both right hand and left hand are transpositionally related by seconds - that is, a semitone or a whole tone apart.

The next time Motif 2 comes back in $\mathrm{mm} .187-188$, it is transposed a perfect $4^{\text {th }}$ lower (or, unordered pitch-class interval 5) in the right hand of the piano part, while the left hand introduces two sets of rising 3-note cells with a new intervallic relationship of a second —again, a semitone or a whole tone apart—between each corresponding pitch in the cells (see Figure 4.41c). This set of Motif 2 is repeated a measure later in $\mathrm{m}$. 189, with the third cell group being eliminated. Note that in the first vertical set of notes between both right hand and left hand, the right hand notes plus the top note of the left hand (i.e. $\mathrm{B} b-\mathrm{C}-\mathrm{F}$ ) is the same set class as the cell from Motif 1, G-A-D (see Figure 4.41d).

The subsequent measures, mm. 190-191, repeat the falling broken chord figures seen in m. 182, only this time the third cell group is added (see Figures $4.41 \mathrm{~b}$ and $4.41 \mathrm{e}$ ). However, the main notes in the left hand do not keep the same intervallic relationship as that of the right hand, in that the distance between the second and third main notes is a whole tone apart, instead of being a semitone apart. Later on in mm. 197-201, the right hand of the piano part also carries a number of repeated figures that are similar to that seen in mm. 190-191 (see Figures 4.39 and 4.41e).

In the second half of m. 191, yet another figure is introduced: the tremolo effect is used here, but the pitches are stacked on top of each other to form dyads and tetrachords (see Figure 4.42). Interestingly, the intervals between each dyad in both hands reflect the same intervallic 
relationships seen in Motif 2 in mm. 187-188, as do the collections framed by the simultaneity of the two hands.
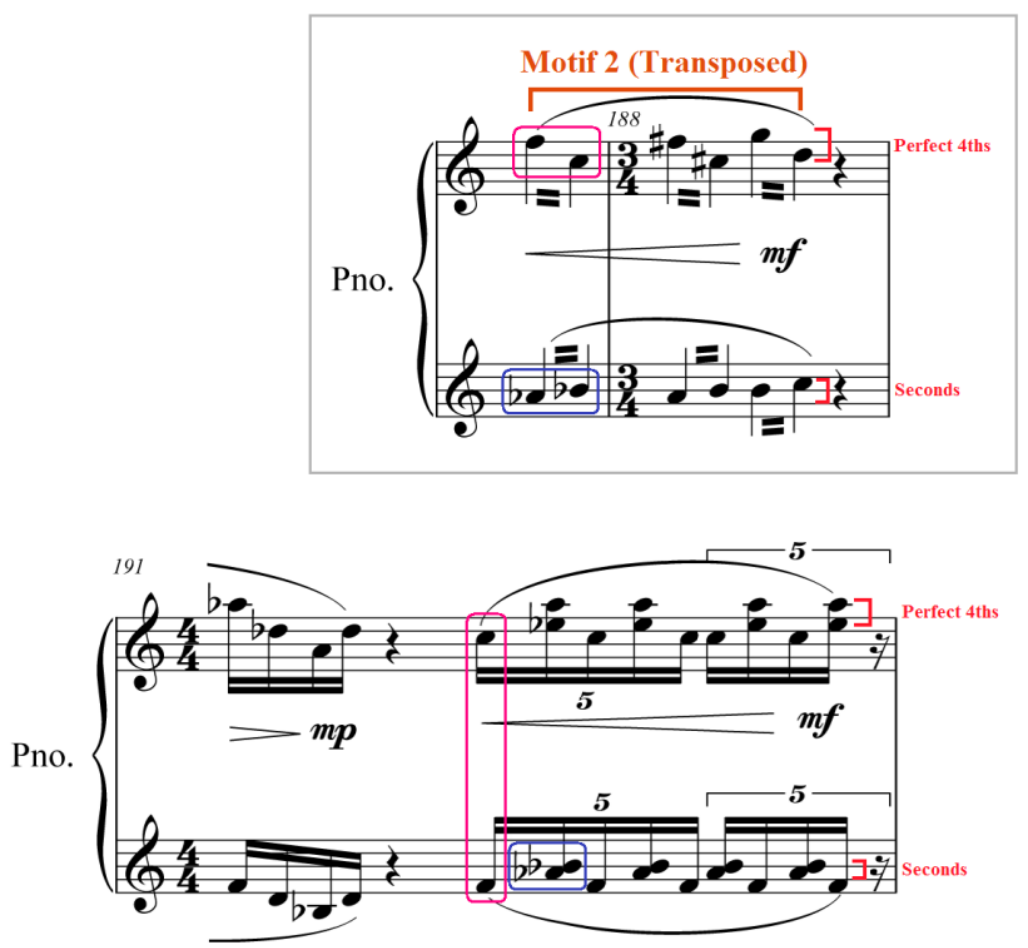

Figure 4.42 Common traits between Motif 2 and its variants in mm. 187-188 and m. 191.

Worthy of note is the fact that these means of variations, applied to Motif 2, are also applied to Motif 1, particularly in mm. 192-195, where the motives in the piano parts are rearranged into the broken chord figures seen in mm. 182 and 190-191 (see Figures 4.43, 4.41b, and 4.41e). The last group of four $16^{\text {th }}$ notes in $\mathrm{m} .194$ is repeated with quintuplets in the next measure, and the right hand carries on with the same figure for another two measures. The left hand also plays fragments of this figure later in mm. 198-201. The distance between the pitches in these figures in each respective hand is either a perfect $5^{\text {th }}$ apart or a perfect $4^{\text {th }}$ apart, both of which maps onto each other when inverted and belong to interval class 5 . This is the same 
intervallic relationship that is used extensively in Motif 2 and its variants, hence creating a connection between Motives 1 and 2 .
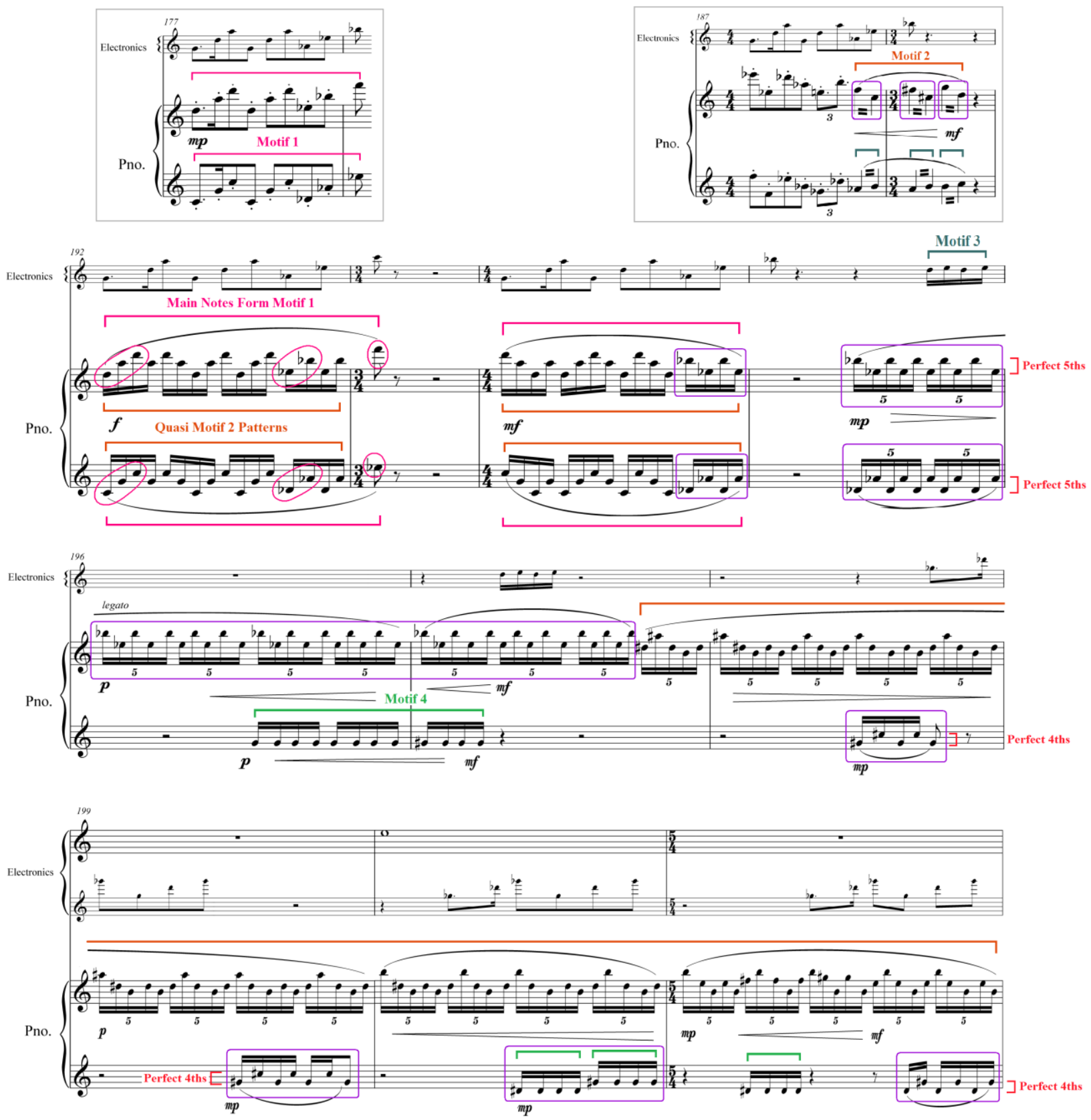

Figure 4.43 Traces of Motives 1, 2, 3, and 4 in Part A, mm. 192-201.

In mm. 195 and 197, the motif seen in the electronics, labeled as Motif 3, could also be traced back to Motif 2 in mm. 187-188, in the left hand of the piano part (see Figure 4.43). 
Rather than a rapid tremolo, Motif 3 is measured and notated as two sets of alternating pitches a tone apart. Both pitches in Motif 3 are then transposed a $5^{\text {th }}$ lower, and are prolonged to become two sets of repeated-note figures a semitone apart in mm. 196-197, in the left hand of the piano part. This new figure is labeled as Motif 4, and is seen shortly after that in mm. 200-201-again, in the left hand of the piano part—but this time, it is applied to a fragment of Motif 2.

On the concept of spaces between pitches, it is interesting to note that the distance between the pitches in all four motives, including Motif 1, progressively shortens: from perfect fifths (Motif 1), to perfect fourths (Motif 2), then to major seconds (Motif 3), and finally minor seconds (Motif 4). This idea of closing the gap between pitches is also evident in Part A, in the treatment of the motives in each phrase, as well as the space - or the length of silence-between motives (see Figure 4.44a). Not only that, such concept is also seen in the counterpoint between the electronics and the piano parts (see Figure 4.44b).

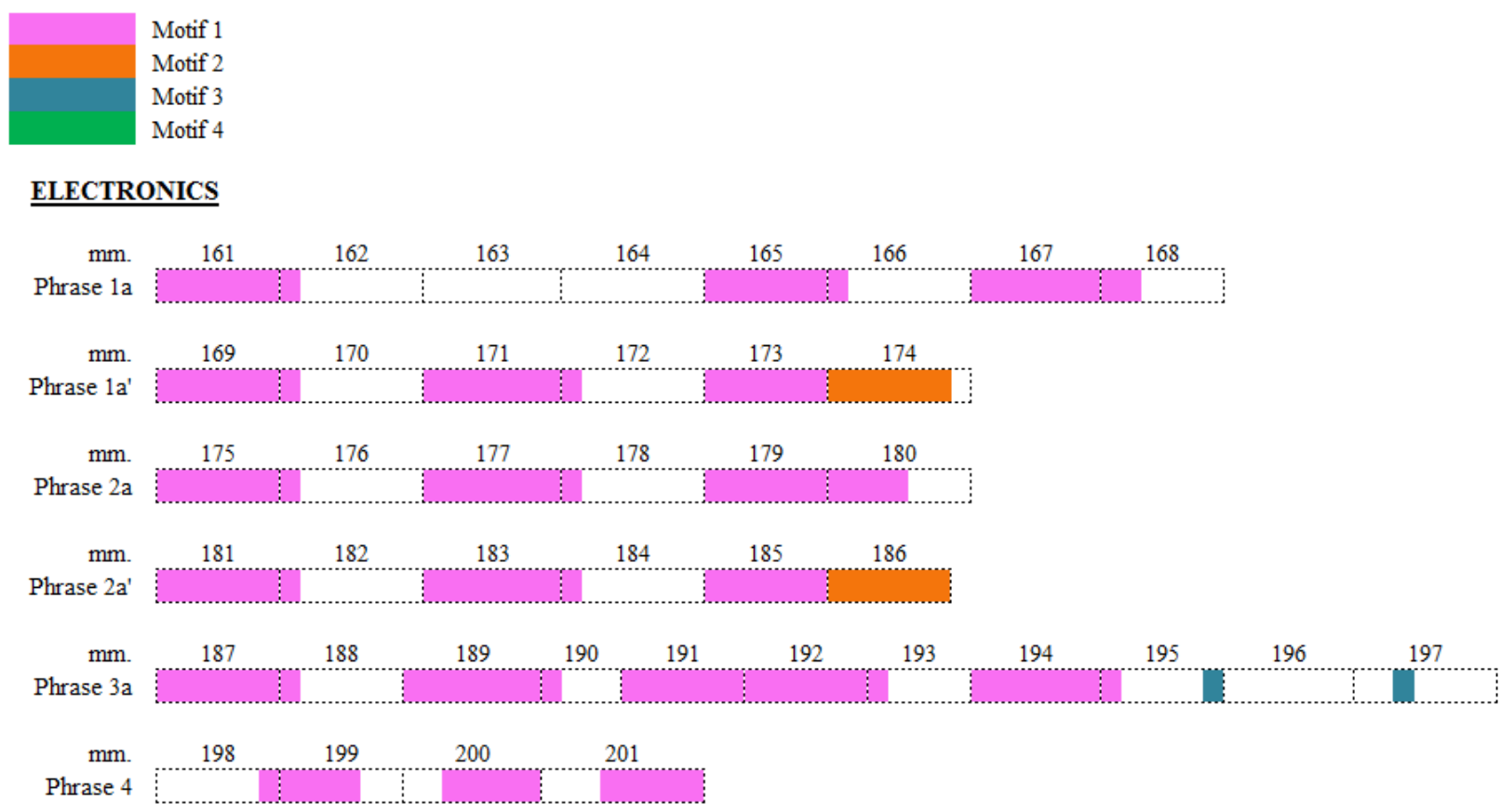

Figure 4.44a Treatment of gaps between motives in the electronics in Part A. 


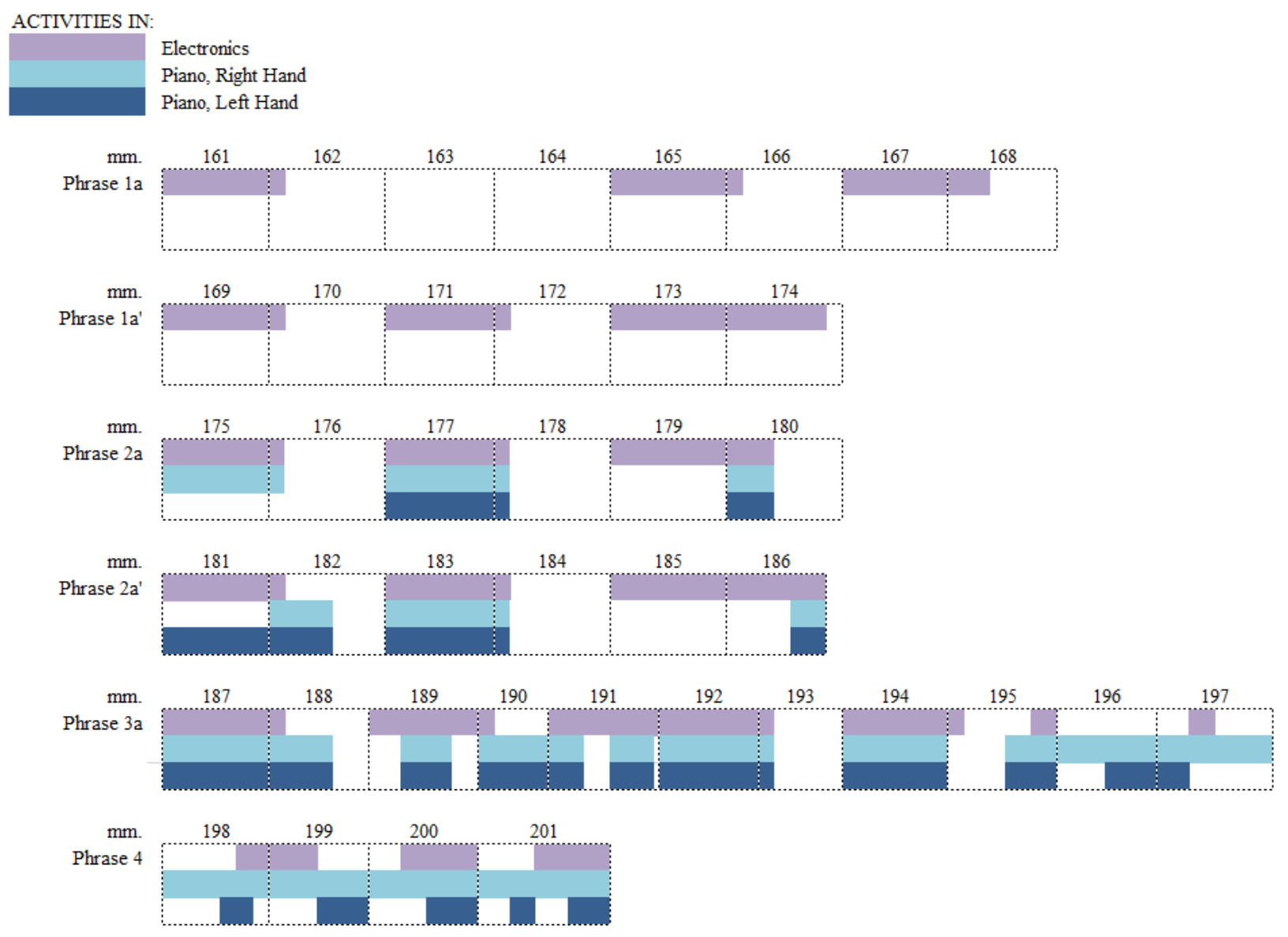

Figure 4.44b Treatment of gaps between electronics and piano parts in Part A.

\section{$\underline{\text { Part B }}$}

Motives 2, 3, and 4 are carried from Part A into Part B (Figure 4.45): Motive 2 is carried by the left hand of the piano part in mm. 203-204; Motive 3 is heard in the electronics in m. 203, and mm. 207-208; while Motive 4 is seen throughout the right hand of the piano part. 


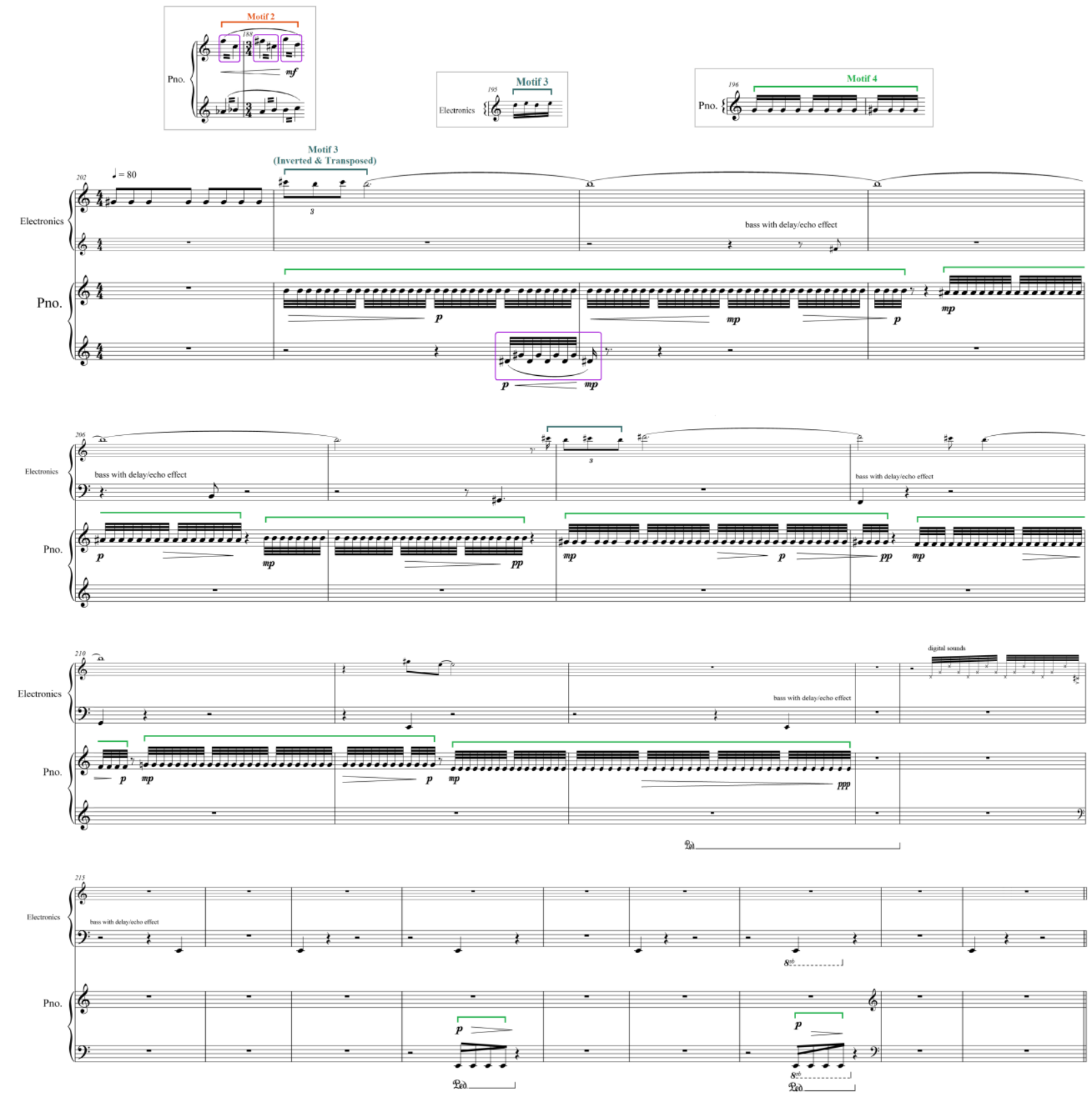

Figure 4.45 Traces of Motives 2, 3, and 4 in Part B, mm. 202-223.

Also noteworthy is the organization of the pitch content in Part B. The electronics present a high-pitched melody that recalls the Brief Introduction of Section III: Piano Solo. This melodic phrase, together with the piano parts, can be divided into three segments: 1) mm. 203-207, 2) mm. 208-210, and 3) mm. 211-212. The pitch content in these segments exhibits an interesting 
intervallic relationship between one segment and another (see Figures 4.46a and 4.46b). The first segment consists of a set of five pitch-classes with the distances, measured by semitones, of [21-2-2]. The second segment can be broken into two groups of three-note cells, which also exemplifies the distances of [2-1] and [2-2]. The third segment consists of only two pitchclasses, which is separated by four semitones, which is the total of [2-2].

\begin{tabular}{|c|c|c|}
\hline Segment & Measure & Pitch-Class Collection \\
\hline 1 & $203-207$ & G\#, A\#, B, C\#, D\# \\
\hline 2 & $208-210$ & F, G, G\#, B, C\#, D\# \\
\hline 3 & $211-212$ & E, G\# \\
\hline
\end{tabular}

Figure 4.46a Pitch content in Part B, Segments 1-3.

Segment 1

Segment 2

Segment 3

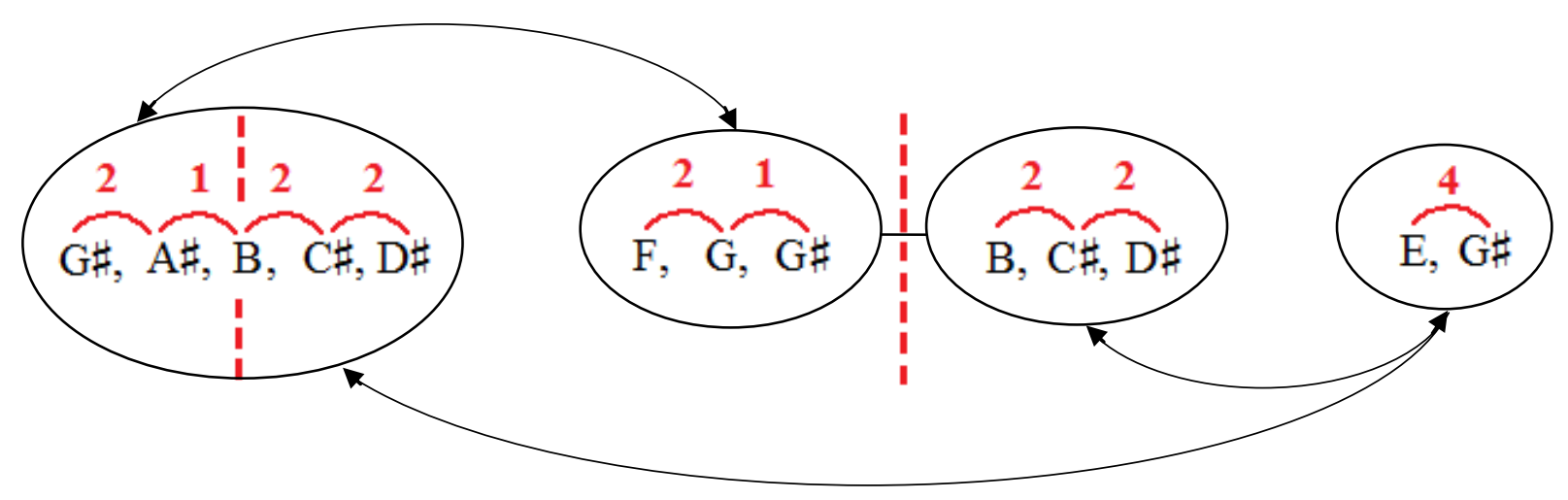

Figure 4.46b Intervallic relationships between pitch content in Part B, Segments 1-3. 


\section{$\underline{\text { Part C }}$}

The idea of open fifths and fourths (or, interval class 5) — the intervallic relationships between pitches seen in Motif 2 in Part A-is used in the first half of Part C (see Figure 4.47a). These dyads outline a familiar chord progression heard in Section III: Piano Solo (see Figure 4.47b).

The second half of Part $\mathrm{C}$ repeats these chord progressions by adding both more pitches to the dyads and also a counter melody, which is made of an ascending B mixolydian scale (see Figure 4.47a). The pitch selection in these chords is closely related to the pitch collections seen in Section III, especially that of the Brief Introduction, Part A, and Part B (see Figure 4.48). 


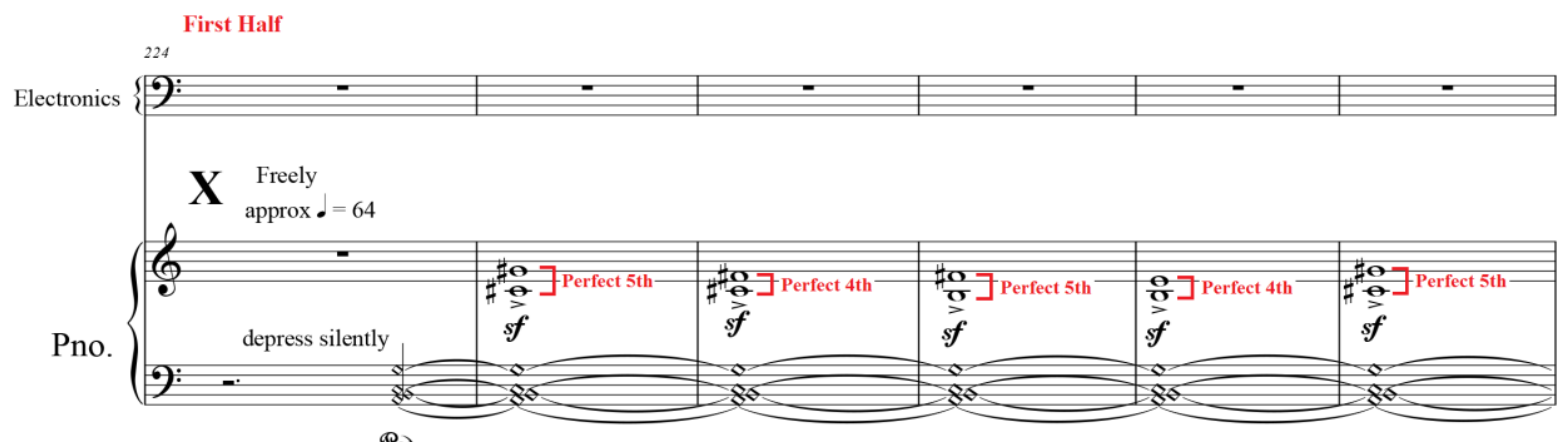

Red
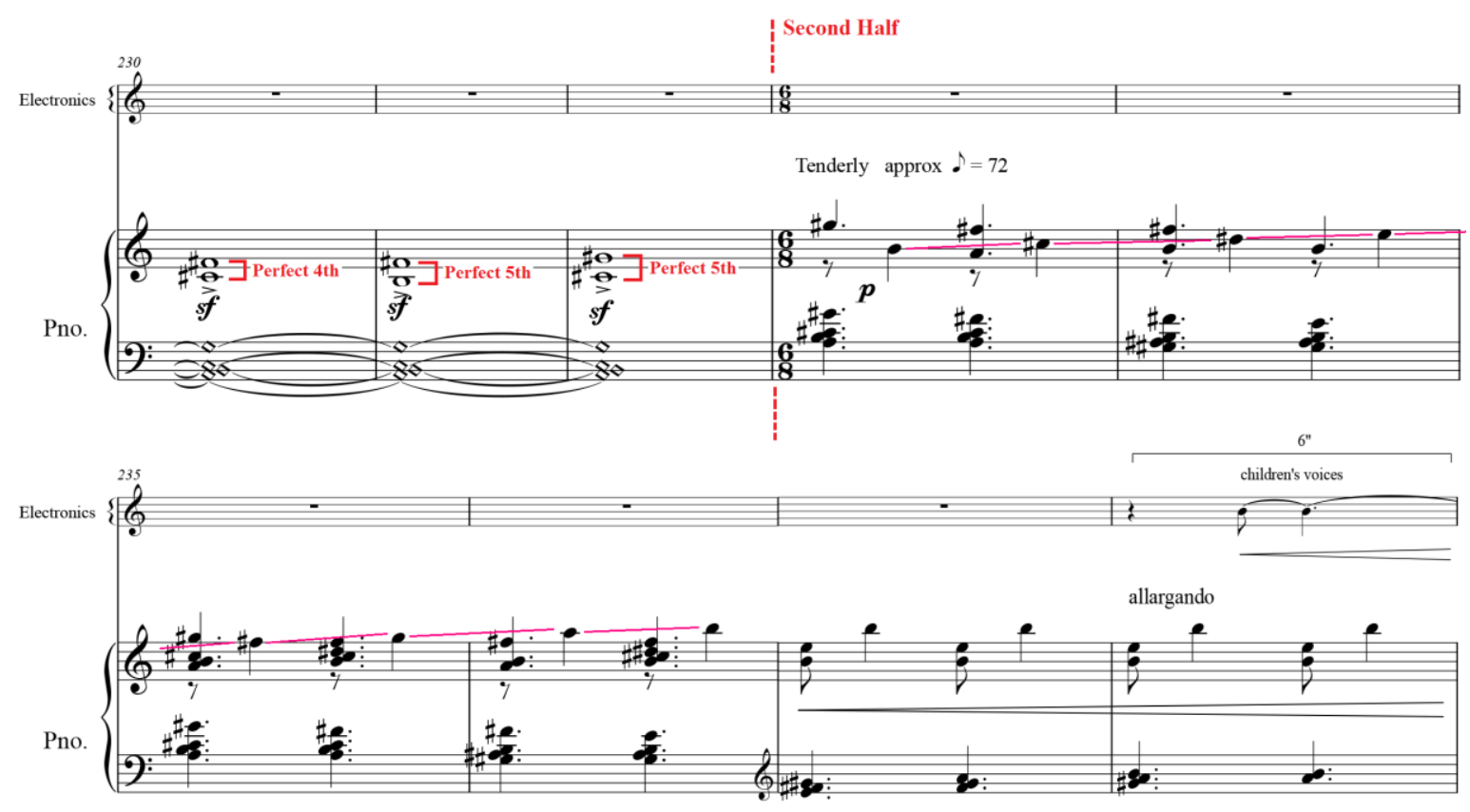

$14 "$

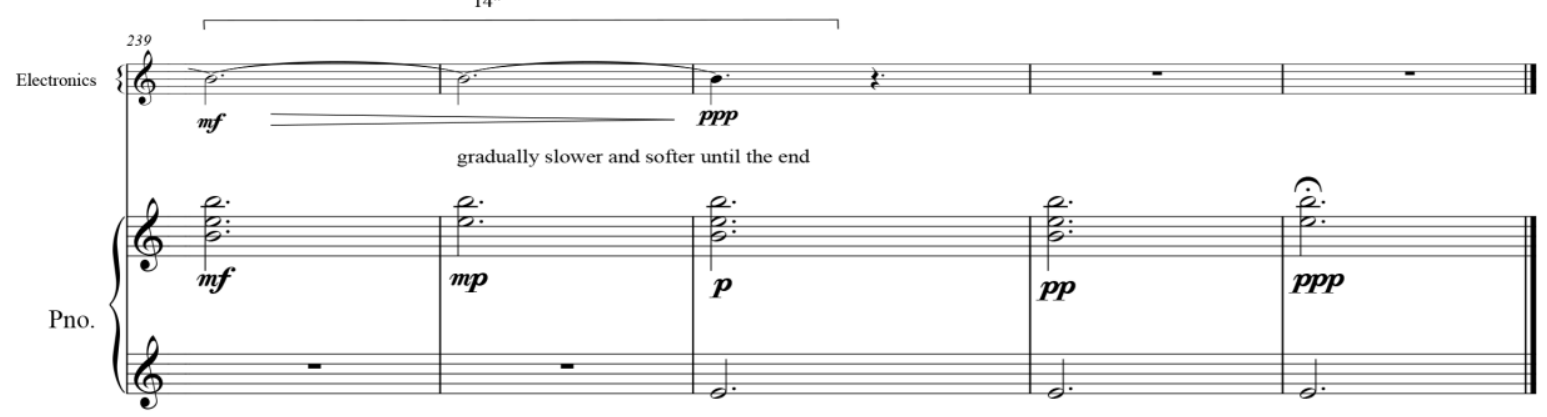

Figure 4.47a

Adeline Wong: Paces, Section IV, “Gameboy/Digital,” Part C, mm. 224-243. 


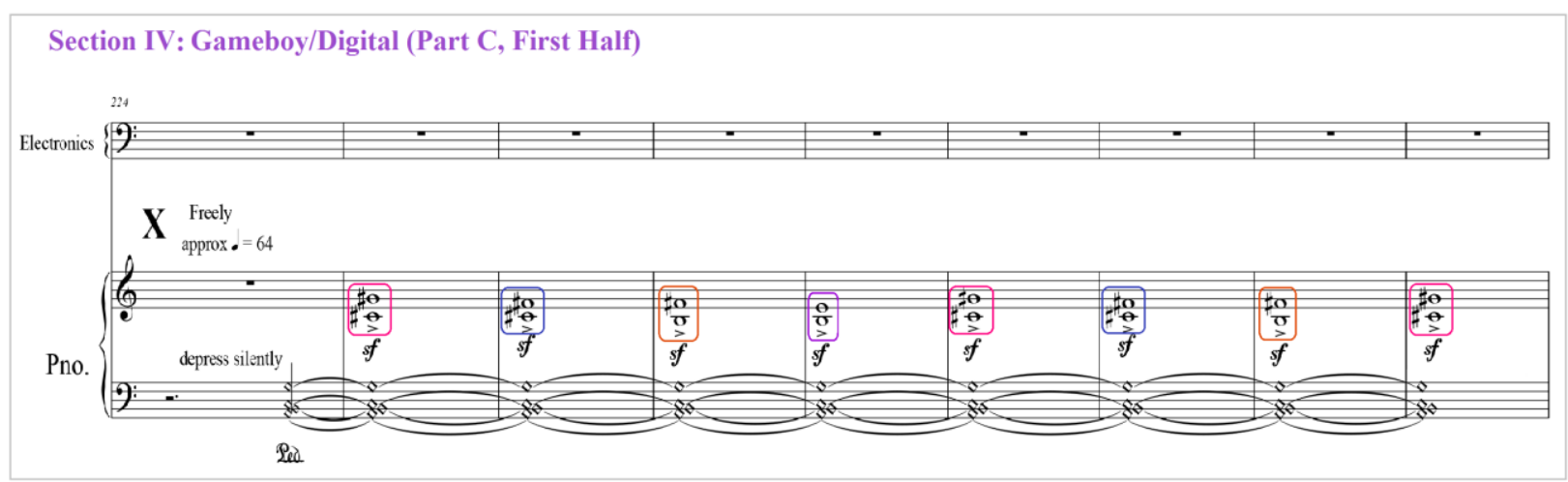

Section III: Piano Solo (Part A')
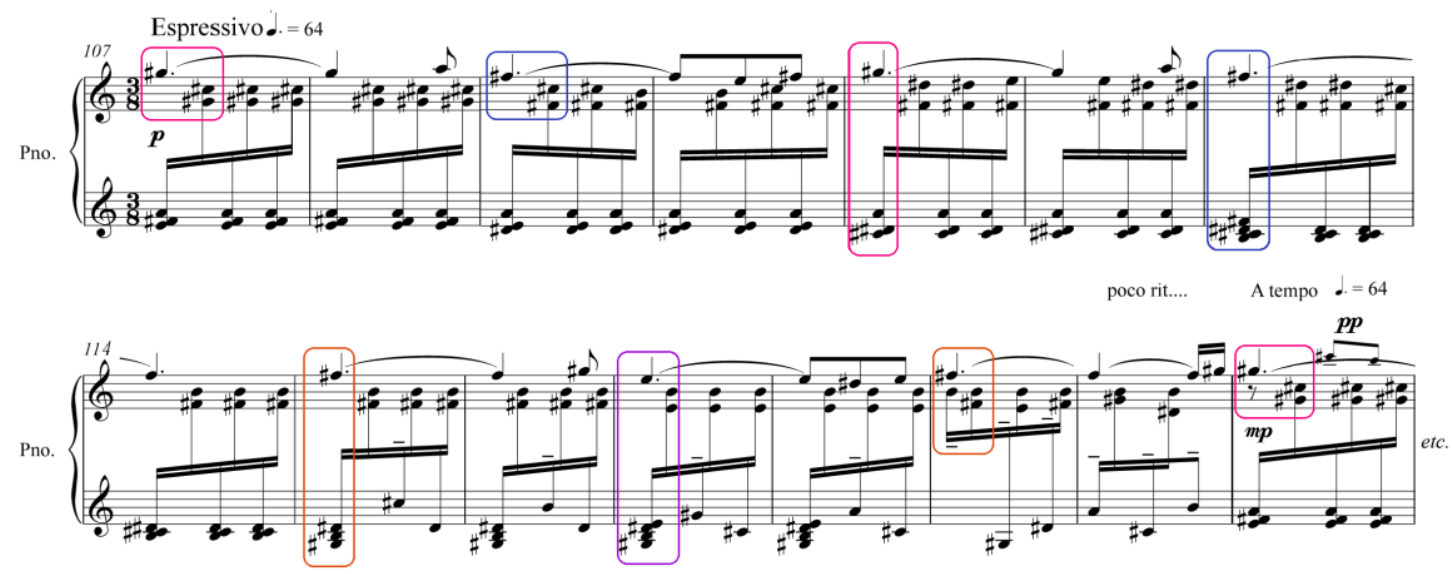

Figure 4.47b Similarities in harmonies between Section IV, Part C and Section III, Part A'. 


\begin{tabular}{|c|c|c|c|c|c|c|}
\hline \multicolumn{4}{|c|}{ Section IV, Part C } & \multirow{2}{*}{ Relationship } & \multicolumn{2}{|l|}{ Section III } \\
\hline Measure & Beat & Pitch-Class Collection & Pitch-Class Set & & Pitch-Class Set & Label \\
\hline \multirow{2}{*}{233} & 1 & $\mathrm{G} \#, \mathrm{~A}, \mathrm{~B}, \mathrm{C} \#$ & {$[0,2,4,5]$} & Exact Form & {$[0,2,4,5]$} & $\mathrm{I} 1$ \\
\hline & 2 & $\mathrm{~F} \#, \mathrm{~A}, \mathrm{~B}, \mathrm{C \#}$ & {$[0,2,4,7]$} & Subset & {$[0,2,4,5,7]$} & $\mathrm{I} 2$ \\
\hline \multirow{2}{*}{234} & 1 & $\mathrm{D} \#, \mathrm{~F} \#, \mathrm{G} \#, \mathrm{~A} \#, \mathrm{~B}$ & {$[0,1,3,5,8]$} & Exact Form & {$[0,1,3,5,8]$} & A1.1 \\
\hline & 2 & $\mathrm{E}, \mathrm{G} \#, \mathrm{~A} \#, \mathrm{~B}$ & {$[0,1,3,7]$} & Subset & {$[0,1,3,5,7,9]$} & A3 \\
\hline \multirow{2}{*}{235} & 1 & $\mathrm{~F} \#, \mathrm{G} \#, \mathrm{~A}, \mathrm{~B}, \mathrm{C \#}$ & {$[0,2,4,5,7]$} & Exact Form & {$[0,2,4,5,7]$} & $\mathrm{I} 2$ \\
\hline & 2 & $\mathrm{~F} \#, \mathrm{G} \#, \mathrm{~A}, \mathrm{~B}, \mathrm{C} \#, \mathrm{D \#}$ & {$[0,2,4,6,7,9]$} & Exact Form & {$[0,2,4,6,7,9]$} & B1.3 \\
\hline \multirow{5}{*}{236} & \multirow{4}{*}{1} & \multirow{4}{*}{$\mathrm{F} \#, \mathrm{G} \#, \mathrm{~A}, \mathrm{A \# ,} \mathrm{B}$} & \multirow{4}{*}[0,1,2,3,5]{} & Subset & {$[0,1,2,3,4,5,7,8]$} & $\mathrm{A}^{\prime} 1.4$ \\
\hline & & & & Subset & {$[0,1,2,3,5,6,8]$} & C1.c \\
\hline & & & & Subset & {$[0,1,2,3,5,8]$} & $\mathrm{C} 2 . \mathrm{j}$ \\
\hline & & & & Subset & {$[0,1,2,3,5,7]$} & Cd.f \\
\hline & 2 & $\mathrm{~F} \#, \mathrm{G} \#, \mathrm{~A} \#, \mathrm{~B}, \mathrm{C} \#, \mathrm{D} \#$ & {$[0,2,4,5,7,9]$} & Exact Form & {$[0,2,4,5,7,9]$} & A 2.2 \\
\hline \multirow{2}{*}{237} & 1 & 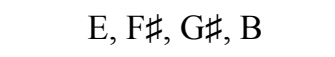 & {$[0,3,5,7]$} & Exact Form & {$[0,3,5,7]$} & B2.1 \\
\hline & 2 & $\mathrm{E}, \mathrm{F} \#, \mathrm{G} \#, \mathrm{~A}, \mathrm{~B}$ & {$[0,2,3,5,7]$} & Exact Form & {$[0,2,3,5,7]$} & A 2.3 \\
\hline \multirow{2}{*}{238} & 1 & E, G\#, A, B & {$[0,2,3,7]$} & Subset & {$[0,2,3,5,7]$} & A 2.3 \\
\hline & 2 & $\mathrm{~A}, \mathrm{~B}, \mathrm{E}$ & {$[0,5,7]$} & Subset & {$[0,2,4,5,7]$} & $\mathrm{I} 2$ \\
\hline $\begin{array}{c}239- \\
243\end{array}$ & & $\mathrm{~B}, \mathrm{E}$ & {$[0,5]$} & Subset & {$[0,2,4,5,7]$} & $\mathrm{I} 2$ \\
\hline
\end{tabular}

Figure 4.48 Interrelationships between pitch content in Section IV, Part C and other parts in Section III.

In short, Section IV combines all of the different musical ideas presented in previous sections, besides introducing new perspectives in the relationship between pitches, motives, and parts. The concept of 3-note cells from Section I is used here, and such cells are further developed into new motives, which become the foundation in creating coherence in this section. Besides pitch manipulation, this section also gives attention to varying the rhythm of such cells - an aspect seen in Section II. Finally, the rich harmonic palette in Section III is recalled in simplification at the end of Section IV. 


\section{Conclusion}

Although Paces has four sections, there is undoubtedly a strong unity in this entire work. Such unity does not only come from the program itself, but is also a result of the various musical elements - or concepts - that are present throughout all four sections: namely, the concept of a three-note cell and its expansion into new motives in the grouping of four $16^{\text {th }}$ notes. The interplay between the electronics and the piano parts - how they play together and move away from each other, and are later reunited again — is also a highlight of this piece.

To recapitulate, Section I: Construction/Industrial shows the different methods used to manipulate a short motive, a three-note cell, to become a scale. Such methods include altering the pitch-classes of the cell; reordering such pitch-classes; adding more pitch-classes to the cell, but keeping the same rhythm through stacking the pitch-classes; and modifying the rhythm of such a cell by expanding the grouping of three $16^{\text {th }}$ notes into four $16^{\text {th }}$ notes, or reducing them to two $16^{\text {th }}$ notes. Throughout this section, the electronics and the piano play simultaneously with each other.

Meanwhile, Section II: Metal Grating concentrates on the rhythmic aspect of the threenote cell from Section I. It also acts as a rhythmic transition between the rather fragmented first section to the more fluid third section. Here, the electronics play a more prominent role than the piano.

Perhaps the centerpiece of Paces, Section III: Piano Solo presents a high level of complexity for both analysis and performance. Such complexity is exemplified through pitch content, and the frequent changes in tempo, meter, dynamics, and articulation. These musical aspects altogether provide dramatic contrasts in the character and mood in this section, which also add intensity to this piece as a whole. 
The final section, Section IV: Gameboy/Digital, unites all four sections by combining the musical ideas presented in preceding sections, particularly the concept of three-note cells and the concept of altering the rhythm of such cells into groups of four beats. Here, the three-note-cell motif also generates new motives through expansion and permutation. The electronics and the piano parts play together at first, but gradually move apart, competing with one another by playing different motives at the same time. In the middle of this section, the piano blends in with the electronics and becomes a part of the soundscape. At the end of this piece, the piano plays by itself, recalling fragments of the chord progressions in Section III. It is then joined by the sounds of children's voices, bringing a peaceful close to this piece.

Paces is perhaps like a short film that conveys a story aurally. The storyline-the city, and how one copes with it—is certainly one that audiences world-wide could identify with. Being an expert in film music, Wong successfully captures the audience's interest and attention through the various electronic and sampled sounds - especially the exotic sounds of cimbalom and the gamelan, as well as the catchy mobile ringtone - and the interactions between the piano and the recording.

Moreover, she also excels in combining and presenting a variety of styles within such a short time frame, including but not limited to new age, rock, ethno music, film music, avantgarde, digital music, and trance music.

The contrasts in the music — between stability and instability, as well as simplicity and complexity —also very much reflect the state of mind of mankind when coping with a busy lifestyle in the city. However, the strongest message of all is perhaps the fact that we determine or contribute to the environment we live in, and the musical genre that we listen to; but, the future — be it trend of lifestyle, or music — is in the hands of the generations to come. On another 
note, this work also demonstrates that organized sound is music, and that music by itselfwithout text or motion picture-is indeed capable of telling a story. 


\section{CHAPTER FIVE}

\section{Kah Hoe YII}

\section{Biography}

Born in 1970, Kah Hoe Yii hails from a small remote village in Sibu, Sarawak, East Malaysia surrounded by Mother Nature — rain forest, river, and without electricity! "In fact, I did not even know what a television was!"1 Yii added amusedly.

Yii's first encounter with music was when he started learning the Chinese bamboo flute, dizi (笛子), in his secondary school, which led to his involvement in musical activities such as playing in the local Chinese Orchestra. After finishing high school, he traveled across the ocean to Kuala Lumpur to study at the Malaysian Institute of Arts, where he majored in Chinese ink painting. He received a Diploma in Fine Art in 1991 and went on to spend four years in China, studying ethnomusicology and dizi at the Xi'an Conservatory of Music.

Upon receiving his Bachelor of Music degree in 1997, Yii returned to Kuala Lumpur and began working as a researcher at the Eastern Arts Research Center. At the same time, he also gave lectures on Eastern Instrumentation and Malay Traditional Music at the Music Department of the Malaysian Institute of Art. His keen interest in ethnomusicology continues to lead him to be engaged in various ongoing fieldwork projects across Southeast Asia, especially researching folk and ethnic music in his home state, Sarawak, as well as traditional Malay music such as the wayang kulit (shadow puppet) and the gamelan.

The pivotal point of his career was when his first composition for Chinese orchestra won the $3^{\text {rd }}$ Prize in the 2006 International Competition for Chinese Orchestral Composition,

\footnotetext{
${ }^{1}$ Kah Hoe Yii, e-mail message to author, January 9, 2013.
} 
organized by the Singapore Chinese Orchestra, after which Yii seriously considered becoming a professional composer. A year later, he won the second Malaysian Philharmonic Orchestra Forum for Malaysian Composers and was a finalist in the 2010 "Città di Udine” International Composers Competition held in Italy.

Yii's years of fieldwork is evident in his music, in which he "blends Western and nonWestern aesthetics, concepts, traditions, [and instruments] together to create his own sound which he categorizes as conceptually traditional in every sense." ${ }^{2}$ He also applies the Chinese ink painting concepts, particularly sensitivity to space, into his music where he "uses musical space as a canvas to do sound calligraphy." ${ }^{, 3}$ Outside of Malaysia, his music has been performed in Singapore, Indonesia, Thailand, Taiwan, Hong Kong, South Korea, the United Kingdom, Germany, the United States of America, Mexico, and Australia.

Yii was the Director of the 2009 Kuala Lumpur Contemporary Music Festival and currently serves as the Vice President of the Society of Malaysian Contemporary Composers (SMCC). In the meantime, he is a senior lecturer at the SEGi College in Subang Jaya, Selangor, Malaysia while maintaining an active profile as a composer.

\footnotetext{
2 "Members: Yii Kah Hoe," The Society of Malaysian Contemporary Composers, accessed January 16, 2013, http://www.smccomposers.com/yii-kah-hoe.html.

${ }^{3}$ Kah Hoe Yii, e-mail message to author, January 9, 2013.
} 


\section{Complete List of Works}

\section{Orchestral (Western)}

1. “A” Note Promenade (2006)

2. Opening of the Stage for orchestra (2007)

3. The Green Walk for orchestra (2012)

\section{Orchestral (Chinese)}

1. Inang $^{4}$ for Chinese orchestra (2005)

2. Buka Panggung [Opening of the Stage $]^{5}$ for Chinese orchestra (2006)

3. Inner Voices $I V$ for dizi ${ }^{6}$ and Chinese orchestra (2009)

4. Yao.Sen [圭。森] ${ }^{7}$ for Chinese orchestra (2009)

5. Inner Voices $V$ for yangqin ${ }^{8}$ and Chinese orchestra (2010)

6. Entropy for bass suona ${ }^{9}$ and Chinese orchestra (2012)

\footnotetext{
${ }^{4}[$ Mak] inang is a genre of Malay folk dance. Kah Hoe Yii, e-mail message to author, December 15, 2013.

${ }^{5}$ Buka Panggung is a ritual opening ceremony in a wayang kulit performance. Kah Hoe Yii, e-mail message to author, December 18, 2013.

${ }^{6}$ Dizi (笛子) is a Chinese bamboo flute. Kah Hoe Yii, e-mail message to author, January 9, 2013.

${ }^{7}$ Yao (圭) is Yii’s daughter's first name, while Sen (森) is his son’s first name. Kah Hoe Yii, e-mail message to author, December 15, 2013.

${ }^{8}$ Yangqin (扬琴) is “a Chinese hammered dulcimer, originally from Persia." "Yangqin," Wikipedia, last modified January 20, 2014, accessed January 27, 2014, http://en.wikipedia.org/wiki/Yangqin.

${ }^{9}$ Suona (唢呐) is a Chinese double-reed instrument with “a conical wooden body ... similar to that of the European oboe, but uses a tubular brass or copper bocal ... [and] a detachable metal bell at its end." "Suona," Wikipedia, last modified November 19, 2013, accessed December 18, 2013, http://en.wikipedia.org/wiki/Suona.
} 


\section{Chamber (Western)}

1. Inner Voices I for clarinet, bassoon, trumpet, trombone, vibraphone, violin, and double bass (2007)

2. Gongan $^{10}$ for oboe and piano (2008)

3. Drunken Madness for trombone and piano (2008)

4. How the Crocodile got his Teeth for narrator and wind ensemble (2008)

5. Wild Cursive for violin, viola, cello, and vibraphone (2010)

6. My Spirit is Chanting for soprano, bass clarinet, and percussion (2011)

7. My Ears are still Ringing for flute and alto saxophone (2011)

8. CHEERS for flute, piano, teacups, and teapot (2013)

9. Secret Book of Sun Bu'er for soprano and piano (2013)

10. Imagery IIb for flute and viola (2013)

\section{Chamber (Chinese)}

1. Kuang Cao [狂草, Wild Cursive ${ }^{11}$ for gaohu, erhu, Zhonghu, ${ }^{12}$ and Zhongruan ${ }^{13}$ (2009)

2. Equatorial Rainforest for Ruan quartet (2011)

3. Reflection for 8 Gehu-s ${ }^{14}(2013)$

${ }^{10}$ Gongan, or gong units, is "a temporal cycle [in gamelan music,] which [is] marked internally at specific points by specific gongs, and at the end by the lowest-pitched gong." Kah Hoe Yii, e-mail message to author, December 15, 2013.

${ }^{11}$ Kuang Cao (狂草) is script or style of writing in Chinese calligraphy. Kah Hoe Yii, e-mail message to author, December 18, 2013. See also “Cursive Script,” entry by Ponte Ryuurui, May 29, 2013, accessed December 18, 2013, http://www.ink-treasures.com/history/calligraphy/chinese-calligraphy/calligraphy-scripts/cursive-script.

${ }^{12}$ Gaohu (高胡), erhu (二胡), and zhonghu (中胡) belong to the huqin (胡琴) family of Chinese bowed string instruments. Gaohu (高胡) has the highest tuning register; erhu (二胡) has a middle tuning register; while zhonghu (中胡) has a lower tuning register. "Huqin," Wikipedia, last modified February 26, 2013, accessed December 18, 2013, http://en.wikipedia.org/wiki/Huqin.

${ }^{13}$ Ruan (阮) is “a Chinese plucked string instrument [or lute]." Zhongruan (中阮) is the tenor lute. "Ruan," Wikipedia, last modified October 16, 2013, accessed December 18, 2013, http://en.wikipedia.org/wiki/Ruan.

${ }^{14}$ Gehu (革胡) also belongs to the huqin (胡琴) family of Chinese bowed string instruments. It is a bass instrument, equivalent to - and shares the exact tuning as - the cello in Western orchestra. "Gehu," Wikipedia, last modified November 9, 2013, accessed December 18, 2013, http://en.wikipedia.org/wiki/Gehu. 


\section{Mixed Ensemble (Orchestra and Chamber)}

1. Menghadap $\operatorname{Rebab}^{15}$ for erhu, rebab, and mixed orchestra (2006)

2. Qin.Sheng [琴。笙] ${ }^{16}$ for harmonica and Chinese orchestra (2008)

3. Bayang [Shadows] for wayang kulit/shadow puppet and Chinese orchestra (2008)

4. Wild Cursive for zhongruan, violin, viola, and cello (2009)

5. How the Crocodile got his Teeth for shadow puppet and small ensemble (2009)

\section{Solo Instrumental}

1. Inner Voices I for solo flute (2007)

2. Inner Voices III for solo shakuhachi ${ }^{17}$ (2009)

3. Timang Burung ${ }^{18}$ for solo piano (2009)

4. My Spirit is Dancing! for solo piano (2010)

5. Imagery for solo flute and wind chimes (2011)

6. Imagery for solo viola (2011)

7. My Spirit is Singing for solo oboe (2011)

8. My Spirit is Soaring for solo trombone (2012)

9. My Spirit is Playing for solo piano (2013)

\section{Multi-media}

1. The Green Snake for live musicians, dancers, and installation arts (2013)

2. The Spirits Play for live musicians, dancers, and video art (2013)

\footnotetext{
${ }^{15}$ Menghadap Rebab is "the most important piece [in a mak yong—a traditional dance-drama—performance], ... performed by the entire troupe to salute and honor the rebab." Matusky and Tan, Music of Malaysia, 38-39.

${ }^{16} \operatorname{Qin}$ (琴) is a harmonica, while sheng (笙) is a Chinese reed instrument with vertical pipes. Kah Hoe Yii, e-mail message to author, December 15, 2013.

${ }^{17}$ Shakuhachi is a Japanese bamboo flute. "Shakuhachi," Wikipedia, last modified December 2, 2013, accessed December 18, 2013, http://en.wikipedia.org/wiki/Shakuhachi.

${ }^{18}$ Timang Burung is a well-known song in joget gamelan—court gamelan and dance. Kah Hoe Yii, e-mail message to author, December 15, 2013.
} 


\section{Analysis of Selected Work for Piano}

\section{My Spirit is Dancing! for solo piano (2010)}

Dedication: Tomoko Honda.

Premiere: July 14, 2010 at the Thailand International Composition Festival in Bangkok. Performed by Tomoko Honda.

Duration: Approximately 8 minutes.

\section{Background}

My Spirit is Dancing! is essentially a realization in musical form of a dance-in this case, the Indonesian baris dance-with the concept of turning gestures in space into sounds in pitch space. Derived from the term, bebarisan (Indonesian, literally "a line or file formation" 19 ), the baris dance is a ritual dance in Bali which makes reference to the ancient warriors who battled in wars to protect the Balinese kings and their kingdom. ${ }^{20}$ There exist various forms of baris dance - depending on the type of weapon used - but the most remarkable of all is the baris melampahan, a dramatic dance drama that depicts the great Hindu epics of Ramayana and Mahabharata. $^{21}$

As a visual artist, Yii is particularly sensitive to visual effects and movements. During his first encounter with the baris dance, he was fascinated by the dancer's hands movements, as though the dancer was playing the keyboard in the air. This intrigued him and instilled in him the desire to experiment with the idea of "dancing" while playing an instrument. The opportunity to

\footnotetext{
${ }^{19}$ I Made Bandem, “The Baris Dance,” Ethnomusicology 19, no. 2 (May 1975): 259.

${ }^{20}$ Ibid.

${ }^{21}$ Ibid: $260-61$.
} 
do so came when he was invited by his Japanese friend, Tomoko Honda, to compose a solo piano piece for her performance at the 2010 Thailand International Composition Festival.

The center of My Spirit is Dancing! is the hands' gestures and feet stamping motions as seen in the baris dance, with which Yii relates the position of the dancer's hands gestures directly to the different registers of the keyboard. In other words, a hand movement over the dancer's head or above his shoulder would correspond to a note of the right hand in a relatively high range on the keyboard, and vice versa. Yii calls this "off-key playing." There are also moments of brief pauses in the music between gestures, which correspond to that illustrated in the dance.

Also inspired by Indian dance, Yii included the use of bells in this piece to add different timbres. The bells are to be attached around the performer's wrists and ankles, which in a way further dramatize the body movements, especially during off-key playing. ${ }^{22}$ Although the gamelan orchestra that accompanies the baris dance follows closely the dancer's movements, $M y$ Spirit is Dancing! is in no way intended as a piece of music that complements such dance. In contrary, it IS the dance, but interpreted on an instrument instead.

\footnotetext{
${ }^{22}$ In an interview on January 13, 2013, Yii clarified that the hand position during off-key playing is approximately above the notes indicated in the music. While one may attempt to imitate the movements of a baris dancer, Yii also encourages individual creativity. As he put it, "Everybody dances differently!"
} 


\section{$\underline{\text { Analysis }}$}

In order to define the large-scale formal structure of this piece, one ought to first consider what to include as a musical gesture. Based on rhythm, articulation, contour, and such performance mechanism as on-key and off-key playing, as well as stamping and shaking of the feet, it is evident that there are small gestures that get repeated and often varied. In this piece, the pitch selection is of secondary importance. ${ }^{23}$ Instead, it is the physical character of the motion that defines a gesture. There are six such gestures in the piece, each also represented by variants. Once such small gestures are identified and characterized, they can be examined to see how they fit together to form larger musical patterns. When the larger patterns are established, it is possible to divide the music into sections and further determine the structure of the music. First, we shall trace each gesture in its trajectory through this piece. Along the way we shall construct a map of relationships between gestures. Finally, we shall address large-scale form.

\section{Gesture 1}

The first few measures at the beginning of this piece present several small gestures. The opening measure, labeled as Gesture 1, is a gesture that comes back often throughout this piece (see Figure 5.1). This gesture is modified each time it reappears; hence, each such occurrence is labeled as a variant of Gesture 1. This gesture comes back in a way in $\mathrm{m} .3$ wherein a second cluster is added to the left hand, followed by a trill motion in the air, and ending in the subsequent measure with two single rhythmic figures, first in the right hand and then in the left hand. The first off-key trill motion in the right hand is also modified in terms of register and range.

\footnotetext{
${ }^{23}$ Kah Hoe Yii, interview with author, January 13, 2013.
} 


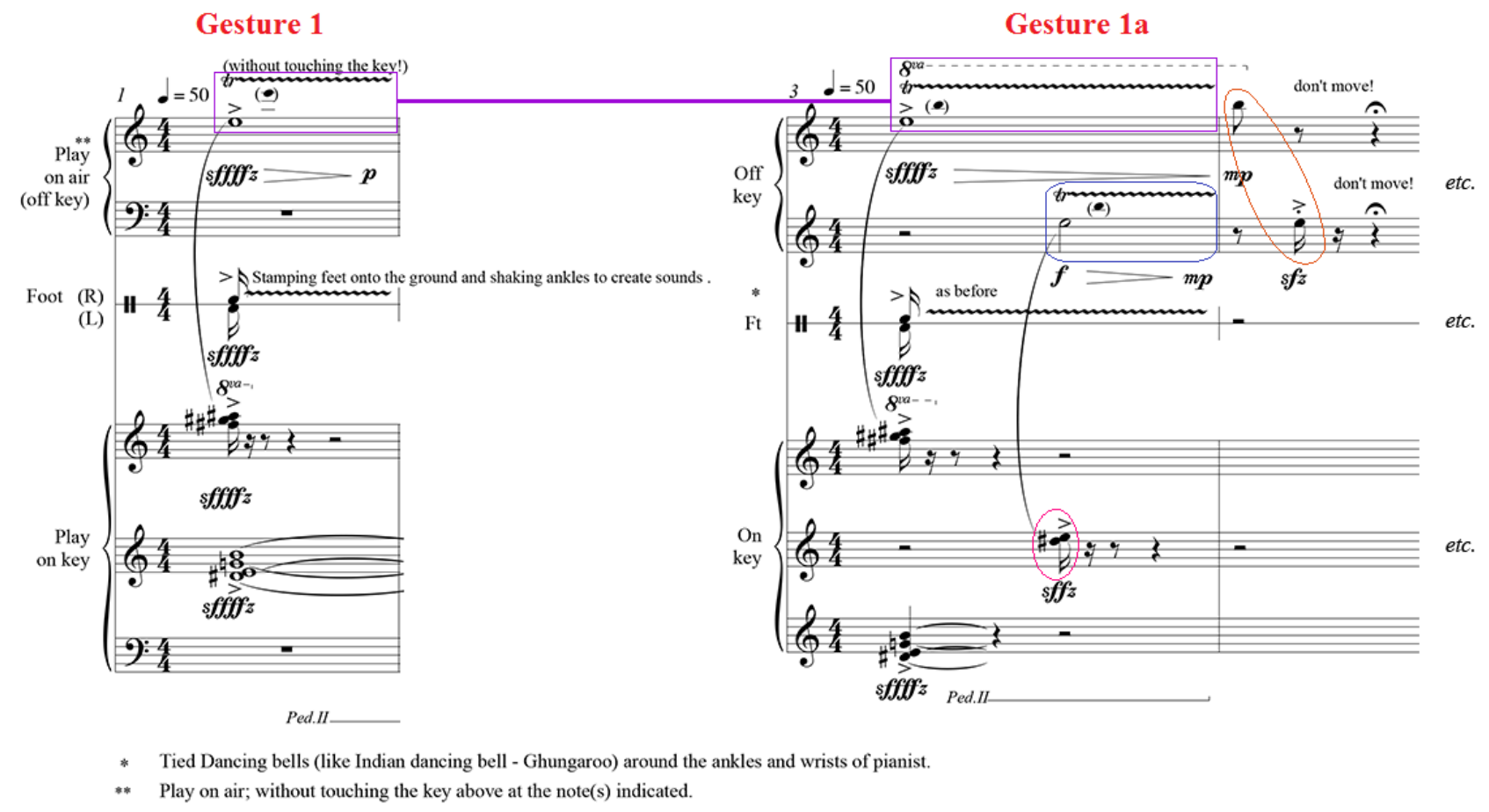

Figure 5.1

Kah Hoe Yii: My Spirit is Dancing!, Gestures 1 (m. 1) and 1a (mm. 3-4).

Gesture 1a recurs in $\mathrm{m} .8$ with a slight alteration to the pitches in the left hand cluster and removing the shaking action from the right foot, creating Gesture $1 \mathrm{~b}$ (see Figure 5.2). In addition to the existing left hand off-key trill motion, the right hand also plays another set of trill motion in the higher range of the keyboard, but omitting the ending rhythmic figures seen in m. 4 . 
Gesture 1a

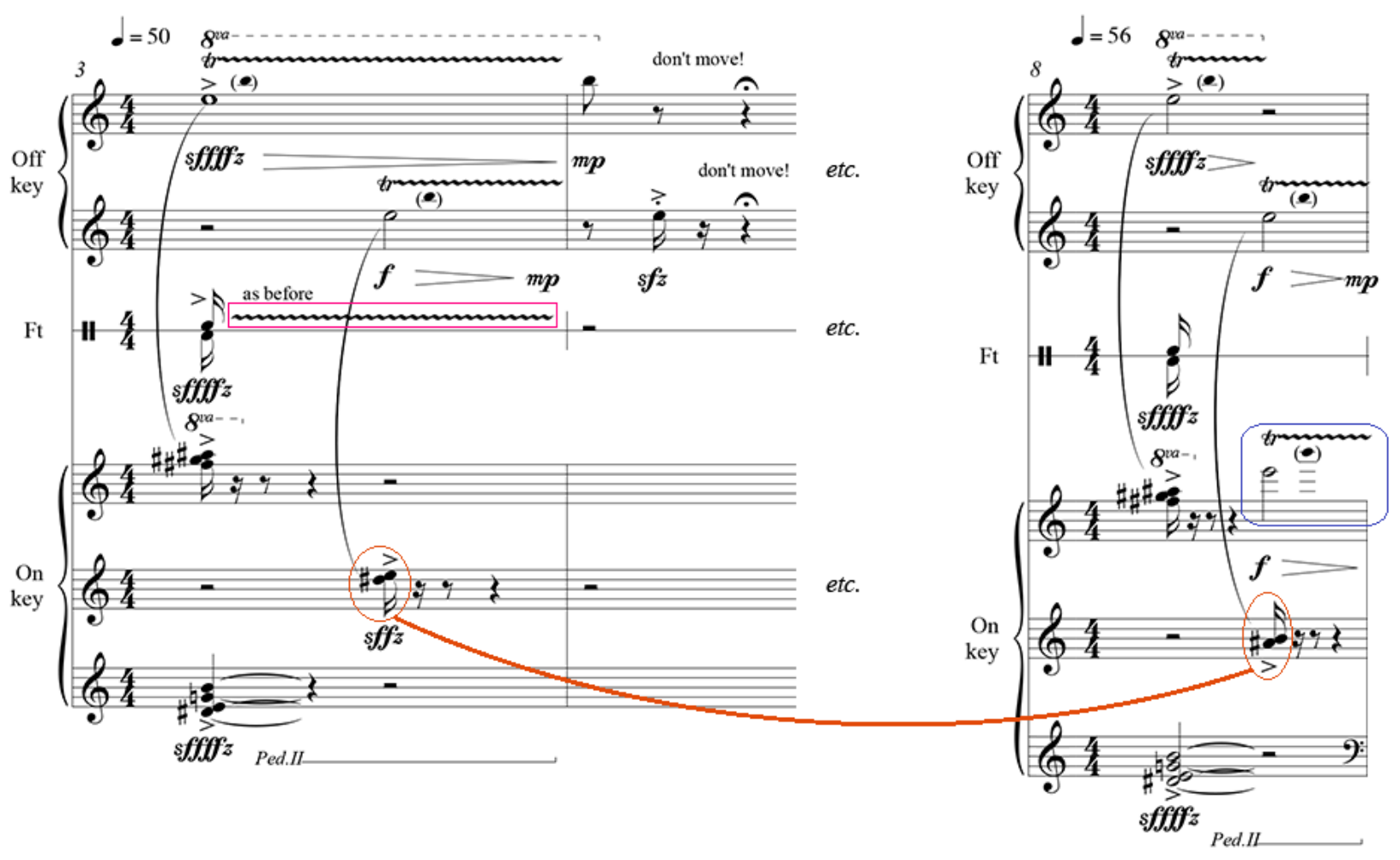

Gesture 1b

Figure 5.2

Kah Hoe Yii: My Spirit is Dancing!, Gestures 1a (mm. 3-4) and 1b (m. 8).

The next occurrence of Gesture $1 \mathrm{in} \mathrm{mm.} \mathrm{17-18,} \mathrm{labeled} \mathrm{as} \mathrm{Gesture} \mathrm{1c,} \mathrm{could} \mathrm{be} \mathrm{seen} \mathrm{as} \mathrm{a}$ combination of Gestures 1a and 1b (see Figure 5.3). Reference to Gesture 1a is evident in the right foot shaking action and the ending single rhythmic figures that extend from the hands to the foot. In addition to this connection, Gesture 1c also shares similar chords with Gestures 1a and $1 \mathrm{~b}$, more so with the latter, from which the pitches are transposed a whole step lower. While the right hand on-key trill figure from Gesture $1 \mathrm{~b}$ is retained here on E5, the range between the trilled notes is modified, as are those played off-key. 


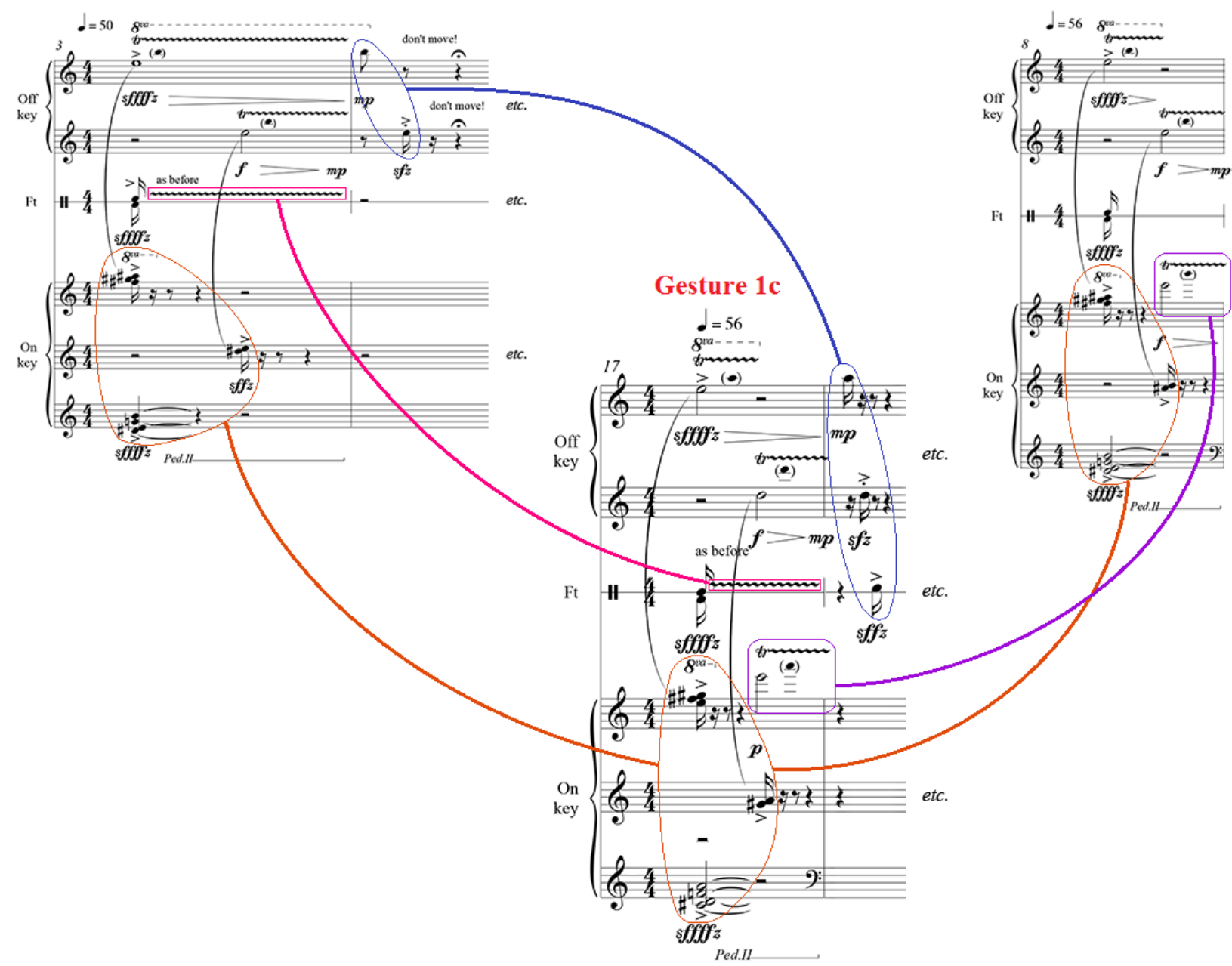

Figure 5.3

Kah Hoe Yii: My Spirit is Dancing!, Gesture 1c (mm. 17-18) and corresponding gestures.

It is apparent that mm. $28-30$ is made of a series of three successive variants of Gesture 1: $\mathrm{m} .28$ is a variant of Gesture 1c without the single rhythmic figures at the end; $\mathrm{m} .29$ is a variant of Gesture 1b with the interval span between the on-key trilled notes being shortened; and $\mathrm{m} .30$ is perhaps also a variant of Gesture $1 \mathrm{~b}$ due to similarity in the foot stamping action as well as the placement of the chords in both hands and the trill motion in the right hand. However, the off-key trill motions in both hands are left out (see Figure 5.4). 
Gesture 1c

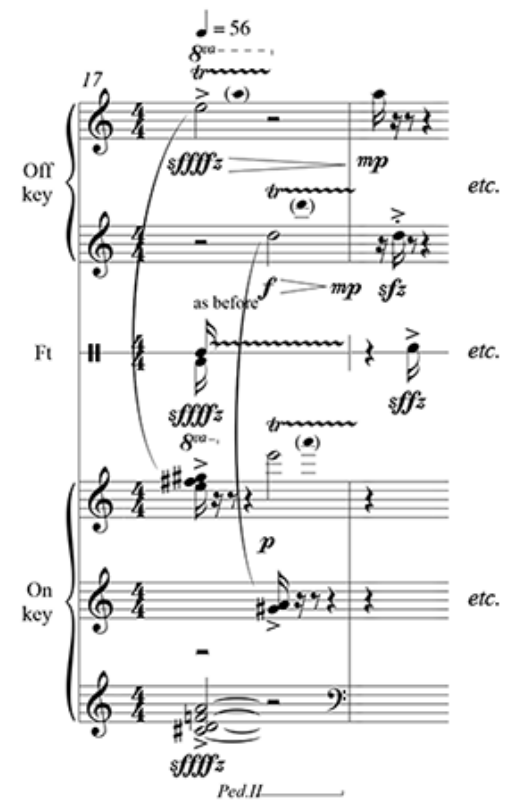

Gesture 1b

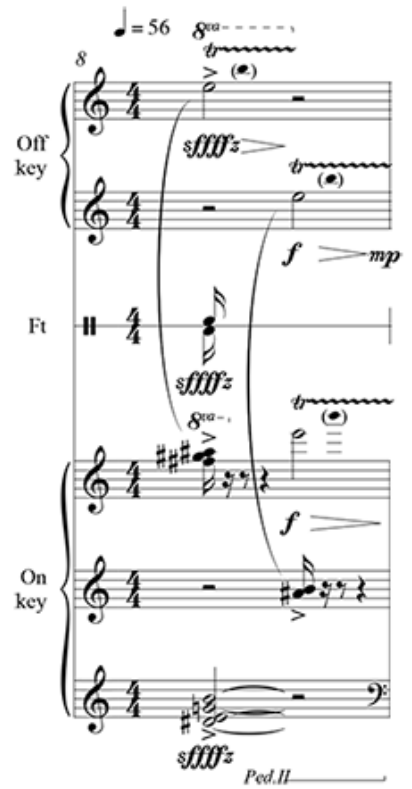

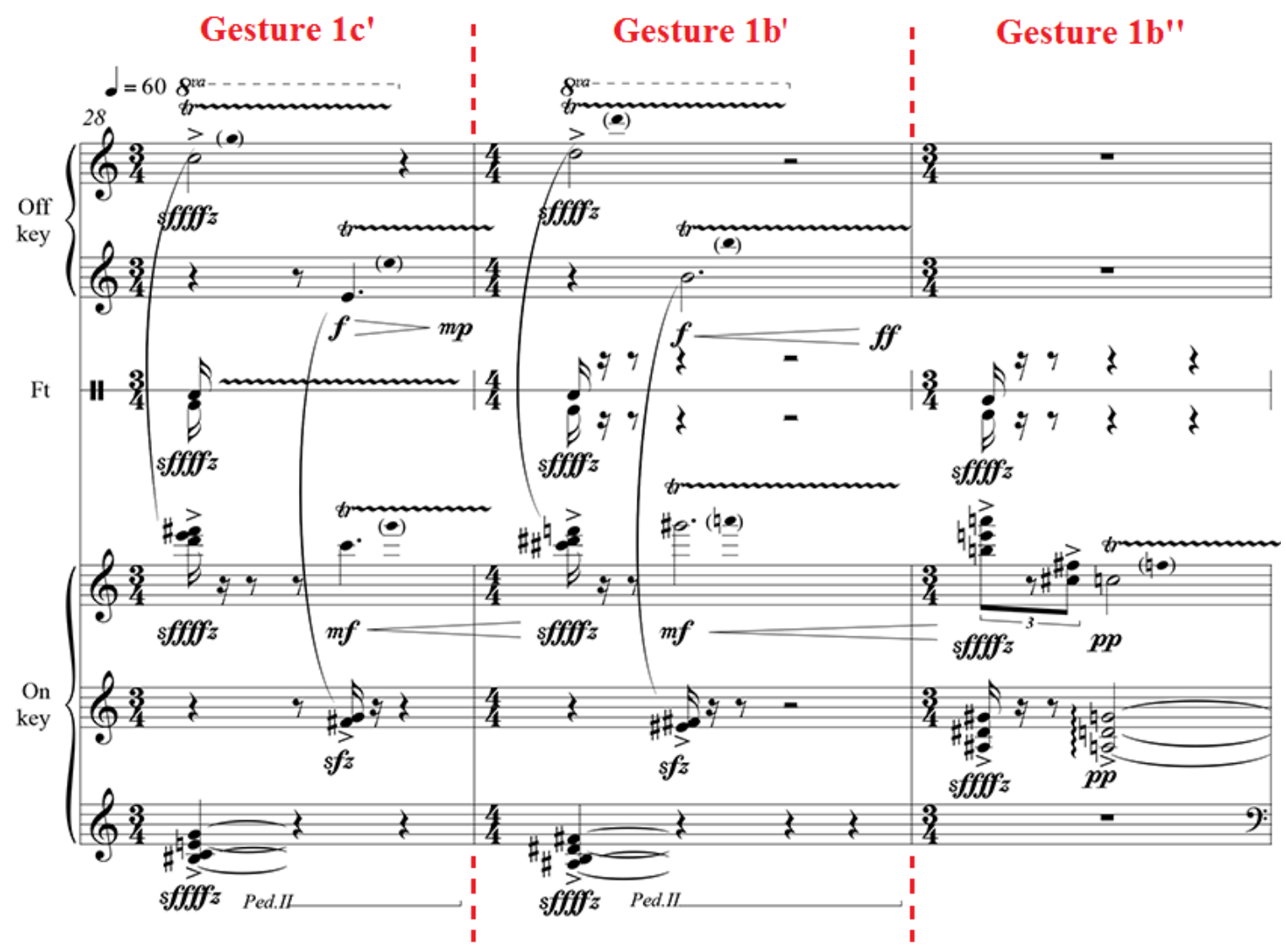

Figure 5.4

Kah Hoe Yii: My Spirit is Dancing!, Gestures 1c' (m. 28), 1b' (m. 29), 1b" (m. 30) and corresponding gestures. 
These three measures recur later in $\mathrm{mm} .63-65$ in the same order with the exact same musical contents. However, preceding them in $\mathrm{m} .62$ is a gesture, Gesture $1 b^{\prime \prime}$, similar to that seen on the second beat of Gesture 1b" (see Figure 5.5).

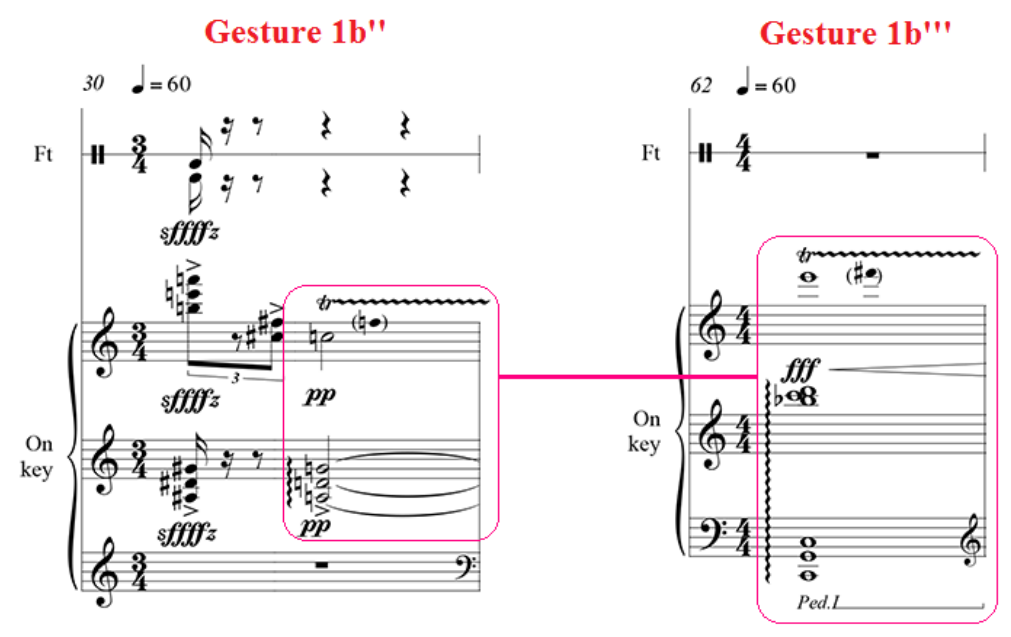

Figure 5.5

Kah Hoe Yii: My Spirit is Dancing!, Gestures 1b" (m. 30) and 1b"' (m. 62).

Although the pitch selection in this piece is of secondary importance, it is interesting to note that each time Gesture 1 is varied - except in the instances of Gestures 1a, 1b, and 1b"- the sounding pitches in such gestures for the most part progressively move down by steps (see Figures 5.6a and 5.6b). 

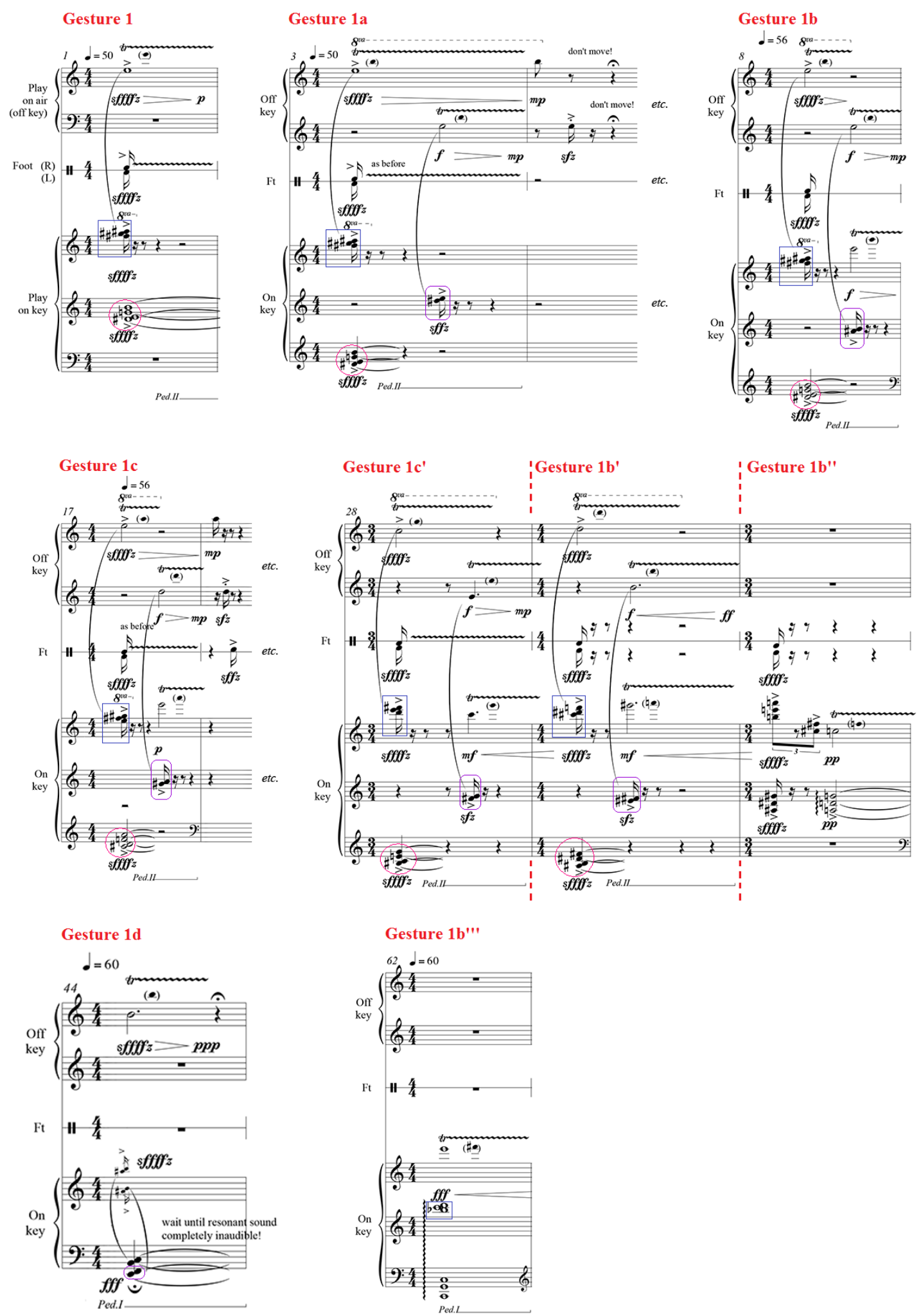

Figure 5.6a

Kah Hoe Yii: My Spirit is Dancing!, Gesture 1 (m. 1) and its variants: demonstration of step-wise descending motions in sounding pitches. 


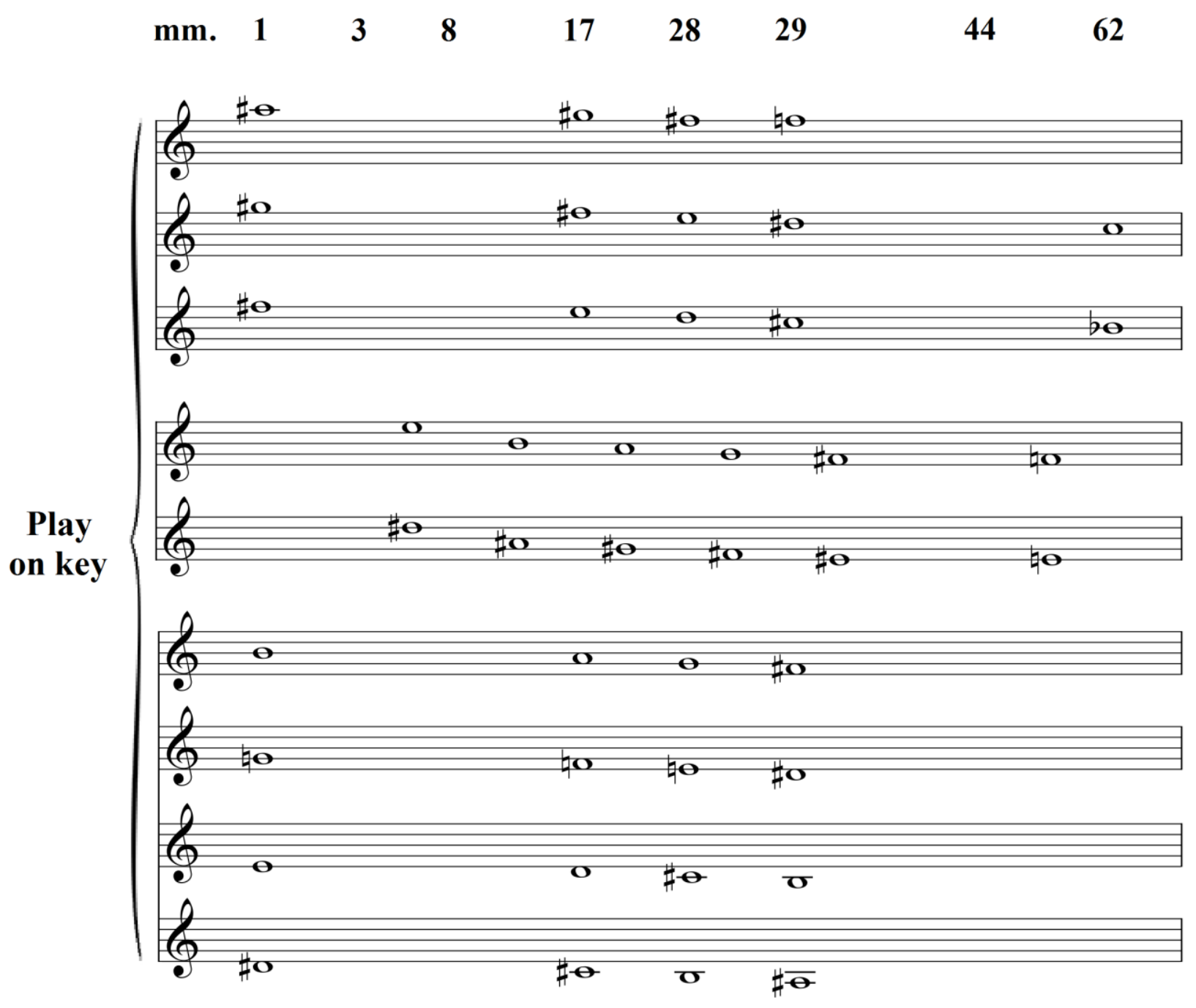

Figure 5.6b Simplification of step-wise descending motions in sounding pitches. 


\section{Gesture 2}

The second measure in this piece introduces a new gesture, Gesture 2, significantly different from that of Gesture 1 in $\mathrm{m} .1$ (see Figure 5.7). There is neither off-key playing nor any

foot stamping in this gesture; instead, it begins with two $16^{\text {th }}$ notes followed by a series of $32^{\text {nd }}$ notes played on the keyboard by alternating hands. Of particular importance is the figure at the end of the measure where the A\#'s are played hands alternatively an octave apart, which is developed and further expanded later on in this piece.

Gesture 2 is seen again in m. 5 as Gesture 2a (see Figure 5.7), in which the rhythm is fully preserved but the pitches are for the most part altered. Besides that, some off-key motions are also added at the beginning and the ending of this gesture. The gesture still ends with the A\#'s, but this time without switching back and forth between the octaves, and the execution of such notes changes from an alternating-hand figure to a repeated-note figure in one hand.

The following two measures could be treated as an extension of Gesture $2 \mathrm{a}$ in that the ending repeated-note figure is repeated in $\mathrm{m} .6$ with the addition of the feet stamps at the beginning. Subsequently, m. 7 concludes Gesture $2 \mathrm{a}$ - in a manner somewhat similar to that of Gesture 1a - with a single note rhythmic figure comprises the A\# and the feet stamps (see Figure $5.7)$. 
Gesture 1a

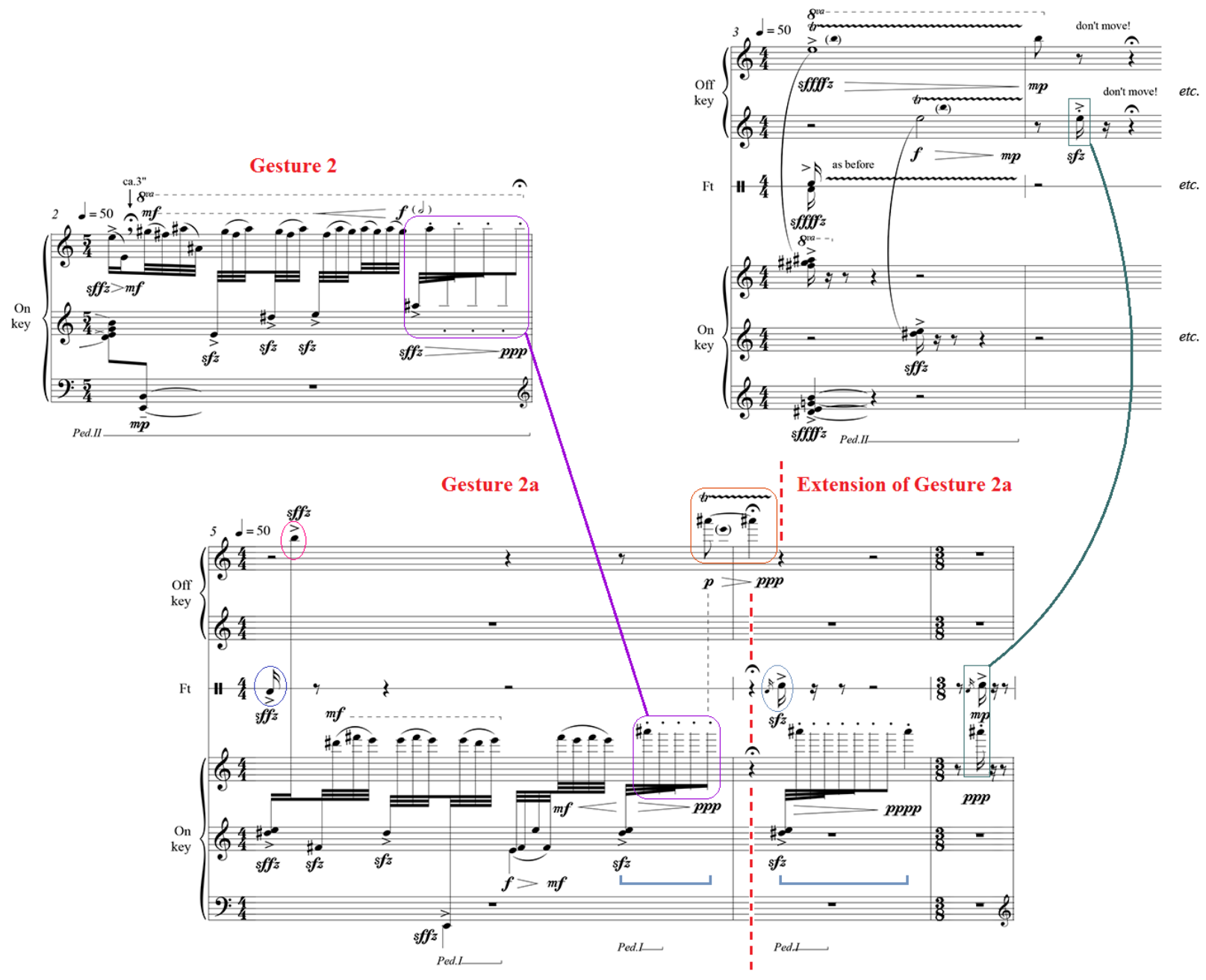

Figure 5.7

Kah Hoe Yii: My Spirit is Dancing!, Gesture 2a (mm. 5-7) and corresponding gestures.

\section{Gesture 3}

In contrast to Gesture 2, Gesture 3 (m. 3) consists of mostly movement in the air following a harmonic semitone on the keyboard, played simultaneously with a foot stamp (see Figure 5.8). Although it uses the same rhythm as the opening of Gesture 2, the difference between these two gestures is so clear-one is sounding pitches and the other is mostly the sounds of bells - that they should be labeled as two distinctive gestures. 
Of all three gestures seen so far, Gesture 3 is the only gesture that gets repeated unaltered elsewhere in the piece: in mm. 13, 27 (with slight alteration of pitch registers), and 68. In fact, there is only one instance, in m. 26, where this gesture is slightly adjusted. This is done by changing a movement into a sounding pitch (see Figure 5.8).

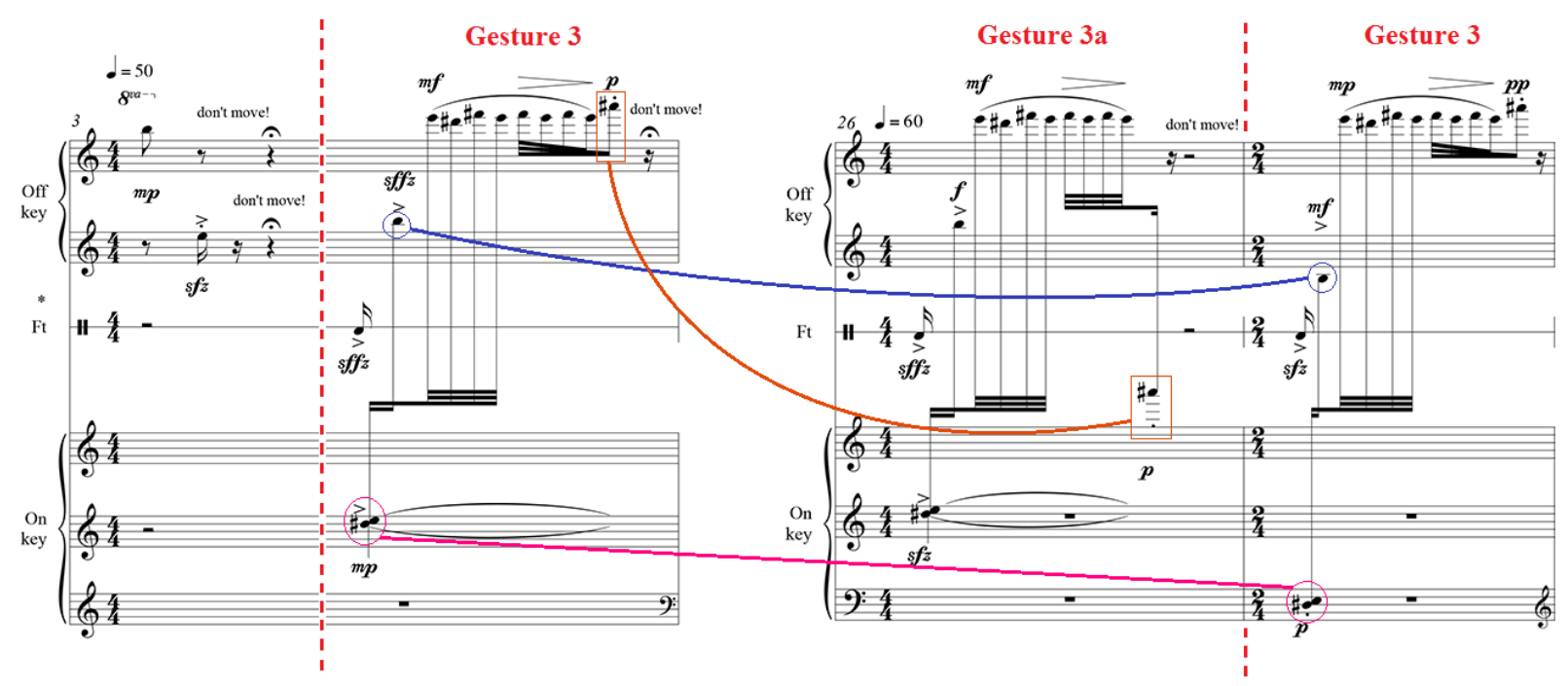

Figure 5.8

Kah Hoe Yii: My Spirit is Dancing!, Gestures 3 (mm. 4 and 27) and 3a (m. 26).

\section{Gesture 4}

Gesture 4 (m. 9) and its variant, Gesture 4a (m. 10), are interrelated in that they begin with the same rhythmic figure, within which they also share the first four notes (see Figure 5.9). These gestures introduce a series of new rhythmic grouping of $16^{\text {th }}$ and $32^{\text {nd }}$ notes. The varied repetitions of this gesture later in this piece include this feature along with the falling pitches and quintuplet grouping of $16^{\text {th }}$ notes in Gesture 4a. Like Gesture 3, Gesture 4 is among the few gestures that gets repeated in its original form. However, it does not literally recur as often as Gesture 3; it is only seen once more in m. 54. 


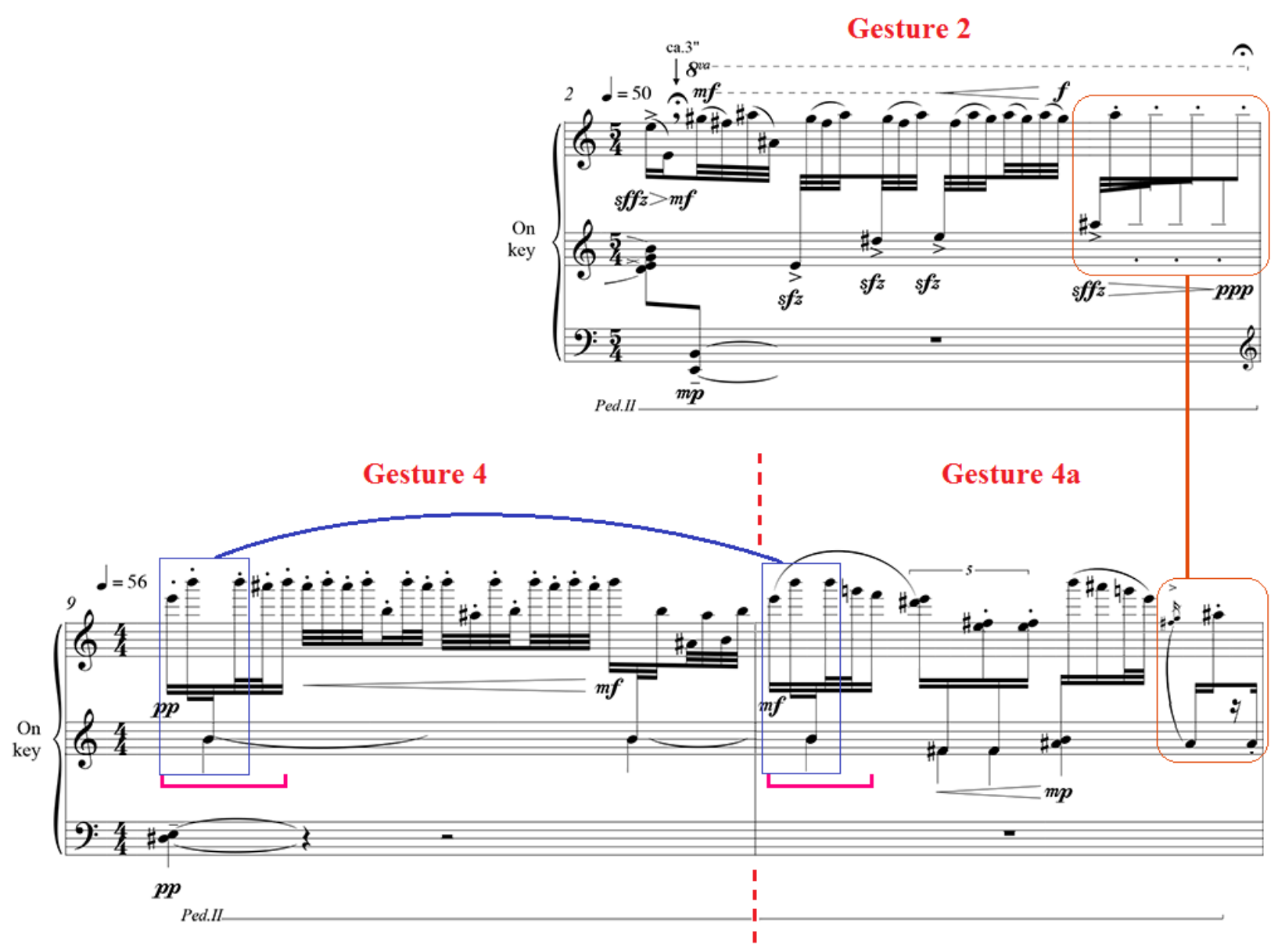

Figure 5.9

Kah Hoe Yii: My Spirit is Dancing!, Gestures 4 (m. 9), 4a (m. 10) and 2 (m. 2).

Both Gestures 4 and 4a are in a way related to Gesture 2 (m. 2) (see Figure 5.9). The ending of both Gestures $4 \mathrm{a}$ and 2 are related in terms of pitch material and the alternating-hand figure. In comparison to Gesture 4, both of these gestures have a more equal distribution of notes between hands. Therefore, it could be suggested that Gesture 4a is a variant of Gesture 2; and because Gesture 4 and $4 \mathrm{a}$ shares similarities at the beginning, Gesture 4 is perhaps a variant of Gesture 2 as well. However, since both Gestures 4 and 4 a present a more varied rhythm and melodic contour in comparison to Gesture 2, they should be treated as a new gesture, one that is 
indeed derived from Gesture 2, but is also distinctive enough to be characterized as independent from it. Figure 5.10 shows the derivations of all four main gestures discussed up to this point.

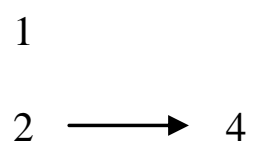

3

Figure 5.10 Derivations of Main Gestures: Gestures 1-4.

\section{Gesture 5}

Subsequently, Gesture 5 (m. 11) has some traits of Gestures 1 (m. 1) and 2 (m. 2) (see Figure 5.11). First of all, both hands in Gesture 5 play an on-key embellished broken chord that is rather similar to that of Gesture 1 in terms of pitch content. Indeed, both chords contain subset $[\mathrm{D} \#, \mathrm{E}, \mathrm{G} \#, \mathrm{~B}]$, which maps onto subset $[\mathrm{A} \#, \mathrm{~B}, \mathrm{D} \#, \mathrm{~F} \#]$ in $\mathrm{m} .1$ when transposed at level 7 (see Figures 5.12a and 5.12b). Besides that, subset [G\#, B, D, D\#] in $\mathrm{m} .11$ also maps onto subset [E, $\mathrm{G}, \mathrm{A \# ,} \mathrm{B}]$ in $\mathrm{m} .1$ by transposition at $\mathrm{T}_{8}$.

In addition to the similarities in pitch content, the off-key trill figure in the right hand seen in Gesture 1 is also employed in Gesture 5 in a different range, immediately following the opening chords. On the other hand, the rhythm of the left hand broken chord in Gesture 5 is the same as that of the beginning of Gesture 2. A connection to both Gestures 1 and 2 is also observed in the foot, where the shaking action in Gesture 1 is realized in a way similar to the repeated-note figure at the end of Gesture 2 in terms of rhythm, dynamic, and the ritardando motion. 


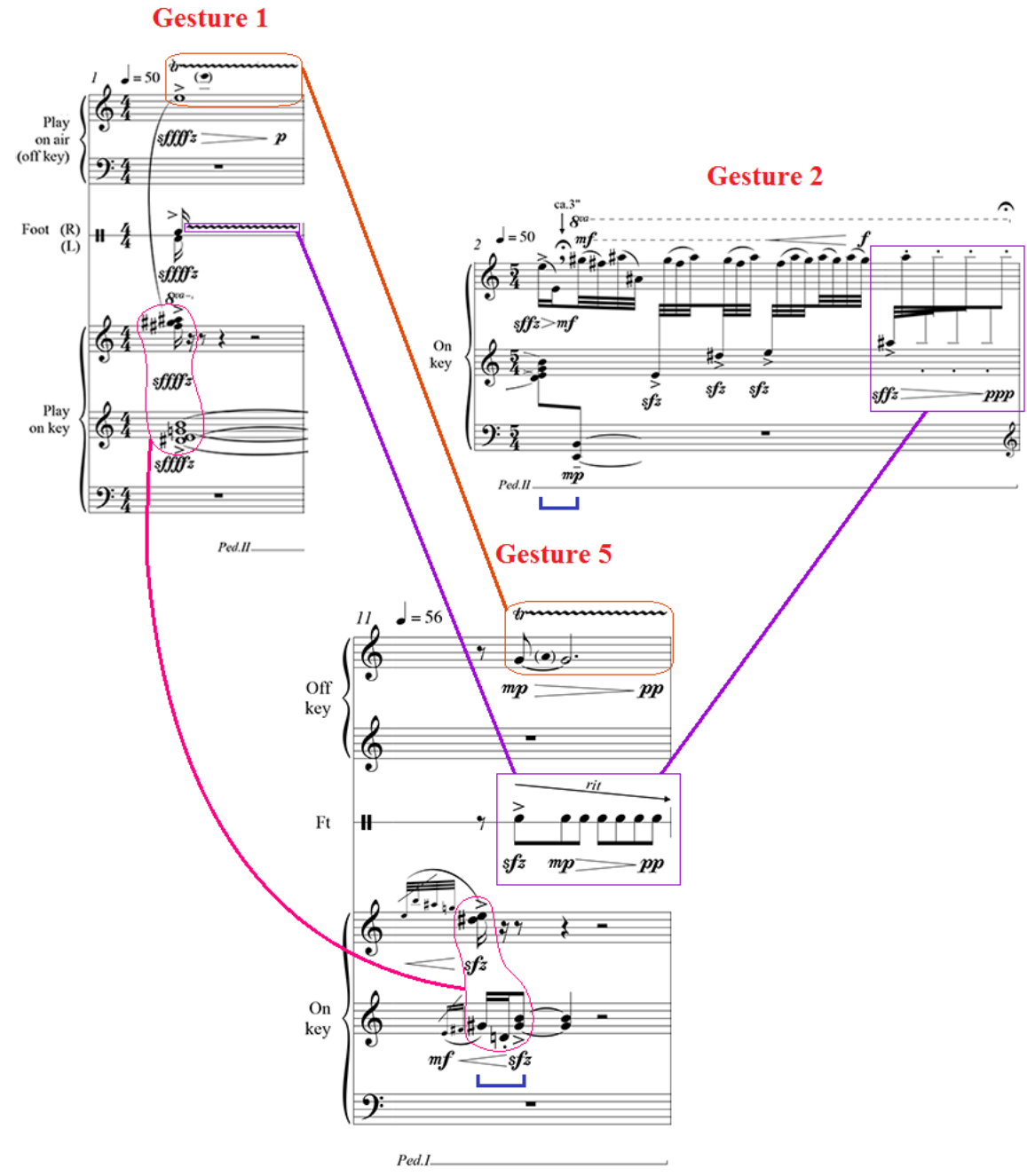

Figure 5.11

Kah Hoe Yii: My Spirit is Dancing!, Gesture 5 (m. 11) and corresponding gestures.

\begin{tabular}{|l|c|c|}
\cline { 2 - 3 } \multicolumn{1}{c|}{} & $\begin{array}{c}\text { Gesture 1 } \\
\text { (m. 1) }\end{array}$ & $\begin{array}{c}\text { Gesture 5 } \\
(\mathrm{m} .11)\end{array}$ \\
\hline $\begin{array}{l}\text { Pitch-Class Collection } \\
\text { (On-key Main Notes Only) }\end{array}$ & $\mathrm{D} \#, \mathrm{E}, \mathrm{F} \#, \mathrm{G}, \mathrm{G} \sharp, \mathrm{A} \sharp, \mathrm{B}$ & G\#, B, D, D\#, E \\
\hline Pitch-Class Set & {$[0,1,3,4,5,7,8]$} & {$[0,1,2,5,8]$} \\
\hline
\end{tabular}

Figure 5.12a Pitch content in Gestures 1 (m. 1) and 5 (m. 11). 


\begin{tabular}{|c|c|c|c|c|}
\hline \multicolumn{2}{|c|}{ Gesture 5 } & \multirow{2}{*}{ Relationship } & \multicolumn{2}{c|}{ Gesture 1 } \\
\cline { 4 - 5 } & & \multicolumn{2}{|c|}{ Pitch-Class Subset } \\
\hline \multicolumn{2}{|c|}{ Pitch-Class Subset } & $\mathrm{T}_{7}$ & {$[10,11,3,6]$} & A\#, B, D\#, F\# \\
\hline D\#, E, G\#, B & {$[3,4,8,11]$} & $\mathrm{T}_{8}$ & {$[4,7,10,11]$} & E, G, A\#, B \\
\hline G\#, B, D, D\# & {$[8,11,2,3]$} & $\mathrm{T}_{8}$ & \multicolumn{2}{c}{} \\
\hline
\end{tabular}

Figure 5.12b Relationships between pitch content in Gestures 5 and 1.

For the above-mentioned reasons, Gesture 5 could be characterized as a combination of Gestures 1 and 2. However, due to the fact that Gesture 5 presents a distinctive character from that of Gestures 1 and 2, as well as the fact that it is further varied and developed, it is thus given its own ordinal number. Figure 5.13 illustrates the derivation of Gesture 5 in addition to other connections established earlier.

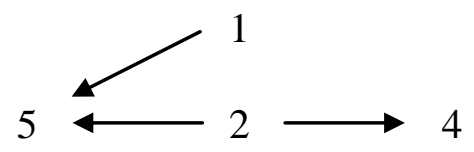

3

Figure 5.13 Derivations of Main Gestures: Gestures 1-5.

As mentioned, Gesture 5 is then modified—or perhaps, simplified—in the succeeding measures: $\mathrm{m} .12$ could be seen as a variant of Gesture 5, and mm. 14-16 contains two variants of m. 12, all due to similarities in rhythm and texture (see Figure 5.14). Although these three variants of Gesture 5 open with a chord and end with a repeated-note figure, the execution of such figures differs.

In Gesture 5a, the beginning chord is held in full length, then most of the note values are shortened in Gesture 5a', and the chord is rolled in Gesture 5a". Meanwhile, the repeated-note figure is shortened to three notes in Gestures 5a and 5a', and is extended to four notes in Gesture 
$5 \mathrm{a}$, wherein the note values are altered. Not only that, the figure also changes from being sounded by the foot (Gesture 5), to being played in the middle register of the keyboard while muted (Gesture 5a), to being sounded in the foot again (Gesture 5a'), and finally to being played in the lowest register of the keyboard (Gesture 5a") (see Figure 5.14).

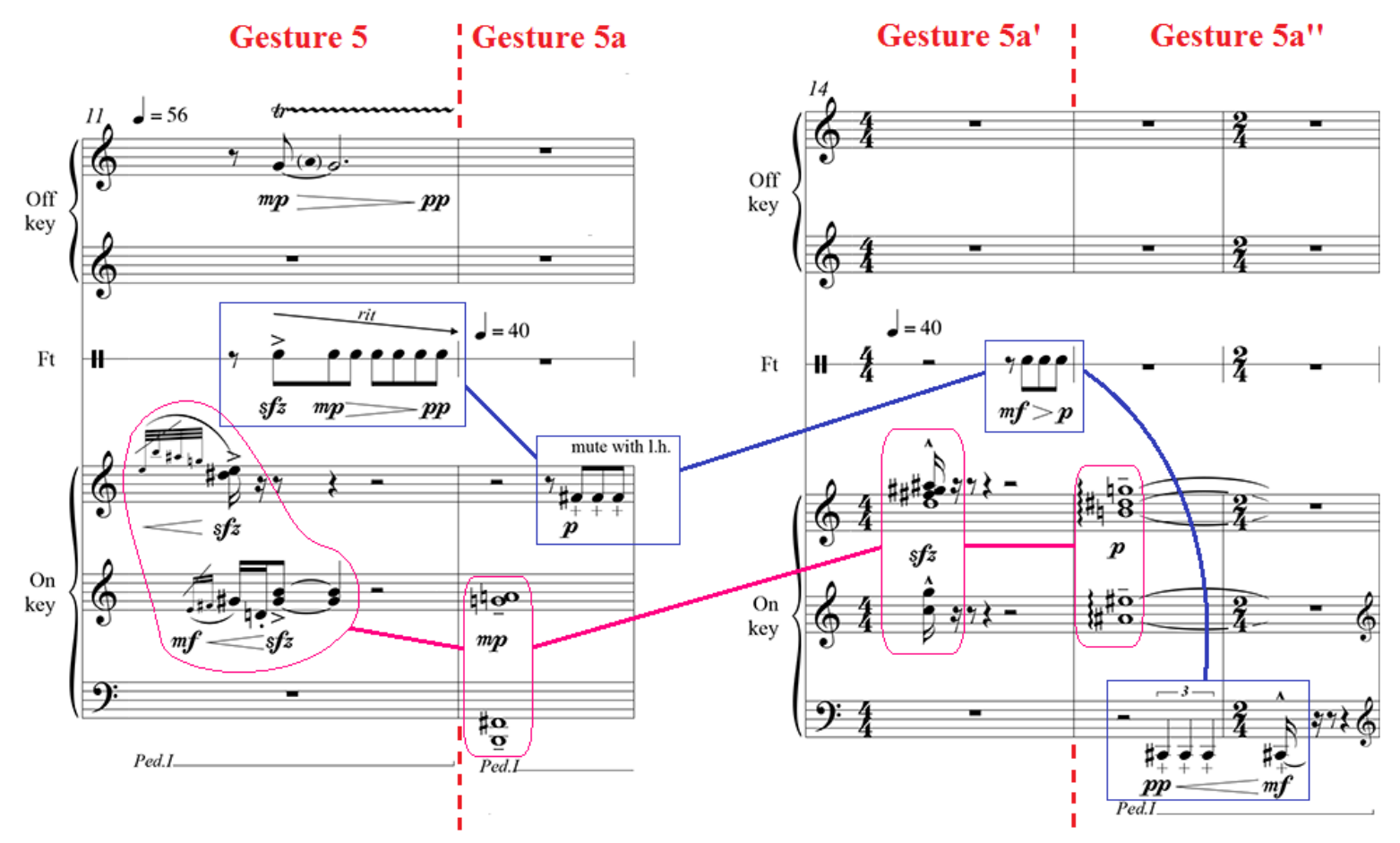

Figure 5.14

Kah Hoe Yii: My Spirit is Dancing!, Gesture 5 (m. 11) and its variants (mm. 12 and 14-16).

These three variants of Gesture 5 are also closely connected to one another in terms of pitch content (see Figures 5.15a and 5.15b). Firstly, Gestures 5a and 5a' are related by inversion: pitch-class set [F\#, G, A, B] (Gesture 5a) maps onto subset [F\#, G\#, A\#, B] (Gesture 5a') under $T_{5}$ I. On the other hand, subset [A\#, B, D, E, F\#] (Gesture 5a') maps onto pitch-class set [G, G\#, $\mathrm{B}, \mathrm{C} \#, \mathrm{D} \#]$ (Gesture $5 \mathrm{a}$ ") by transposition at $\mathrm{T}_{9}$. 


\begin{tabular}{|l|c|c|c|}
\cline { 2 - 4 } \multicolumn{1}{c|}{} & $\begin{array}{c}\text { Gesture 5a } \\
(\mathrm{m} .12)\end{array}$ & $\begin{array}{c}\text { Gesture 5a' } \\
\text { (m. 14) }\end{array}$ & $\begin{array}{c}\text { Gesture 5a" } \\
\text { (m. 15) }\end{array}$ \\
\hline $\begin{array}{l}\text { Pitch-Class Collection } \\
\text { (On-key Notes Only) }\end{array}$ & F\#, G, A, B & D, E, F\#, G\#, A\#, B & G, G\#, B, C\#, D\# \\
\hline Pitch-Class Set & {$[0,2,4,5]$} & {$[0,1,3,5,7,9]$} & {$[0,2,4,7,8]$} \\
\hline
\end{tabular}

Figure 5.15a Pitch content in Gestures 5a (m. 12), 5a' (m. 14), and 5a" (m. 15).

\begin{tabular}{|c|c|c|c|c|}
\hline Gesture & $\begin{array}{l}\text { Pitch-Class } \\
\text { Subset }\end{array}$ & Relationship & Pitch-Class Subset & Gesture \\
\hline \multirow{2}{*}{$5 \mathrm{a}$} & $\mathrm{F} \#, \mathrm{G}, \mathrm{A}, \mathrm{B}$ & \multirow{2}{*}{$\mathrm{T}_{5} \mathrm{I}$} & $\mathrm{F} \#, \mathrm{G} \#, \mathrm{~A} \#, \mathrm{~B}$ & \multirow{2}{*}{$5 a^{\prime}$} \\
\hline & {$[6,7,9,11]$} & & {$[6,8,10,11]$} & \\
\hline \multirow{2}{*}{$5 \mathrm{a}^{\prime}$} & $\mathrm{A} \#, \mathrm{~B}, \mathrm{D}, \mathrm{E}, \mathrm{F} \#$ & \multirow{2}{*}{$\mathrm{T}_{9}$} & $\mathrm{G}, \mathrm{G} \#, \mathrm{~B}, \mathrm{C \#}, \mathrm{D \#}$ & \multirow{2}{*}{$5 \mathrm{a}^{\prime \prime}$} \\
\hline & {$[10,11,2,4,6]$} & & {$[7,8,11,1,3]$} & \\
\hline
\end{tabular}

Figure 5.15b Relationships between pitch content in Gestures 5a, 5a', and 5a".

Gesture 5a' in particular is later seen again in $\mathrm{m} .66$ without the repeated-note figure in the foot, and with a change in meter. Then, most of the notes in this gesture are transposed a step lower in the following measure, and the pitch that is sustained is altered from the lowest note to the highest note in the chord (see Figure 5.16).

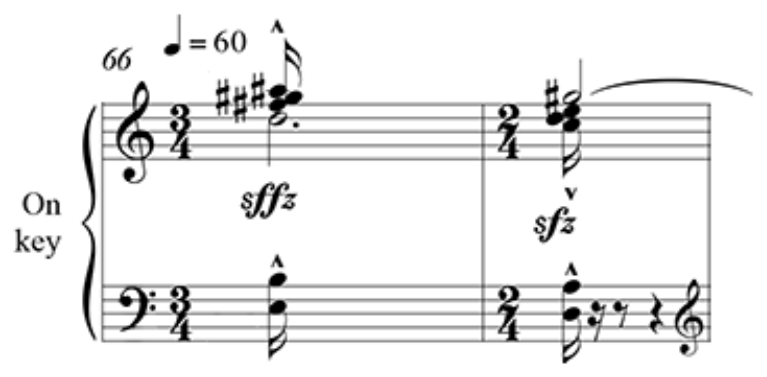

Figure 5.16

Kah Hoe Yii: My Spirit is Dancing!, Gesture 5a' (mm. 66 and 67). 


\section{Gesture 6}

It is apparent that much of the rhythmic material and, to some extent, pitch material in Gesture 6 and its variants (mm. 18-25) are derived from Gesture 2 (m. 2) and its variantsGestures 2a (m. 5), 4 (m. 9), and 4a (m. 10). Starting on the second quarter beat of m. 18, the rhythmic groupings of two $16^{\text {th }}$ notes and four $32^{\text {nd }}$ notes followed by a succession of eight $32^{\text {nd }}$ notes could be traced back to m. 2 (see Figure 5.17). On the other hand, the last group of two $16^{\text {th }}$ notes and four $32^{\text {nd }}$ notes in $\mathrm{m} .18$ is similar to that seen at the beginning of $\mathrm{m} .5$ : opening with a harmonic semitone, followed by an accented shake of the right hand in the air, and immediately shifting back to playing on the keyboard. Arguably, the first rhythmic group in m. 18 could also be connected to that of $\mathrm{m}$. 5. Disregarding the second and third notes in the group, both sets are transpositionally related to each other.

In the next measure, the first three quarter beats could be compared to the materials in $\mathrm{m}$. 18 (see Figure 5.18). Although the first quarter beat in m. 19 seems to have little connection with the second quarter beat in $\mathrm{m} .18$, what follows is a set of eight $32^{\text {nd }}$ notes, most of which are transposed up a whole step from that seen in the previous measure on the third beat and slightly varied at the end. Meanwhile, the third quarter beat in $\mathrm{m} .19$ is rather like an inversion of the last quarter beat of m. 18: the on-key clusters are inverted to become off-key motions, while the onkey $32^{\text {nd }}$-note trill-like figure is inverted and transposed to begin on D. Therefore, it may be suggested that the first quarter beat in $\mathrm{m} .19$ is a variant of the second quarter beat in $\mathrm{m} .18$, using the rhythm seen at the end of Gesture 4 in m. 9 . 

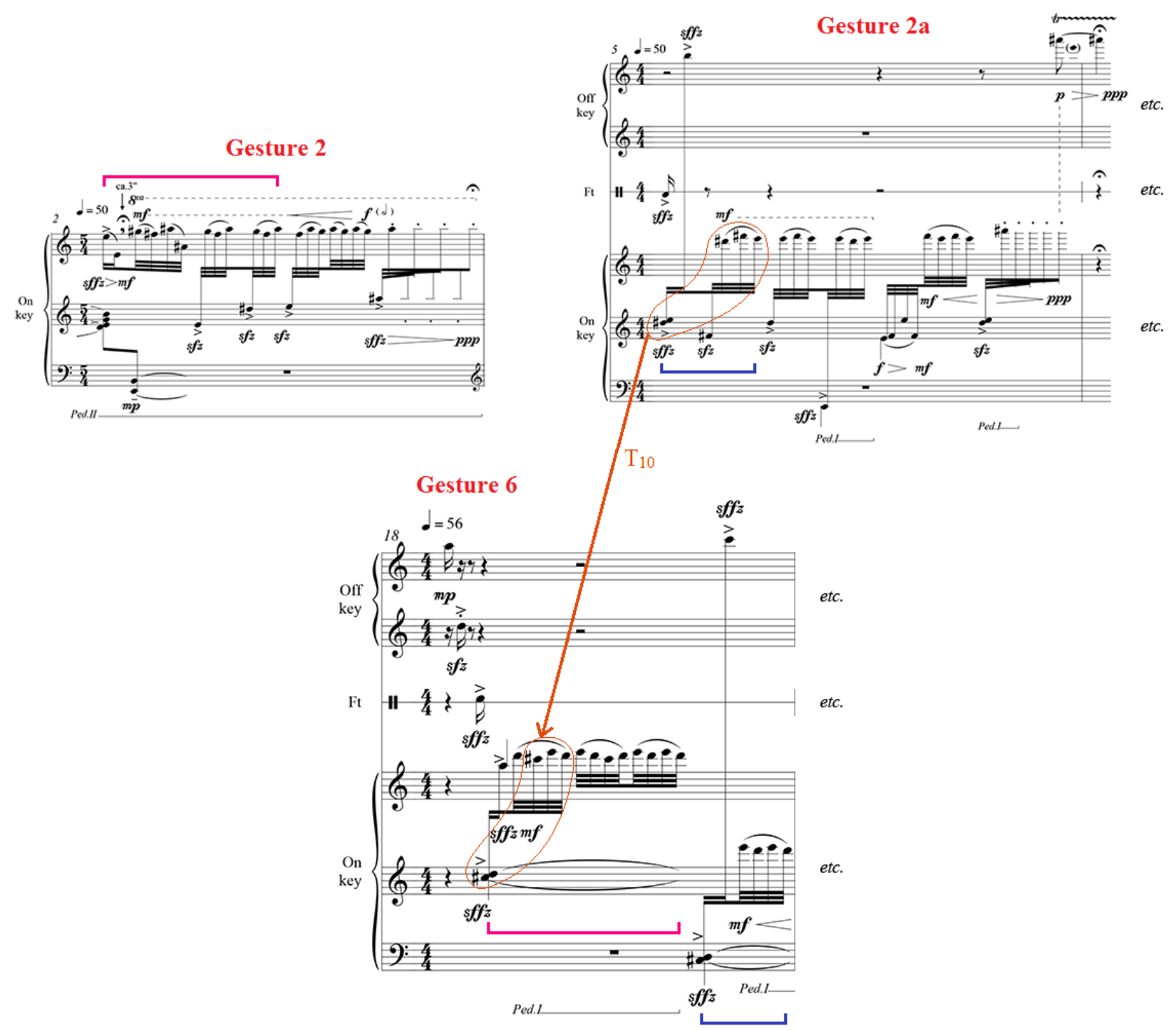

Figure 5.17

Kah Hoe Yii: My Spirit is Dancing!, Gesture 6 (m. 18) and corresponding gestures. 


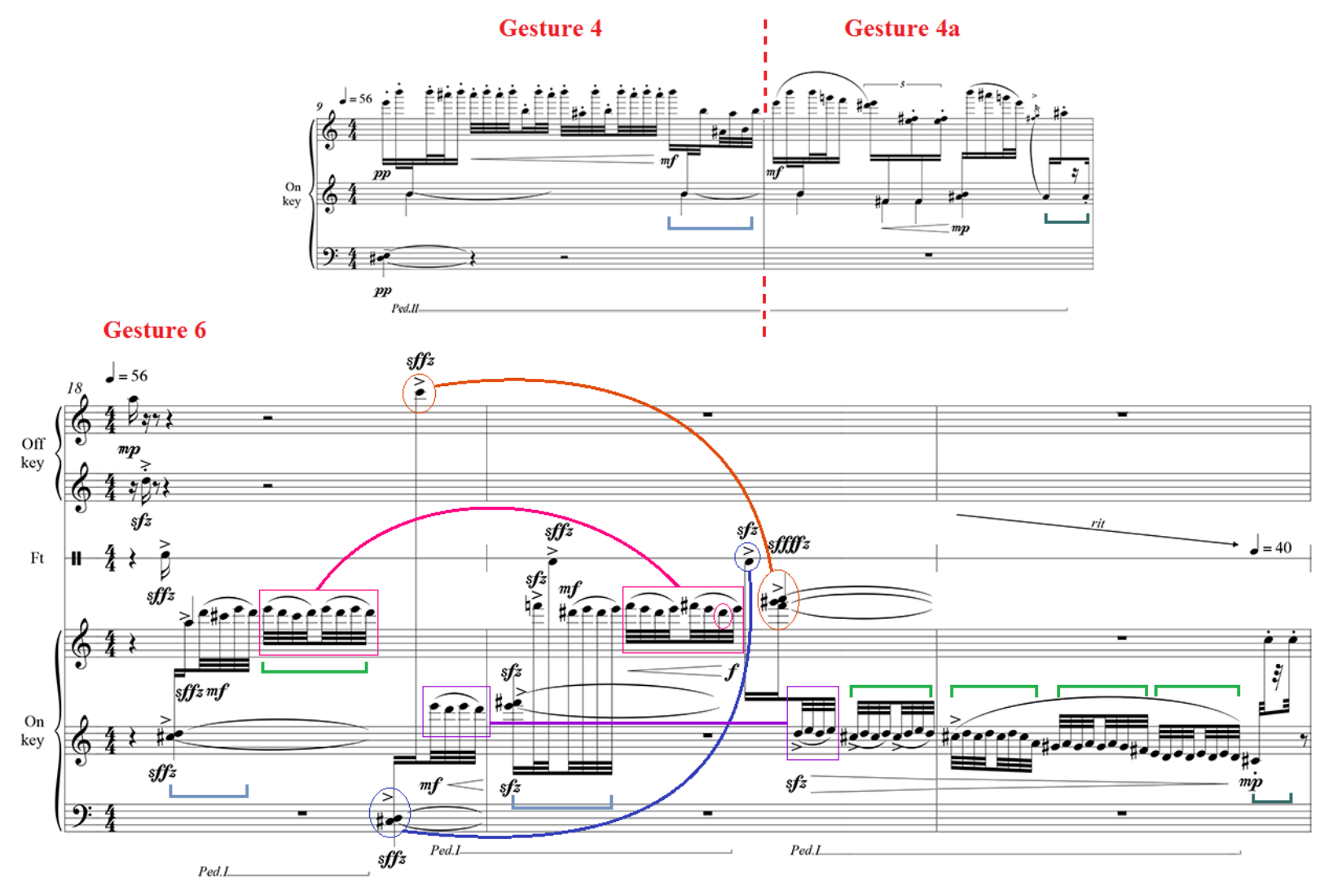

Figure 5.18

Kah Hoe Yii: My Spirit is Dancing!, Gestures 6 (mm.18-20) and corresponding gestures.

For the above-mentioned reasons, it could be concluded that Gesture 6 is indeed a variant of Gesture 2 and bears some traits of Gesture 4, which is also another variant of Gesture 2.

However, like Gesture 4, the characteristic of Gesture 6 clearly distinguishes it from Gesture 2, thus allowing it to be labeled as a new gesture, one which also becomes the basis for development in subsequent measures. Figure 5.19 shows the derivation of Gesture 6 in addition to other connections established earlier. 


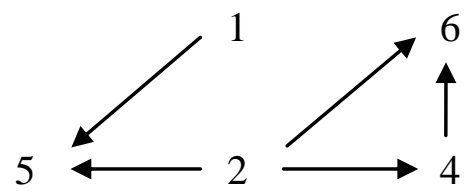

3

Figure 5.19 Derivations of Main Gestures: Gestures 1-6.

The last quarter beat of $\mathrm{m} .19$ expands and develops the $32^{\text {nd }}$ note motives seen in $\mathrm{m} .18$ into a series of continuous trill-like and turn-like descending figures consisting of $\mathrm{C} \#, \mathrm{D}, \mathrm{E}, \mathrm{F} \#$, G\#, and A (see Figure 5.16). This set of pitch collection outlines the whole-tone scale, and could perhaps be associated to the gamelan pelog scale as well (see Figure 5.20). This figure ends in a manner similar to that of Gesture $4 \mathrm{a}$ (m. 10), with a diminution in note values.

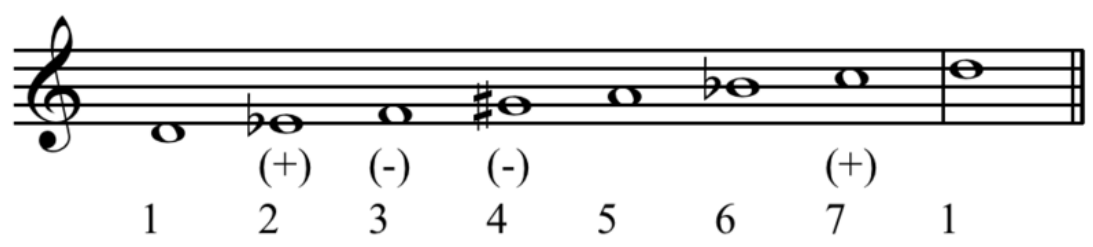

Figure 5.20 Pelog scale on D. Image taken from "Pelog," Wikipedia, last modified February 26, 2013, accessed March 11, 2013, http://en.wikipedia.org/wiki/Pelog.

The subsequent three measures (mm. 21-23) are labeled as Gesture 6a because they employ similar materials from Gesture $6(\mathrm{~mm} .18-20)$. The beginning of $\mathrm{m} .21$ repeats the last two quarter beats of m. 19, but with some alterations in rhythm, articulation, dynamics, and tempo (see Figure 5.21). However, the first two $16^{\text {th }}$ notes are changed to the rhythmic grouping of a triplet $8^{\text {th }}$ note and $16^{\text {th }}$ note. This new rhythmic pattern followed by a succession of $32^{\text {nd }}$ notes occupies the entire of $\mathrm{mm} .21$ and 22 , except for the first group in $\mathrm{m} .22$ where a $16^{\text {th }}$ note 
is used. It is also observed that within the triplet figure, the order of the $8^{\text {th }}$ note and $16^{\text {th }}$ note switches back and forth between groups.

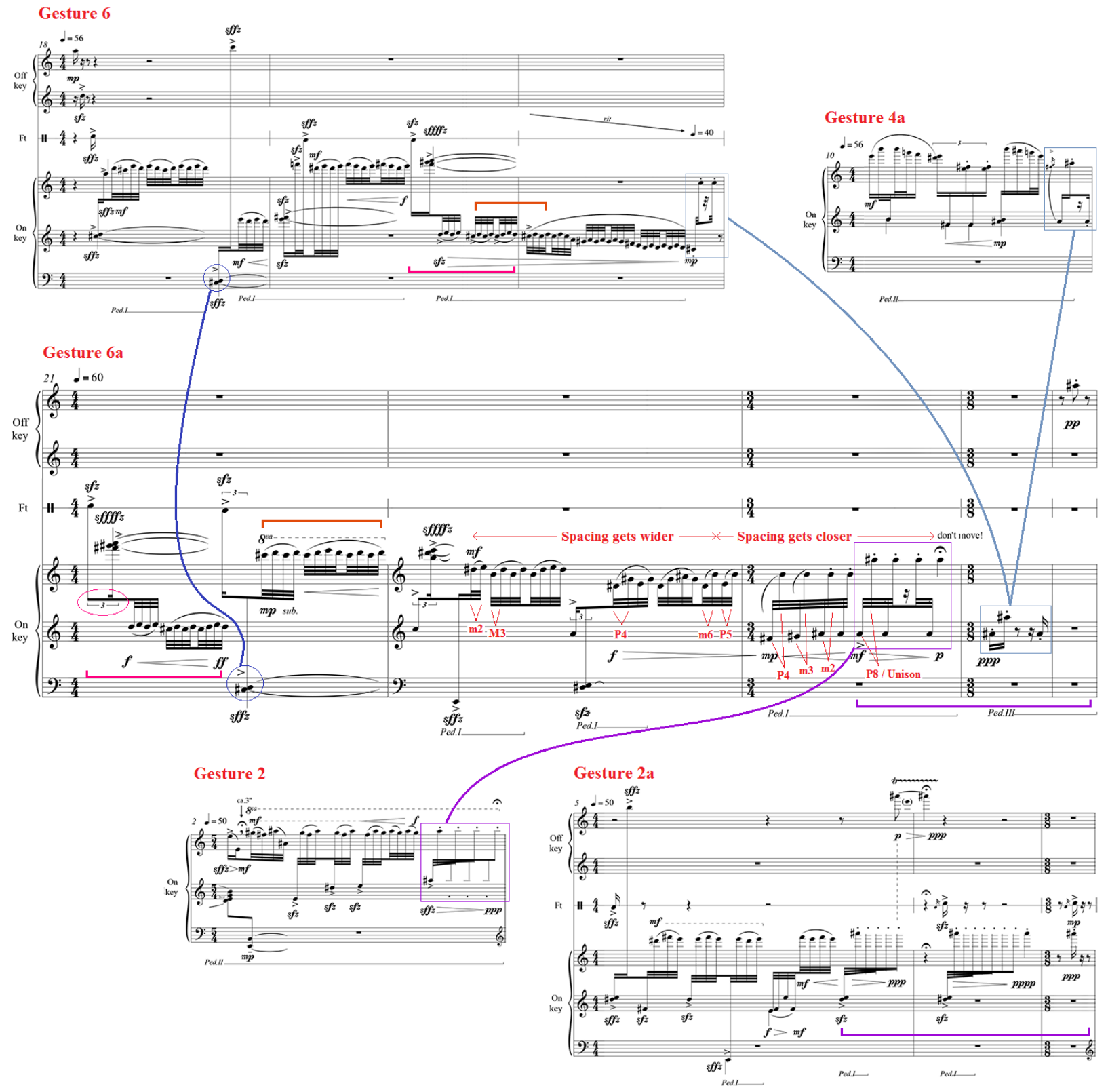

Figure 5.21

Kah Hoe Yii: My Spirit is Dancing!, Gesture 6a (mm. 21-25) and corresponding gestures.

The second half of m. 21 also borrows materials from Gesture 6: the harmonic semitone in the left hand is first seen on the fourth quarter beat of $\mathrm{m} .18$, while the $32^{\text {nd }}$-note figure in the 
right hand reuses the material from the end of m. 19 into the first eighth beat of $\mathrm{m} .20$ by transposing them two octaves higher (see Figure 5.21).

Instead of continuing with the rest of the material in $\mathrm{m} .20$, a new material is introduced in $\mathrm{m} .22$ - one that employs the rhythmic pattern in $\mathrm{m} .21$, but perhaps explores the spacing between pitches (see Figure 5.21) — which leads to the repeated A\#'s in the end of m. 23. This alternating-hand repeated-note gesture resembles that at the end of Gesture 2 (m. 2), and its extension into mm. 24 and 25 is like that of Gesture $2 \mathrm{a}(\mathrm{mm} .5-7)$. In addition, a familiar rhythm similar to that at the end of Gesture $4 \mathrm{a}(\mathrm{m} .10)$ which has already been utilized at the end of Gesture 6 (m. 20) is also seen here in m. 24. Once again, the fact that Gesture 6a also contains materials derived from Gestures 2 and its variants further supports the notion of Gesture 6 being a variant of Gesture 2.

Much of the material in mm. 31-33 and 34-37 resembles that of Gestures 6 (mm. 18-20) and $6 a(\mathrm{~mm} .21-25)$, which means that these passages are in a way related to Gesture 2 and its variants as well. The former, mm. 31-33, is marked as Gesture $6 \mathrm{~b}$ for the following reasons.

First, the beginning of m. 31 is very similar to that of Gesture 2 (m. 2), in that they both opens with a relatively widely spaced falling gesture, followed by a brief pause before continuing with a series of flowing $32^{\text {nd }}$-note figures (see Figure 5.22).

However, the $32^{\text {nd }}$-note figures are perhaps more closely connected to that of Gestures 4 (m. 9) and 4a (m. 10) due to the similarities in the opening three pitch-classes as well as the falling figures. Meanwhile, the second half of $\mathrm{m} .32$ and the first half of $\mathrm{m} .33$ could be treated as a variation of the second half of m. 19 (Gesture 6), while the gesture in the second half of m. 33 is also rather similar to that of Gesture $4 \mathrm{a}(\mathrm{m} .10)$ in the use of alternating-note figure and the falling-notes figure. Because much of the materials in mm. 31-33 are derived from Gestures 2 
and 4, as well as Gesture 6 (which draws from Gestures 2 and 4), it is characterized as Gesture $6 \mathrm{~b}$ instead of a completely new gesture.
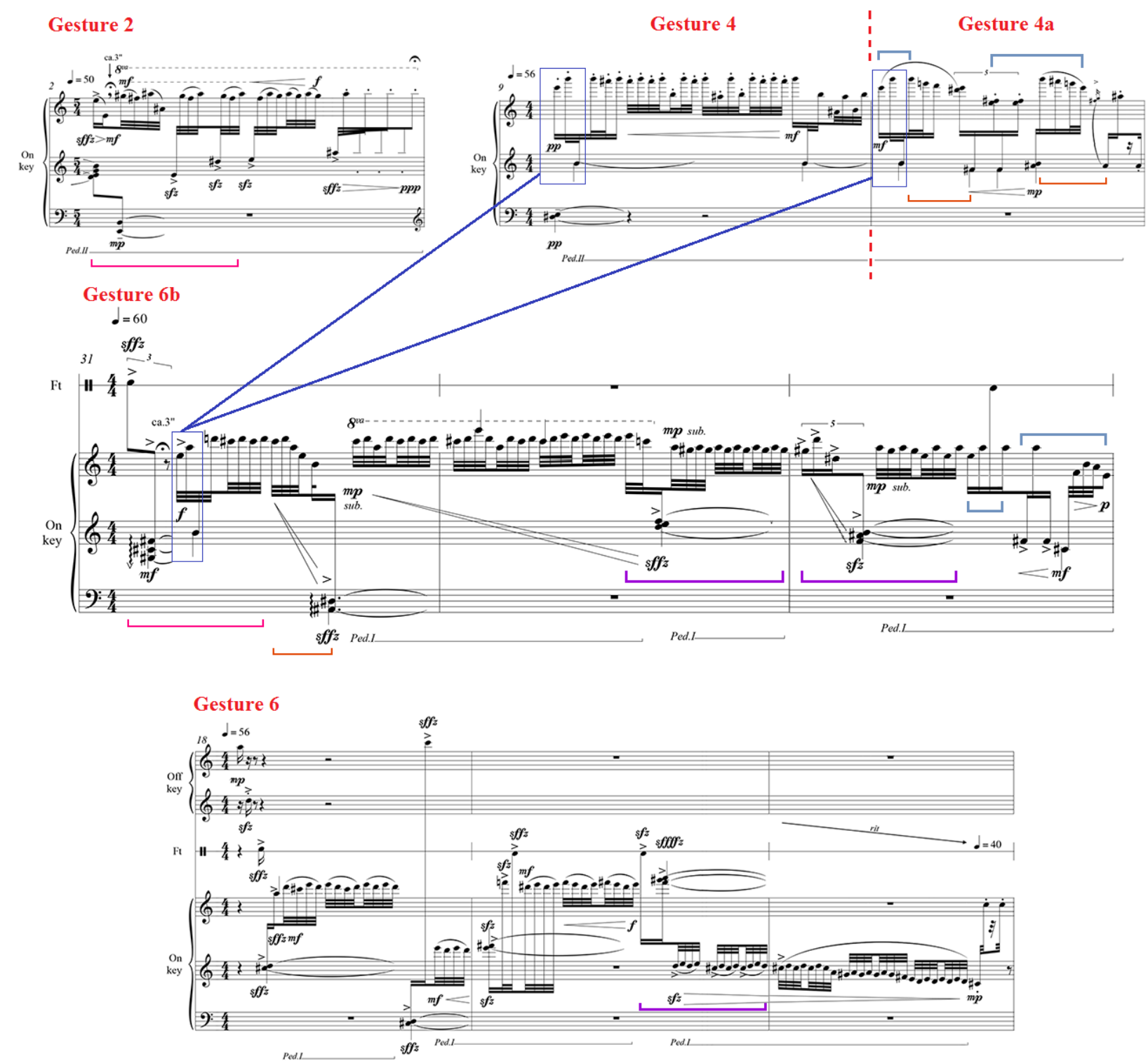

Figure 5.22

Kah Hoe Yii: My Spirit is Dancing!, Gesture 6b (mm. 31-33) and corresponding gestures.

Following Gesture $6 \mathrm{~b}$ in $\mathrm{mm} .34-37$ is a repetition of materials from Gesture 6a with slight modifications, creating Gesture 6a'. Omitting the materials in m. 21, the materials in mm. 
22 and 23 are directly quoted here in $\mathrm{mm} .34$ and 35, but two on-key figures in $\mathrm{m} .22$ are changed to foot stamps, and the alternating-hand figure at the end of m. 23 is stretched out (see Figure 5.23).
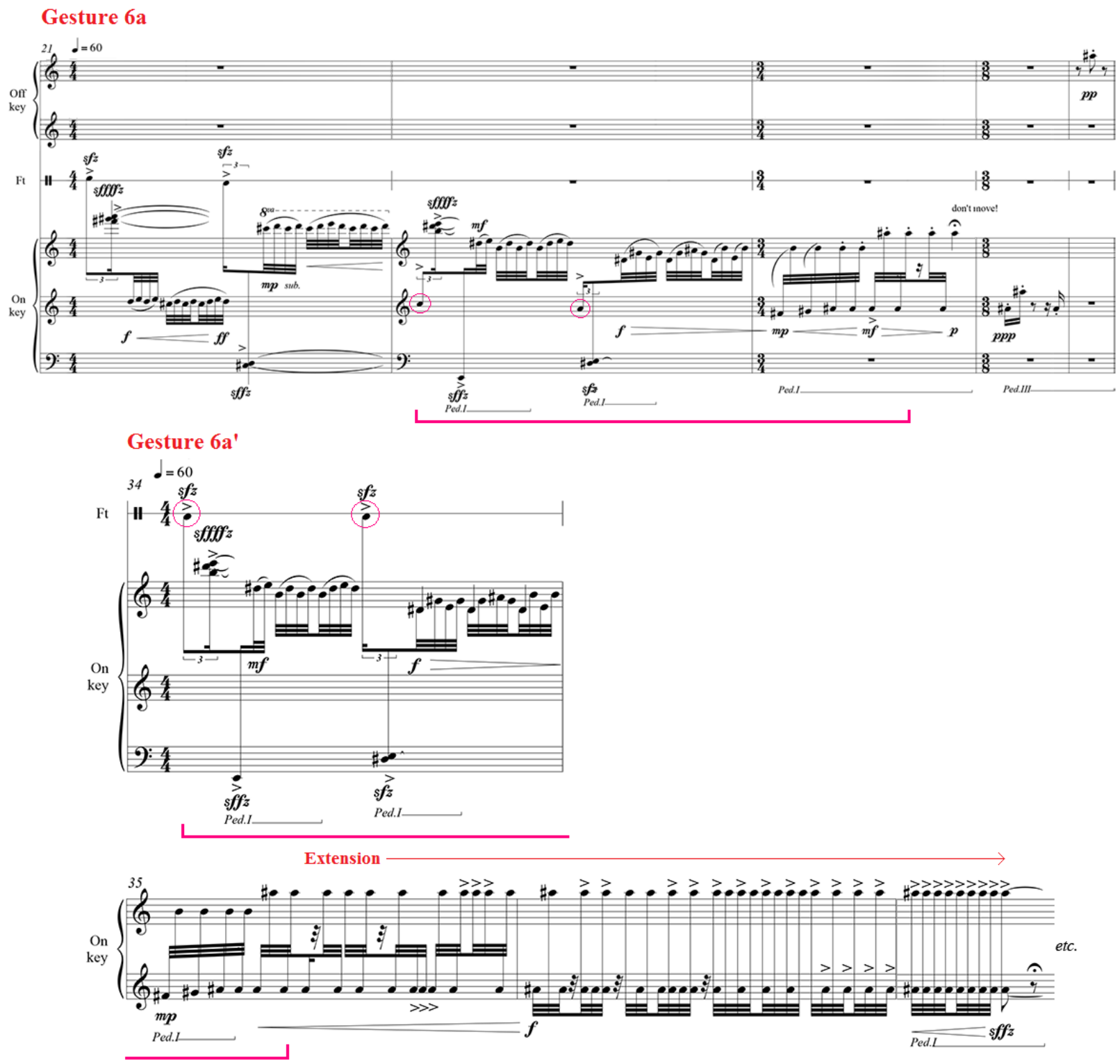

Figure 5.23

Kah Hoe Yii: My Spirit is Dancing!, Gestures 6a (mm. 21-23) and 6a' (mm. 34-37). 
The alternating-hand figure is then transposed a semitone higher and further extended into an improvisatory, meditative passage that lasts for about a minute - for which, mm. $37-43$ is hence labeled as Gesture 6a", another variant of Gesture 6a (see Figure 5.24). The shaking actions of the feet and hands are gradually added towards the end of the meditative passage, leading to a close in a manner resembling that of Gesture 1 at the very beginning of this piece, but without the stamping and shaking of the foot.
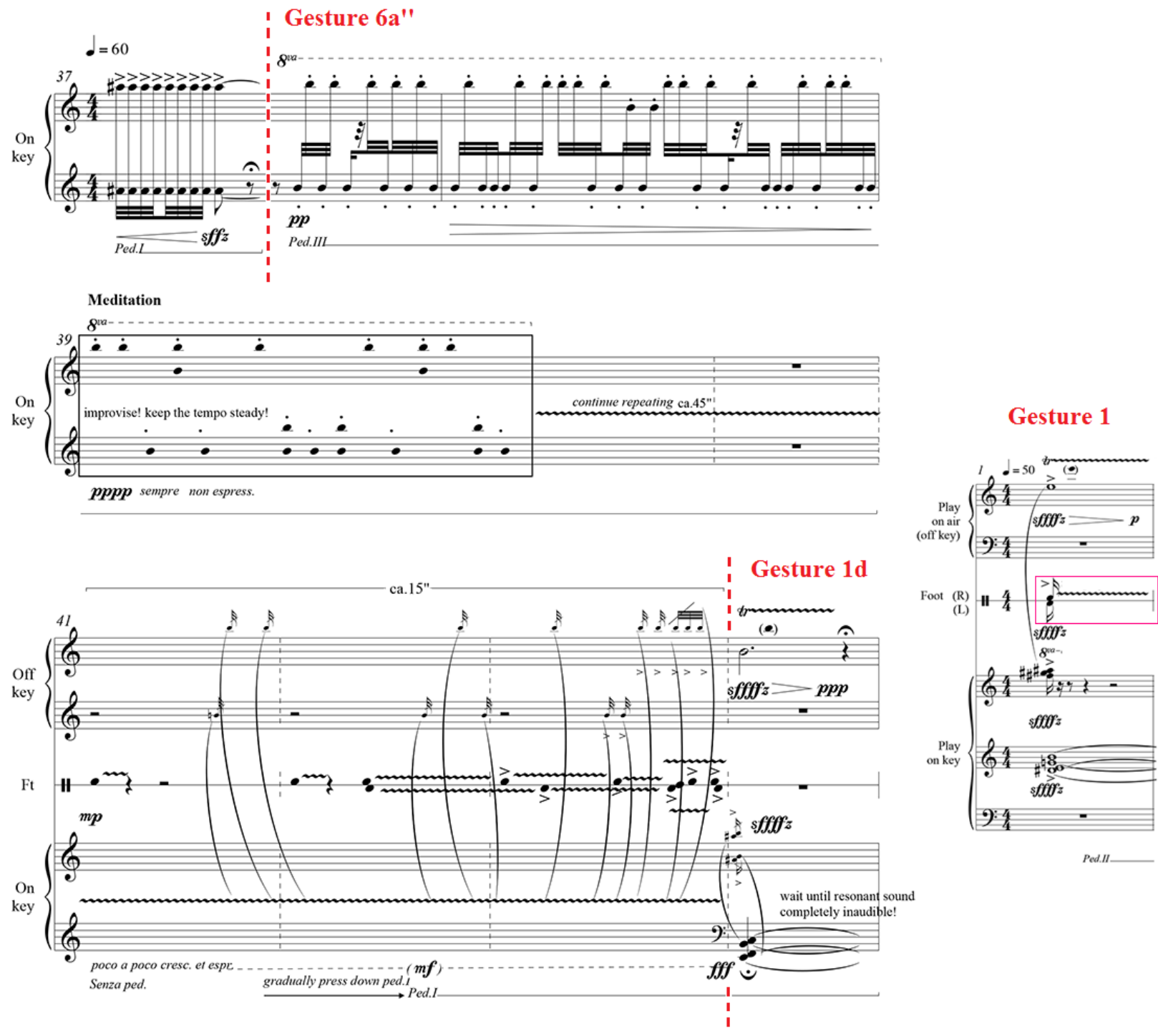

Figure 5.24

Kah Hoe Yii: My Spirit is Dancing!, Gestures 6a" (mm. 37-43), 1e (m. 44), and 1 (m. 1). 
Later on in this piece, fractions of the above-mentioned materials in Gesture 6 and its variants are recalled: Gesture 6a'" (m. 50) recalls the alternating-hand figure in Gesture 6a" (mm. 37-38) in a relatively condensed way (see Figure 5.25); and mm. 51-53 directly quotes from Gestures 6a (m. 21), 6a' (m. 34), and 6a (m. 23) respectively (see also Figure 5.23).

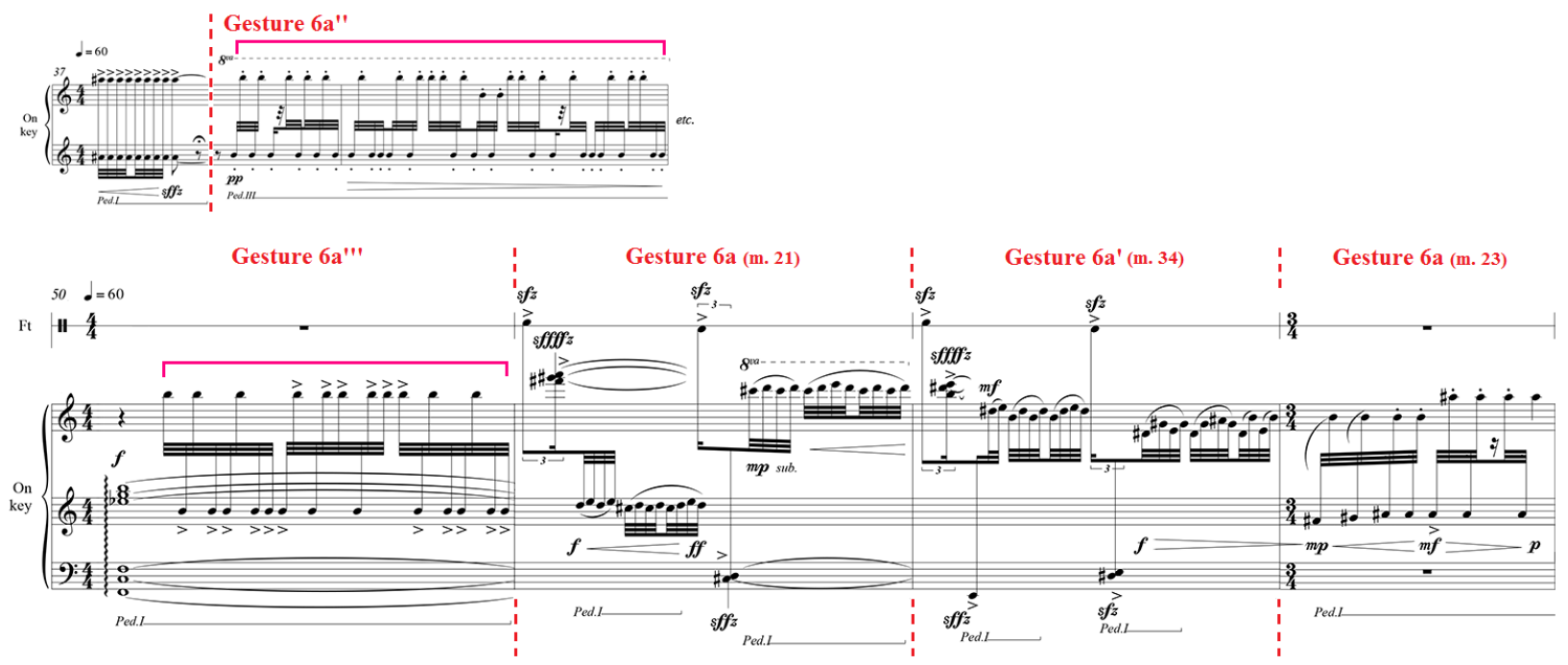

Figure 5.25

Kah Hoe Yii: My Spirit is Dancing!, Gesture 6a" (m. 37), Gesture 6a"' (m. 50), and corresponding gestures (mm. 52-54).

While it is not uncommon to see some of the gestures come back in a way throughout this piece, it is significant when a few successive gestures are repeated in the original order, even though there may be a change in the performance method of such gestures. Such an instance occurs from m. 70 to the end of this piece where Gestures 6b, 6a', and 6a" (as seen in mm. 3140) are repeated. The performance method changes are threefold: 1) all on-key playing is switched to off-key; 2) there is a minor alteration in switching a foot shake action to the hand in m. 72; and 3) the meditative passage in Gesture 6a" (m. 76) is played muted this time (see Figure 5.26). The shaking actions of the feet and hands at the end of Gesture 6a" (mm. 41-43) are also removed. Thus, this gesture is labeled as Gesture 6a'"'. 
Gesture 6b
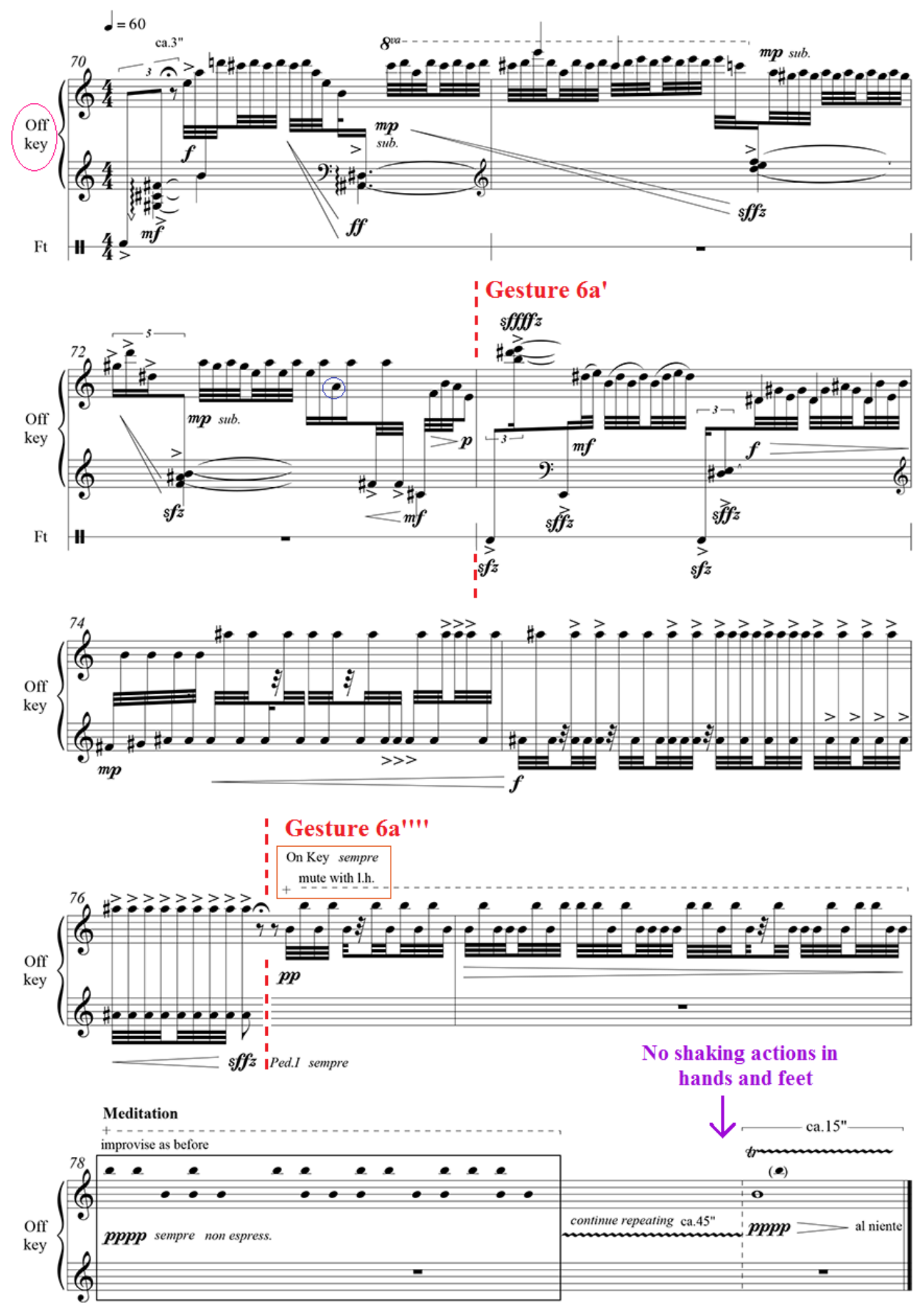

Figure 5.26

Kah Hoe Yii: My Spirit is Dancing!, mm. 70-78. 


\section{More Complex Derivations}

The materials in mm. 45-49 show the characteristics of a combination of several gestures. For example, the trill on the right hand in $\mathrm{m} .46$ could be traced back to Gesture $1 \mathrm{~b}(\mathrm{~m}$. 8). However, some of the materials are based on Gesture 6b (mm. 31-33); in particular, the falling quintuplet figure followed by a succession of eight $32^{\text {nd }}$ notes at the end of $\mathrm{m} .45$ is derived from m. 33 (see Figure 5.27). Since this figure recurs in mm. 47 and 49, this is the dominant source for mm. 45-49. Therefore, mm. 45-49 is characterized as Gesture 6c.
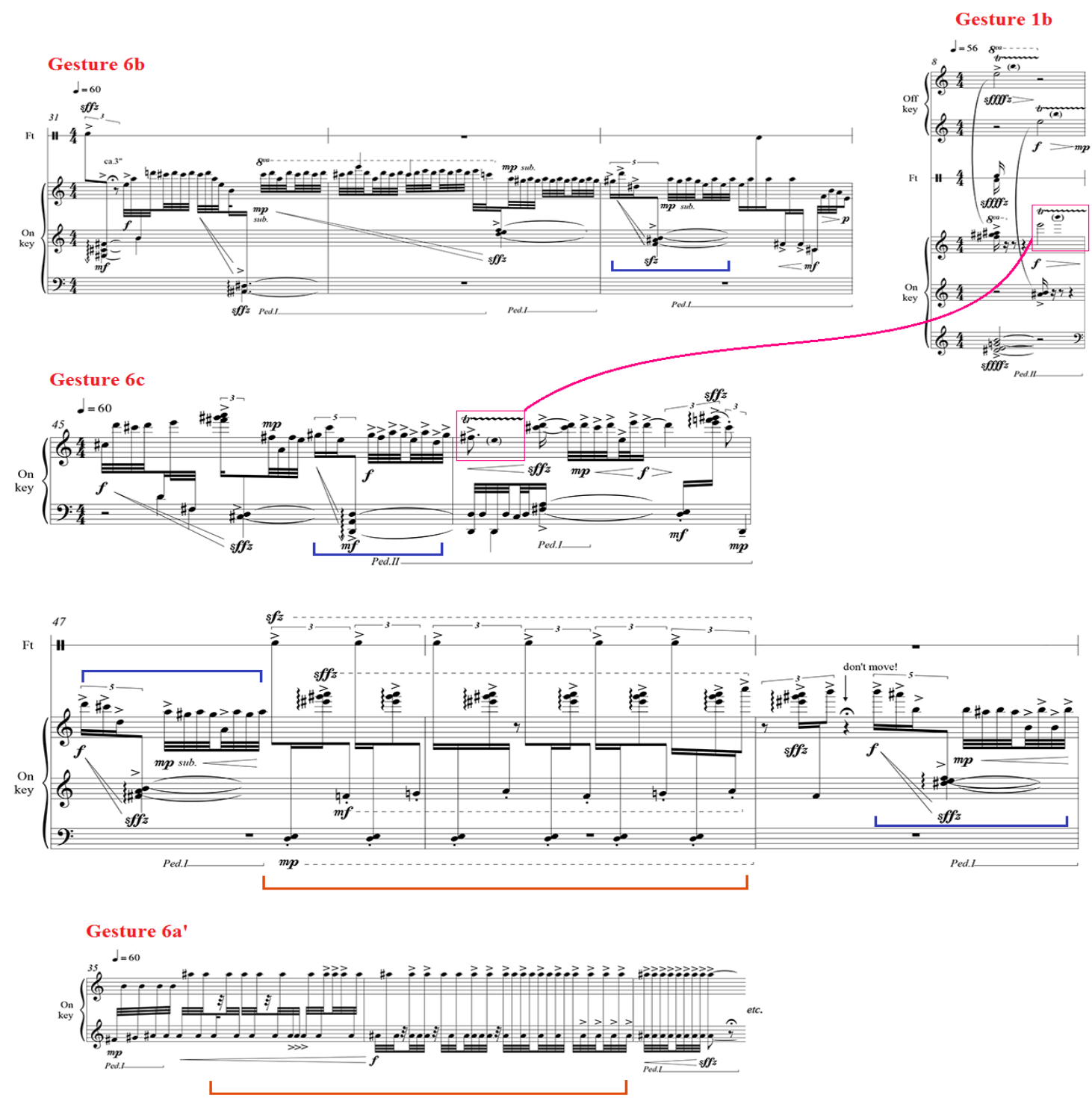

Figure 5.27

Kah Hoe Yii: My Spirit is Dancing!, Gesture 6c (mm. 45-49) and corresponding gestures. 
Interestingly, within Gesture $6 \mathrm{c}$ in mm. $47-48$ there occurs a gesture that imitates the alternating-hand figure seen at the end of Gesture 6a' (mm. 35-37) but in a more complex texture (see Figure 5.27). Instead of playing single notes, clusters - played simultaneously in the left hand, and rolled in the right hand — are also used. In addition, foot stamps are also added. Perhaps due to the complexity in texture, the rhythm is also changed to a relatively slower and widely spaced triplet figure.

Gesture $6 \mathrm{c}$ comes back again in a way in $\mathrm{mm} .55-60$, but most of the materials are modified, hence the new label of Gesture $6 c^{\prime}$. The first half of $\mathrm{m}$. 55 is somewhat similar to that of Gesture $6 \mathrm{c}$ in $\mathrm{m} .45$, while the second half quotes the material from Gesture 6 in m. 19. The next measure reuses the exact materials from Gesture $6 \mathrm{c}$ in $\mathrm{m} .46$, but transposes and switches the materials between hands on the first quarter beat (see Figure 5.28). 


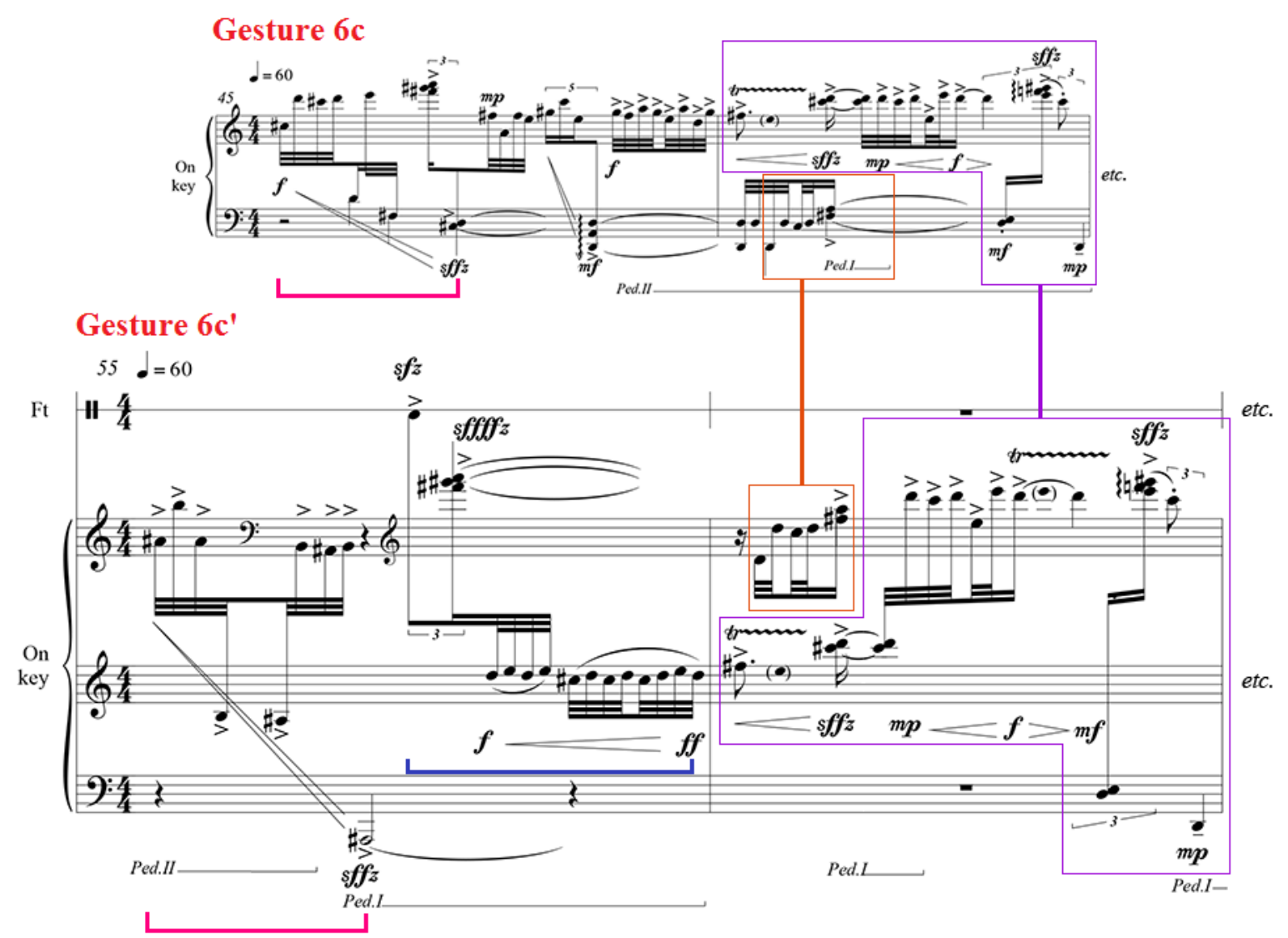

Gesture 6

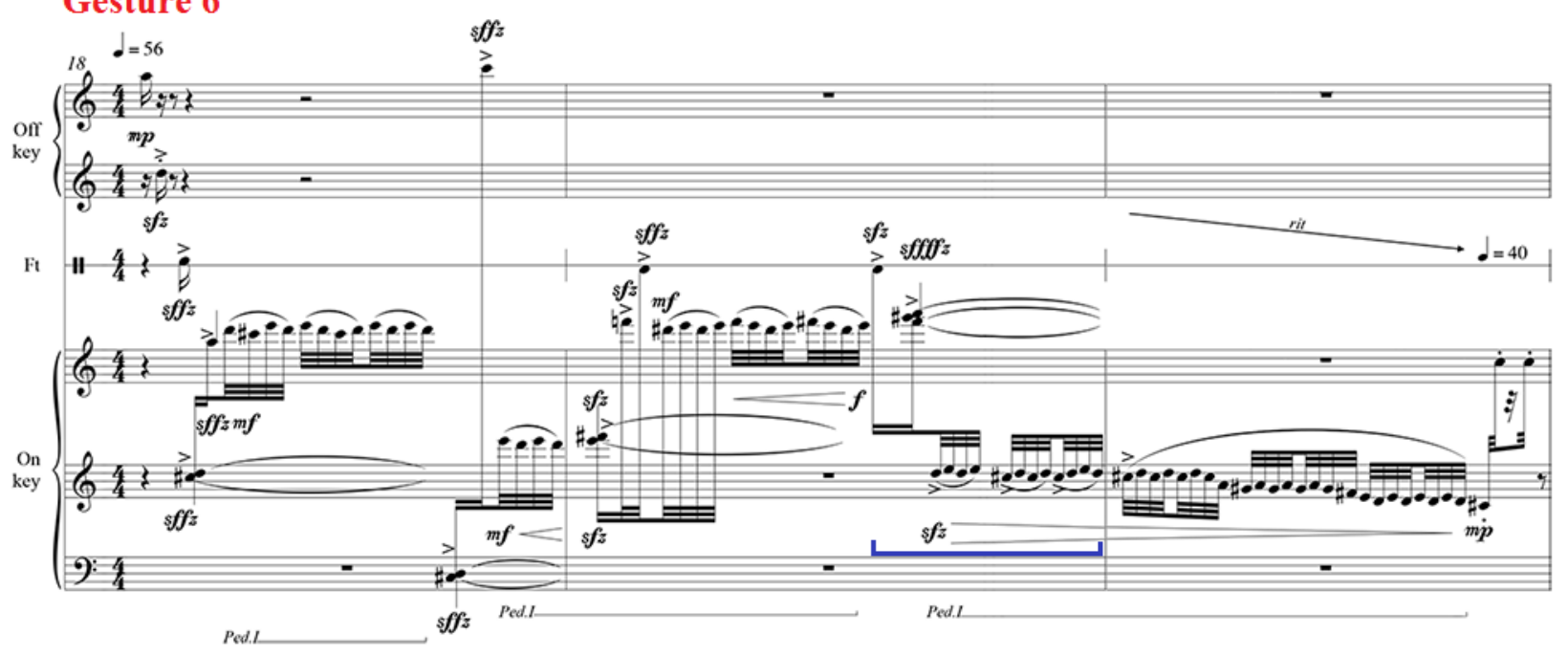

Figure 5.28

Kah Hoe Yii: My Spirit is Dancing!, Gesture 6c' (mm. 55-56) and corresponding gestures. 
In mm. 57-59, the alternating-hand figure - as seen at the end of Gestures 6a' (mm. 3537) and $6 \mathrm{c}(\mathrm{mm} .47-48)$ — returns in a whole new way. Up to this point, the composer has demonstrated a few ways to modify this figure by altering several aspects: 1) the rhythm of the figure is developed from straight $16^{\text {th }}$ notes to triplets; 2) the number of pitch-classes used increases from a single pitch-class to clusters; and 3) the sounding method changes from alternating between two hands to the inclusion of the foot.

M. 57 opens with a triplet figure similar to the alternating-hand figures seen in $\mathrm{mm}$. 4748 - in fact, the trichord contains the same exact pitches (see Figure 5.29). This is followed by a succession of $16^{\text {th }}$ and $32^{\text {nd }}$ notes, as seen before in Gesture 6 and its variants, which is then proceeded by the alternating-hand figure. However, this time the right hand carries dyads at the beginning of this gesture and alternates with single notes in the left hand in a quintuplet rhythmic group, which is an action first seen in Gesture 4a (m. 10).

Halfway into the gesture, the single notes in the left hand are changed to a series of fournote trill-like figures that lead to both hands playing dyads alternatively in m. 59, immediately followed by a short trill again in the left hand. The right hand continues with a series of $32^{\text {nd }}$ notes in a combination of turn and trill before spinning out into a rising passage comprising short trill-like figures in both hands in $\mathrm{m}$. 60. In a way, this passage in mm. 60-61 is a contrasting idea — somewhat like a mirror - to that seen at the end of Gesture 6 (mm. 19-20). Not only does the direction of the passage change from falling to rising, the order of the trill-like figures is also opposite of those seen in Gesture 6. Besides that, the dynamic also changes from decrescendo to crescendo (see Figure 5.29). 

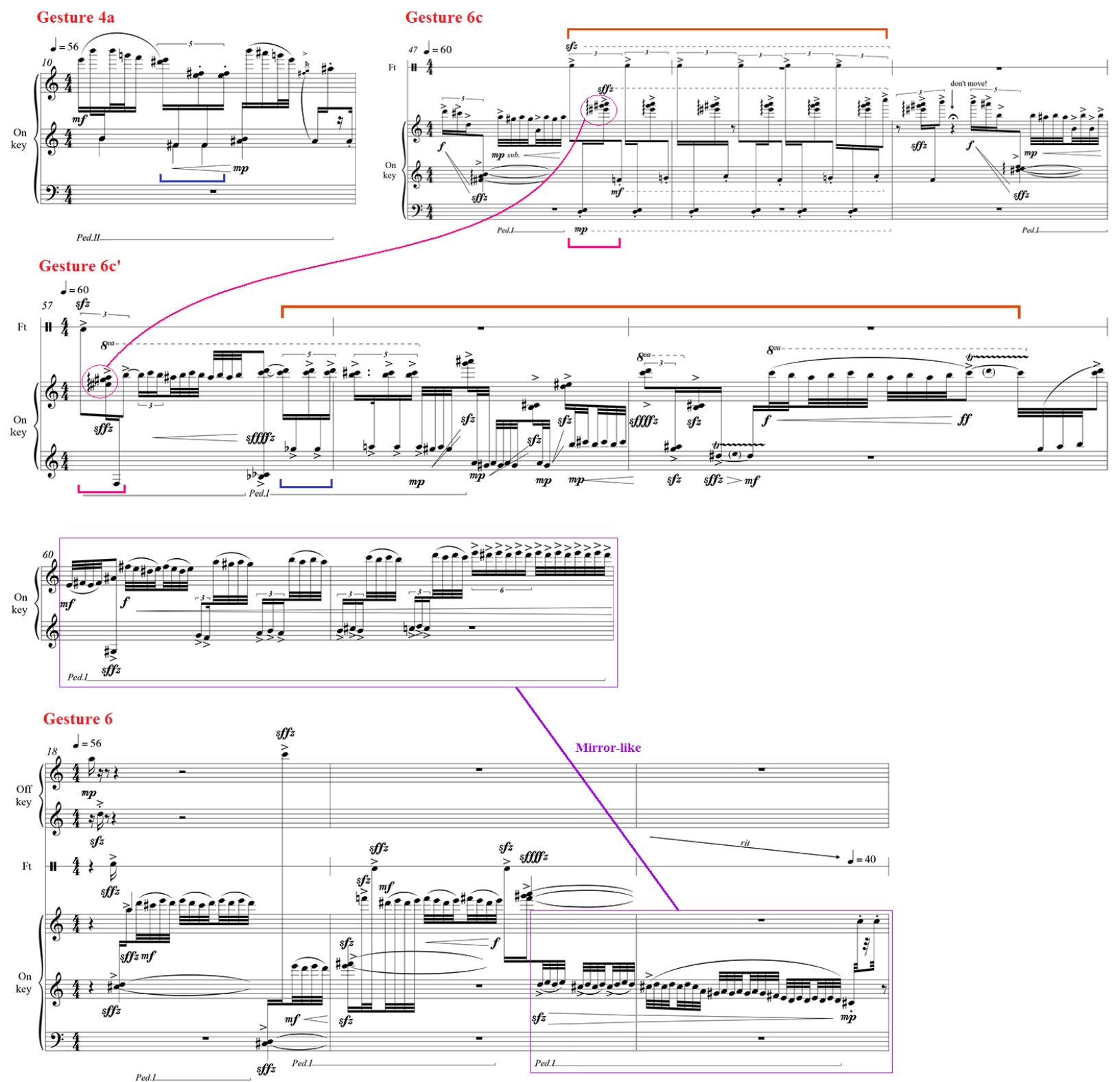

Figure 5.29

Kah Hoe Yii: My Spirit is Dancing!, Gesture 6c' (m. 57-61) and corresponding gestures.

To summarize, there are three basic gestures that get varied and developed, so much so that three additional gestures are formed. Upon classifying such musical gestures, it is easier to see the way they interact throughout this piece and further define the formal structure of the music (see Figure 5.30). 


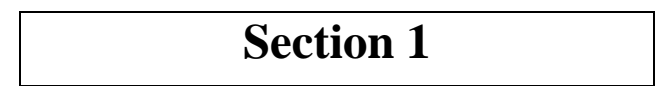

$\underline{\text { Measure }}$

1

2

3

4

5

8

9

10

11

12

13

14

15

17

18

21

26

27

28

29

30

31

34

37

44 $\underline{\text { Gesture }}$

1

2

$1 \mathrm{a}$

3

$2 \mathrm{a}$

$1 \mathrm{~b}$

4

$4 \mathrm{a}$

5

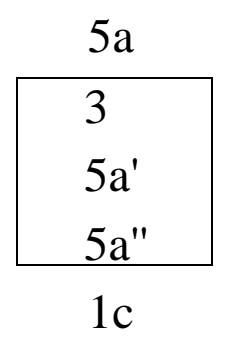

6

6a

$3 a$

3

\begin{tabular}{|c|}
\hline $1 c^{\prime}$ \\
$1 b^{\prime}$ \\
$1 b^{\prime \prime}$ \\
\hline $6 \mathrm{~b}$ \\
$6 a^{\prime}$ \\
$6 a^{\prime \prime}$ \\
\hline
\end{tabular}

$1 \mathrm{~d}$

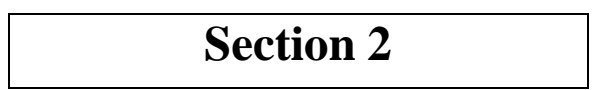

Measure Gesture

45

$6 c$

50

$6 a^{\prime \prime \prime}$

51

$6 a$

52

$6 a^{\prime}$

53

$6 a$

54

4

55

$6 c^{\prime}$

62

$1 b^{\prime \prime}$

63

64

65

66

67

68

70

73

76

\begin{tabular}{|l|}
\hline $1 c^{\prime}$ \\
$1 b^{\prime}$ \\
$1 b^{\prime \prime}$ \\
\hline $5 a^{\prime}$ \\
$5 a^{\prime}$ \\
3 \\
\hline
\end{tabular}

\begin{tabular}{|c|}
\hline $6 \mathrm{~b}$ \\
$6 \mathrm{a}^{\prime}$ \\
$6 \mathrm{a}^{\prime \prime \prime}$ \\
\hline
\end{tabular}

Figure 5.30

Formal structure of Kah Hoe Yii's My Spirit is Dancing! 
It is significant to note that a succession of gestures which occurs in the middle of this piece gets repeated at the end: the notion of Gestures 1c', 1b', and 1b" as a group (mm. 28-30) proceeding to the next group consisting of Gestures $6 \mathrm{~b}, 6 \mathrm{a}^{\prime}$, and 6a" (mm. 31-43) recurs in mm. 63-78, with the insertion of two sets of Gesture 5a' followed by Gesture 3 between them. Note also that Gestures 5 and 3 were grouped together earlier on in $\mathrm{mm} .13-15$.

These two groups of Gestures 1 and 6 act like a cadential structure that clearly divides this piece into two major sections: Section 1 spans from the beginning of this piece until m. 44, and Section 2 spans from m. 45 until the end of this piece. Gesture 1d in m. 44 functions as a closure for Section 1, presumably because Section 1 begins with, and returns to, Gesture 1, while Section 2 begins with, and returns to, Gesture 6 . Therefore, it may be suggested that this piece is binary in structure.

The first half of this piece has an introductory section that presents the most important materials-Gestures 1, 2, and 3, mm. 1-4. It then demonstrates how these materials could be varied, and how new gestures are formed when the materials from two gestures are combined. Other than that, the majority of Section 1 is devoted to the development of Gesture 2 into Gestures 4 and 6.

The above-mentioned cadential structure and Gesture $1 \mathrm{~d}$ in $\mathrm{m} .44$ marks the end of Section 1, followed immediately by the second half of this piece, beginning with a variant of Gesture 6. This section continues to focus on the development of Gesture 6, with an occasional insertion of previous material in Gesture 4. The cadential structure at the end is similar to that earlier, with an insertion of Gestures 5 and 3, as well as some slight modifications at the very end. 


\section{Conclusion}

At first glance, it is rather difficult to define the formal structure of this piece. In fact, it almost seems that it is loosely composed, rather like a "free-spirited" improvisatory piece. It is not until after each gesture is characterized that the design of this piece as a whole- one which ties the materials that get repeated, reused, and developed-begins to surface.

There are six main gestures in this piece, but there are only three that predominate and form the basis for development. These gestures are Gestures 1, 2, and 3; they either combine with one another, or they combine with their variants to form new gestures: Gesture 2 further develops into Gesture 4, and the combination of Gestures 2 and 4 generates Gesture 6; meanwhile, the combination of Gestures 1 and 2 results in the formation of Gesture 5. This structure is best illustrated in Figure 5.19, which - for the ease of reference - is recapitulated here as Figure 5.31.

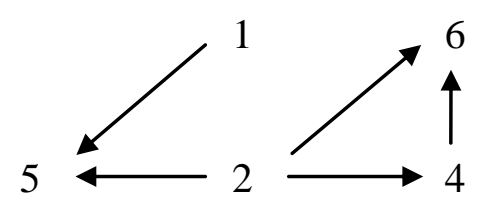

3

Figure 5.31 Derivations of Main Gestures: Gestures 1-6.

All six gestures are varied no less than once, but some of the gestures get repeated more often than others. In most instances, these gestures come back with slight modifications (e.g., Gestures 1, 5, and 6), but occasionally some are repeated exactly in their original form (e.g., Gestures 3 and 4).

Some gestures get varied and further developed to the extent that their variants form new independent gestures. For example, Gesture 2 gets varied into Gesture 2a, but it also develops 
into Gesture 4. Meanwhile, some gestures combine traits from different gestures and develop such traits into a whole new gesture. For instance, Gesture 5 contains materials from Gestures 1 and 2, while Gesture 6 bears characteristics of Gestures 2 and 4.

After characterizing the main gestures and their variants, it becomes clear that this piece is divided into two sections, each of which closes with a similar cadential structure. The first section introduces the main gestures and focuses largely on the development of Gesture 2, while the second section is largely devoted on the development of Gesture 6, which is also a variant of Gesture 2. However, it does not seem as though there is a clear structure to the order of appearance of these gestures within each section.

All in all, it seems that during the course of attempting to translate the gestures of baris dance into sounds, Yii is finding a way that makes sense to him-somewhat like improvising his way through My Spirit is Dancing! in a way that he finds satisfying. From the conception to the realization of the dance in musical form, this piece is certainly non-traditional in every aspect. It also presents such high level of performance complexity as switching between on-key and offkey playing in addition to the incorporation of feet stamps, as well as variations of meter, tempo, rhythms, and dynamics.

Nevertheless, the biggest attraction of this piece is perhaps the fact that it reinforces the visual aspect of playing an instrument, an aspect that is more often than not considered as secondary during instrumental performances. Not only does it invite performers to think of sounds in terms of physical gestures, and vice versa, it also allows performers to look within themselves and to go beyond what is notated on the scores - perhaps, to dance with the instrument, and be free in spirit! 


\section{CHAPTER SIX}

\section{Summary}

While the solo piano works selected and examined in this study do not do justice to each of these Malaysian composers' individual artistry, they certainly provide a glimpse into each of their musical background and aesthetics.

Chong Lim Ng's compositional technique very much reflects his education in Europe. $A$ Distant Voice of the Rain Forest, in particular, could be associated with the Darmstadt School, as evident by the methods used in manipulating the pitch content, as well as the elements of chance and spontaneity — whereby the performer gets to choose the performance order of each fragment (with no limit to repeating any fragment), and determine if any fraction of any fragment gets repeated.

$\mathrm{Ng}$ 's love for nature, simplicity, and freedom is also effectively portrayed in this piece: the use of loose form and loose rhythms; repeated-note and trill figures that mimic the sounds of insects and birds; swift passages that depict falling leaves and rustling water; and pauses between musical ideas that create a sense of tranquility and mystery. To contrast this, there are times when unforeseen loud dissonant harmonies or sudden changes in texture and rhythm occur within a single fragment. It is random moments like this that further enhance the quietness and stillness, perhaps also a sense of distance, in the music.

This piece is also undoubtedly influenced by the Javanese gamelan — references to the pelog scale, the evocation of the sound of gongs, and occasionally a polyphonic texture similar to that of a gamelan orchestra-making it a good and vital example of the acculturation of Western compositional techniques and Southeast Asian musical traditions. Not only that, it also presents a 
balance between structure (pitch content) and the lack of structure (loose form), serenity and chaos, as well as between simplicity and complexity.

Adeline Wong's Paces certainly demonstrates diversity at its best: firstly, by the combination of live acoustic and audio recording; and secondly, by the combination of various musical genres, both traditional and modern, West and East—such as classical, avant-garde, new age, rock, trance, digital, film, and ethno-in a single work. This perhaps also shows Wong's interest in contemporary popular music, electronic music, and film music.

Despite the diverse styles, Paces is constructed based on the concept of utilizing a short and simple cell motif as a unifying force in a multi-sectional work-a compositional technique commonly employed by many Western European masters, such as Beethoven and Schubert.

The music also successfully conveys the idea of how one copes with life in a modern city—sometimes the individual is synchronized with the busy city life, while other times competing with it and trying to catch up to its fast pace-and of who determines the future of the city and the urban soundscapes. This piece also presents a strong contrast between stability and instability, as well as simplicity and complexity, which could be associated with the state of the human mind when coping with a hectic urban lifestyle.

Kah Hoe Yii's life-long interests in ethno music and visual arts are strongly evident in his My Spirit is Dancing! which effectively merges two forms of performing arts—dance and instrumental playing. To achieve this, Yii turns gestures in space into sounds in pitch space, not just merely by assigning pitches to such gestures, but also through bells attached to the performer's wrists and ankles, which produce sounds when the performer executes actions such as stamping and shaking of the feet. Therefore, the performer is, to an extent, required to "dance" and make music at the same time. 
This piece is structured but at the same time calls for freedom, to a certain degree. Yii employs the concept of extending and expanding a basic gesture into other new gestures. The development of these gestures is for the most part clear and traceable, and the formal structure of this piece is defined by the reoccurrences of a set of cadential-like gestures. However, these gestures and their variants often vary in length, and there is also no fixed sequence of order in which each gesture occurs. In addition, there are two similar occasions which require the performer to improvise.

Besides combining two forms of performing arts, this piece also has several crosscultural references, particularly the Indian (the use of bells), Indonesian (drawing inspirations from the baris dance and the gamelan), and, to an extent, Malay (the gamelan) cultures. Many contemporary composers experiment with extended instrumental techniques, but very few combine different art forms, movements, and sounds into a single instrumental piece. Therefore, Yii's work is simply authentic and brilliant.

Despite the fact that these three composers' compositional techniques and approaches to piano playing differ greatly, it is surprising to find that, though unique and stylistically distinct, these works share some common traits with one another: all three works are programmatic in nature and present various cultural references, one of the most prominent influences being the Javanese gamelan. Ng's work draws inspiration from the Javanese gamelan pelog scale and the evocation of the sound of gongs. On the other hand, Wong's piece not only blends Western European classical and $20^{\text {th }}$ century avant-garde styles with contemporary popular music, it also blends both Western and Southeast Asian sounds through the inclusion of ethno music, such as that of the gamelan. Last but not the least, Yii's work is inspired by Indian and Indonesian dances, and often displays a familiar scale of the gamelan. 
This shows that although these Malaysian composers have different musical backgrounds and compositional styles, they share a common aspiration to incorporate and retain a certain quality or sound that defines their identities and cultural origins, which is not necessarily determined by ethnicity or nationality. These works also show that Malaysian composers can be traditional and experimental, national and international at the same time. In fact, these compositional strategies_ - assimilating foreign knowledge and technique with local influences and inspirations - are not uncommon among contemporary composers in Malaysia.

This small but carefully chosen sampling of contemporary art music by Malaysian composers not only symbolizes the country's diversity in culture, it also represents the essence of the contemporary art music in Southeast Asia. In addition, this collection further solidifies the fact that contemporary composers in the Southeast Asian region have a lot to offer to the contemporary art-music scene, and that new music in this region is worth exploring. 


\section{CHAPTER SEVEN}

\section{Conclusion}

Education in Western European art music in Malaysia, particularly through the study of piano, has blossomed over the past five decades. However, quantity does not always equal quality; the massive numerical growth in the musically literate is more often than not superficial and secondary when it comes to cultivating a healthy musical culture.

The musical growth in Malaysia is often said to be much slower than expected, as evident in the lack of homegrown professional musicians and composers, as well as the lack of interest in commissioning, performing, publishing, and publicizing works by local composers. As mentioned in the introductory chapter, the lack of local interest in Malaysian composers' works is partly due to the fact that art music is a cultivated culture in Malaysia, and therein we find several problems.

First of all, many do not relate to Western European art music, let alone contemporary art music. Some still regard such musical education as a symbol of social supremacy, while others merely consider this a hobby or an extra skill that aids in university entrance. Most importantly, there is still prejudice and doubt towards the quality of local craftsmanship because of the general perception that the West is superior. Therefore, a lot of people are unaware of the local talents, or they are simply skeptical towards local craftsmanship.

A concrete illustration can help. In an interview about the planning of the MPO Forum for Malaysian Composers—-presumably at the beginning of the new millennium—conductor Kevin Field recalled a phone conversation about an incident from when the MPO was initially formed, in which local composers were gathered and "advised one to one [by] a key official 
[who no longer works for the MPO] that no individual composer in Malaysia was capable of writing for an orchestra of this standard."1

In light of this Eurocentrism, many musicians who study abroad prefer to remain abroad, where there are relatively more promising opportunities for artists and there is more room for the appreciation of artistic creativities.

The "professional prize-winning" composer Kee Yong Chong also made a few remarks in an interview, presumably some time in 2004, where he openly shared the dilemmas he faced as a composer:

"When people play your music, sometimes they think, "I am giving you a chance." I think no, I can wait until I'm 50 years old. You don't have to play my music. But this is the key to an artist: you want an audience, but you don't want to need the audience.

I washed dishes and was a waiter [at a Taiwanese restaurant while attending the Royal Flemish Conservatory of Music of Brussels]... My boss was also a composer; he had been a student in the Vienna Conservatory! But he got married and had a family, so he needed to earn a living, and decided to open a restaurant. His advice to me was, "Kee Yong, if you want to start a family, don't be a composer"!

$\cdots$

[My parents] have never heard my music. They think I compose songs (laughs). I would never play them my recordings: I'm afraid they would have a big shock! My father is still not so happy, maybe because of the financial thing. He always says, "You made the wrong choice!"... I don't come from a music family. My grandfather on my mum's side was a musician, a storyteller who travelled from village to village. I never heard him but I saw him when I was little. I remember an image of him, lonely, with his instrument. In Europe I dedicated a piece to him. My family is ashamed of him... it was a bit shameful at that time: music, singing for people, little money... I always think, if I don't work hard, one day I'll be him!",2

\footnotetext{
${ }^{1}$ CH Loh, "Risky Business."

${ }^{2}$ Saidah Rastam, “The Professional Composer Prizewinner.” Originally published on March 10, 2004 on www.kakiseni.com but has since been removed from the web site. Article was obtained from Kakiseni's archive through personal request.
} 
It is not uncommon to hear that a career as an artist is discouraged, yet many have chosen this path, responding to a higher calling despite the hardship that comes with it. Following the success of the MPO Forums — which had proven that "Malaysia's got talent"-many composers and musicians have returned to their native homeland, eager to contribute to the local art-music scene and help raise awareness about art music. Despite the MPO's unfortunate decision to remove the "Contemporary Series" from its performance schedule since $2007,{ }^{3}$ several organizations have since been joining forces in organizing music festivals and concerts to promote the growth of contemporary art music, as well as to nurture young talents in Malaysia.

Several researchers pointed out the need of connecting, or re-connecting, Malaysians with their cultural roots by introducing local compositions with elements of Malaysian traditions into the musical repertoire and recital program. While some might question what constitutes a "Malaysian" identity since the country has several cultural heritages and a colonial past, this hesitation actually constitutes a failure to recognize that it is exactly its cultural diversity that makes Malaysia a unique country. Moreover, during the process of modernizing and industrializing the country, these local musical traditions are gradually declining in popularity and are at the verge of extinction. The works by contemporary Malaysian composers remind us clearly of that fact.

These composers express through their compositions "the assimilation of their musical experience, education, and upbringing as 'Malaysians,' regardless of their ethnicity." meaningful music that the local society could identify with and relate to, and this out of sincere appreciation for the cultural diversity, rather than to please and attract a certain group or

\footnotetext{
${ }^{3}$ Chong, Hashim, and Yeo, MPO Composers Forum, 57.

4 ““'Acquiring a Music Education,” 1065-66.
} 
audience. Some might even see this as one of the ways to preserve the essence of local musical traditions. Nevertheless, these composers undoubtedly expand the horizon and instill a new perspective of what "Malaysian" art music is: a truly international style of music!

This is especially evident in all three of the selected solo piano works examined in this study. Through detailed examinations of these works, including background surveys and theoretical analyses, the concept and structure of each work, as well as each composer's intention, are uncovered. These works are each unique stylistically, and each of them also reflects its composer's musical background and experience abroad; yet all of these works have an unmistakably Southeast Asian quality and sound. Together, they certainly represent the full breadth of contemporary art music for solo piano in Malaysia.

Although research in Malaysia's traditional music and popular music is vital and ongoing, this study nevertheless shows that the contemporary art music by Malaysian composers is also worth investigating. As a start, this study identifies several other Malaysian composers who have not been mentioned in previous research. It also demonstrates a few analytical methods that could be applied to other contemporary works. Therefore, this study could serve as a model for future research into similar topics.

It is the author's hope that future researchers will continue to identify, compile, and examine works by contemporary Malaysian composers through literature and pedagogical surveys, as well as stylistic and theoretical analyses. Such study, especially the study of works by those composers who have been identified, should also be expanded to include genres other than solo piano works.

This study is also hoped to help promote interest, and raise awareness, in works by Malaysian composers among music students and teachers, both locally and globally. The solo 
piano literature included in this study, together with those works listed in the appendix, should be programmed more often and be made available to the general public through publication.

It is hoped that Malaysian composers will receive greater attention and due recognition within their home country and internationally. It is also hoped that composers and musicians alike will continue to work together in cultivating a healthy musical culture in Malaysia. As Adeline Wong craftily voices in her work, Paces, the future of music is determined by the generations to come. Meanwhile, it is very much in our own hands, whether or not these musical innovations and traditions get passed down to them. 


\section{BIBLIOGRAPHY}

\section{Dictionaries and Encyclopedias}

Matusky, Patricia and James D. Chopyak. "Peninsular Malaysia." In The Garland Encyclopedia of World Music, edited by Terry E. Miller and Sean Williams. Vol. 4, Southeast Asia, 401-43. New York: Routledge, 1998.

Dobbs, Jack Percival Baker and Patricia Matusky. "West Malaysia." In The New Grove Dictionary of Music and Musicians, $2^{\text {nd }}$ ed., edited by Stanley Sadie. Vol. 15, 662-73. New York: Grove, 2001.

\section{Books}

"“Acquiring a Music Education': Social and Symbolic Significance of External Public Music Examinations in Malaysia." In Sentuhan: Proceedings of the 27th World Conference of the International Society for Music Education, 16-21 July, 2006, Kuala Lumpur, Malaysia, edited by Wendy L. Sims and Ramona Tahir, 1064-72. Nedlands, WA, Australia: International Society for Music Education (ISME), 2006.

Ang, Minni Kim Huai. An Introduction to Malaysian Music. $2^{\text {nd }}$ ed. Malaysia: Musicmall Conservatoire Productions, 2002. Accessed March 5, 2012. http://www.musicmallasia.com/minni/General/Malaysian_Music.pdf. Site discontinued, but PDF file is available at http://jiwaansos.webs.com/Malaysian_Music.pdf (accessed January 24, 2014).

- See also under Websites.

Chong, HueyChing, Mohd Nasir Hashim, and Young-Hwan Yeo, eds. The MPO Composers Forum: And its Impact on the Performance of Contemporary Western Classical Music by Malaysian Composers in Kuala Lumpur. Saarbrücken, Saarland, Germany: VDM Verlag, 2009.

Hamzah, Daud. "Malaysia." In New Music in the Orient: Essays on Composition in Asia since World War II, edited by Harrison Ryker, 91-96. Buren, Netherlands: Frits Knuf, 1991.

Jayatilaka, Basil. "Developing Trends in Malaysian Music." In Challenges in Music Education: Proceedings of the 11th International Conference of the International Society for Music Education Held in Perth, Western Australia, 5 to 12 August, 1974, edited by Frank Callaway, 394-99. Perth, Australia: University of Western Australia, 1976. 
Kok, Roe-Min. "Music for a Postcolonial Child: Theorizing Malaysian Memories." In Learning, Teaching, and Musical Identity: Voices Across Cultures, edited by Lucy Green, 73-90. Bloomington, IN: Indiana University Press, 2011.

Matusky, Patricia and Sooi Beng Tan. The Music of Malaysia: The Classical, Folk and Syncretic Traditions. Ashford, UK: Ashgate, 2004.

Wong, David Tze Wan. Music of the Chinese in Sabah: The Keyboard Culture. Kota Kinabalu, Malaysia: Opus, 2009.

\section{Periodicals}

Abdullah, Johami. "Music Education in Malaysia: An Overview." The Quarterly Journal of Music Teaching and Learning 1, no. 4 (Winter 1990): 44-53.

Bandem, I Made. “The Baris Dance.” Ethnomusicology 19, no. 2 (May 1975): 259-65.

Brown, John Robert. "Twin Peaks (Malaysian Philharmonic Orchestra Audience Receptive to New Music)." Classical Music: The Magazine of the Classical Music Profession (England) no. 711 (June 8, 2002): 24-25.

Chopyak, James D. "The Role of Music in Mass-media, Public Education and the Formation of a Malaysian National Culture.” Ethnomusicology 31, no. 3 (Fall 1987): 431-54.

James, Jamie. “The Rise of a Musical Superpower.” Time, June 28, 2004. Accessed March 13, 2012. http://www.time.com/time/asia/magazine/article/0,13673,501040705658369,00.html.

Lam, Ming Huey. "Malaysian Music and Composer Valerie Ross." Journal of the IAWM (International Alliance for Women in Music) 7, no. 3 (2001). Accessed September 20, 2011. http://www.iawm.org/articles_html/huey_valerie_ross.html (page removed).

Lie, Lena Pek Hung. "The MPO Forum for Malaysian Composers." Wacana Seni: Journal of Arts Discourse (Universiti Sains Malaysia) 2 (2003): 167-72. Accessed February 26, 2012. http://wacanaseni.usm.my/WACANA\%20SENI\%20JOURNAL\%20OF\%20ARTS\%20D ISCOURSE/JOURNAL_2\%20PDF/ws2_article14.pdf.

. "Music of the Malaysian Philharmonic Orchestra (MPO) Forum 2 Finalists: Reflections on Malaysian Multiculturalism." Wacana Seni: Journal of Arts Discourse (Universiti Sains Malaysia) 12 (2013): 59-81. Accessed January 26, 2014. http://wacanaseni.usm.my/WACANA\%20SENI\%20JOURNAL\%20OF\%20ARTS\%20D ISCOURSE/wacanaSeni_v12/WS-ART\%203\%20\%20(57-81).pdf. 
Loo, Fung Chiat. "A Case Study of the Audience at Three Art Music Concerts in Malaysia." Pertanika Journal of Social Science and Humanities (Universiti Putra Malaysia) 17, no. 2 (September 2009): 79-92. Accessed March 9, 2012. http://www.pertanika.upm.edu.my/Pertanika\%20ARCHIVES/JSSH/2009/JSSH\%20Vol $\% 2017 \% 20(2) \% 20$ Sep\%202009.pdf (article removed).

Macy, Carleton. "Tradition and Concert Music in Malaysia, 2002." Macalester International 12, no. 1 (October 2002): 187-92. Accessed March 2, 2012. http://digitalcommons.macalester.edu/macintl/vol12/iss1/19.

Malm, William P. "Music in Malaysia." World of Music 21, no. 3 (1979): 6-18.

MySinchew (Malaysia). "Orchestra is Part of Petronas' CSR.” June 30, 2008. Accessed April 8, 2012. http://www.mysinchew.com/node/13309?tid=14.

Othman, Johan. "Cultural Decentralization within a Post Colonial Territory: Movements in Malaysia's Music Culture." Wacana Seni: Journal of Arts Discourse (Universiti Sains Malaysia) 1 (2002): 79-86. Accessed March 2, 2012. http://wacanaseni.usm.my/WACANA\%20SENI\%20JOURNAL\%20OF\%20ARTS\%20D ISCOURSE/JOURNAL_1\%20PDF/CULTURAL\%20DECENTRALIZING\%20WITHIN \%20A\%20POST\%20COLONIAL\%20TERRITORY\%20MOVEMENTS\%20IN\%20MA LAYSIA'S\%20MUSICAL\%20CULTURE_JOHAN\%20OTHMAN.pdf.

Tan, Sooi Beng. "The Performing Arts in Malaysia: State, Society and the Entertainment Industry." Asian Music 21, no. 1 (Fall-Winter 1989): 137-71.

Tarmizi, Jastin Ahmad. "Boost for Arts, Culture and Heritage." The Star Online (Petaling Jaya, Malaysia), March 21, 2011. Accessed April 4, 2012. http://thestar.com.my/metro/story.asp?sec=central\&file=/2011/3/21/central/ 8283478 .

Tenzer, Michael. "José Maceda and the Paradoxes of Modern Composition in Southeast Asia: With List of Maceda's Compositions to Date." Ethnomusicology 47, no. 1 (Winter 2003): 93-120.

The Star Online (Petaling Jaya, Malaysia). "Festival Features Classes and Concerts for Young Musicians." November 2, 2011. Accessed February 26, 2012. http://thestar.com.my/metro/story.asp?file=/2011/11/2/central/9763531\&sec=central.

\section{Theses and Dissertations}

Chan, Amy Wai Yee. "Composing Race and Nation: Intercultural Music and Postcolonial Identities in Malaysia and Singapore." PhD diss., Australian National University, Canberra, Australia, 2005.

Dobbs, Jack Percival Baker. "Music in the Multi-Racial Society of West Malaysia.” MPhil thesis, University of London, United Kingdom, 1972. 
Lam, Ming Huey. "Art Music Composition in Malaysia: A Focus on Three Composers.” MS thesis, Universiti Putra Malaysia, Malaysia, 2000.

Leong, Grace Kah Yan. 'Love It, Love It Not: Parental Attitudes Regarding Children's Music Learning in Kuala Lumpur.” BMus hons thesis, University of Sydney, Australia, 2008. Accessed February 29, 2012. http://hdl.handle.net/2123/3993.

Ooi, Patricia Marie. "A Description and Comparison of Two Prominent Keyboard Music Education Systems and Their Implications for Music Education in Malaysia.” MM thesis, University of Miami, 1999.

Ross, Valerie. "External Public Piano Examinations in Malaysia: Social and Symbolic Significance." PhD diss., Deakin University, Victoria, Australia, 2002. Accessed December 29, 2013. http://dro.deakin.edu.au/eserv/DU:30023143/rossexternalpublicpiano-2002.pdf.

Siagian, Charmaine Blythe. "Selected Solo Piano Works by Contemporary Malaysian and Indonesian Composers from 1979 to 2007: An Introduction." DMA diss., University of Oklahoma, 2007. Accessed October 22, 2010. http://gradworks.umi.com/32/88/3288838.html.

Yong, John Lah Boh. "The Roles of the Malaysian Government and Private Sectors in the Development of Music Education." MM thesis, University of Florida, 2003. Accessed November 19, 2010. http://etd.fcla.edu/UF/UFE0000829/yong_j.pdf.

\section{Websites}

Albertson, Dan and Ron Hannah, eds. The Living Composers Project. Accessed April 17, 2012. http://www.composers21.com.

Allegro Music \& Arts. "Piano \& Keyboard: Visiting Guest Artists.” Accessed January 18, 2013. http://www.allegromusic.info/faculty/clng.html.

Ang, Minni Kim Huai. An Introduction to Malaysian Music. $2^{\text {nd }}$ ed. Malaysia: Musicmall Conservatoire Productions, 2002. Accessed March 5, 2012. http://www.musicmallasia.com/minni/General/Malaysian_Music.pdf. Site discontinued, but PDF file is available at http://jiwaansos.webs.com/Malaysian_Music.pdf (accessed January 24, 2014).

- See also under Books.

. Musical Malaysia. Accessed March 4, 2012. http://www.musicmallasia.com/malaysia (site discontinued). 
Annexe Gallery. “About The Annexe Gallery.” Accessed 5 March 2012. http://www.annexegallery.com/index.php?option=com_content\&view=article\&id=45\&It emid=54.

Asian Composers League. "Full Members.” Accessed April 8, 2012. http://asiancomposersleague.com/members/fullmembers.html\#malaysia.

Central Intelligence Agency. "Introduction: Malaysia." The World Factbook. Last updated January 8, 2014. Accessed January 24, 2014. https://www.cia.gov/library/publications/the-world-factbook/geos/my.html.

Cho, Jessica. Personal website. Accessed January 22, 2014. http://jessicachomusic.wordpress.com.

Chong, HueyChing. Personal website. Accessed January 26, 2014. http://hueychingchong.yolasite.com.

Chong, Kee Yong. Personal website. Accessed January 22, 2014. http://www.chongkeeyong.com.

Chow, Jun Yan. Personal website. Accessed January 26, 2014. http://www.chowjunyan.com/index.html.

Department of Music, University of New Mexico. John Donald Robb Composers'Symposium. Program booklet. Accessed January 18, 2013. http://music.unm.edu/media/pdfs/CompSymp2011_Program.pdf.

Department of Statistics, Malaysia. "Population Distribution and Basic Demographic Characteristic Report 2010." Last updated August 5, 2011. Accessed March 19, 2012. http://www.statistics.gov.my/portal/index.php?option=com_content\&view=article\&id=1 215\%3Apopulation-distribution-and-basic-demographic-characteristic-report-populationand-housing-census-malaysia-2010-updated-2972011\&catid=130\%3Apopulationdistribution-and-basic-demographic-characteristic-report-population-and-housing-censusmalaysia-2010\&lang=en.

Goethe-Institut Malaysia. “About Us.” Accessed March 5, 2012. http://www.goethe.de/ins/my/kua/uun/enindex.htm.

Gopinath, Anandhi. "Defining Malaysian Music.” Malaysiancomposers.com. Malaysian Composers Collective. Accessed February 27, 2012. http://www.futureasia.net/malaysiancomposers/resources/media_art2_options08.pdf. Originally published in Options February 4, 2008.

HSBC Bank Malaysia. "About HSBC in the Arts.” Accessed April 4, 2012. http://www.hsbc.com.my/1/PA_ES_Content_Mgmt/content/website/pdf/about_us/arts/art s_profile.pdf. 
HSBC Cultural Exchange. "HSBC Classics Music Festival and Bursary." April 17, 2010. Accessed April 5, 2012. http://www.hsbcculturalexchange.com/page/HSBC-ClassicsMusic-Festival-and-Bursary/114 (site discontinued).

Loh, CH. "On the Quiet - Interview with Ng Chong Lim.” Malaysiancomposers.com. Malaysian Composers Collective. June 1, 2010. Accessed February 28, 2012. http://www.futureasia.net/malaysiancomposers/focus/focus30_chonglim.htm. Originally published in Off The Edge July, 2007.

. "Risky Business." CH Loh's Portfolio. Accessed February 27, 2012. http://www.geocities.ws/contact_chloh/articles/riskybusiness.htm. Originally published in Options ${ }^{2}$, The Edge November, 2004.

. "Sowing the Seeds." CH Loh's Portfolio. Accessed February 26, 2012. http://www.geocities.ws/contact_chloh/articles/sowingseeds.html. Originally published in Options, The Edge March, 2003.

. "Young Malaysians - Adeline Wong Offers Snapshots." Accessed March 24, 2013. Malaysiancomposers.com. Malaysian Composers Collective. August 31, 2010. http://www.futureasia.net/malaysiancomposers/focus/focus32_adeline.htm. Originally published in Off The Edge September, 2005.

Malaysian Composers Collective. "About KLCMF." Malaysiancomposers.com. Accessed April 8, 2012. http://www.futureasia.net/malaysiancomposers/klcmf09/about.htm.

. “About Malaysian Composers.” Malaysiancomposers.com. Accessed March 4, 2012. http://www.futureasia.net/malaysiancomposers/composers/about_composers.htm.

. “About Us.” Malaysiancomposers.com. Accessed March 4, 2012. http://www.futureasia.net/malaysiancomposers/general/about_us.htm.

."Faith, Hope \& Chaos: About the Pieces: 3 Sketches for 2 Pianos." Malaysiancomposers.com. Accessed January 18, 2013. http://www.futureasia.net/malaysiancomposers/special/faith3-8.htm.

. "HSBC Classics Piano Festival 2008 to include Works by 9 Malaysian Composers as Compulsory Piano Competition Set Pieces.” Malaysiancomposers.com. January 31, 2008. Accessed February 26, 2012.

http://www.futureasia.net/malaysiancomposers/general/news2.htm\#news2.

"HSBC Young Composers Workshop 2008." Malaysiancomposers.com. Accessed April 8, 2012. http://www.futureasia.net/malaysiancomposers/special/ycw2008.htm.

. "We Built This City: Malaysian Voices and Their Songs of the City." KL

Contemporary Music Festival '09. Malaysiancomposers.com. Accessed March 24, 2013. http://www.futureasia.net/malaysiancomposers/klcmf09/concert27.htm. 
Malaysian Philharmonic Orchestra. "About Dewan Filharmonik PETRONAS." Accessed January 25, 2014. http://mpo.com.my/About-DFP/About-Us.aspx.

. "Conductors: Kevin Field, Associate Conductor." Accessed February 27, 2012 and December 23, 2013. http://www.mpo.com.my/Meet-The-MPO/Conductors/KevinField.aspx.

_. "Encounter Ensembles.” Accessed December 23, 2013, http://www.mpo.com.my/Education---Outreach/Encounter-Ensembles.aspx.

—. "Orchestra History.” Accessed February 27, 2012. http://www.mpo.com.my/MeetThe-MPO/World-Tours.aspx.

Malaysian Youth Orchestra Foundation. “About MYOF.” Accessed January 26, 2014. http://www.myof.org.my/about.

. "Malaysian Youth Music Festival.” Accessed January 26, 2014. http://www.myof.org.my/festival.

Off The Edge's Facebook page. Accessed March 5, 2012. https://www.facebook.com/pages/OFF-THE-EDGE/118269411534527.

Persatuan Chopin Malaysia (Chopin Society Malaysia). “About Us.” Accessed January 26, 2014. http://chopinsociety.com.my/main/page/about-us.

—. "Our Mission.” Accessed January 26, 2014. http://chopinsociety.com.my/main/page/our-mission.

Rastam, Saidah. "The Professional Composer Prizewinner.” March 10, 2004. Originally published on www.kakiseni.com but has since been removed from the website. Article was obtained from Kakiseni's archive through personal request.

Ryuurui, Ponte. “Cursive Script.” May 29, 2013. Accessed December 18, 2013. http://www.inktreasures.com/history/calligraphy/chinese-calligraphy/calligraphy-scripts/cursive-script.

Society of Malaysian Contemporary Composers. "About SMCC.” Accessed December 23, 2013, http://www.smccomposers.com/about-smcc.html.

Tan, Su Lian. Personal website. Accessed February 14, 2014. http://suliantan.com.

Tan, Zihua. Personal website. Accessed January 26, 2013. http://www.zihuatan.com.

Tajuddin, Tazul Izan. Personal website. Accessed January 24, 2014. http://www.tazultajuddin.com.

The Associated Board of the Royal Schools of Music. "About Us.” Accessed January 24, 2014. http://gb.abrsm.org/en/about-us. 
The Kuala Lumpur Performing Arts Centre. "Malaysia Composer Series $2011\left(30^{\text {th }}-31^{\text {st }}\right.$ July)." Accessed April 8, 2012. http://www.klpac.org/?p=2161.

The Society of Malaysian Contemporary Composers. "About SMCC," Society of Malaysian Contemporary Composers. Accessed December 23, 2013. http://www.smccomposers.com/about-smcc.html.

. "Members: Yii Kah Hoe.” Accessed January 16, 2013. http://www.smccomposers.com/yii-kah-hoe.html.

Wikimedia Foundation. "Gehu," Wikipedia. Last modified November 9, 2013. Accessed December 18, 2013. http://en.wikipedia.org/wiki/Gehu.

. "Huqin," Wikipedia. Last modified February 26, 2013. Accessed December 18, 2013. http://en.wikipedia.org/wiki/Huqin.

"Malaysian Contemporary Music." Wikipedia. Last modified December 15, 2013. Accessed March 4, 2012 and January 26, 2014. http://en.wikipedia.org/wiki/Malaysian_contemporary_music.

"Music of Malaysia." Wikipedia. Last modified October 31, 2013. Accessed March 4, 2012 and January 26, 2014. http://en.wikipedia.org/wiki/Malaysian_music.

-. "Pelog." Wikipedia. Last modified February 26, 2013. Accessed March 11, 2013. http://en.wikipedia.org/wiki/Pelog.

. "Ruan," Wikipedia. Last modified October 16, 2013. Accessed December 18, 2013. http://en.wikipedia.org/wiki/Ruan.

. "Shakuhachi," Wikipedia. Last modified December 2, 2013. Accessed December 18, 2013. http://en.wikipedia.org/wiki/Shakuhachi.

_. "Suona," Wikipedia. Last modified November 19, 2013. Accessed December 18, 2013. http://en.wikipedia.org/wiki/Suona.

“Wikipedia.” Wikipedia. Last modified January 25, 2014. Accessed January 26, 2014. http://en.wikipedia.org/wiki/Wikipedia.

. "Yangqin," Wikipedia. Last modified January 20, 2014. Accessed January 27, 2014. http://en.wikipedia.org/wiki/Yangqin.

Yamaha Music Foundation. "Features of Yamaha Music Education System." accessed January 28, 2014, http://www.yamaha-mf.or.jp/english/edu_system/about/index.html.

. "Three Features for Nurturing the Musical Skills of Children in a Relaxed Environment." Accessed January 28, 2014. http://www.yamahamf.or.jp/english/edu_system/about/features.html. 
. "What is Yamaha Grade?" Accessed January 28, 2014. http://www.yamaha-

mf.or.jp/english/grade/about.html.

. "Yamaha Grade Examination Chart." Accessed January 28, 2014.

http://www.yamaha-mf.or.jp/english/grade.

Yii, Kah Hoe. Personal website. Accessed January 24, 2014. http://www.yiikahhoe.com.

\section{Musical Scores (Published)}

Abdul-Aziz, Razak. Five Etudes. Penang, Malaysia: The Asian Centre, 2009.

Chong, Kee Yong. Metamporphosis III. Vienna, Austria: Universal Edition, 2001.

Pragas, Peter. Malaysia Piano Interludes. Kota Kinabalu, Malaysia: Pragas Productions Enterprise, 2003. Compact disc attached. Contains 12 original piano solos.

- Music from Sabah, Land below the Wind. Kota Kinabalu, Malaysia: Natural History Publications (Borneo), 2002. Compact disc attached. Contains 15 original piano solos.

Tajuddin, Tazul Izan. Sebuah Pantun (A Malay Poem). In Spectrum 4: An International Collection of 66 Miniatures for Solo Piano, compiled by Thalia Myers. London, UK: The Associated Board of the Royal Schools of Music, 2005.

Tan, Chee-Hwa. A Child's Garden of Verses. Frederick Harris, 2003. Contains 7 original piano solos.

—. Six Pieces. In Circus Sonatinas. Frederick Harris, 2003.

- Through the Windowpane. Frederick Harris, 2005. Contains 6 original piano solos.

Tan, Su Lian. Orfeo in Asia. ECS, 2006.

U-Don Rock. ECS, 2007.

Wong, Adeline. Mind the Gap. Score for solo piano. In Spectrum 4: An International Collection of 66 Miniatures for Solo Piano, compiled by Thalia Myers. London, UK: The Associated Board of the Royal Schools of Music, 2005.

\section{Musical Scores (Unpublished)}

Ng, Chong Lim. “A Distant Voice of the Rain Forest (Fragments from Rimba).” Score. 2008, revised 2012. Unpublished.

Wong, Adeline. "Paces.” Score. 2005. Unpublished. 
Yii, Kah Hoe. “My Spirit is Dancing!” Score. 2010. Unpublished.

\section{Musical Recordings}

Faith, Hope \& Chaos: Malaysian Contemporary Music Vol. 1. Edge Communications, Petaling Jaya, Malaysia, 2008, compact disc. Produced by Hardesh Singh and CH Loh. Released with the February 2008 issue of Off The Edge magazine. Includes Chong Lim Ng's "Three Sketches for Two Pianos" and Johan Othman's "Composition for Piano No. 8."

Lin, Amy. Amy Lin Interprets Contemporary Piano Works. ABW Classics 1001, compact disc, 2005. Includes Kee Yong Chong's "Metamorphosis III."

Pragas, Peter. Malaysia Piano Interludes. Pragas Productions Enterprise/EMI, 2003, compact disc. Contains 12 original piano solos.

. Music from Sabah, Land below the Wind. Pragas Productions Enterprise/EMI, 2002, compact disc. Contains 15 original piano solos.

Tan, Su Lian. Music by Su Lian Tan. ARSIS Audio CD176, compact disc. Includes "U-Don Rock." 


\section{APPENDIX: \\ List of Known Solo Piano Works by Malaysian Composers}

\begin{tabular}{|c|c|c|}
\hline No. & Composer & Work for Solo Piano \\
\hline 1 & $\begin{array}{l}\text { Abdul-Aziz, Razak } \\
\text { (b. 1959) }\end{array}$ & Five Etudes $(2002)^{\S}$ \\
\hline \multirow[t]{4}{*}{2} & \multirow{4}{*}{$\begin{array}{l}\text { Ang, Minni Kim } \mathrm{Huai}^{+} \\
\text {(b. 1966) }\end{array}$} & Let There Be Light (1982) \\
\hline & & Nostalgia (1982) \\
\hline & & Miniature No. 1 (1994) \\
\hline & & Scherzo No. 1 (1997) \\
\hline 3 & $\begin{array}{l}\text { Chan, Cheong Jan } \\
\text { (b. 1968) }\end{array}$ & Mubarak (1995) \\
\hline 4 & $\begin{array}{l}\text { Cho, Jessica*t+ } \\
\text { (b. 1987) }\end{array}$ & $\begin{array}{l}\text { Landscape (2009)* } \\
\text { Five Little Pieces (2010)* }\end{array}$ \\
\hline 5 & $\begin{array}{l}\text { Chong, Julia } *^{+} \\
\text {(b. 1926) }\end{array}$ & 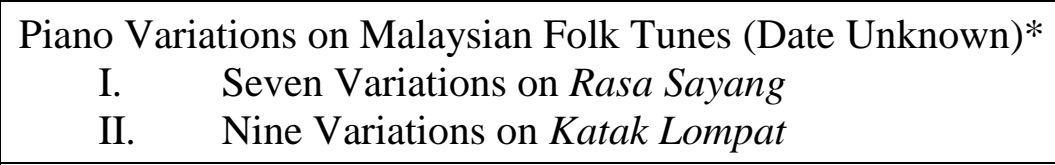 \\
\hline \multirow[t]{5}{*}{6} & \multirow{5}{*}{$\begin{array}{l}\text { Chong, Kee Yong } \\
\text { (b. 1971) }\end{array}$} & Metamorphosis III $(2001)^{\S}$ \\
\hline & & Illusory Angel (2003, revised 2012) \\
\hline & & Splattered Landscape (2005) \\
\hline & & Time Flows (2007)* \\
\hline & & Time Flow II for piano solo and live electronic $(2011)^{*}$ \\
\hline 7 & $\begin{array}{l}\text { Loh, CH (Chan Hong)* } \\
\text { (b. 1966) }\end{array}$ & 2 Portraits (2007)* \\
\hline \multirow[t]{5}{*}{8} & \multirow{5}{*}{$\begin{array}{l}\mathrm{Ng} \text {, Chong Lim } \\
\text { (b. 1972) }\end{array}$} & Two Preludes (1999) \\
\hline & & ...Warna ... [...Colors...] (2001) \\
\hline & & Daun [Leaves] for solo piano and electronic CD (2002) \\
\hline & & A Distant Voice of the Rain Forest (2008, revised 2012)* \\
\hline & & Footprints (2011)* \\
\hline
\end{tabular}




\begin{tabular}{|c|c|c|}
\hline No. & Composer & Work for Solo Piano \\
\hline \multirow[t]{4}{*}{9} & \multirow{4}{*}{$\begin{array}{l}\text { Ng, Chor Guan* } \\
\text { (b. 1981) }\end{array}$} & Sacrifice $(2007) *$ \\
\hline & & Intimacy $(2009)^{*}$ \\
\hline & & Letter Never Sent $(2010)^{*}$ \\
\hline & & Intertwined $(2013)^{*}$ \\
\hline 10 & $\begin{array}{l}\text { Ngiao, Tzu-En* } \\
\text { (b. Unknown) }\end{array}$ & Inconsequentials I-VI (Date Unknown)* \\
\hline 11 & Othman, Johan* & Piano Composition Nos. 1-8 (Date Unknown)* \\
\hline & (b. 1969) & Neutral Space (Date Unknown)* \\
\hline 12 & $\begin{array}{l}\text { Pragas, Peter } \\
\text { (b. 1926) }\end{array}$ & $\begin{array}{cl}\text { Music from Sabah, Land below the Wind }(2002)^{\S} \\
\text { I. } & \text { Blissful Moment } \\
\text { II. } & \text { Joget Kota Kinabalu } \\
\text { III. } & \text { Land Below the Wind } \\
\text { IV. } & \text { 小朋友 (My Little Friend) } \\
\text { V. } & \text { Greetings from Sabah } \\
\text { VI. } & \text { Kasakazan Do Bambazon (Welcoming the Padi } \\
& \text { Spirit-Harvest Festival Song) } \\
\text { VII. } & \text { 给您爸爸, 妈妈 (Just for You Papa Mama) } \\
\text { VIII. } & \text { Penampang } \\
\text { IX. } & \text { A Night in Jesselton } \\
\text { X. } & \text { Broken Circle } \\
\text { XI. } & \text { Pongimpahan } \\
\text { XII. } & \text { Kanou Sumazau } \\
\text { XIII. } & \text { Rafflesia } \\
\text { XIV. } & \text { Tomu } \\
\text { XV. } & \text { Zarmen } \\
\text { XVI. } & \text { Love is in the Air } \\
\text { XVII. } & \text { Seri Paduka Baginda Yang Di-Pertuan Agong (A } \\
& \text { Birthday Song for His Majesty the King) }\end{array}$ \\
\hline
\end{tabular}




\begin{tabular}{|c|c|c|}
\hline No. & Composer & Work for Solo Piano \\
\hline 12 & $\begin{array}{l}\text { Pragas, Peter } \\
\text { (b. 1926)-Continued }\end{array}$ & 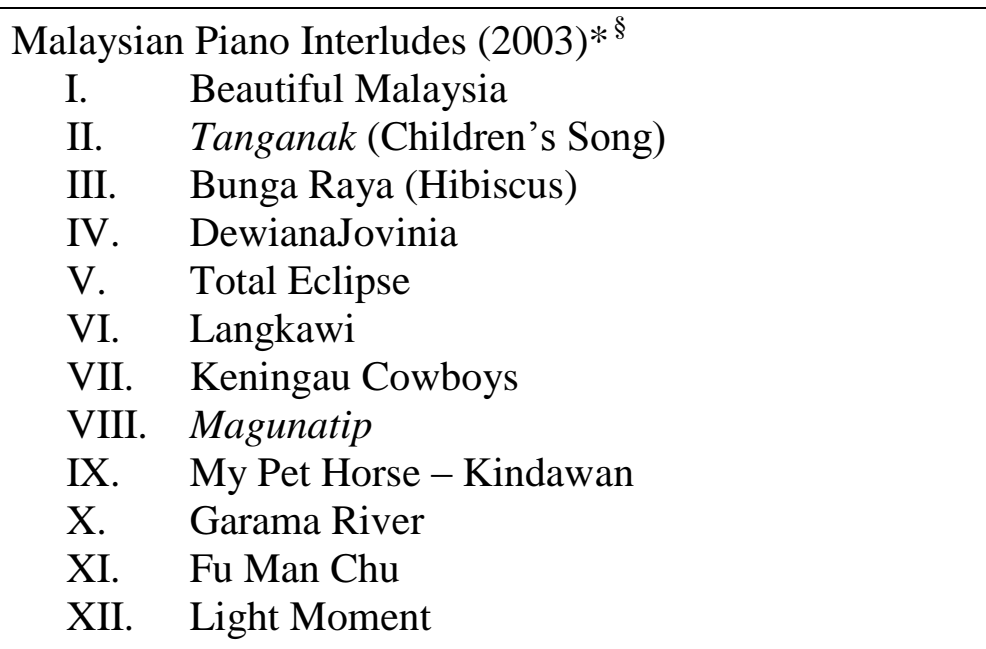 \\
\hline \multirow[t]{3}{*}{13} & \multirow{3}{*}{$\begin{array}{l}\text { Ross, Valerie }^{+} \\
\text {(b. Unknown) }\end{array}$} & Jigsaw Blues (1999) \\
\hline & & Mysteries of the Orient (Date Unknown) \\
\hline & & Ragaslendro (2011)* \\
\hline \multirow[t]{4}{*}{14} & \multirow{4}{*}{$\begin{array}{l}\text { Tajuddin, Tazul Izan } \\
\text { (b. 1969) }\end{array}$} & Piano Sonata (Sketch) (1994) \\
\hline & & Piano Sonata (Etudes) (1995) \\
\hline & & Sebuah Pantun $(2002)^{\S}$ \\
\hline & & $\begin{array}{ll}\text { Torrent of Images-A Memorial (2002-) } \\
\text { I. } & \text { Irrational (2002-3) } \\
\text { II. } & \text { Mediasi Masa-Raja Satariah Memoriam (2004) } \\
\text { III. } & \text { Rational (Work in Progress) }\end{array}$ \\
\hline \multirow[t]{2}{*}{15} & \multirow[t]{2}{*}{$\begin{array}{l}\text { Tan, Chee-Hwa }{ }^{+} \\
\text {(b. 1965) }\end{array}$} & $\begin{array}{cl}\text { A Child's } & \text { Garden of Verses }(1994)^{\S} \\
\text { I. } & \text { My Shadow } \\
\text { II. } & \text { Pirate Story } \\
\text { III. } & \text { Keepsake Mill } \\
\text { IV. } & \text { The Wind } \\
\text { V. } & \text { The Moon } \\
\text { VI. } & \text { At the Seaside } \\
\text { VII. } & \text { The Land of Nod }\end{array}$ \\
\hline & & $\begin{array}{cl}\text { Six Pieces in Circus Sonatinas }(1997)^{\S} \\
\text { I. } & \text { Ferocious Lions (Jump Through the Flames) } \\
\text { II. } & \text { Ringmaster's Parade } \\
\text { III. } & \text { The Flying Trapeze (For the Very Brave) } \\
\text { IV. } & \text { Clown Capers } \\
\text { V. } & \text { Black Bear Boogie } \\
\text { VI. } & \text { Those Amazing Elephant's }\end{array}$ \\
\hline
\end{tabular}




\begin{tabular}{|c|c|c|}
\hline No. & Composer & Work for Solo Piano \\
\hline \multirow[t]{2}{*}{15} & \multirow{2}{*}{$\begin{array}{l}\text { Tan, Chee-Hwa }{ }^{+} \\
\text {(b. 1965)-Continued }\end{array}$} & Toccata Fantasia (1999) \\
\hline & & \begin{tabular}{cl}
\multicolumn{3}{c}{ Through } & the Windowpane $(2004)^{\S}$ \\
I. & Rain \\
II. & Shadow March \\
III. & Winter-Time \\
IV. & The Swing \\
V. & Looking Glass River \\
VI. & ...and Day
\end{tabular} \\
\hline \multirow[t]{5}{*}{16} & \multirow{5}{*}{$\begin{array}{l}\text { Tan, Su Lian** } \\
\text { (b. 1964) }\end{array}$} & A Drole Barcarolle (1993)* \\
\hline & & Go Tango (1995)* \\
\hline & & Intro to Van Hop (2004)* \\
\hline & & Orfeo in Asia $(2006)^{* \S}$ \\
\hline & & U-don-Rock $(2007)^{* \S}$ \\
\hline \multirow[t]{2}{*}{17} & \multirow{2}{*}{$\begin{array}{l}\text { Teh, Tze Siew** } \\
\text { (b. 1971) }\end{array}$} & Search $(2008)^{*}$ \\
\hline & & 击 (Beat) $(2010)^{*}$ \\
\hline \multirow[t]{3}{*}{18} & \multirow{3}{*}{$\begin{array}{l}\text { Wong, Adeline }{ }^{+} \\
\text {(b. 1975) }\end{array}$} & Alternating Current (2000) \\
\hline & & Mind the Gap $(2003)^{\S}$ \\
\hline & & 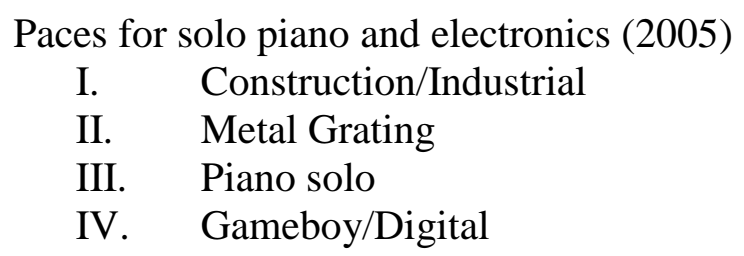 \\
\hline \multirow[t]{3}{*}{19} & \multirow{3}{*}{$\begin{array}{l}\text { Yii, Kah Hoe* } \\
\text { (b. 1970) }\end{array}$} & Timang Burung (2009)* \\
\hline & & My Spirit is Dancing! (2010)* \\
\hline & & My Spirit is Playing (2013)* \\
\hline
\end{tabular}

* New addition to the list provided by Charmaine Siagian in her DMA dissertation, "Selected Solo Piano Pieces by Contemporary Malaysian and Indonesian Composers from 1979 to 2007: An Introduction" (University of Oklahoma: 2007), 120-21.

${ }^{+}$Female composer.

${ }^{\S}$ Published work. For publication information, see Bibliography, under "Musical Scores (Published)." 